March 1999 • NREL/SR-710-24738

\title{
New Technology \\ Demonstration Program, \\ Kennedy Space Center, \\ Hangar L Heat Pipe Project: \\ Performance Evaluation Report
}

\section{Period of Performance June 1996 to February 1998}

C.E. Hancock

Paul Reeves

Mountain Energy Partnership

Boulder, Colorado

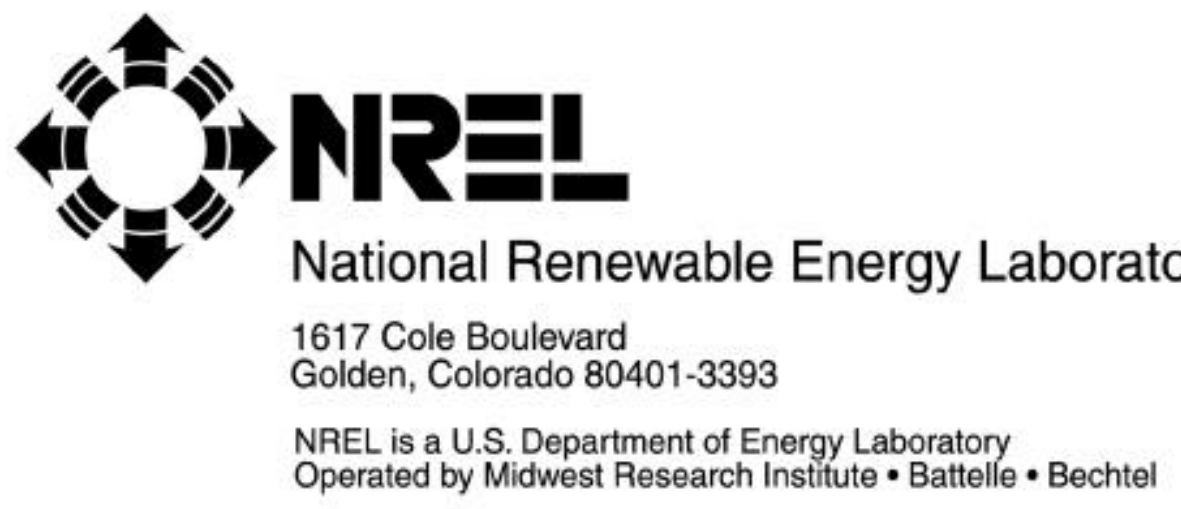




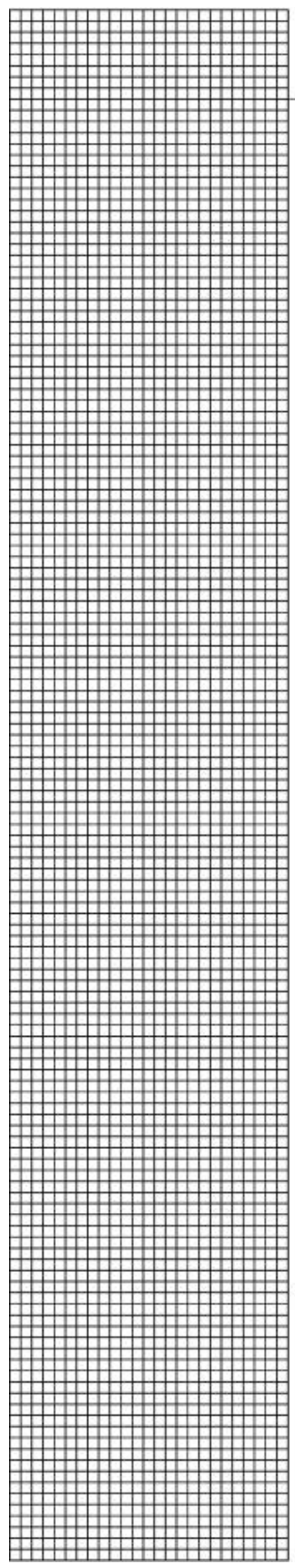
March 1999 • NREL/SR-710-24738

\section{New Technology Demonstration Program, Kennedy Space Center, Hangar L Heat Pipe Project: Performance Evaluation Report}

\section{Period of Performance June 1996 to February 1998}

C.E. Hancock

Paul Reeves

Mountain Energy Partnership

Boulder, Colorado

NREL technical monitor: Richard Parish

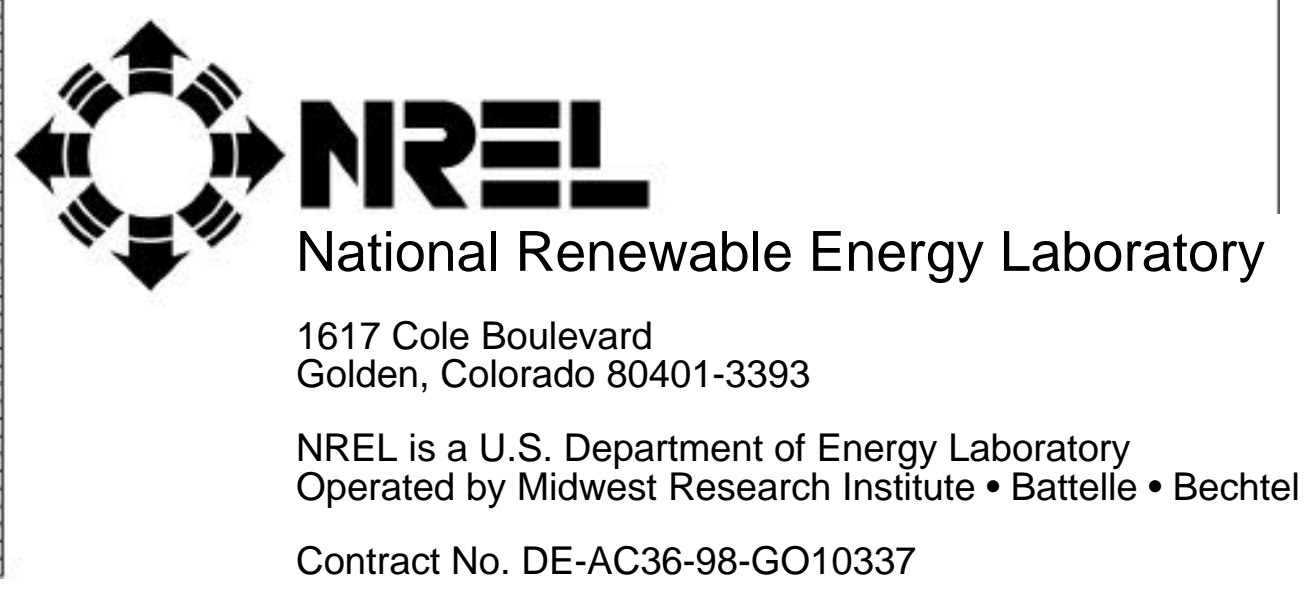




\section{NOTICE}

This report was prepared as an account of work sponsored by an agency of the United States government. Neither the United States government nor any agency thereof, nor any of their employees, makes any warranty, express or implied, or assumes any legal liability or responsibility for the accuracy, completeness, or usefulness of any information, apparatus, product, or process disclosed, or represents that its use would not infringe privately owned rights. Reference herein to any specific commercial product, process, or service by trade name, trademark, manufacturer, or otherwise does not necessarily constitute or imply its endorsement, recommendation, or favoring by the United States government or any agency thereof. The views and opinions of authors expressed herein do not necessarily state or reflect those of the United States government or any agency thereof.

Available to DOE and DOE contractors from:

Office of Scientific and Technical Information (OSTI)

P.O. Box 62

Oak Ridge, TN 37831

Prices available by calling (423) 576-8401

Available to the public from:

National Technical Information Service (NTIS)

U.S. Department of Commerce

5285 Port Royal Road

Springfield, VA 22161

(703) $605-6000$ or (800) 553-6847

or

DOE Information Bridge

http://www.doe.gov/bridge/home.html

This publication received minimal editorial review at NREL

Printed on paper containing at least $50 \%$ wastepaper, including $20 \%$ postconsumer waste 


\section{Preface}

This work was funded by the DOE/NREL FEMP program under NREL Subcontract No. KAP-6-16318-08. We appreciate the support and encouragement of Karen Thomas as the NREL project manager. We thank Will Miner and his staff (Dynamac Corp.) and Bill Ruppert and Dave Koval (EG\&G) for their substantial assistance in our work on-site at the Kennedy Space Center. 


\section{Executive Summary}

In December of 1996, heat pipe heat exchangers were installed on three air handlers at Hangar L at the Cape Canaveral Air Station, Kennedy Space Center, Cape Canaveral, Florida. These retrofits were implemented with the intent to improve the dehumidification performance of the cooling systems, reduce the electric and steam energy required for reheating air, and reduce electric energy used by the chillers.

Audits were conducted before and after the heat pipes were installed and a detailed monitoring system was set up to record hourly operating conditions of each of the three air-handling units. The audit information and monitored data were used to create a simulation model of the three air-handling systems and annual energy savings were predicted.

Energy savings for air handling unit 1 (AHU-1) were found to be negligible. Heat pipe installation in AHU-1 may have been inappropriate because of the design of the original cooling coils. Annual savings for AHU-2 are small, primarily because the required reheat for the system was already small. AHU-3 was the best application for the heat pipes and showed savings of $70,000 \mathrm{kWh}$ per year. Interior humidity conditions improved after installation of the heat pipes for AHU-2 and AHU-3.

\section{Summary of Heat Pipe Installation Savings}

\begin{tabular}{|l|l|l|l|}
\hline Savings Component & AHU-1 & AHU-2 & AHU-3 \\
\hline Reheat Savings (kWh*) & 0 & 3,000 & 51,600 \\
\hline Cooling Coil Load Reduction (ton-hours) & 0 & -880 & 11,000 \\
\hline Total Energy Savings (kWh) & 0 & 1,600 & 69,600 \\
\hline Humidity Control Improvement & None & $5-10 \%$ & $5-10 \%$ \\
\hline
\end{tabular}

*kilowatt-hours 


\section{Contents}

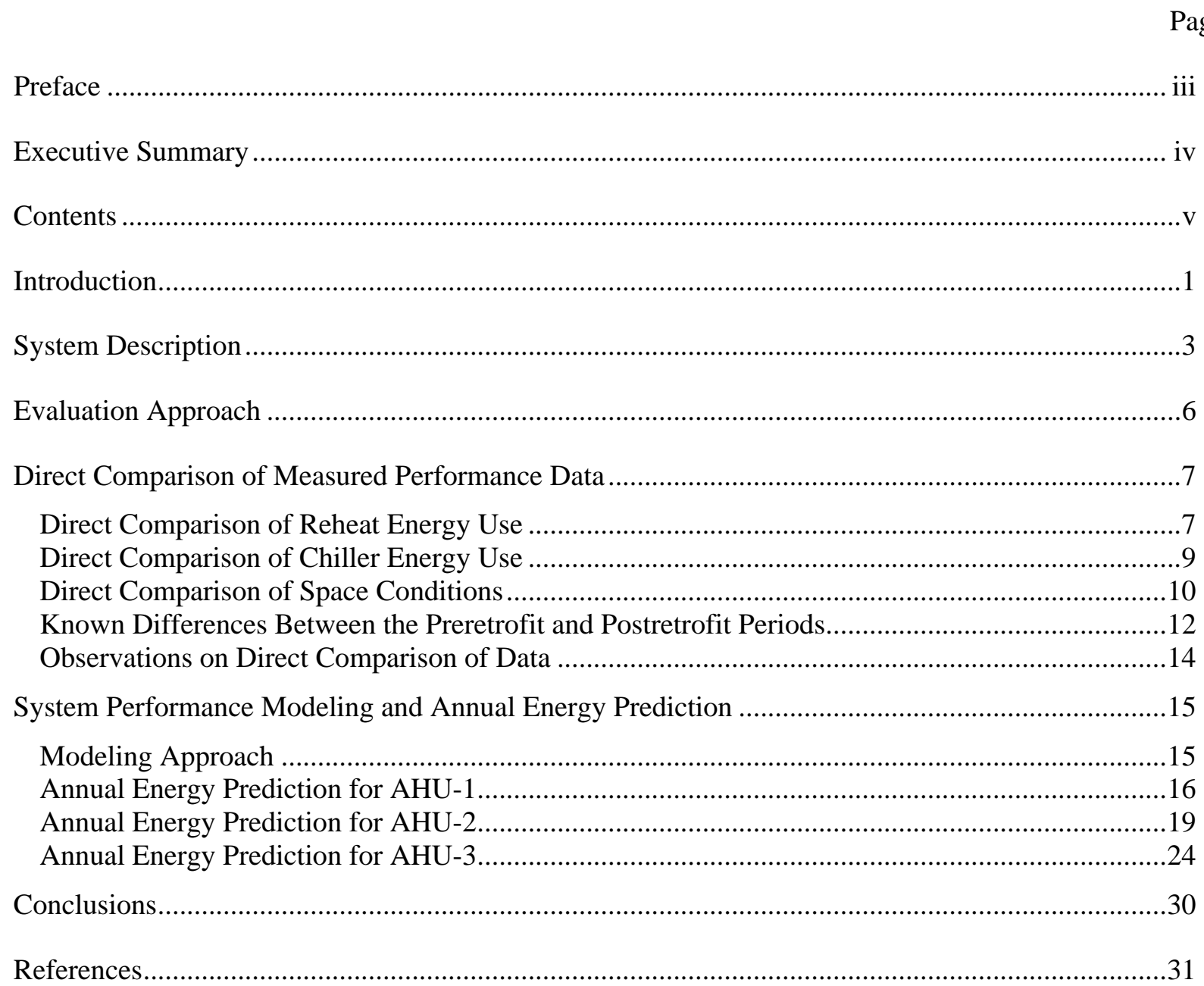

Appendix A -- Pre-Retrofit Evaluation Report

Appendix B -- Post-Retrofit Evaluation Report

Appendix C -- Detailed Measured Performance Graphs 
List of Tables

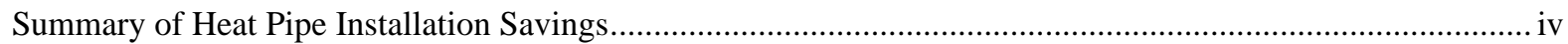

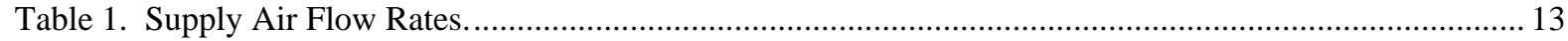

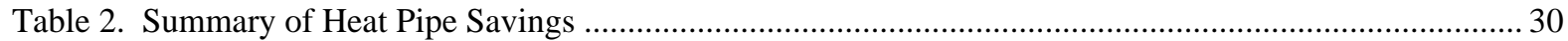

\section{List of Figures}

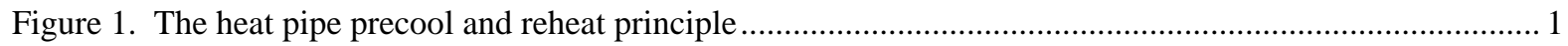

Figure 2. Heat pipe dehumidification process...................................................................................... 1

Figure 3. Schematic of AHU-1 with heat pipe installed ............................................................................ 3

Figure 4. Schematic of AHU-2 and AHU-3 with heat pipe installed.......................................................... 4

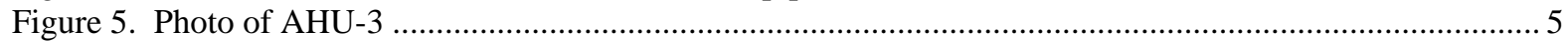

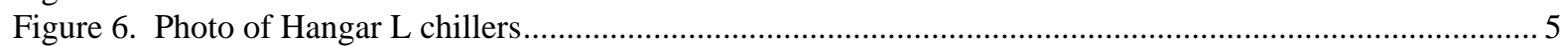

Figure 7. Direct comparison of electric reheat energy, AHU-2 …........................................................... 7

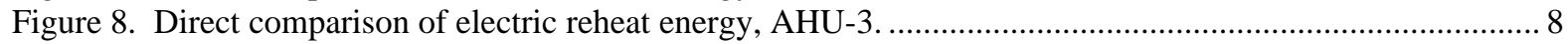

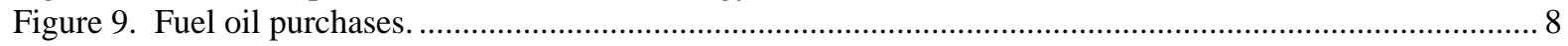

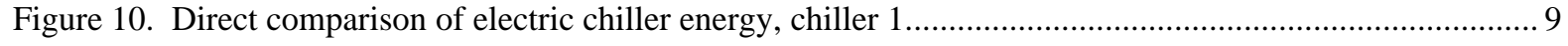

Figure 11. Direct comparison of electric chiller energy, chiller 2............................................................. 10

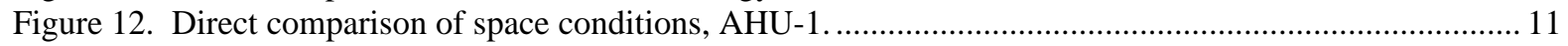

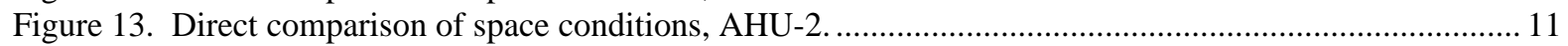

Figure 14. Direct comparison of space conditions, AHU-3 ..................................................................... 12

Figure 15. Total heat removed, AHU-3, showing increased cooling capacity in the postretrofit period............ 13

Figure 16. Chilled water supply temperatures during preretrofit and postretrofit periods................................. 14

Figure 17. Average delivered air temperatures for AHU-1 .......................................................................... 17

Figure 18. SHR for precool and main cooling coils, AHU-1, preretrofit and postretrofit periods..................... 18

Figure 19. SHR for combined precool + main cooling coils, AHU-1, preretrofit and postretrofit periods.......... 18

Figure 20. Average space sensible load used for simulation, AHU-2 ………............................................. 20

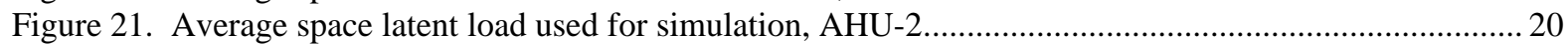

Figure 22. Predicted vs. measured SHR for AHU-2, preretrofit period.......................................................... 21

Figure 23. Predicted vs. measured SHR for AHU-2, postretrofit period ........................................................ 22

Figure 24. Daily average predicted SHR, with and without the heat pipe retrofit ......................................... 22

Figure 25. Predicted daily reheat, with and without the heat pipe, AHU-2 …............................................... 23

Figure 26. Average space sensible load used for simulation, AHU-3 .......................................................... 25

Figure 27. Average space latent load used for simulation, AHU-3 .............................................................2

Figure 28. Predicted vs. measured SHR for AHU-3, preretrofit period.......................................................... 26

Figure 29. Predicted vs. measured SHR for AHU-3, postretrofit period ........................................................ 27

Figure 30. Daily average predicted SHR, with and without the heat pipe retrofit ............................................2 27

Figure 31. Predicted daily reheat, with and without the heat pipe, AHU-3 ….............................................. 28

Figure 32. Reheat energy savings due to the heat pipe installation, AHU-3 ................................................. 29 


\section{Introduction}

Heat pipes can transfer some sensible heat from air entering a coil to the air leaving the coil, thus reducing or eliminating the need for additional auxiliary reheat for moisture control. The heat pipes thus reduce the sensible heat ratio (SHR) of the coil. (See Figure 1.) This process can reduce the energy need for reheat and for chilled water. The precool section of the heat pipe is located immediately upstream of the cooling coil to facilitate this process. (See Figure 2.)

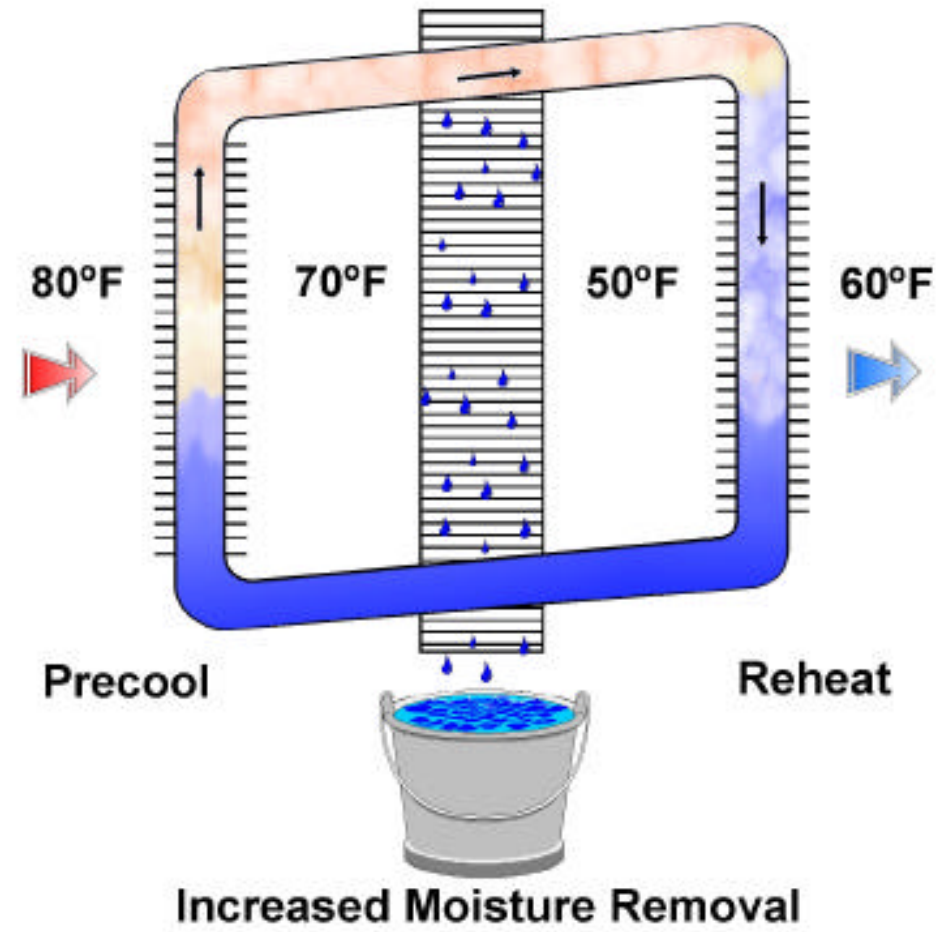

Figure 1. The heat pipe precool and reheat principle

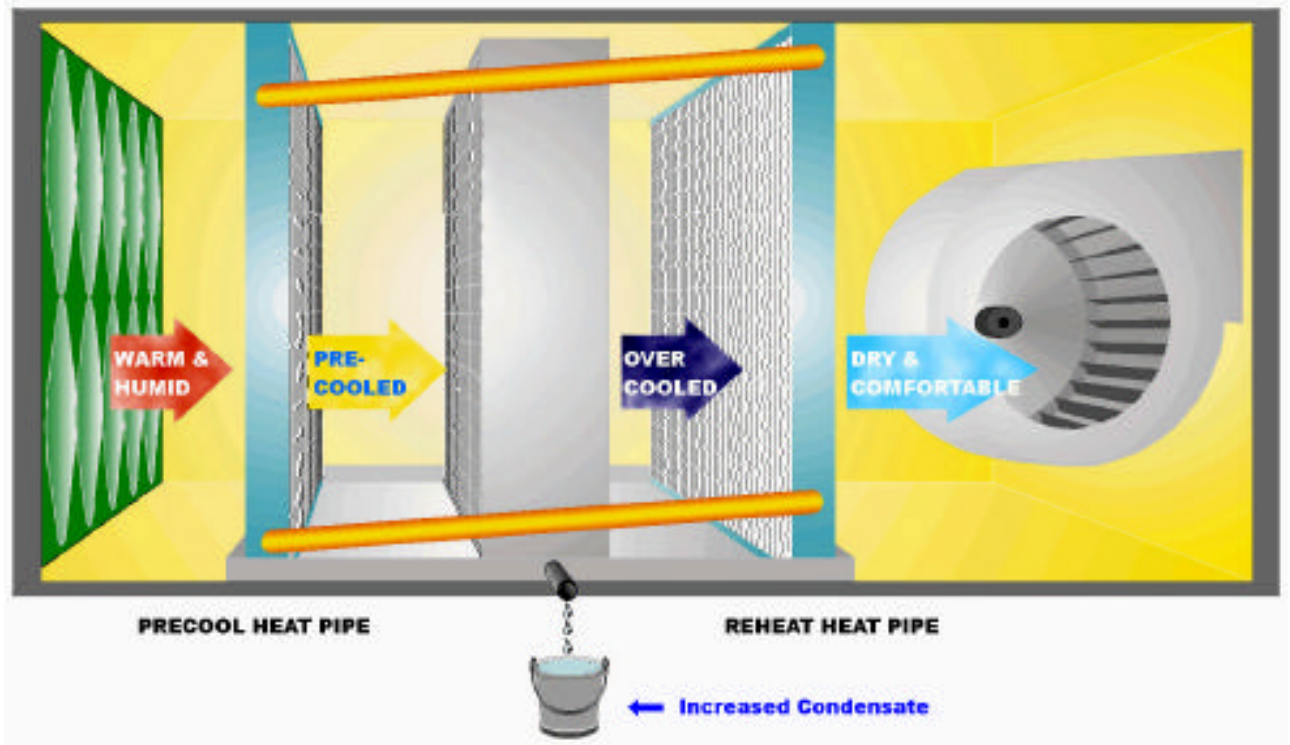

Figure 2. Heat pipe dehumidification process. 
Heat pipe heat exchangers were installed on three air handlers at Hangar $L$ at the Cape Canaveral Air Station, Kennedy Space Center, Cape Canaveral, Florida, in December of 1996. The intent of these retrofits was to improve the dehumidification performance of the cooling systems, reduce the electric and steam energy required for reheating air, and reduce electric energy used by the chillers.

Direct measurements of the primary energy quantities have been made over an extended period, both before and after the retrofit. The instrumentation and the measured preretrofit and postretrofit performance were described in previous reports (January 1997 and October 1997). This report describes the annual energy savings attributed to the heat pipe installation.

Direct comparisons have been made between the measured performances of the three systems for the same months before and after the retrofit. Changes in reheat and chiller electric power were observed, as well as changes in interior space temperature and relative humidity $(\mathrm{RH})$. Because other system operating parameters changed between 1996 and 1997, this direct comparison is not a complete and accurate quantitative representation of savings attributable to the heat pipes. Significant changes that affected the performance of the air-handling systems that are not attributable to the heat pipe installations include: a new condenser and a new compressor for the chiller serving two of the retrofitted air handlers, changes in supply air flow rates, and possible changes to the cooling coil control mechanism.

The measured data were used to develop thermal performance models of each system. These models were used to calculate the annual savings from the heat pipes for a consistent set of operating conditions. Results of the simulation analysis provide significant insight regarding the appropriate application of heat pipes in existing HVAC systems. 


\section{System Description}

The NASA Life Sciences Support Facility is located in Hangar L at the Cape Canaveral Air Station, Cape Canaveral, Florida. Laboratory and office areas have been constructed inside the original hangar structure. The hangar is approximately 175 feet wide, 150 feet long, and 30 feet high, covering a ground floor area of about 26,000 square feet. There are approximately 20,000 square feet of airconditioned space inside the hangar, including offices, labs, and clean rooms. There are very few windows and essentially no direct solar gains on conditioned spaces. Most of the cooling load is caused by internal gains from operating lights and equipment and from conditioning outside air for ventilation. Normal operating hours for personnel at the building are 0700 through 1700. Much of the equipment and interior lighting operates 24 hours per day.

Three air handlers serve the majority of the conditioned lab and office space. Air handler AHU-1 is on the main floor of the hangar and supplies conditioned air to the clean room areas of the facility. It operates with 100 percent outside air. Figure 3 shows a simple schematic diagram of this air handler. The outside air first passes through a precool coil before it enters the main cooling coil. The heat pipe was installed at the precool coil. The two coils are supplied with chilled water (in parallel) from a 110ton chiller on the north side of the building. Both temperature and RH in the conditioned space are intended to be controlled by this system. During periods of high latent loads, humidity is controlled by cooling the supply air below the point required to meet the sensible load, thus condensing enough moisture from the air to meet the required RH set point. The dry bulb temperature in the space is maintained by reheating the subcooled air to meet the temperature set point. Hot water supplied by a local oil-fired steam boiler is used for reheat in this system. If the RH in the conditioned space drops below the humidistat set point, steam from the boiler is injected in the air flow stream to humidify the air.

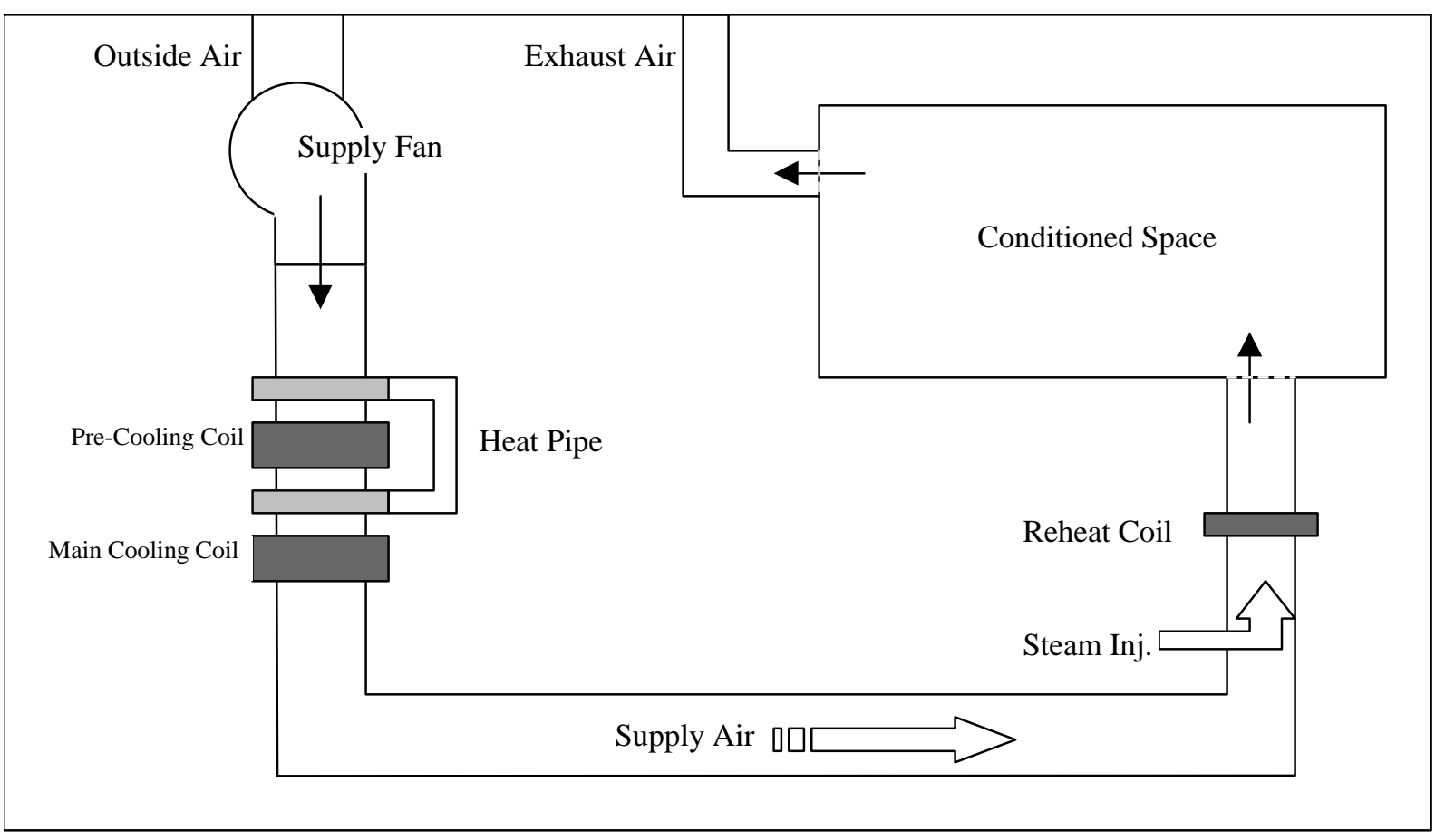

Figure 3. Schematic of AHU-1 with heat pipe installed 
Figure 4 shows a simple schematic diagram typical of AHU-2 and AHU-3. These air handlers are on the mezzanine level above the office spaces on the south side of the building. (Note that our AHU-3 is designated AHU-1 [Mezzanine] in the original mechanical plans.) These AHUs serve a combination of offices and lab space. Chilled water is supplied (in parallel) by a 55-ton air-cooled chiller on the north side of the building. Figure 5 shows a photograph of AHU-3. The chillers on the north side of the hangar are pictured in Figure 6. Humidity is controlled by subcooling the air flow to condense sufficient moisture from the air, and then reheating to maintain the dry bulb temperature set point. Reheating is accomplished by electric heaters in the supply ducts to each zone. Steam can be injected in the supply ducts to humidify the air during rare periods of low humidity in cool weather.

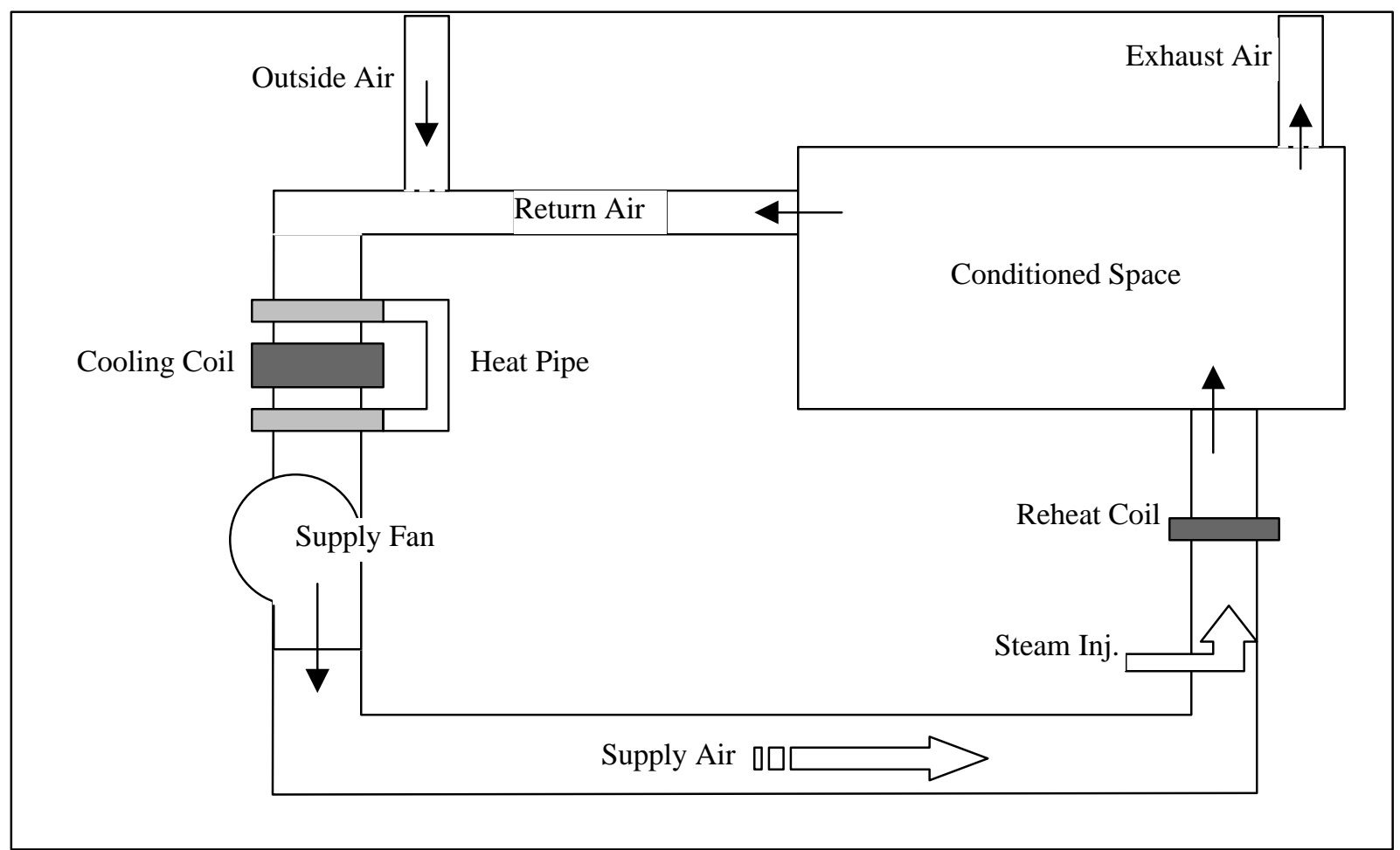

Figure 4. Schematic of AHU-2 and AHU-3 with heat pipe installed

The heat pipes are intended to transfer some of the sensible heat from the air entering the coil to the air leaving the coil, thus reducing or eliminating the need for additional auxiliary reheat for moisture control (assuming that the supply air was indeed already cooler than was required to meet the sensible space load). The heat pipes essentially reduce the SHR of the coil. The purpose of the heat pipe retrofit was to use less energy for reheat and for chilled water. It was recognized that the heat pipe installation could cause a large drop in pressure, and thus could slightly increase fan power. 


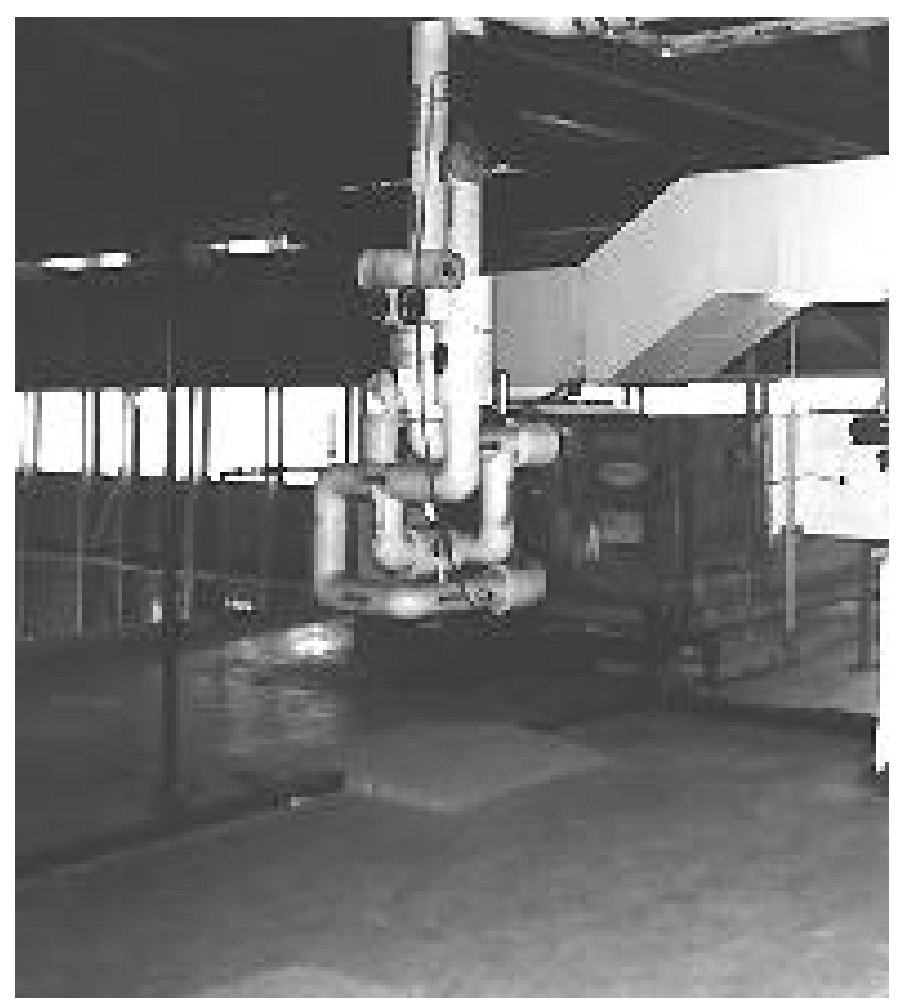

Figure 5. Photo of AHU-3

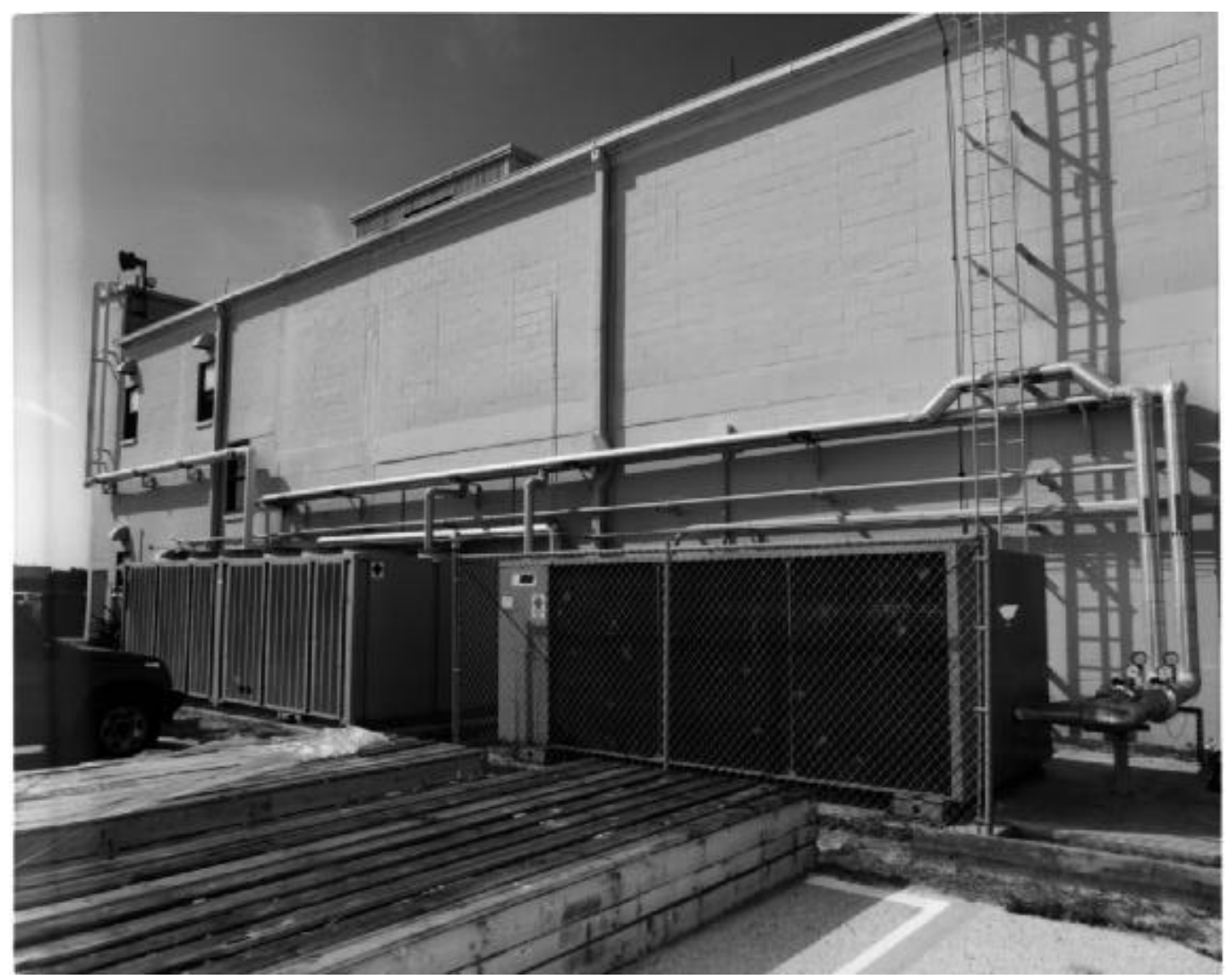

Figure 6. Photo of Hangar L chillers 


\section{Evaluation Approach}

Direct measurements of the primary energy quantities have been made over an extended period both before and after the retrofit. The instrumentation and the measured preretrofit and postretrofit performance were described in previous reports (Pre-Retrofit Evaluation Report, January 1997 [Appendix A] and Post-Retrofit Monitoring and Evaluation Report, October 1997 [Appendix B]). This report describes the annual energy savings attributed to the heat pipe installation.

Direct comparisons were made between the measured performance of the three systems for the same months before and after the retrofit. Because other system operating parameters changed between 1996 and 1997, this direct comparison is not an accurate quantitative representation of savings attributable to the heat pipes. The measured data were used to develop thermal performance models of each system. These models were used to calculate the savings from the heat pipes for a consistent set of operating conditions.

The energy savings attributed to the heat pipes were expected to be derived from:

Reduced reheat power - during periods when either electric or steam reheat would be used to raise the main supply air to the minimum temperature required by the space loads.

Reduced chiller power — during periods when main supply air reheat is required and the chiller is running at less than full load.

In addition, interior space conditions may be improved by the heat pipes.

Direct comparisons of daily total electric reheat power for AHU-2 and AHU-3 are made for the comparable periods before and after the retrofit (August through November). Direct comparisons of daily total electric power for both chillers are also made for the period of overlapping data. Interior dry bulb temperature and $\mathrm{RH}$ are compared for typical summer periods before and after the retrofit.

Measured data were used to characterize the individual components and a simulation model of each HVAC system was developed. These model components were used to simulate the energy use of each HVAC system on an hourly basis, using a consistent set of driving functions and operating conditions. Changes caused by the heat pipes were accounted for in the preretrofit and postretrofit simulations, while changes caused by other factors were adjusted for and eliminated from the analysis. Details of the model development and the predicted annual energy savings are presented. 


\section{Direct Comparison of Measured Performance Data}

Having collected long-term data, it is compelling to directly compare the monitored energy use of the various systems before and after the heat pipe retrofits to assess the energy savings. Though this approach does offer valuable insight into the system operation, there are a number of reasons why savings are not accurately represented in such a direct comparison. These reasons will be enumerated after presenting a direct comparison of the monitored data. More sophisticated techniques are needed to determine the actual energy savings.

\section{Direct Comparison of Reheat Energy Use}

Electric reheat energy was measured for AHUs 2 and 3 and is presented in the following two figures (hot water reheat for AHU-1 was not measured). The preretrofit period extends from mid-August 1996 to mid-November 1996. The postretrofit period includes all of 1997. For the preretrofit period, the xaxis of Figure 7 is the Julian day number in 1996; for the postretrofit period, the $\mathrm{x}$-axis is the Julian day number in 1997.

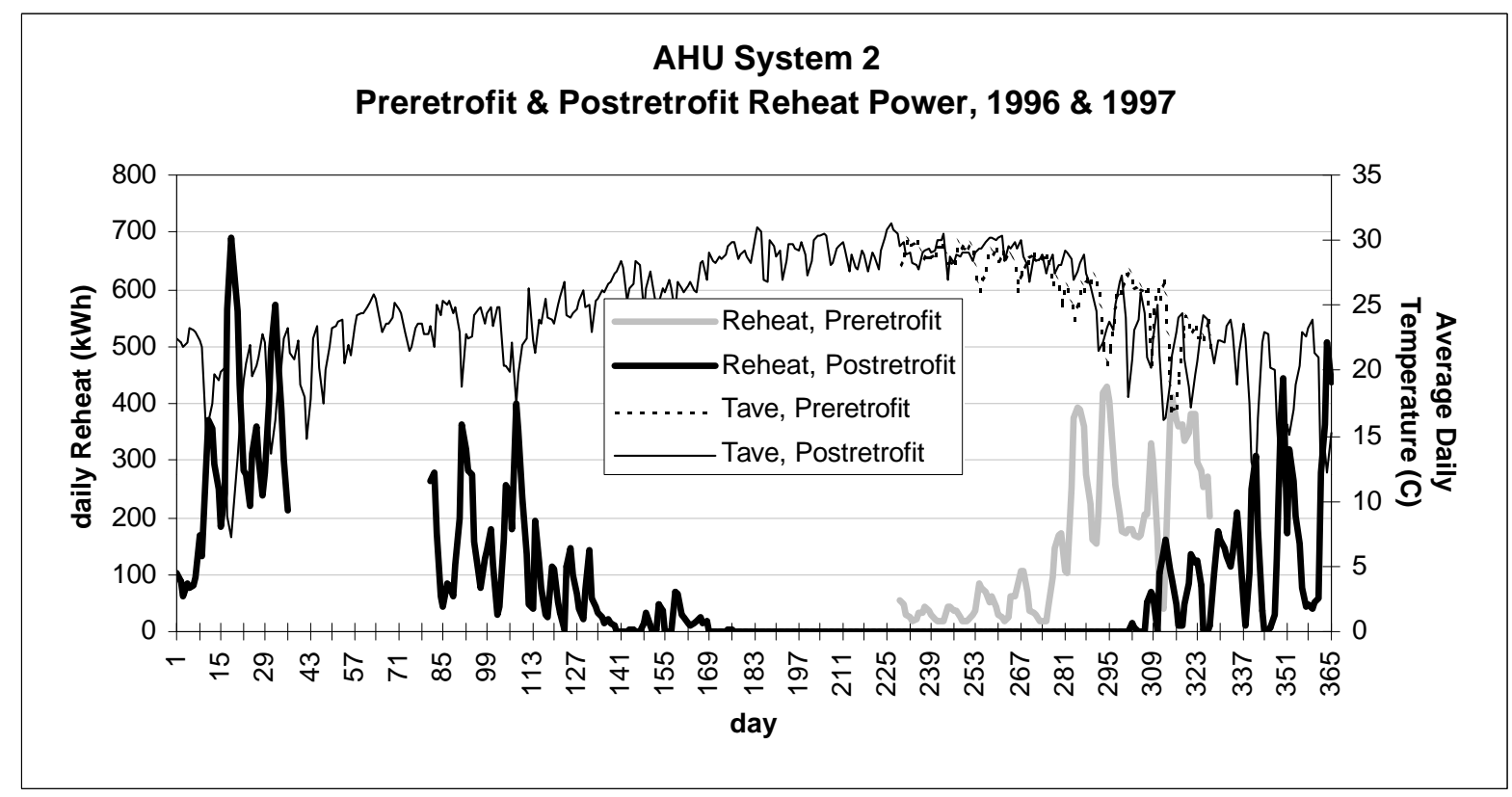

Figure 7. Direct comparison of electric reheat energy, AHU-2.

As shown in Figure 7, there is minimal reheat for AHU-2 during the hot summer days with increasing reheat as the daily average outdoor temperature begins to cool down. For the postretrofit period, there is no reheat energy during summer months (June through September) and significant reheat energy used during the winter, spring, and late fall. Note that there is no reheat data for this air handler during parts of February and March 1997 because of equipment problems. This data set shows that there was much less reheat energy used after the heat pipe was installed for the period August through November. It is not possible to quantify the amount of annual savings attributed to the heat pipe from this data, partly because of the wide variation in reheat energy required for any given period. The figure also shows that the average daily outdoor temperature (Tave) was not significantly different from year to year. 


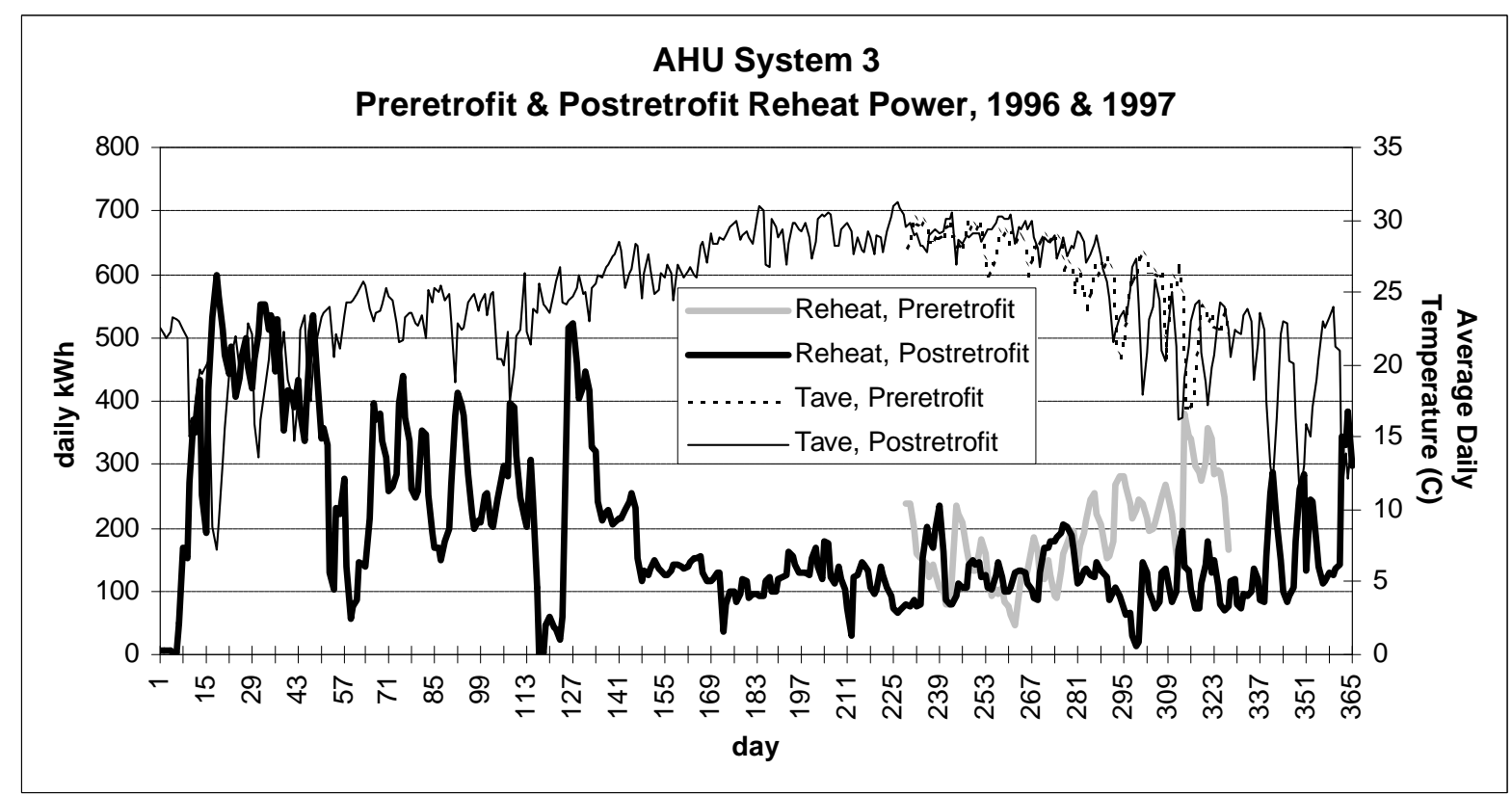

Figure 8. Direct comparison of electric reheat energy, AHU-3.

Figure 8 shows similar amounts of reheat energy for AHU-3 being used during the summer for the preretrofit and postretrofit periods. Daily reheat energy varies between $100 \mathrm{kWh}$ and $200 \mathrm{kWh}$ for the period June though October. As the average daily temperature decreases in the fall, there appears to be much less reheat energy used after the heat pipes were installed. It is not apparent from this direct comparison how much annual reheat energy was saved.

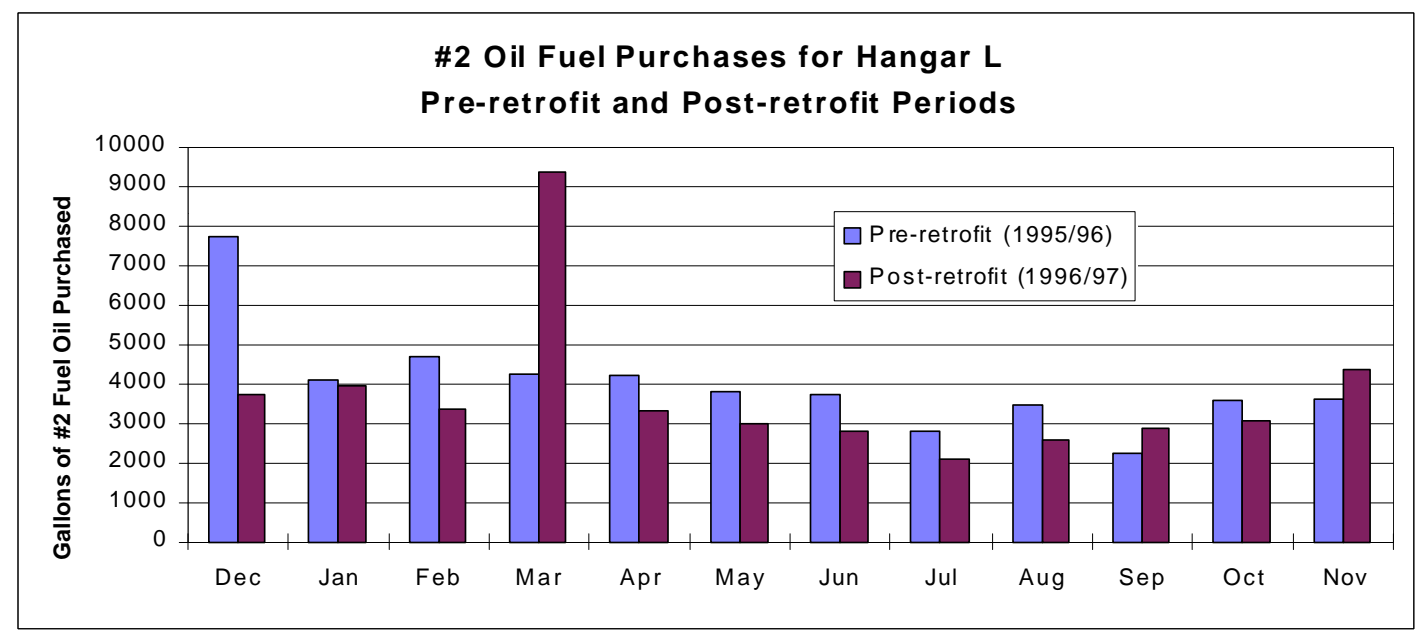

Figure 9. Fuel oil purchases.

AHU-1 uses steam reheat, produced from an oil-fired boiler. A practical measurement of the reheat energy was therefore not possible. Figure 9 shows the history of oil purchases for Hangar L for a period of 1 year before and after the heat pipe retrofit. Approximately $8 \%$ less oil was purchased 
during the year following the heat pipe retrofit. It is not apparent that this usage difference can be attributed to changes in reheat energy, as opposed to other factors, such as maintenance, purchase dates, and changes in other end uses.

\section{Direct Comparison of Chiller Energy Use}

One possible effect of the heat pipes is to lower cooling coil loads, assuming that the coils are being controlled based upon dehumidification requirements. As noted in the previous two reports however, the chillers appeared to run at maximum capacity during the summer months, with or without the heat pipes. It is only during off-peak periods, then, that some chiller energy might be saved.

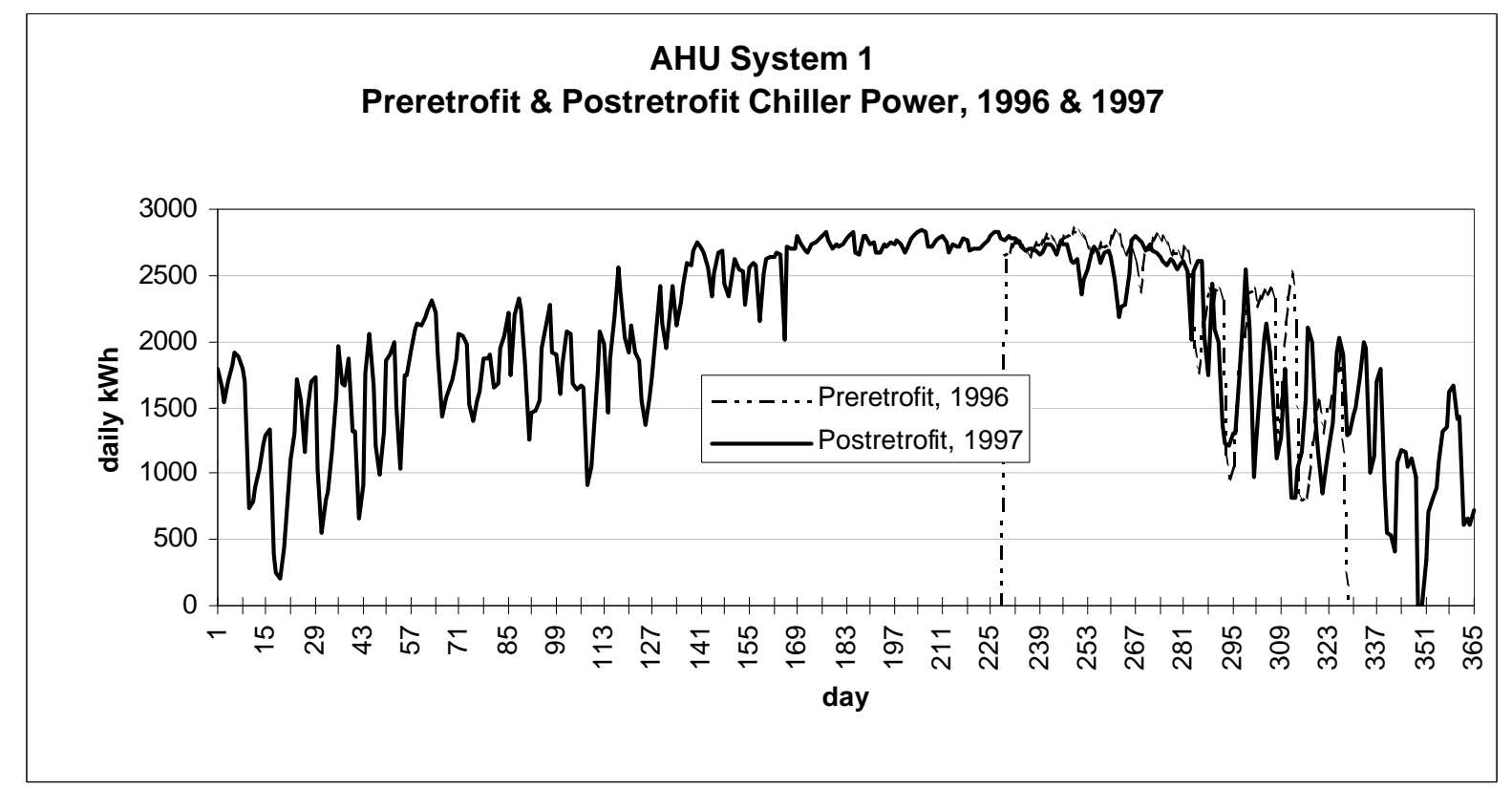

Figure 10. Direct comparison of electric chiller energy, chiller 1.

Figure 10 shows comparable chiller energy use for the 110-ton chiller (chiller 1) for the preretrofit and postretrofit periods. It is not apparent that there is a difference in chiller energy use during the overlapping summer and fall periods, leading to the conclusion that chiller energy use was not significantly influenced by the heat-pipe retrofit. 


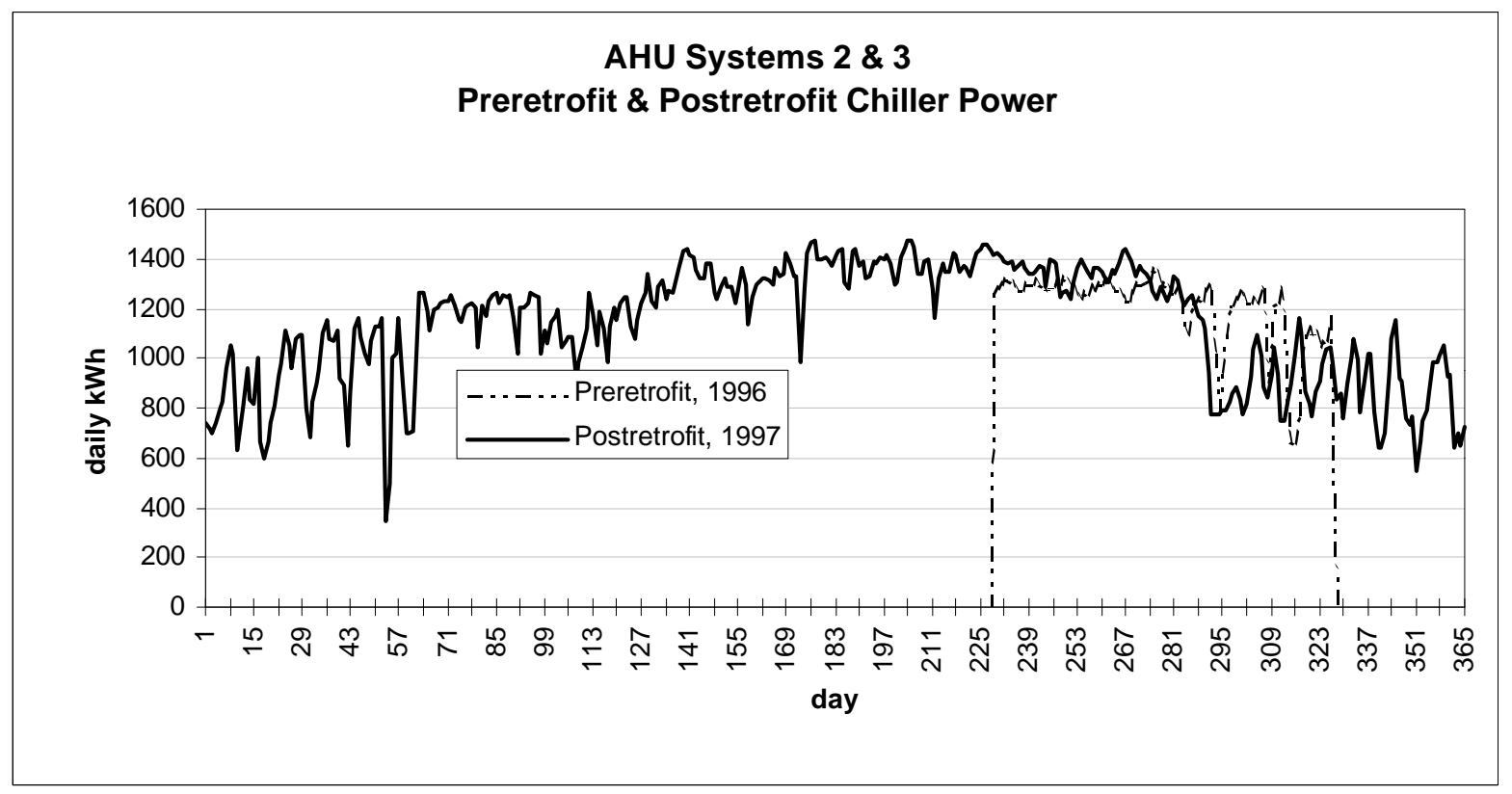

Figure 11. Direct comparison of electric chiller energy, chiller 2.

Figure 11 shows comparable chiller energy use for the 55-ton chiller (chiller 2) serving AHUs 2 and 3 for the preretrofit and postretrofit periods. The chiller appears to have used more energy during the summer and less during the fall after the heat pipes were installed. This unexpected result is due to changes in the chiller equipment (detailed later in this section). Without a full year's worth of preretrofit data, it is not apparent which period has greater annual energy use.

\section{Direct Comparison of Space Conditions}

The primary effect of the heat pipe is to improve the cooling coil's ability to remove moisture from the air stream by lowering the SHR of the coil. For the same amount of heat removed from the air stream, the supply air should be dryer and warmer with the heat pipe in place. A direct comparison of the data does show improved humidity levels in the spaces, as indicated by the return air conditions.

During the preretrofit period, adequate control of the $\mathrm{RH}$ in the space was not achieved during peak cooling conditions for any of the AHUs. The RH of the air exhausted from the spaces served by AHU-1 is consistently near or above $70 \%$. Air handlers 2 and 3 control the humidity levels somewhat better, but the return air RH is still often above $60 \%$ for these units. The target RH for these spaces, which include animal care areas, was $50 \%$. 


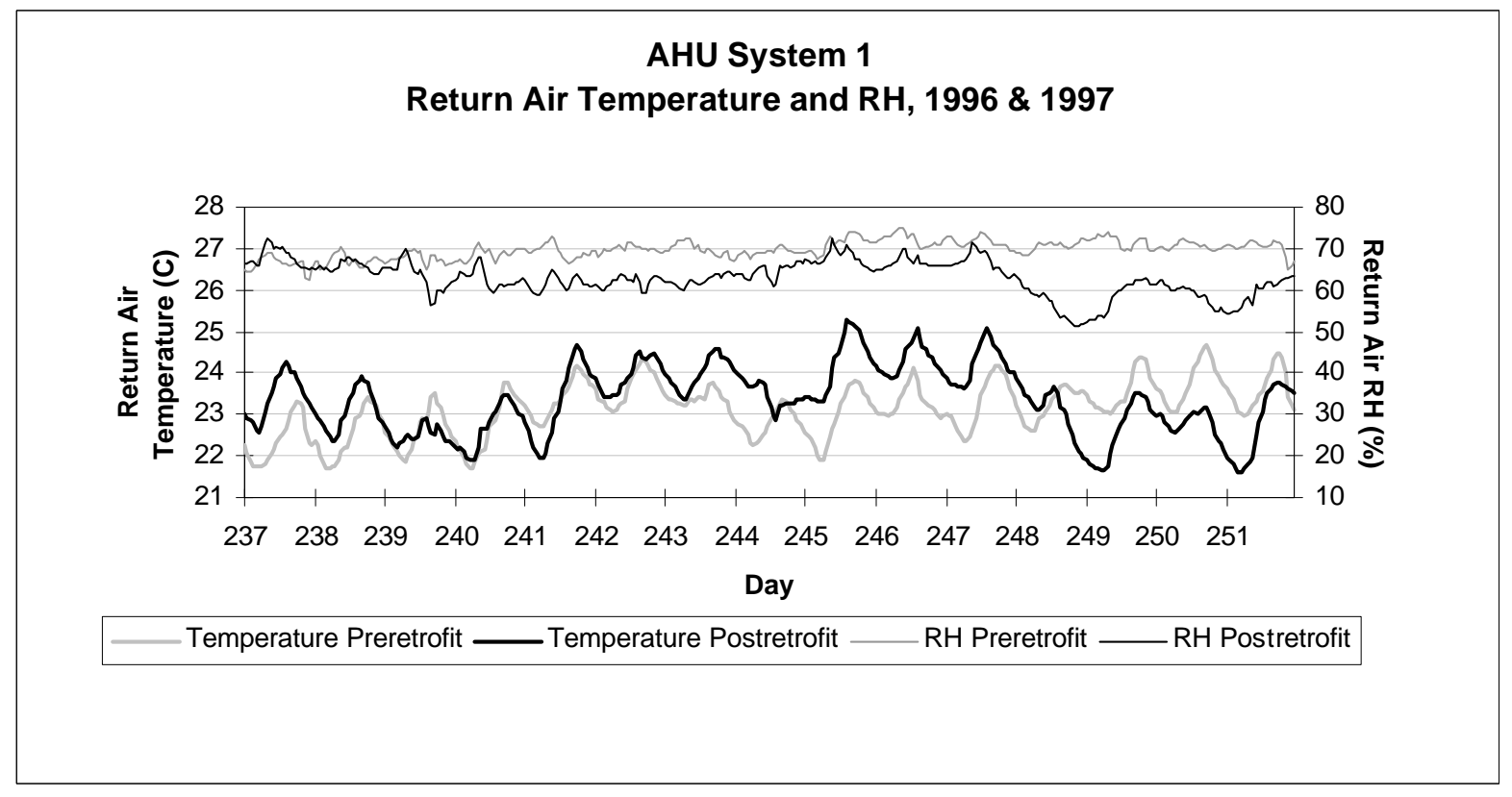

Figure 12. Direct comparison of space conditions, AHU-1.

Figures 12 through 14 show interior space conditions for typical summer periods. The RH in all the spaces is improved during some of the postretrofit monitored period. During the summer, AHUs 2 and 3 show average RH levels consistently lower after the heat pipes were installed. Postretrofit return-air drybulb temperatures were maintained or improved.

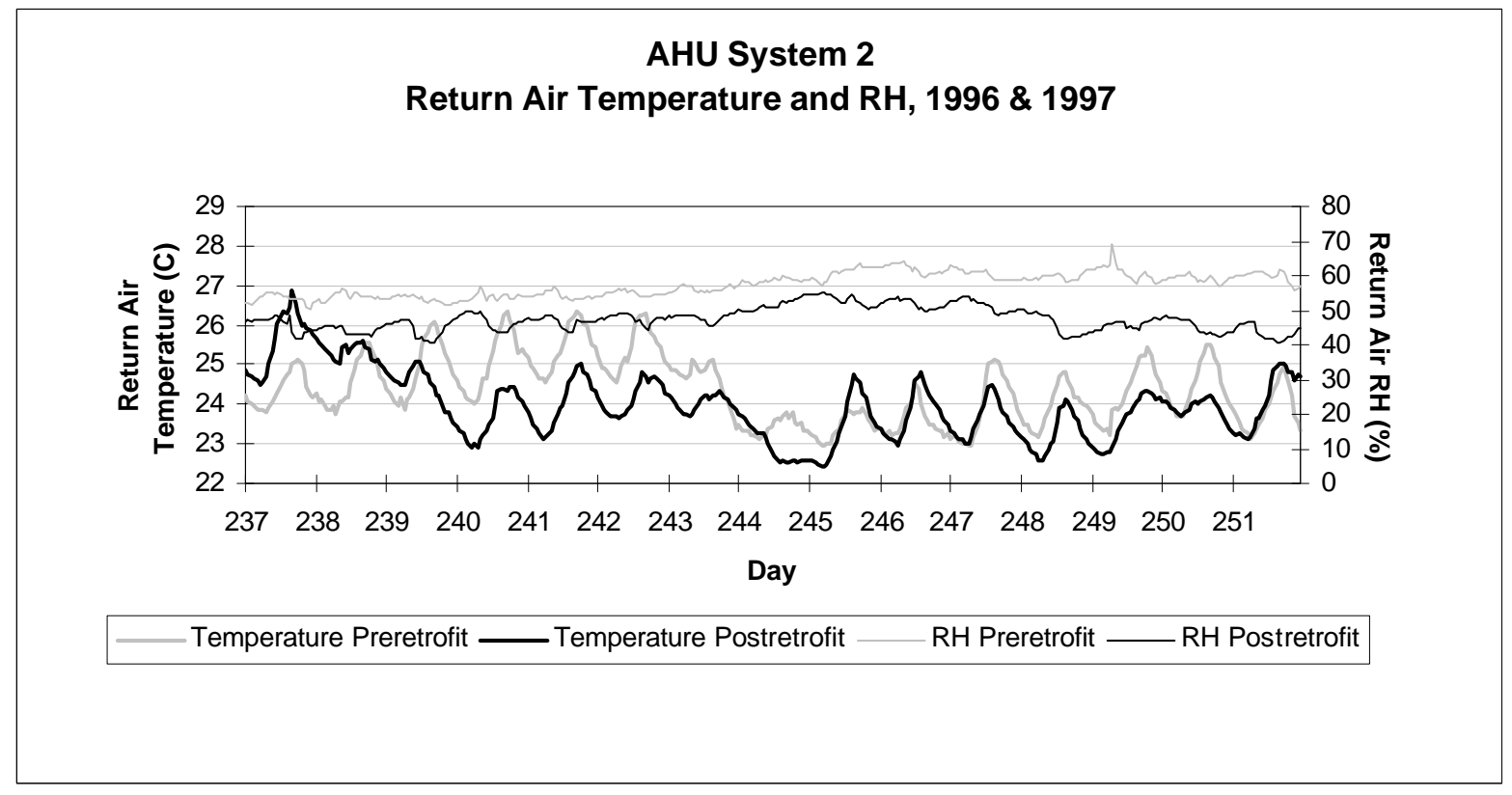

Figure 13. Direct comparison of space conditions, AHU-2. 


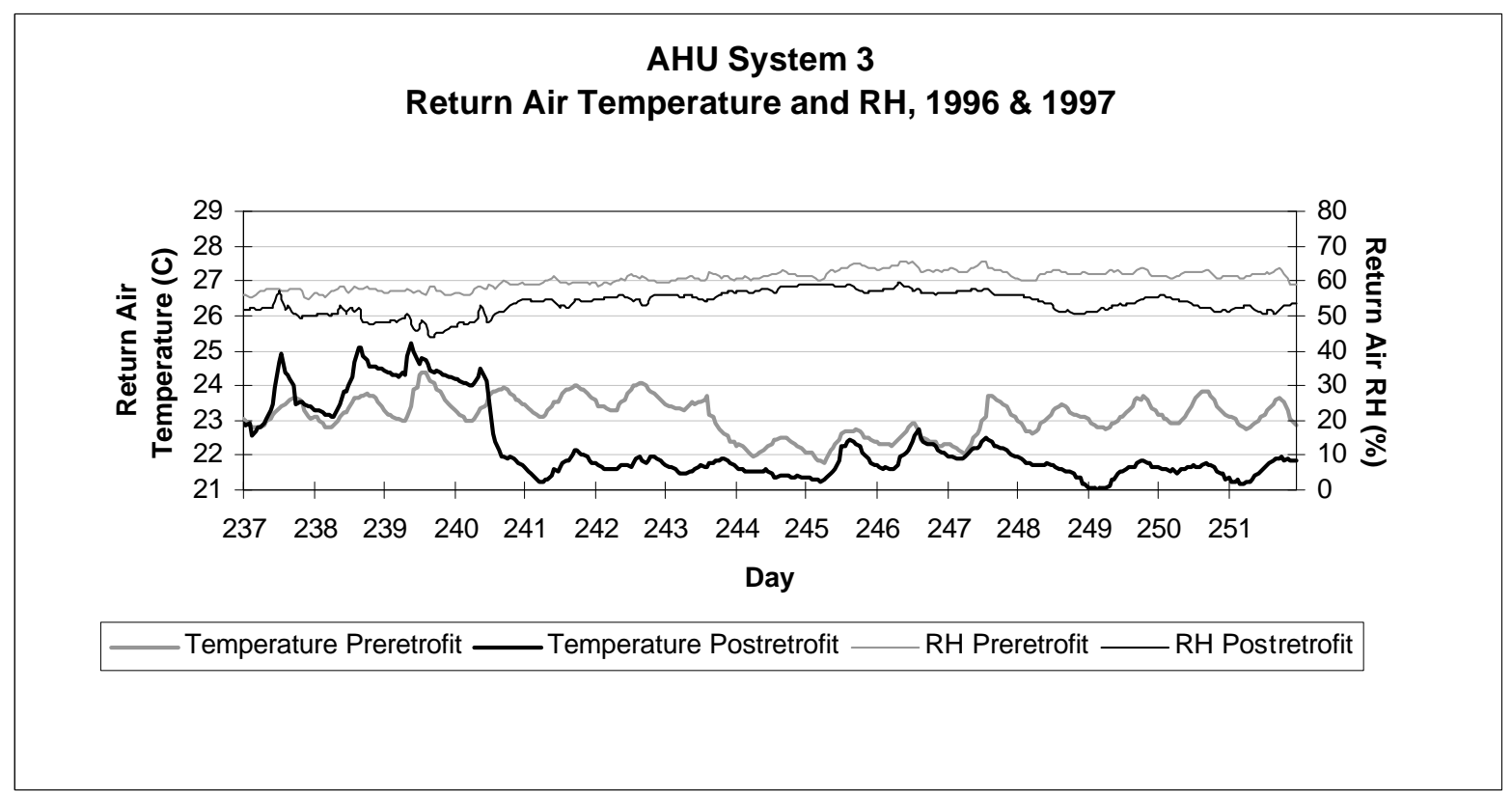

Figure 14. Direct comparison of space conditions, AHU-3.

\section{Known Differences Between the Preretrofit and Postretrofit Periods}

For a direct comparison of data to be meaningful, the only appreciable difference between the two periods should be the addition of the heat pipes. Other changes, such as maintenance improvements, equipment replacement, new control mechanisms, changes in space loads and outdoor conditions could easily alter the chiller energy use, reheat consumption, or space conditions. A direct comparison of the data might wrongly attribute the sum of all these changes to the heat pipes. Because Hangar L was in continuous use and not placed under any constraints regarding these issues, it is certain that some of these changes did take place during the monitored period.

All of the known and likely differences between the preretrofit and postretrofit periods will be described in this section. These issues will then be addressed in the chapter on System Performance Modeling.

\section{New Condenser and Compressors for 55-ton Chiller}

Possibly the most significant difference between the preretrofit and postretrofit periods, other than the addition of the heat pipes, is in the improvements made to the 55-ton chiller. Soon after the heat pipe retrofit, the condensers were replaced as part of regular maintenance (figure 6 shows the new condensers waiting in crates to be installed.) New compressors were installed in the summer of 1997, effectively replacing the chiller. The new condensers and compressors significantly increased the cooling capacity of this "new" chiller. The old chiller was not meeting the high sensible and latent loads during the summer. The new chiller utilized all of its additional capacity during these months. As shown in Figure 15, this had the effect of increasing chiller energy use as well as improving the space conditions served by this chiller. The increased capacity of the chiller also allowed for greater dehumidification, which in turn, may have led to higher reheat requirements. 


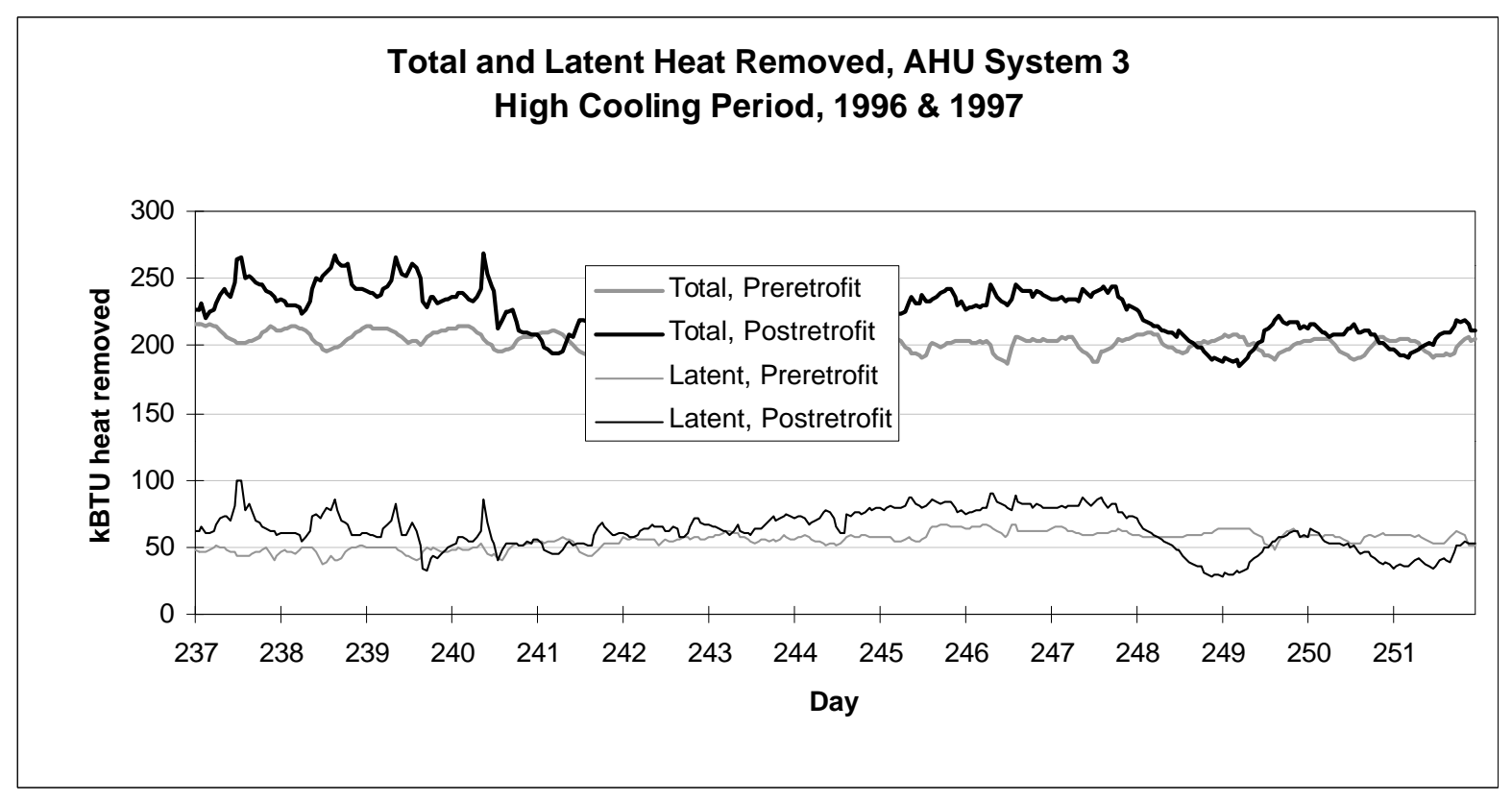

Figure 15. Total heat removed, AHU-3, showing increased cooling capacity in the postretrofit period.

The changes caused by the new chiller affect the same HVAC system parameters that the heat pipe installation was intended to affect (reheat power, chiller power, and space conditions), and create some ambiguity regarding the effects of the heat pipe. This problem will be addressed in the following chapter that describes the System Performance Model.

\section{Air Flow Rates}

As discussed in Post-Retrofit Monitoring and Evaluation Report dated November 1997 (Appendix B), the supply air flow rates were measured for each air handler both before and after the retrofit. Table 1 displays the cubic feet per minute (CFM) for each air handler as specified in the design documents, as measured before the retrofit, and as measured after the retrofit.

A significant change in airflow can alter the HVAC system capacity and the SHR of the cooling coil. Though some decrease in flow rate may be associated with the installation of the heat pipe, as with AHU-3, the airflow increase of AHU-1 and the 25\% decrease in air flow of AHU-2 are assumed to be independent changes to the HVAC systems.

Table 1. Supply Air Flow Rates.

\begin{tabular}{|c|c|c|c|}
\hline Air Handler & $\begin{array}{c}\text { As Designed } \\
\text { CFM }\end{array}$ & $\begin{array}{c}\text { Before Retrofit } \\
\text { CFM }\end{array}$ & $\begin{array}{c}\text { After Retrofit } \\
\text { CFM }\end{array}$ \\
\hline AHU-1 & 15,800 & 12,600 & 13,800 \\
\hline AHU-2 & 5,765 & 6,800 & 5,000 \\
\hline AHU-3 & 8,675 & 9,900 & 9,400 \\
\hline
\end{tabular}




\section{Chilled Water Control}

There is some evidence that the mechanism for controlling the cooling coil capacities changed during the course of the monitoring period. Figure 16 indicates that the chilled water temperature was lower after the retrofit, especially for chiller 2 . This is most likely a result of changing the condenser and possibly changes in the control settings. The chilled water supply temperature can affect the SHR of the coil.

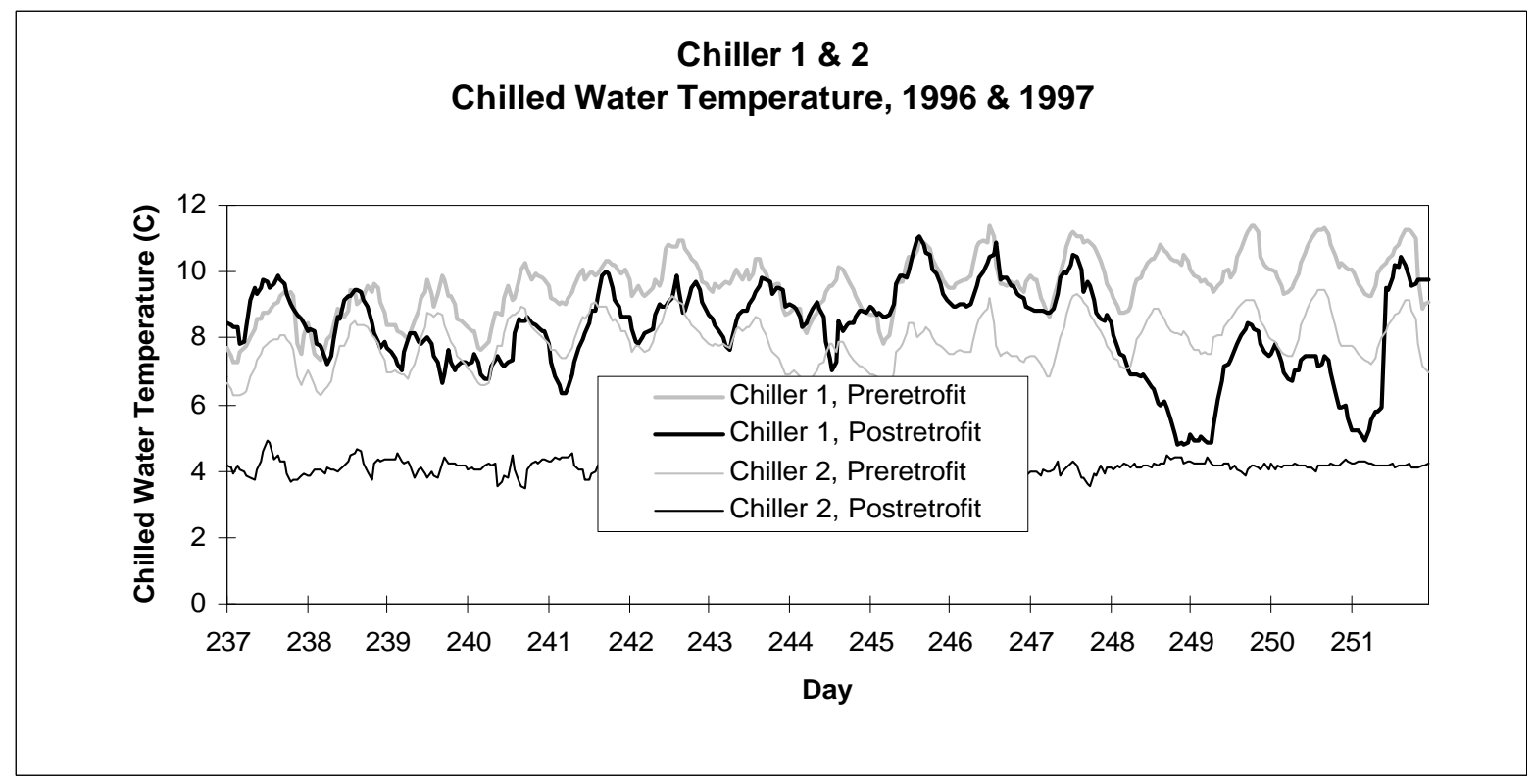

Figure 16. Chilled water supply temperatures during preretrofit and postretrofit periods.

\section{Changes in Load and Ambient Conditions}

There is no evidence that the load of the spaces served by these HVAC systems changed significantly between the preretrofit and postretrofit periods. It is known, however, that the loads in the animal care area served by AHU-1 can vary from month to month as some projects are completed and others begin. Changes observed in the return air RH between the two different periods could be caused by differing humidity loads in the spaces.

Ambient conditions were very similar between the preretrofit and postretrofit periods, especially during the overlapping period of late summer and early fall. Over any extended period, it is not likely that changes in the weather lead to any significant differences in energy use between the two monitored periods.

\section{Observations on Direct Comparison of Data}

This chapter has shown that a direct comparison of the monitored data does not necessarily lead to any satisfying answers regarding the heat pipe performance. However, the monitored data does lead to some general, qualitative inferences:

- For most systems, space conditions improved after the heat pipes were installed

- The monitored electric reheat energy appears to be smaller during the postretrofit period

- Chiller energy did not differ greatly between the preretrofit and postretrofit periods. 


\section{System Performance Modeling and Annual Energy Prediction}

In order to predict the annual energy savings of the heat pipe retrofit, it is necessary to distinguish between the influence of the heat pipes and the influence of other factors on the annual energy use of the HVAC systems under analysis. The previous section points to a number of other known differences between the preretrofit and postretrofit periods that might affect the HVAC energy use. In this chapter, the analysis will attempt to isolate the changes due to the heat pipes and then apply these changes to an annual simulation of the HVAC systems. The simulation will predict the annual energy use of each HVAC system with and without the changes attributed to the heat pipes, leading to an annual energy savings prediction.

\section{Modeling Approach}

The modeling approach utilizes the monitored data to characterize individual components of each HVAC system. These components are then used to simulate the energy use of each HVAC system on an hourly basis. Changes caused by the heat pipe are accounted for in the preretrofit and postretrofit annual simulations, while changes due to other influences can be adjusted for and eliminated from the analysis. The individual components are described below, with a description of how each component is characterized and used. Details of the actual calculation are presented in subsequent sections of the report.

- Space sensible heat load:

The space sensible heat load is determined from the monitored data, based on the temperature of the air delivered to the spaces (after any reheat), the return air temperature and the supply air flow rate. By applying regression analysis to a year's worth of calculated space sensible heat load and ambient conditions, the sensible heat load can be predicted based on ambient conditions of drybulb temperature and relative humidity. During the annual simulation, the estimated space sensible heat load is used to calculate the required supply air temperature as well as the return air temperature.

- Space latent heat load:

The space latent heat load is determined from the monitored supply and return air relative humidity. Regression analysis applied to the calculated latent heat load and ambient conditions yields a prediction of the latent load based on ambient conditions of drybulb temperature and relative humidity. The space latent heat load is used to determine the conditions of the return air for each hour of the annual simulation.

- Mixed air fractions of return and outdoor air:

The fraction of outdoor air added to the return air was measured during the system audits, and is used to calculate the mixed air temperature (return air plus mixed air).

- Cooling coil capacity:

The maximum cooling coil capacity, as observed from the monitored data, is used as a limit on the hourly heat extraction.

- Chilled water temperature:

It was observed from the monitored data that the chilled water temperature to the coil could be predicted based on the space sensible and latent load. The chilled water temperature is used as an independent variable in predicting the cooling coil SHR.

- Cooling coil SHR:

The cooling coil sensible-heat-ratio is predicted for each cooling coil based on separate regression analyses for the preretrofit and postretrofit periods. The independent variables for the regression analyses are the drybulb temperature of the air entering the coil, the relative humidity of the air entering the coil, and the temperature of the chilled water entering the coil. The SHR is used to determine the conditions of the air leaving the cooling coil. 
- Supply air temperature and RH control:

The supply air temperature used for the simulation is based on the minimum supply air temperature measured in the conditioned spaces. The maximum allowed moisture content of the supply air, expressed as the humidity ratio, is controlled based upon average measured data for each system.

- Ambient conditions:

Ambient conditions of drybulb temperature and relative humidity were measured during the entire 14month monitoring period. A 1-year period of data is used for the simulation model.

The model created for this analysis is fairly simple and is not intended to accurately predict the total energy use of the HVAC system. Instead, it focuses on predicting the change in cooling energy and reheat energy as a direct result of changes in the cooling coil characteristics, as influenced by the heat pipes. Where changes occurred to other aspects of the HVAC system, the conditions that existed after the retrofit are used for the simulation. These changes (supply flow rate and chiller components, for example) would have occurred regardless of the heat pipe installation and actual savings are, therefore, better characterized by the conditions that existed soon after the heat pipe was installed.

There are two components of the reheat energy used in these HVAC systems. One component is reheat energy used as a control mechanism to supply air of the proper temperature to each space. Each multizone, constant volume system must supply air cold enough to cool the zone with the greatest cooling load relative to supply volume that it serves. All other spaces not requiring supply air at this low temperature must reheat the supply air to prevent over-cooling. The heat pipes are not intended nor expected to reduce this type of reheat energy requirement.

The second component of reheat energy is the energy required to reheat the supply air that was cooled (for dehumidification purposes) below the minimum temperature required by the space cooling loads. The heat pipes are intended to reduce or eliminate this reheat requirement by allowing the cooling coils to remove more moisture from the air for the same amount of cooling coil load (i.e. by lowering the cooling coil SHR). The model is intended to predict the cooling coil load and the amount of reheat needed to bring the supply air up to the minimum temperature required by the space loads.

The essential comparison regarding the heat pipe installation is how much energy the HVAC systems would use in a typical year with the heat pipes versus how much energy the systems would use in a typical year without the heat pipes. The simulation model will use the current conditions, including the new air flow rates and increased chiller capacity, to model the systems with and without the heat pipes.

\section{Annual Energy Prediction for AHU-1}

AHU-1 uses chilled water from the 110-ton chiller, has two cooling coils in series and utilizes $100 \%$ outdoor air taken from inside the hangar. Because it uses $100 \%$ outside air, the system has a very large latent load. Figure 12 shows that the system does not adequately regulate humidity levels in the space. Even after the heat pipes were installed, humidity levels have sometimes reached $70 \%$ in the spaces.

\section{Calculating the Space Sensible and Latent Loads}

The Hobo® data loggers recorded supply air temperatures delivered to the areas served by this HVAC system. These temperatures are monitored after any reheat energy is added to the supply air stream. The average sensible load of the spaces is determined by observing the difference in the average return air temperature (return air from all spaces mixed together) and the average delivery air temperature, as recorded by the Hobo data loggers, Figure 17. 


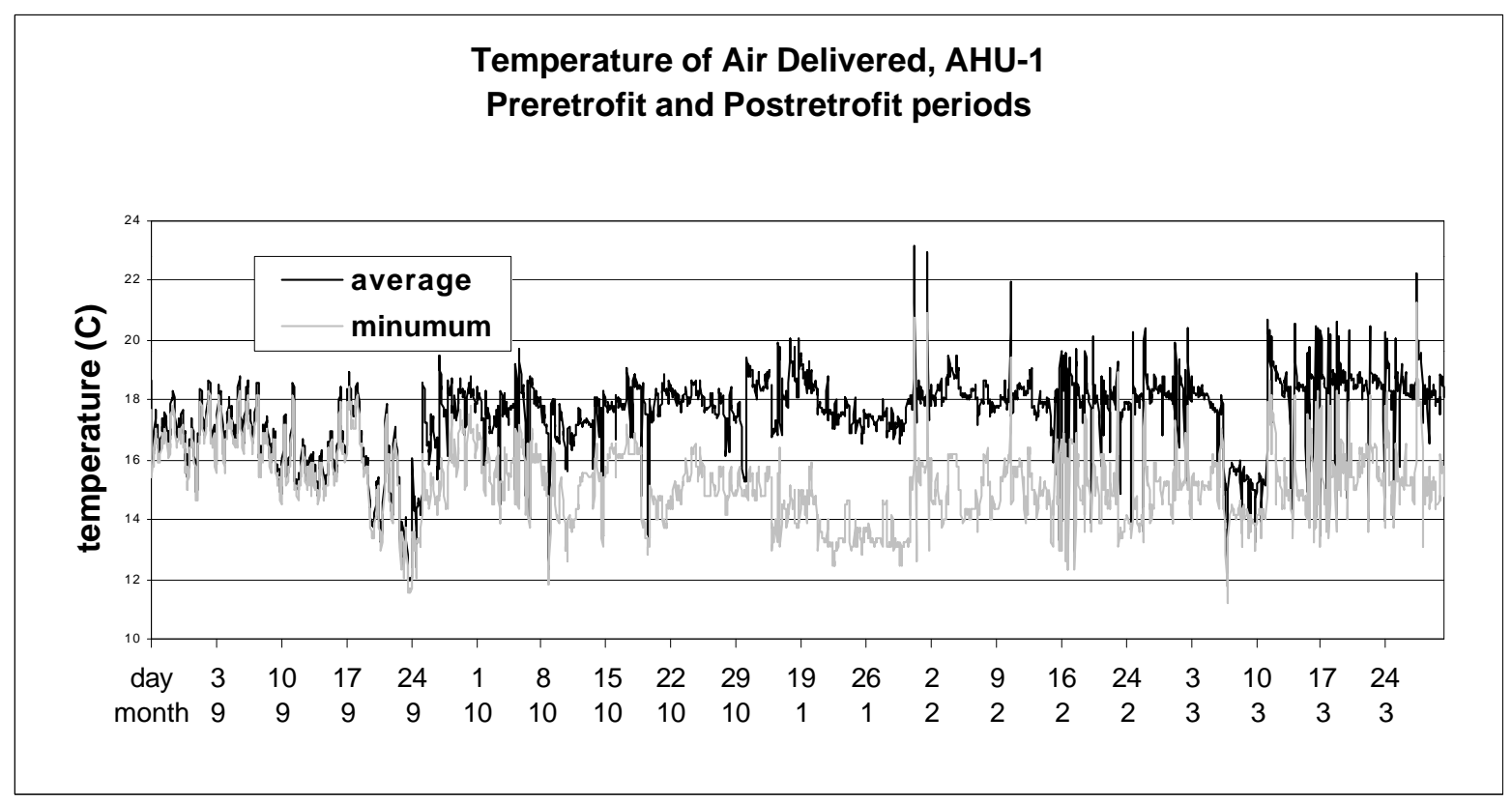

Figure 17. Average delivered air temperatures for AHU-1

The load is calculated as:

Space Sensible Load $=($ Return Air Temperature - Delivered Air Temperature $) *$ Flow Rate

* Sensible Heat Capacity of the Air Flow

or, Load $=($ Tret - Tdel $) *$ Air Flow * 1.08

where: the Load is in BTU/hr,

Temperatures are in degrees $\mathrm{F}$,

Tret is the monitored return air temperature

Tdel is the delivery air temperature, as monitored by the Hobo data loggers,

Air Flow is the Supply/Return air volume, in CFM

A full year of the postretrofit data was used to determine the hourly space sensible loads. This data was then used as the dependent variable in a regression analysis, with ambient temperature used as the independent variable. An equation was thus derived such that the hourly space sensible load can be predicted based on ambient temperature. The space humidity load was determined by comparing the humidity ratio of the air entering the spaces and the humidity ratio of the return air. In a manner similar to the sensible load regression, the space latent load can be predicted based on outdoor humidity ratio and temperature.

\section{Predicting the Coil Sensible Heat Ratio}

The heat pipe's main function is to lower the SHR of the cooling coil. Analysis of the monitored data reveals that no such reduction was achieved with this AHU. Figure 18 shows the SHR of the precool and main cooling coils for the preretrofit and postretrofit periods. While the SHR of the precool coil is sometimes lower during the postretrofit period, it is not typically lower after the heat pipe was installed. The SHR of the main cooling coil is clearly higher after the heat pipe was installed. 


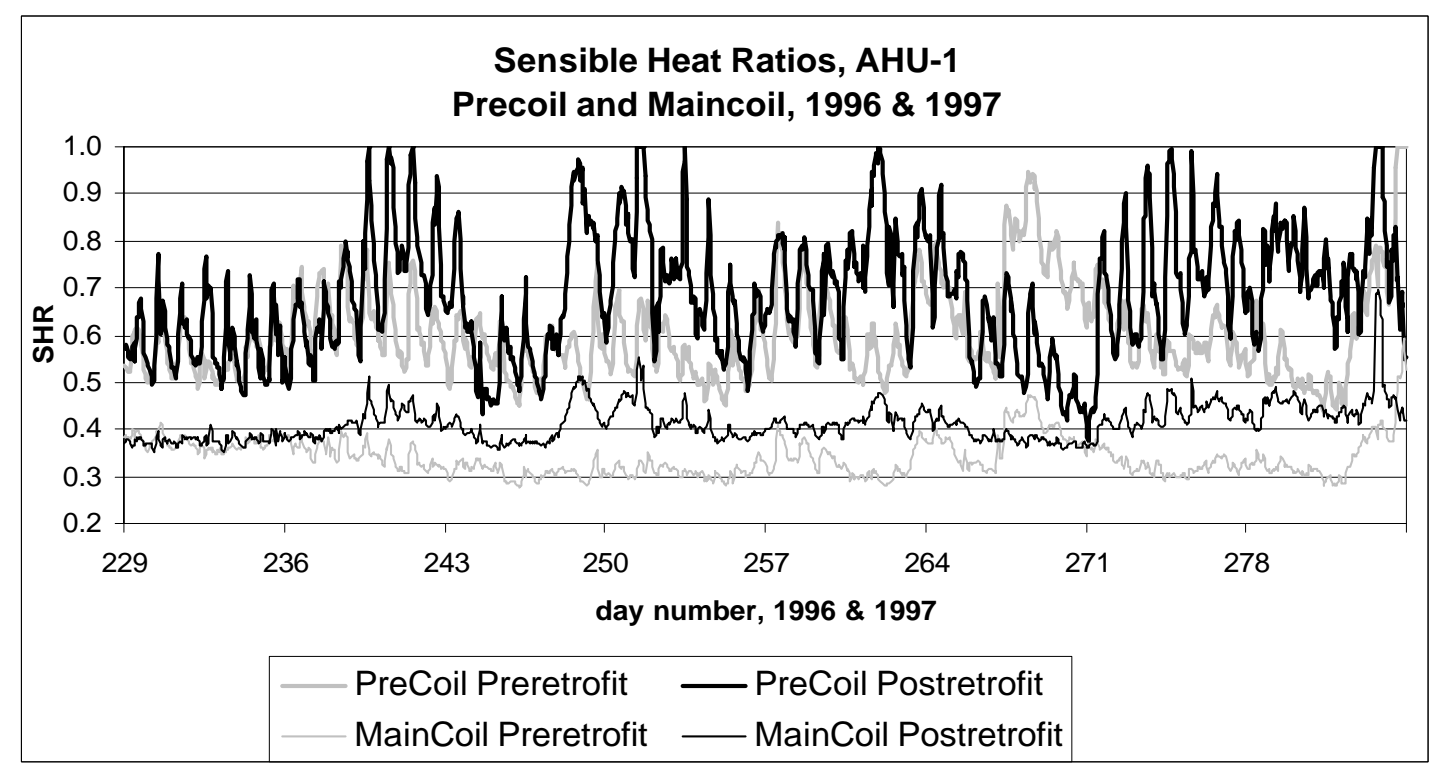

Figure 18. SHR for precool and main cooling coils, AHU-1, preretrofit and postretrofit periods

This AHU has two cooling coils in series so that it can achieve relatively high latent heat removal (see Figure 5). Air coming off the precool coil is close to saturated, allowing the main coil to remove the maximum amount of moisture possible. The introduction of the heat pipe around the precool coil may lower the SHR of this coil slightly, but it also causes the air entering the main coil to be well above its saturation point. Applied in this way, the heat pipe interferes with the AHU's original design, which was already engineered to remove a large amount of moisture.

Figure 19 shows the SHR of the combined coils of AHU-1. The overall SHR does not appear to be significantly different between the two periods. Using regression analysis to predict the SHR based on the entering air conditions and the chilled water temperature confirms this SHR similarity. The overall SHR with the heat pipe is predicted to be slightly higher than without the heat pipe.

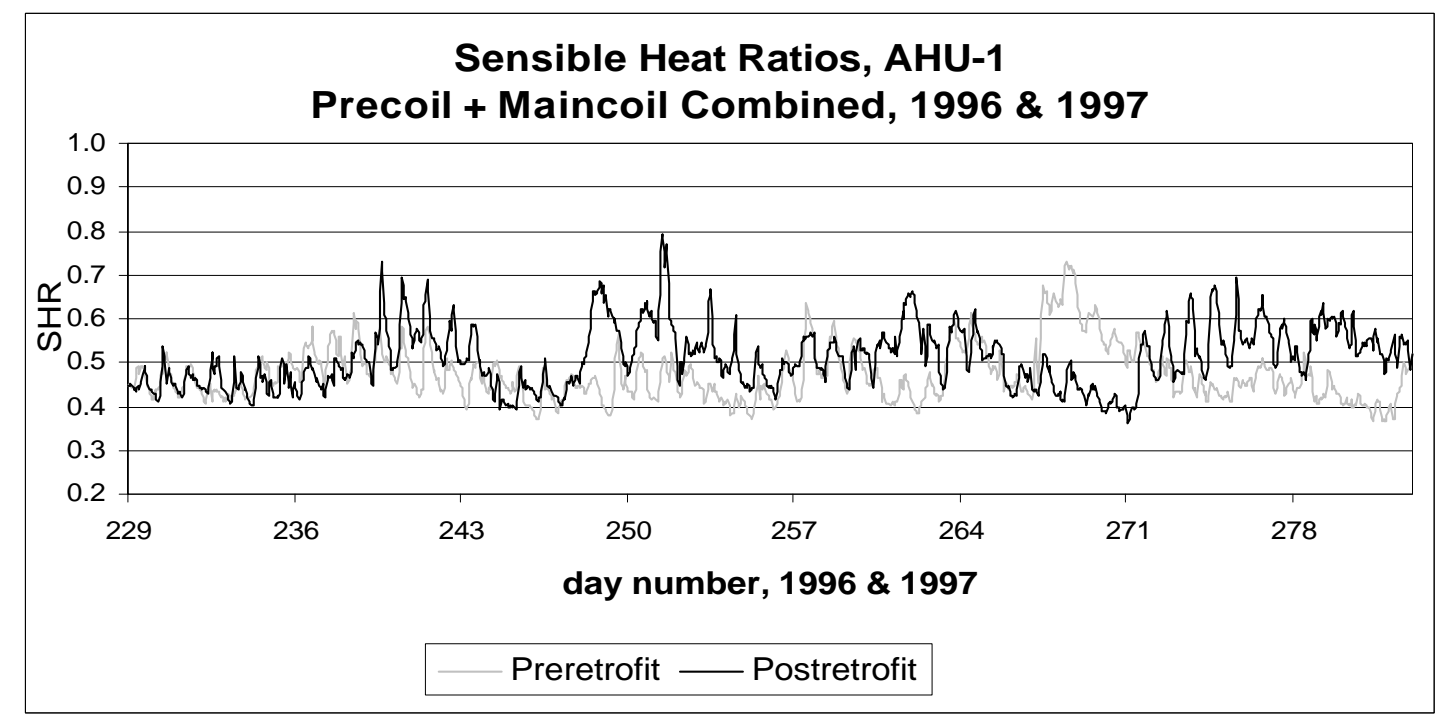

Figure 19. SHR for combined precool + main cooling coils, AHU-1, preretrofit and postretrofit periods 
Because this result has such an important and unexpected impact on the results of this retrofit analysis, efforts were made to verify the accuracy of the monitored data regarding the calculation of the SHRs. The overall SHR was calculated from the monitored data in two ways. Air conditions were monitored before the precool coil, between the two coils, and after the main cooling coil. The first two data points were used to calculate the sensible and latent heat removed by the precool coil. Likewise, the second two data points were used to calculate the sensible and latent heat removed by the main coil. The overall SHR was then calculated by adding the heat removed from each coil. Alternatively, the air conditions entering the precool coil and the air conditions leaving the main coil were used to determine the overall SHR. Both methods led to the same result, lending confidence to the monitored data.

\section{Annual Energy Savings}

The annual energy prediction is based on all conditions being the same, except for the heat pipe's effect of the SHR. For this system, the heat pipe did not have a positive effect on the SHR, and no energy savings are predicted.

\section{Discussion and Conclusions}

The heat pipe had no positive effect on lowering the overall SHR of the two cooling coils. As originally designed, this combination of cooling coils was able to achieve SHRs at, and even below, 0.4. Applying the heat pipe to the precool coil defeated the original design of having saturated air entering the main cooling coil and did not lead to a lower SHR, nor any reheat or chiller energy savings.

\section{Annual Energy Prediction for AHU-2}

AHU-2 uses chilled water from the 55-ton chiller, has a single cooling coil and has a fresh-air ratio of $13 \%$ ducted from outside the hangar. Figure 13 shows that this system achieved very good RH control after the retrofit, but with little change in the space drybulb temperatures.

\section{Calculating the Space Sensible and Latent Loads}

The actual space sensible load can be calculated based on the monitored data for supply air conditions, return air conditions and the amount of reheat used. The sensible load is calculated as:

$$
\begin{aligned}
\text { Space Sensible Load }= & (\text { Return Air Temperature }- \text { Delivered Air Temperature }) * \text { Flow Rate } \\
& * \text { Sensible Heat Capacity of the Air Flow }
\end{aligned}
$$

or, $\quad$ LOADsens $=($ Tret - Tdel $) *$ Air Flow $* 1.08$

In this case, the delivered air temperature is calculated based on the monitored supply air temperature and the amount of reheat energy used:

Tdel $=$ Tsup + Reheat Energy $/($ Air Flow * 1.08)

where: LOADsens is the sensible load, in Btu/hr, Temperatures are in degrees $\mathrm{F}$,

Tret is the monitored return air temperature $(\mathrm{F})$, Tsup is the monitored supply air temperature $(\mathrm{F})$,

Tdel is the delivery air temperature $(F)$, Reheat Energy is the monitored reheat energy (Btu/hr), Air Flow is the Supply/Return air volume, in CFM 
The space sensible load is calculated for each hour of the 1997 postretrofit monitored data and used for the model simulation. Since this load is assumed to be independent of the HVAC performance, the values determined for the 1997 period are used for both the preretrofit and postretrofit simulations. The daily average sensible loads are shown in Figure 20.

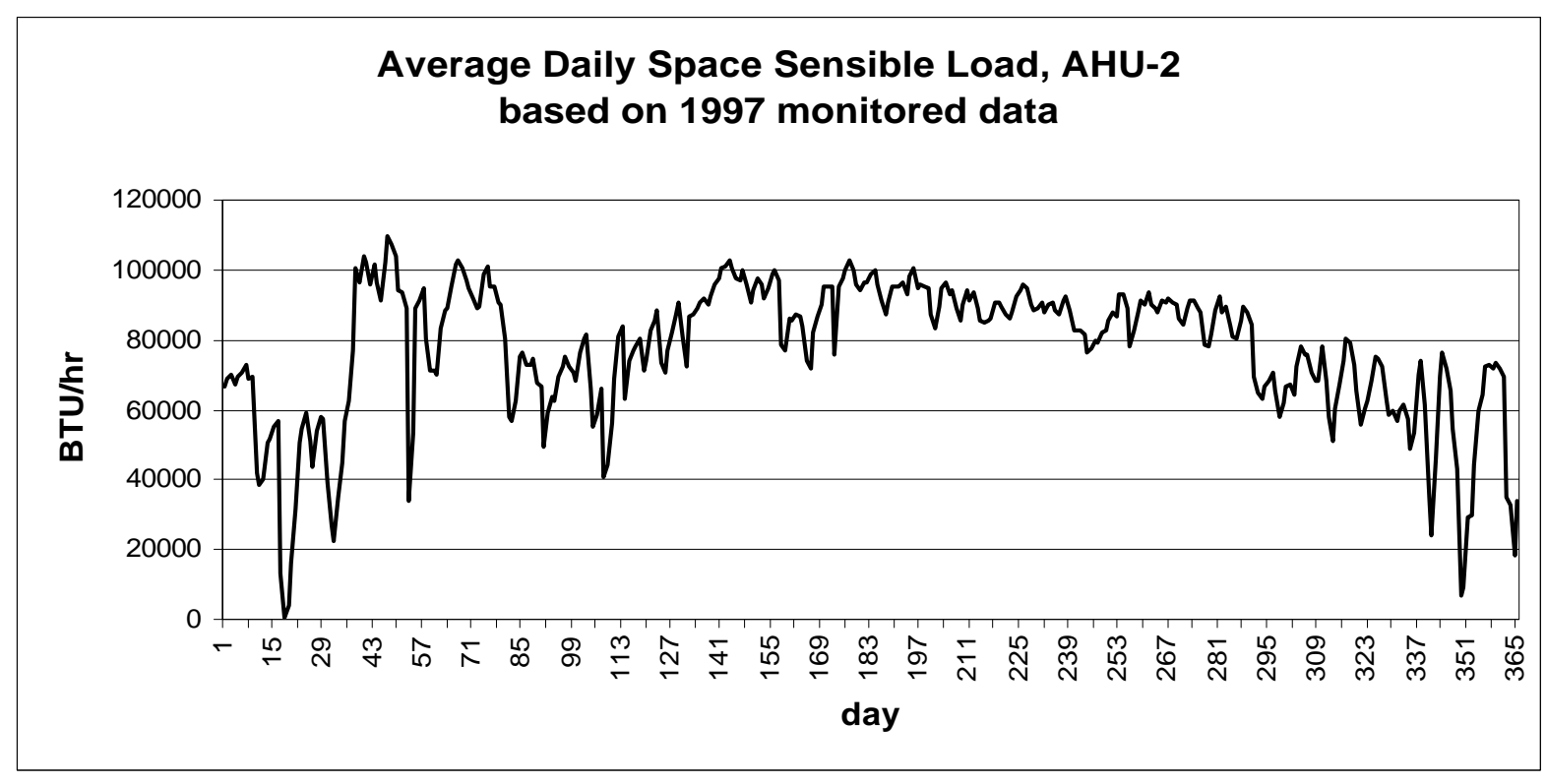

Figure 20. Average space sensible load used for simulation, AHU-2

The space latent load was determined by comparing the humidity ratio of the air entering the spaces and the humidity ratio of the return air. As with the sensible loads, the latent load is determined for each hour of the 1997 period and used for both the preretrofit and postretrofit simulations. The daily average latent loads are shown in Figure 21.

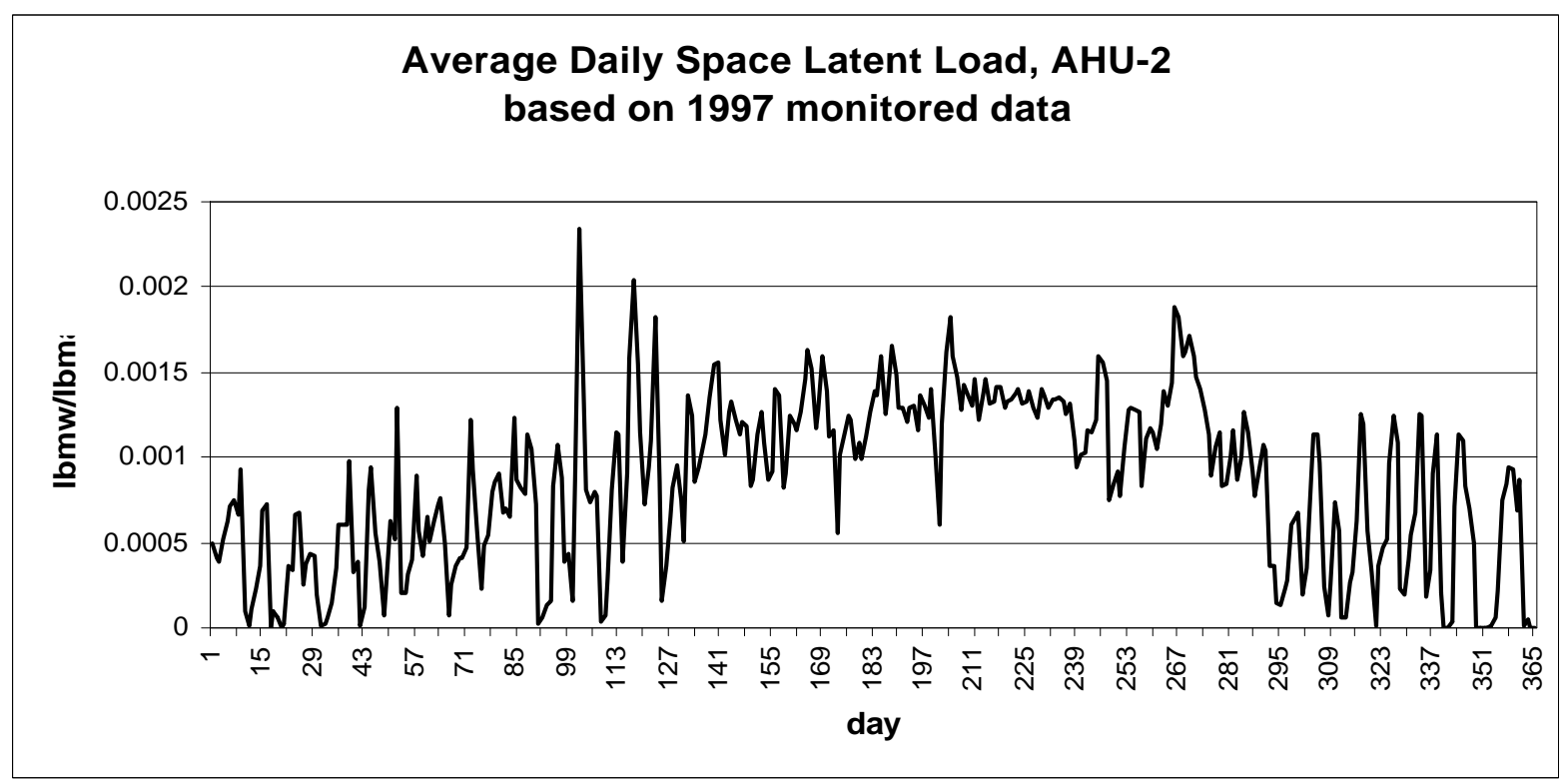

Figure 21. Average space latent load used for simulation, AHU-2 


\section{Predicting the Coil Sensible Heat Ratio}

The SHR for the cooling coil was calculated from monitored data for each hour of the preretrofit and postretrofit periods. Least-squares fit regression analysis was then performed to predict the SHR based on the entering air conditions and entering chilled water temperature for the two different periods. The form of the equation for the SHR is:

$$
\text { SHR }=\mathrm{c} 0+\mathrm{c} 1(\text { Tent })+\mathrm{c} 2(\text { RHent })+\mathrm{c} 3(\mathrm{CWT})
$$

Where: Tent is the entering air temperature (C),

RHent is the entering air $\mathrm{RH}(\%)$

CWT is the entering chilled water temperature $(\mathrm{C})$

$\mathrm{c} 0, \mathrm{c} 1, \mathrm{c} 2, \mathrm{c} 3$ are regression coefficients.

Figures 22 and 23 show the measured and the predicted SHR for the preretrofit period and the postretrofit period. The regression captures hourly and seasonal variations of the SHR; the 4-coefficient equation accounts for more than $90 \%$ of the variation present in the monitored data.

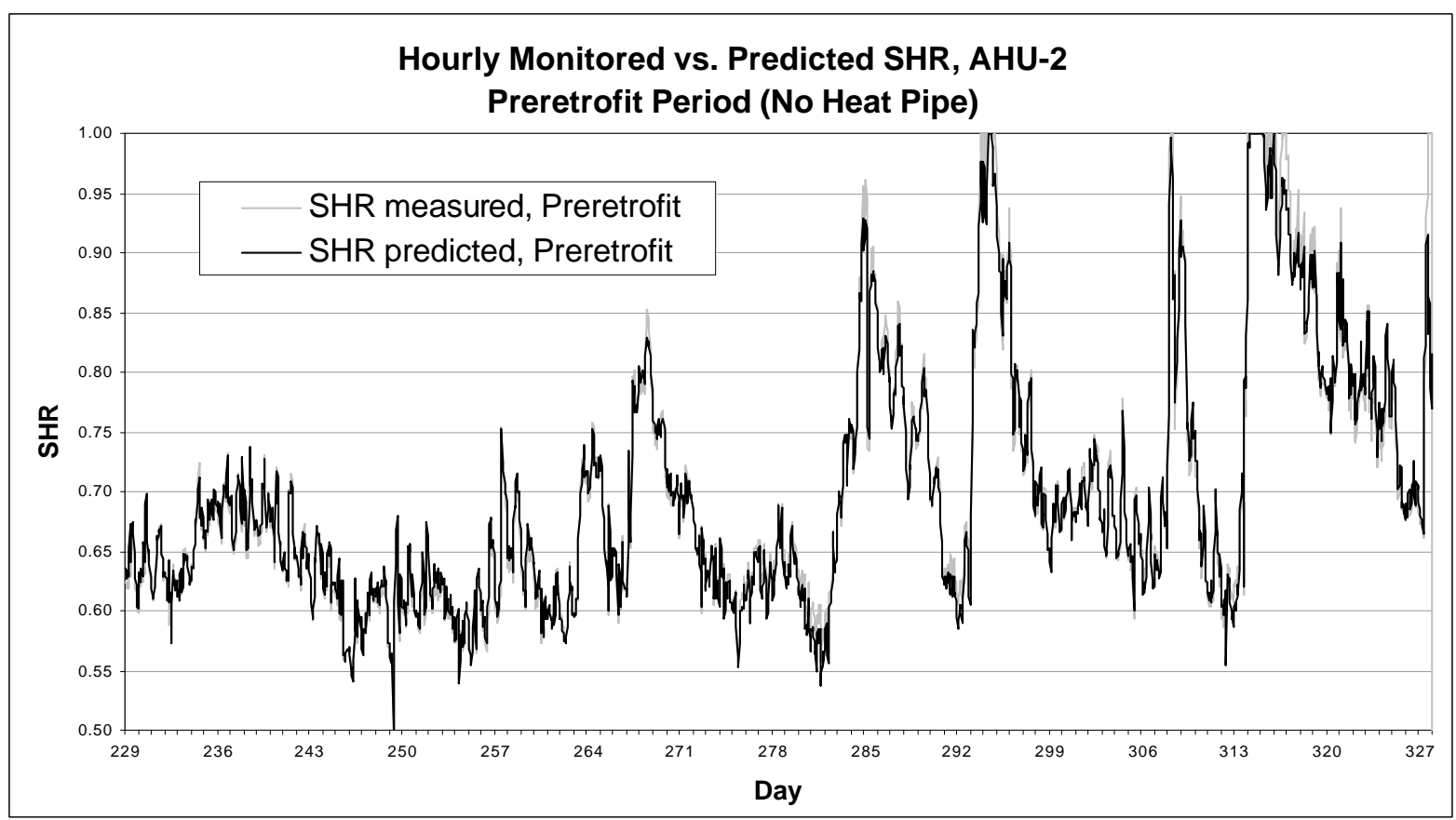

Figure 22. Predicted vs. measured SHR for AHU-2, preretrofit period 


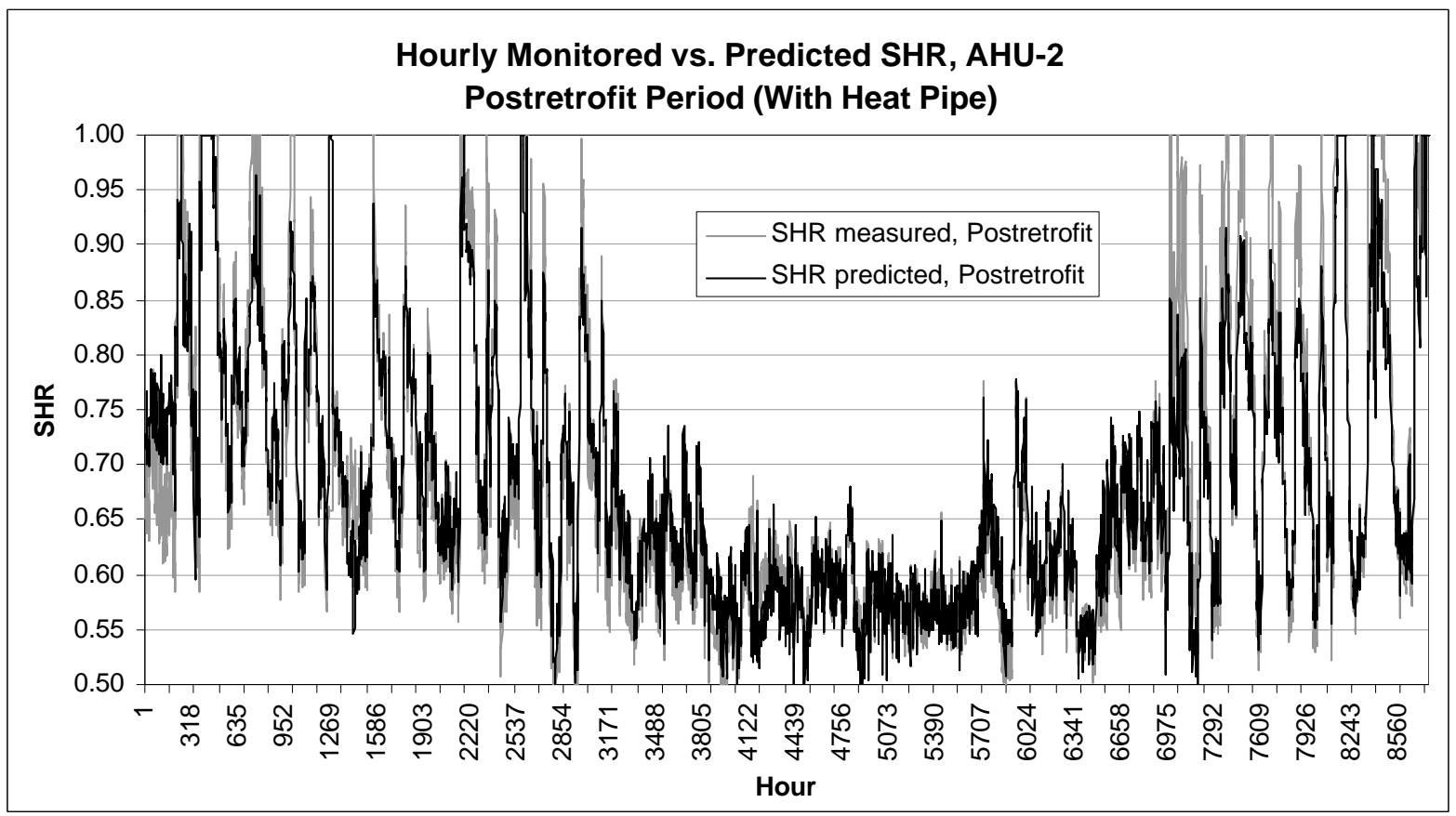

Figure 23. Predicted vs. measured SHR for AHU-2, postretrofit period

Figure 24 shows the daily average predicted SHR for a 1-year period with and without the heat pipe retrofit. The heat pipe clearly lowers the SHR by a significant amount, as much as 5 to $8 \%$ during the summer months.

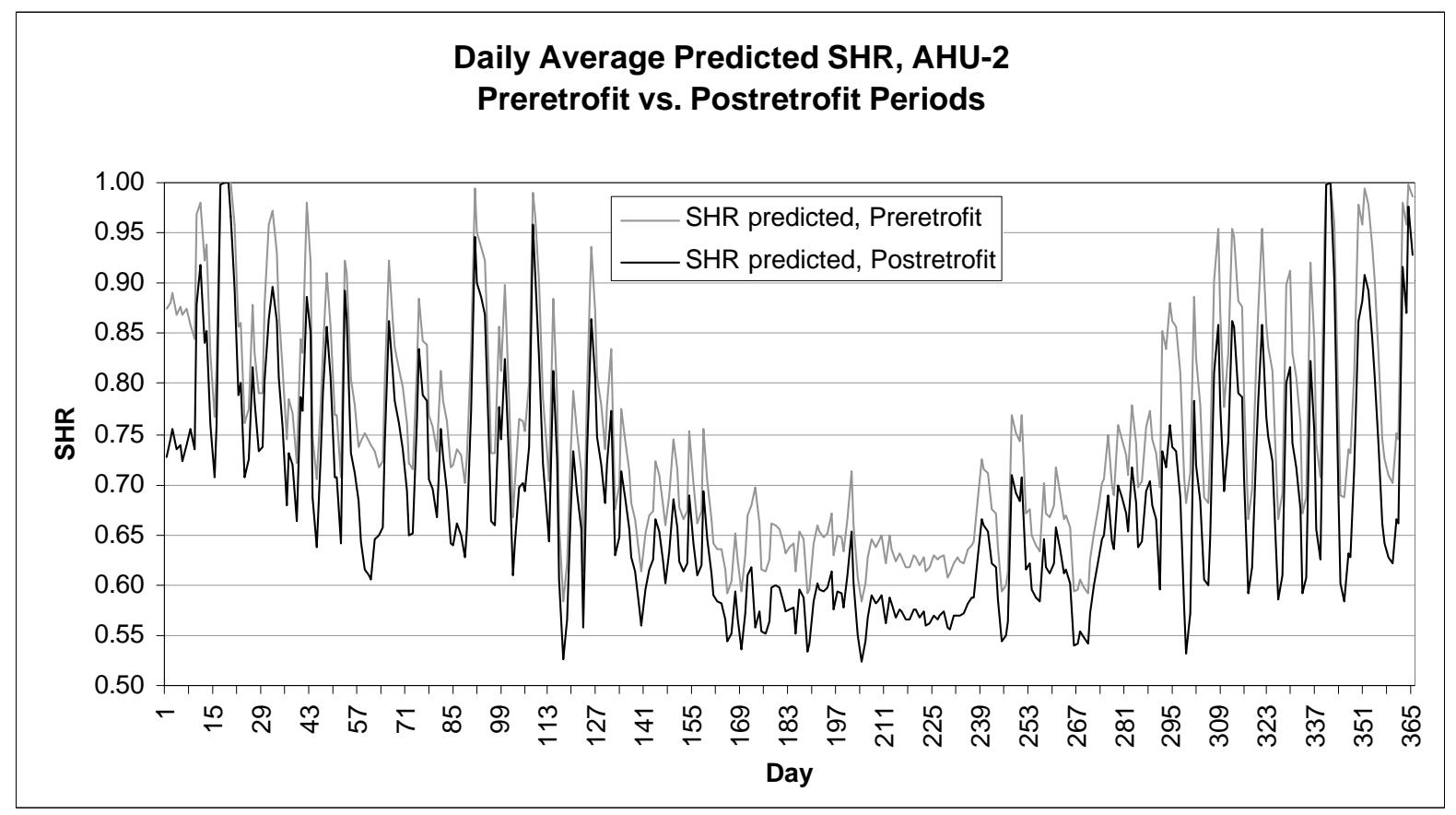

Figure 24. Daily average predicted SHR, with and without the heat pipe retrofit 


\section{Annual Energy Savings}

The HVAC system model predicts energy use based on attempting to meet both the sensible and latent space comfort conditions. The space temperature is controlled to $24^{\circ} \mathrm{C}$, and the supply air humidity ratio is maintained at or below 0.010 pounds mass of water per pound mass of air (lbmw/lbma). The cooling coil and reheat capacities are accounted for, as are the supply flow rate and the variable chilled water temperature. Reheat energy required to raise the supply air temperature above the minimum temperature required by any space is not accounted for, but, as discussed above, is not affected by the heat pipe installation.

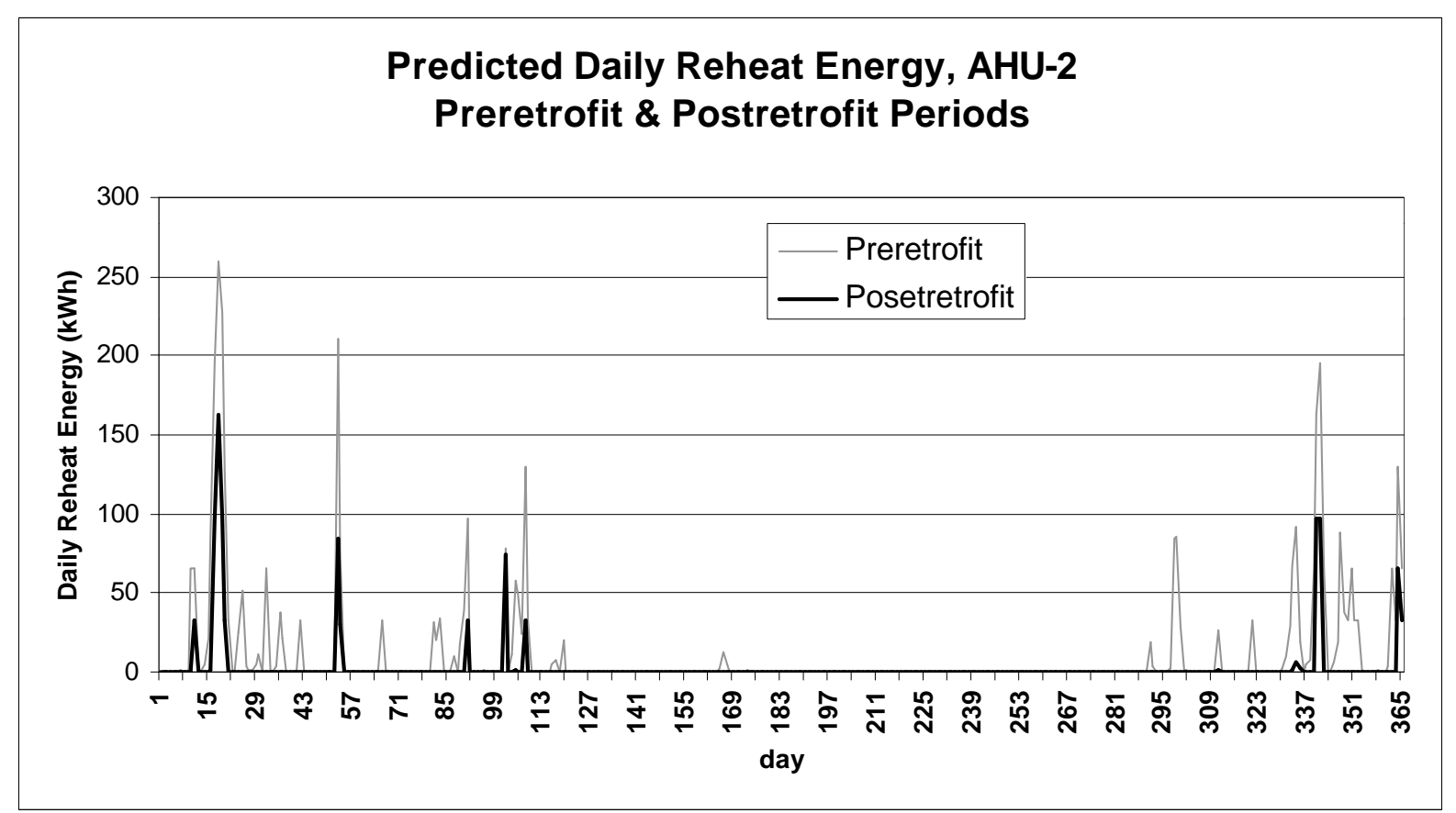

Figure 25. Predicted daily reheat, with and without the heat pipe, AHU-2

The simulation indicates that almost no reheat is required due to dehumidification requirements and that slightly more cooling coil load is needed because of the heat pipe. The reheat requirements are reduced by approximately $3000 \mathrm{kWh}$, while the cooling coil load increases by 880 ton-hours. The net energy savings are approximately $1600 \mathrm{kWh}$.

\section{Discussion and Conclusions}

The monitored data (Figure 7) indicate that this system might have saved a significant amount of reheat energy during the shoulder seasons before and after the summer months. The simulation, however, indicates that dehumidification requirements caused very little reheat energy use, either with or without the heat pipe (Figure 25).

The main cause for this phenomenon is the decrease in the supply air flow rate that coincided with the heat pipe installation. Also, the cooling coil for this HVAC system has a relatively low SHR, even without the addition of the heat pipe. During periods of high latent load, the coil had an SHR between 0.60 and 0.65 (compare this with AHU-3, Figure 30). 
The addition of the heat pipe lowered the cooling coil's SHR and at the same time, the decrease in supply air flow rate lowered the minimum required supply air temperature to meet the space loads. As a result, the system rarely needs to cool the supply air below the minimum temperature required by the hottest space in order to achieve satisfactory humidity control.

Had the supply air flow rate not changed between the preretrofit and postretrofit periods, the simulation indicates that the reheat energy requirements would be significantly higher, and the heat pipe would have displaced approximately $12,000 \mathrm{kWh}$ of the reheat energy. Reducing the supply flow rate, however, saves an even greater amount of energy and does not adversely affect space conditions.

The heat pipe installation for AHU-2 provided little benefit because:

- Increased capacity due to lower chilled water temperature and lower supply air flow rate essentially eliminated the reheat requirement.

- The existing cooling coil has a relatively low SHR.

\section{Annual Energy Prediction for AHU-3}

AHU-3 uses chilled water from the 55-ton chiller, has a single cooling coil and has a fresh-air ratio of $15 \%$ taken from inside the hangar. Figure 14 shows that this system achieved perhaps the best temperature and $\mathrm{RH}$ control in the spaces it serves, both before and after the heat pipe retrofit.

\section{Calculating the Space Sensible and Latent Loads}

The actual space sensible load can be calculated based on the monitored data for supply air conditions, return air conditions, and the amount of reheat used. The sensible load is calculated as:

Space Sensible Load $=($ Return Air Temperature - Delivered Air Temperature $) *$ Flow Rate

* Sensible Heat Capacity of the Air Flow

or, $\quad$ LOADsens $=($ Tret - Tdel $) *$ Air Flow $* 1.08$

In this case, the delivered air temperature is calculated based on the monitored supply air temperature and the amount of reheat energy used:

Tdel $=$ Tsup + Reheat Energy $/($ Air Flow $* 1.08)$

where: LOADsens is the sensible load, in Btu/hr,

Temperatures are in degrees $\mathrm{F}$,

Tret is the monitored return air temperature $(\mathrm{F})$,

Tsup is the monitored supply air temperature $(\mathrm{F})$,

Tdel is the delivery air temperature $(\mathrm{F})$,

Reheat Energy is the monitored reheat energy (Btu/hr),

Air Flow is the Supply/Return air volume, in CFM

The space sensible load is calculated for each hour of the 1997 postretrofit monitored data and used for the model simulation. Because this load is assumed to be independent of the HVAC performance, the values determined for the 1997 period is used for both the preretrofit and postretrofit simulations. The daily average sensible loads are shown in Figure 26. 


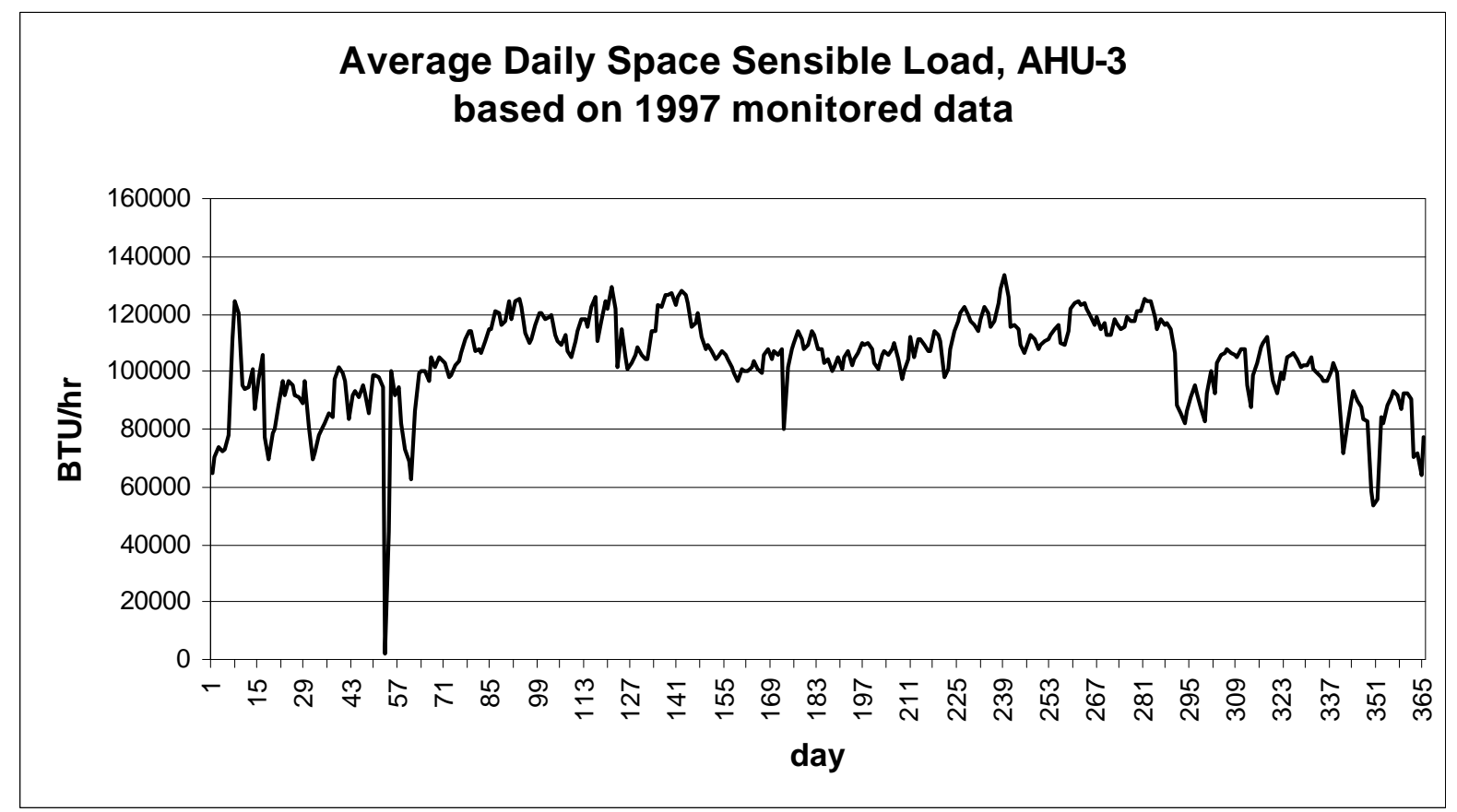

Figure 26. Average space sensible load used for simulation, AHU-3

The space latent load was determined by comparing the humidity ratio of the air entering the spaces and the humidity ratio of the return air. As with the sensible loads, the latent load is determined for each hour of the 1997 period and used for both the preretrofit and postretrofit simulations. The daily average latent loads are shown in Figure 27.

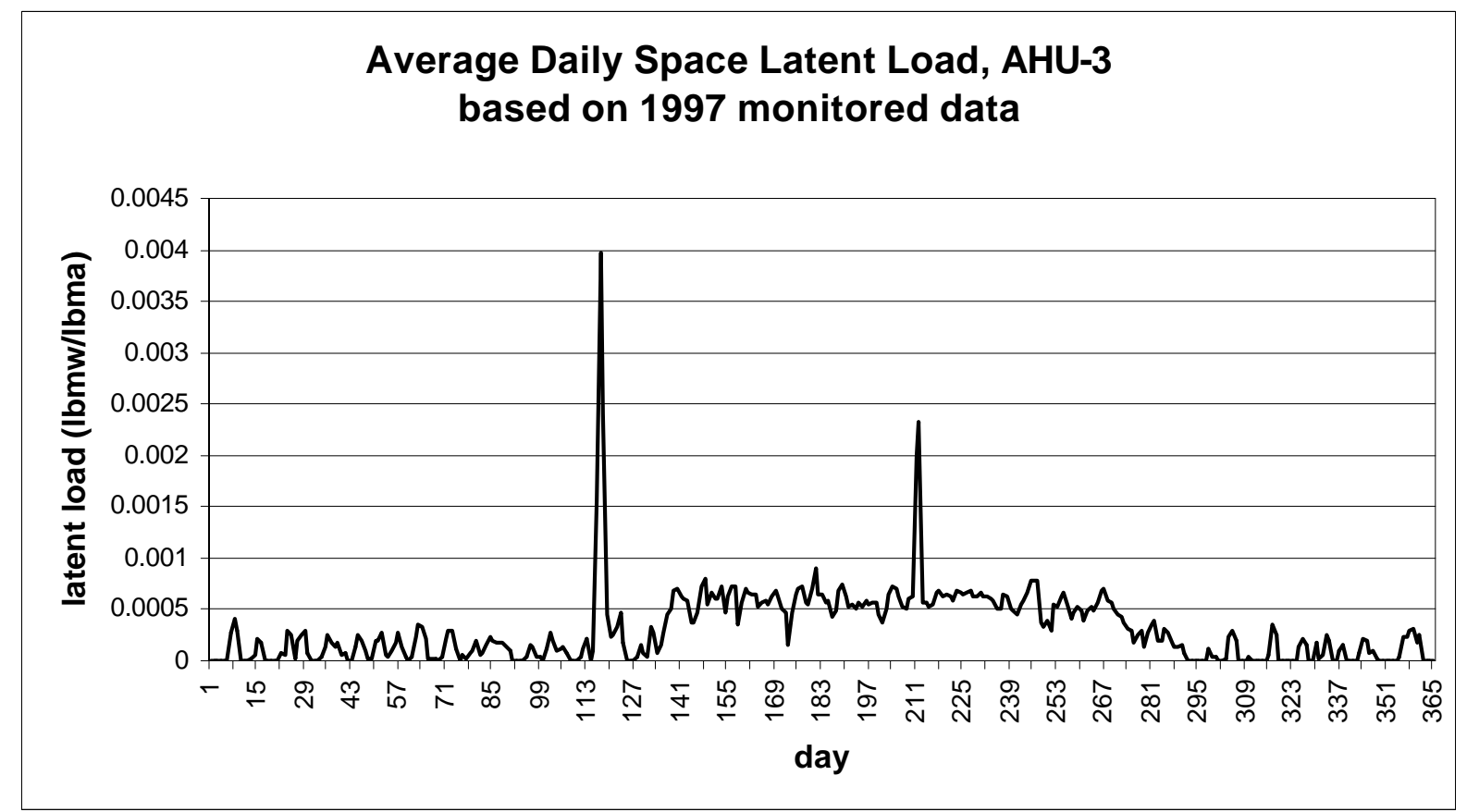

Figure 27. Average space latent load used for simulation, AHU-3 


\section{Predicting the Coil Sensible Heat Ratio}

The SHR for the cooling coil was calculated from monitored data for each hour of the preretrofit and postretrofit periods. Least-squares fit regression analysis was then performed to predict the SHR based on the entering air conditions and entering chilled water temperature for the two different periods. The form of the equation for the SHR is:

$$
\text { SHR }=\mathrm{c} 0+\mathrm{c} 1(\text { Tent })+\mathrm{c} 2(\text { RHent })+\mathrm{c} 3(\text { CWT })
$$

Where: Tent is the entering air temperature $(\mathrm{C})$,

RHent is the entering air $\mathrm{RH}(\%)$

CWT is the entering chilled water temperature $(\mathrm{C})$

$\mathrm{c} 0, \mathrm{c} 1, \mathrm{c} 2, \mathrm{c} 3$ are regression coefficients.

Figures 28 and 30 show the measured and the predicted SHR for the preretrofit period and the postretrofit period. The regression captures hourly and seasonal variations of the SHR; the 4-coefficient equation accounts for approximately $90 \%$ of the variation present in the monitored data.

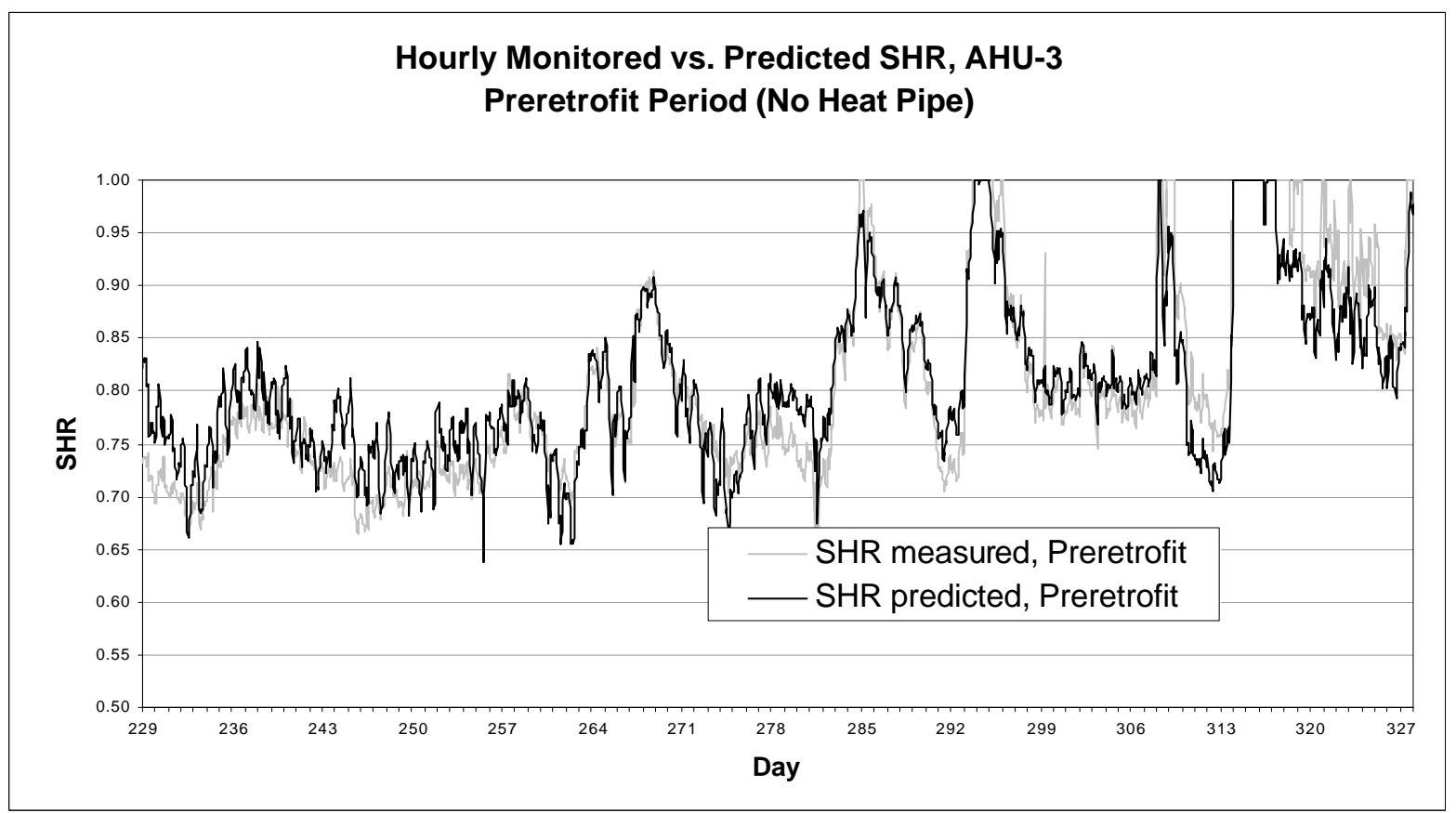

Figure 28. Predicted vs. measured SHR for AHU-3, preretrofit period 


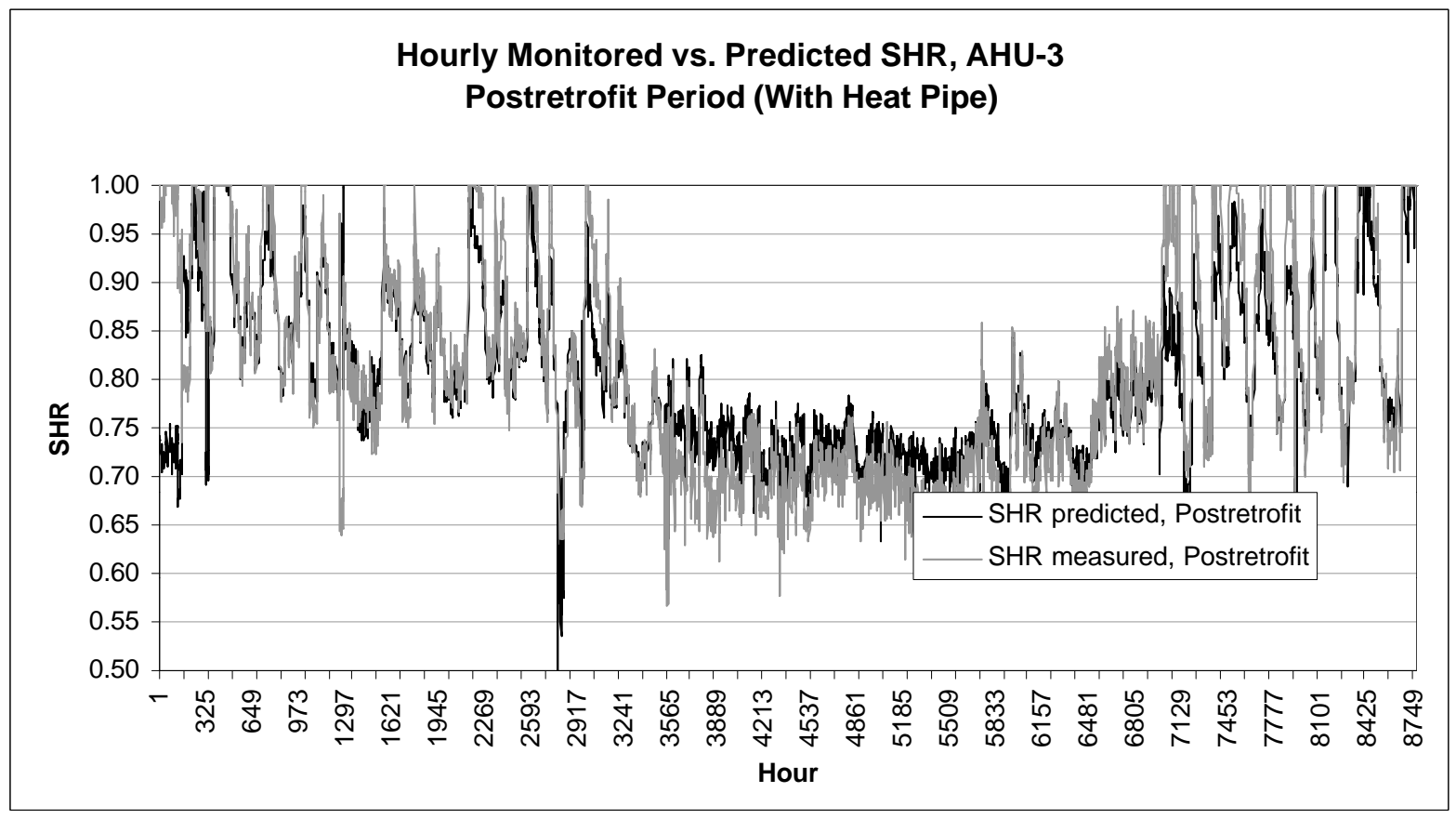

Figure 29. Predicted vs. measured SHR for AHU-3, postretrofit period

Figure 30 shows the daily average predicted SHR for a 1-year period with and without the heat pipe retrofit. The heat pipe clearly lowers the SHR by a significant amount, as much as $10-15 \%$ during the summer months.

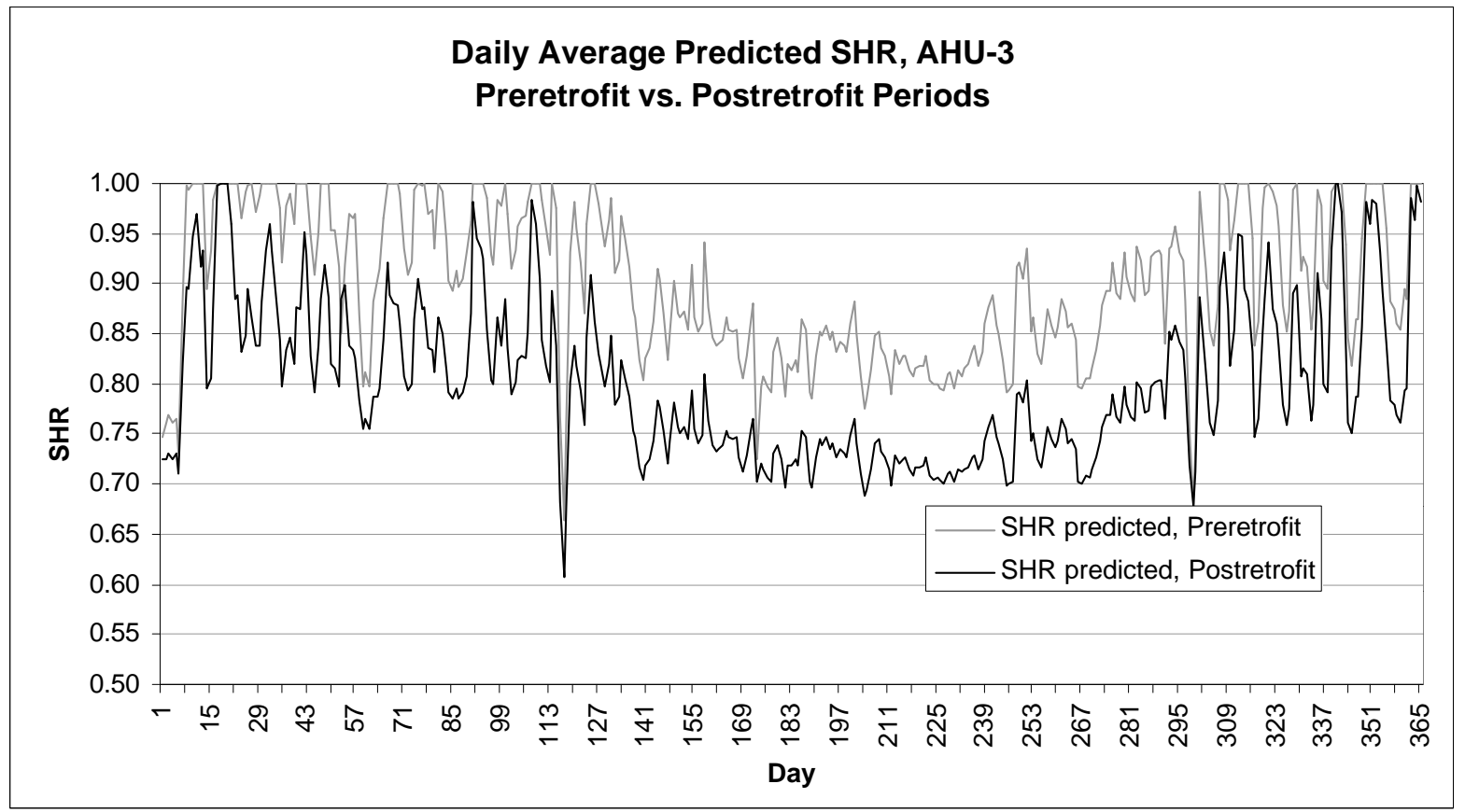

Figure 30. Daily average predicted SHR, with and without the heat pipe retrofit 


\section{Annual Energy Savings}

The HVAC system model predicts energy use based on attempting to meet both the sensible and latent space comfort conditions. The space temperature is controlled to $24^{\circ} \mathrm{C}$, and the supply air humidity ratio is maintained at or below $0.010 \mathrm{lbmw} / \mathrm{lbma}$. The cooling coil and reheat capacities are accounted for, as are the supply air flow rate and the variable chilled water temperature. Reheat energy required to raise the supply air temperature above the minimum temperature required by any space is not accounted for, but, as discussed above, is not affected by the heat pipe installation.

If the heat pipe were not installed, but all other changes discussed in the previous chapter were implemented, the annual reheat energy would be predicted as $62,500 \mathrm{kWh}$. With the heat pipe installed, the annual reheat energy would be predicted as $10,900 \mathrm{kWh}$, representing an annual savings of 51,600 $\mathrm{kWh}$. In addition, the chiller can expect a reduced load of approximately 11,000 ton-hours per year. The reduced chiller load translates to electric savings of approximately $18,000 \mathrm{kWh}$ per year.

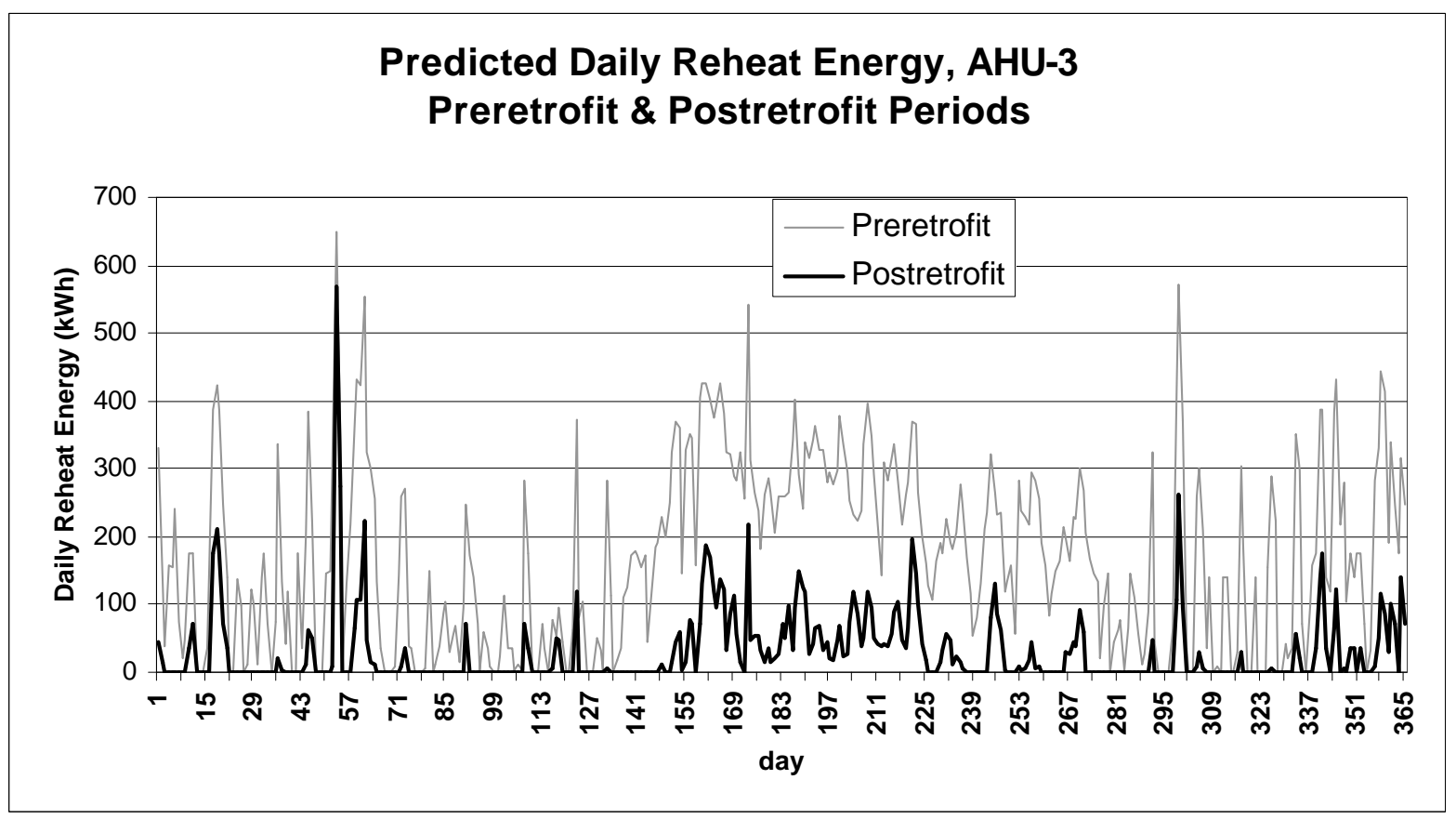

Figure 31. Predicted daily reheat, with and without the heat pipe, AHU-3

It is worth comparing Figures 8 and 31, which show the reheat as monitored during the preretrofit and postretrofit periods, and the reheat as predicted by the simulation. The simulation predicts the most amount of reheat occurring in the summer months, while the monitored data demonstrate just the opposite. This implies that much of the reheat used during the off-peak months is required because of the space load diversity, and not because of dehumidification requirements. Also, the simulation indicates far greater reheat requirements for the preretrofit condition than was measured during the preretrofit period. This large amount of summer reheat in the preretrofit period is a result of the increased cooling coil capacity that occurred after the preretrofit period. The analysis predicts that increasing the cooling capacity to the postretrofit level without installing the heat pipe would have nearly doubled the amount of reheat required to maintain space conditions. 


\section{Discussion and Conclusions}

The monitored data does not indicate that this system saved a large amount of reheat energy during the summer months. The simulation, however, indicates that the increased cooling capacity, due to a new condenser and compressor, would have provided better comfort control at the expense of greatly increased reheat requirements. Had only the chiller improvements been applied, energy use would have increased by approximately 50,000 kWh. Applying both the heat pipe retrofit and chiller improvements to this system reduced energy use by nearly $20,000 \mathrm{kWh}$.

The total savings for this system is approximately $70,000 \mathrm{kWh}$ per year, and includes $18,000 \mathrm{kWh}$ of chiller energy saving. Monthly reheat energy use and savings is shown in Figure 30.

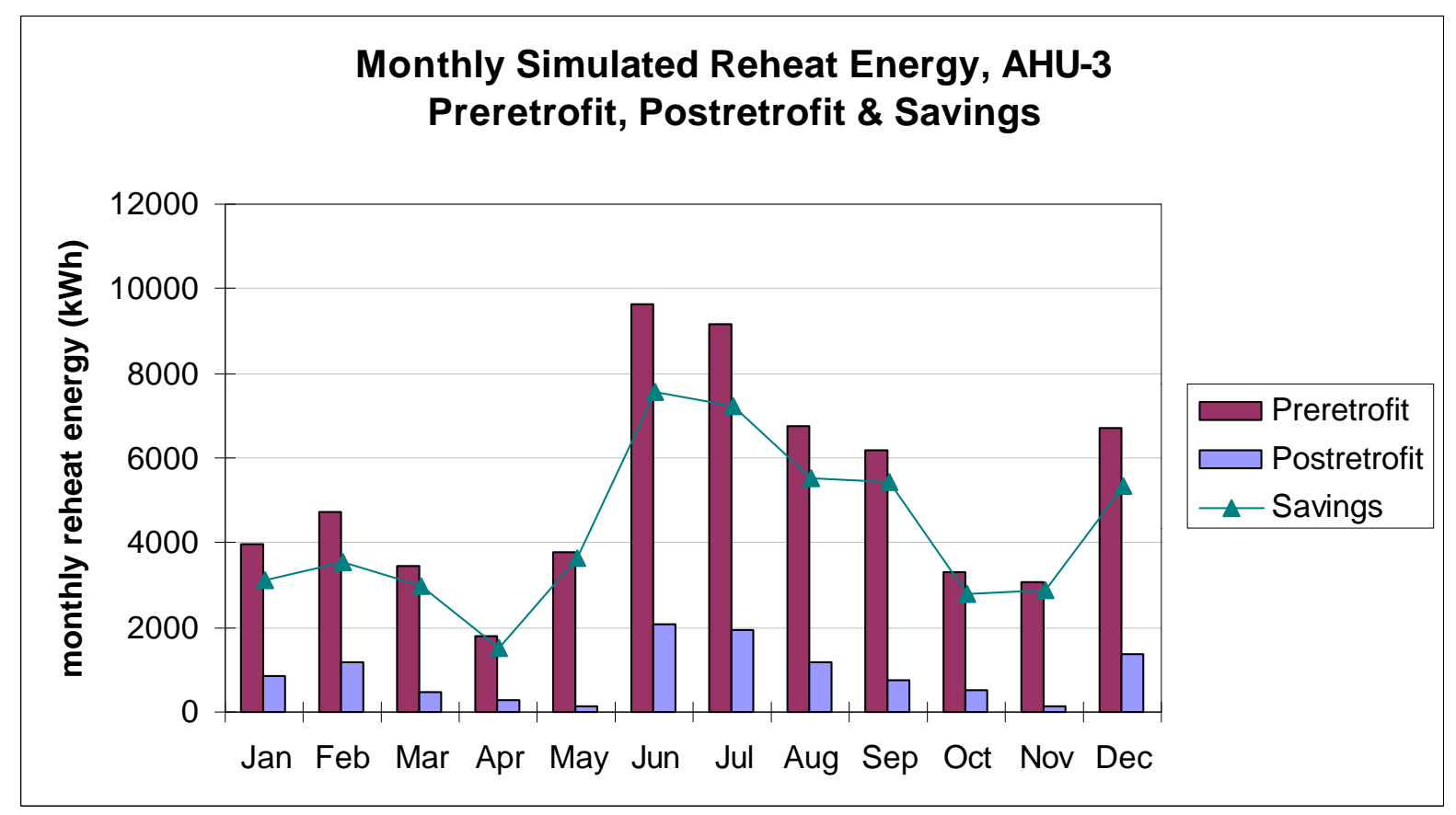

Figure 32. Reheat energy savings due to the heat pipe installation, AHU-3

Of the three heat pipe installations studied in this report, this installation clearly had the greatest impact. The characteristics that contribute to this result are:

- The existing cooling coil has a fairly high SHR.

- The system has adequate capacity to meet humidity and temperature requirements.

- The dehumidification requirements often produce supply air temperatures below the minimum required by the space loads. 


\section{Conclusions}

Energy savings for AHU-1 are found to be negligible. Heat pipe installation in AHU-1 may be inappropriate because of the design of the original cooling coils. Annual savings for AHU-2 are small, primarily because the required reheat for the system was already small. AHU-3 was the best application for the heat pipes and showed savings of $70,000 \mathrm{kWh}$ per year. Interior humidity conditions improved after installation of the heat pipes for AHU-2 and AHU-3.

Table 2. Summary of Heat Pipe Savings

\begin{tabular}{|l|c|c|c|}
\hline Savings Component & AHU-1 & AHU-2 & AHU-3 \\
\hline Reheat Savings (kWh) & 0 & 3,000 & 51,600 \\
\hline Cooling Coil Load Reduction (ton-hrs) & 0 & -880 & 11,000 \\
\hline Total Energy Savings (kWh) & 0 & 1,600 & 69,600 \\
\hline Humidity Control Improvement & None & $5-10 \%$ & $5-10 \%$ \\
\hline
\end{tabular}

The heat pipe installation for AHU-1 had no positive effect on lowering the overall SHR of the two cooling coils. As originally designed, this combination of cooling coils was able to achieve SHRs at, and even below, 0.4. Applying the heat pipe to the precool coil defeated the original design of having saturated air entering the main cooling coil and did not lead to any reheat or chiller energy savings.

The heat pipe installation for AHU-2 provided little benefit because:

- Increased capacity due to lower chilled water temperature and lower supply air flow rate essentially eliminated the reheat requirement.

- The existing coil has a relatively low SHR.

Of the three heat pipe installations studied in this report, the heat pipe installation on AHU-3 clearly had the greatest impact. The favorable characteristics that contribute to this result are:

- The existing cooling coil has a fairly high SHR.

- The system has adequate capacity to meet humidity and temperature requirements.

- The dehumidification requirements often produce supply air temperatures below the minimum required by the space loads.

The analysis of the three heat pipe installations described in this report indicates a wide range of possible results. The heat pipe installation on AHU-3 proved to be quite beneficial, while the installations on AHUs 1 and 2 led to very little savings. It is clear that the effects of a heat pipe on an existing air conditioning system are complex and that a thorough understanding of how the HVAC system meets sensible and latent loads is essential for proper design of a heat pipe retrofit. 


\section{References}

Shirey, D.B. (1999) "Demonstration of Efficient Humidity Control Techniques at an Art Museum", ASHRAE Transactions. Vol. 99; p. 694.

ASHRAE Handbook 1993 Fundamentals, published by American Society of Heating, Refrigerating and AirConditioning Engineers, Inc. 
Appendix A Pre-Retrofit Evaluation Report 


\section{New Technology Demonstration Program Kennedy Space Center Hangar L Heat Pipe Project: Pre-Retrofit Evaluation Report}

January, 1997

National Renewable Energy Laboratory

Subcontract No. AAR-6-16320-01

C. E. Hancock

Paul Reeves

815 Alpine \#6

Boulder, CO 80304

(303) 447-8458 


\section{New Technology Demonstration Program}

\section{Kennedy Space Center Hangar L Heat Pipe Project:}

\section{Pre-Retrofit Evaluation Report}

January, 1997

\section{Summary}

Heat pipe heat exchangers will be installed on three air handlers at Hangar L at the Cape Canaveral Air Station, Cape Canaveral, Florida in the Fall of 1996. The intent of these retrofits is to significantly improve the dehumidification performance of the cooling systems, reduce the electric and steam energy required for re-heating air and reduce electric energy used by the chillers. The energy savings from these retrofits will be evaluated by comparing the energy used before the retrofit and after the retrofit. Direct measurements of the primary energy quantities will be made over an extended period of time. Direct comparisons of before-and-after energy will be shown for periods with comparable cooling loads. Empirical models of the system performance will be derived from the measured data and simulation models will be used to calculate annual energy savings. This report describes the results of pre-retrofit performance monitoring.

Monitoring equipment was initially installed in May 1996 and additional sensors were installed in August 1996. Complete, continuous data have been recorded since August 15, 1996. The retrofit is currently scheduled to be completed by December 15, 1996. The data acquisition system will remain in place during the retrofit and post-retrofit monitoring will begin immediately following the retrofit. Post-retrofit data collection is expected to continue through August 1997. With the retrofit occurring in December, system performance over an appropriate range of weather conditions will be measured both before and after the retrofit. 


\section{System Description}

The NASA Life Sciences Support Facility is located in Hangar L at the Cape Canaveral Air Station, Cape Canaveral, Florida. Laboratory and office areas have been constructed inside the original hangar structure. The hangar is approximately 175 feet wide, 150 feet long, and 30 feet high, yielding a foot print area of about 26,000 square feet. There are approximately 20,000 square feet of conditioned space inside the hangar including offices, labs, and clean rooms. There are very few windows and essentially no direct solar gains on conditioned spaces. Most of the cooling load is due to internal gains from operation of lights and equipment and from conditioning of outside air for ventilation. Normal operating hours for personnel at the building are 0700 through 1700. Much of the equipment and interior lighting remains in operation 24 hours per day. Three air handlers serve the majority of the conditioned lab and office space. Smaller air handlers provide air conditioning for small portions of the building. The nominal air flow rates, water flow rates and cooling capacities for each air handler are listed in Table 1.

Table 1. Nominal flow rates and cooling capacities

\begin{tabular}{|c|c|c|c|c|}
\hline Air Handler & $\begin{array}{c}\text { Cooling Cap., } \\
\text { Btu/hr }\end{array}$ & $\begin{array}{c}\text { Chilled water } \\
\text { flow, GPM }\end{array}$ & $\begin{array}{c}\text { Supply air } \\
\text { flow, CFM }\end{array}$ & $\begin{array}{c}\text { Outside air } \\
\text { flow, CFM }\end{array}$ \\
\hline & & & & \\
\hline AHU-1 & 697,000 & 68 & 15,800 & 15,800 \\
\hline AHU-2 & 314,000 & 64 & 5,765 & 1,970 \\
\hline AHU-3 & 297,000 & 60 & 8,675 & 1,100 \\
\hline
\end{tabular}

Air handler AHU-1 is located on the main floor of the hangar and supplies conditioned air to the clean room areas of the facility. It operates with 100 percent outside air. The outside air first passes through a pre-cool coil before it enters the main cooling coil. The two coils are supplied with chilled water (in parallel) from a 110 ton chiller located on the north side of the building. Two coils are used to meet the large latent load imposed by the large flow rate of outside air. Both temperature and relative humidity in the conditioned space are intended to be controlled by this system. Humidity control is accomplished during periods of high latent loads by cooling the supply air below the point required to meet the sensible load, thus condensing enough moisture from the air to meet the required RH set point. The dry bulb temperature in the space is maintained by re-heating the sub-cooled air to meet the temperature set point. Hot water supplied by a local oil-fired steam boiler is used for re-heat on this system. If the RH in the conditioned space drops below the humidistat set point, steam from the boiler is injected in the air flow stream to humidify the air.

Air handlers AHU-2 and AHU-3 are located on the mezzanine level above the office spaces on the south side of the building. (Note that our AHU-3 is designated AHU-1(Mezzanine) in the original mechanical plans) Chilled water is supplied (in parallel) by a 55 ton air-cooled chiller located on the north side of the building. Figure 1 shows a photograph of AHU-3. 
The chillers located on the north side of the hangar are pictured in Figure 2. Humidity control is accomplished by sub-cooling the air flow to condense sufficient moisture from the air, and then re-heating to maintain the dry bulb temperature set point. Re-heating is accomplished by electric heaters in the supply ducts to each zone. Steam can be injected in the supply ducts to humidify the air during rare periods of low humidity in cool weather.

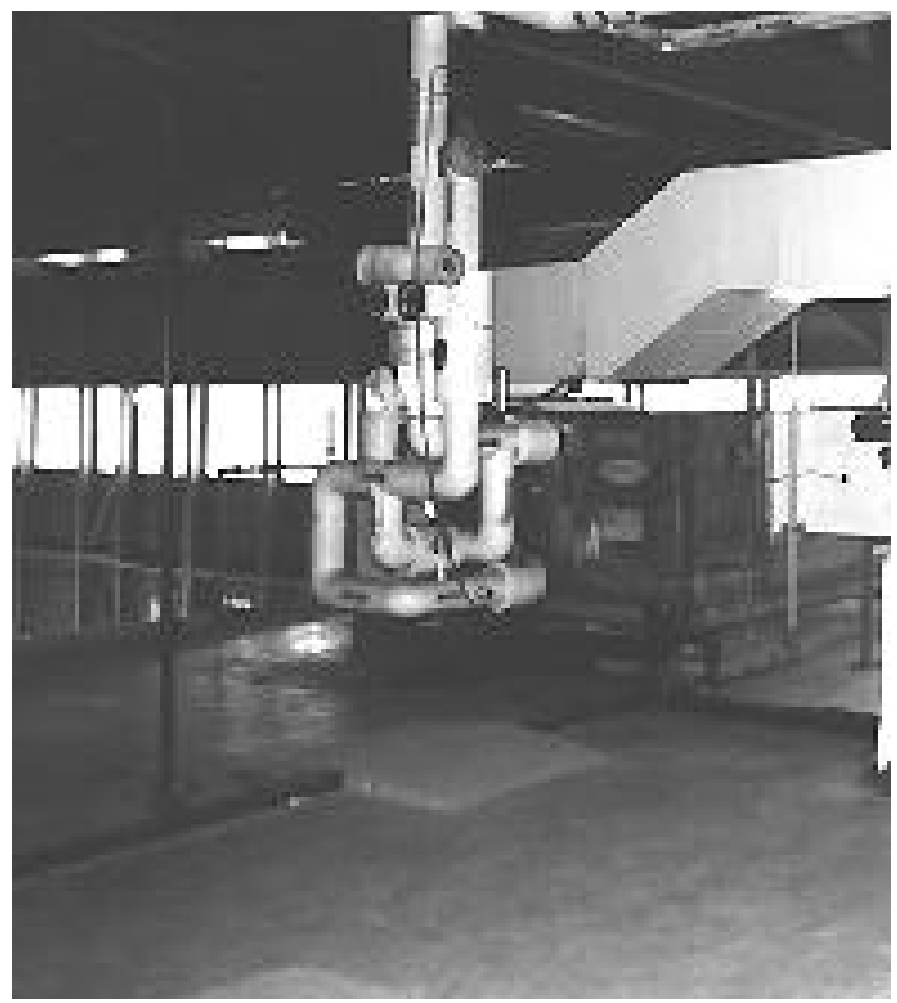

Figure 1 AHU-3 


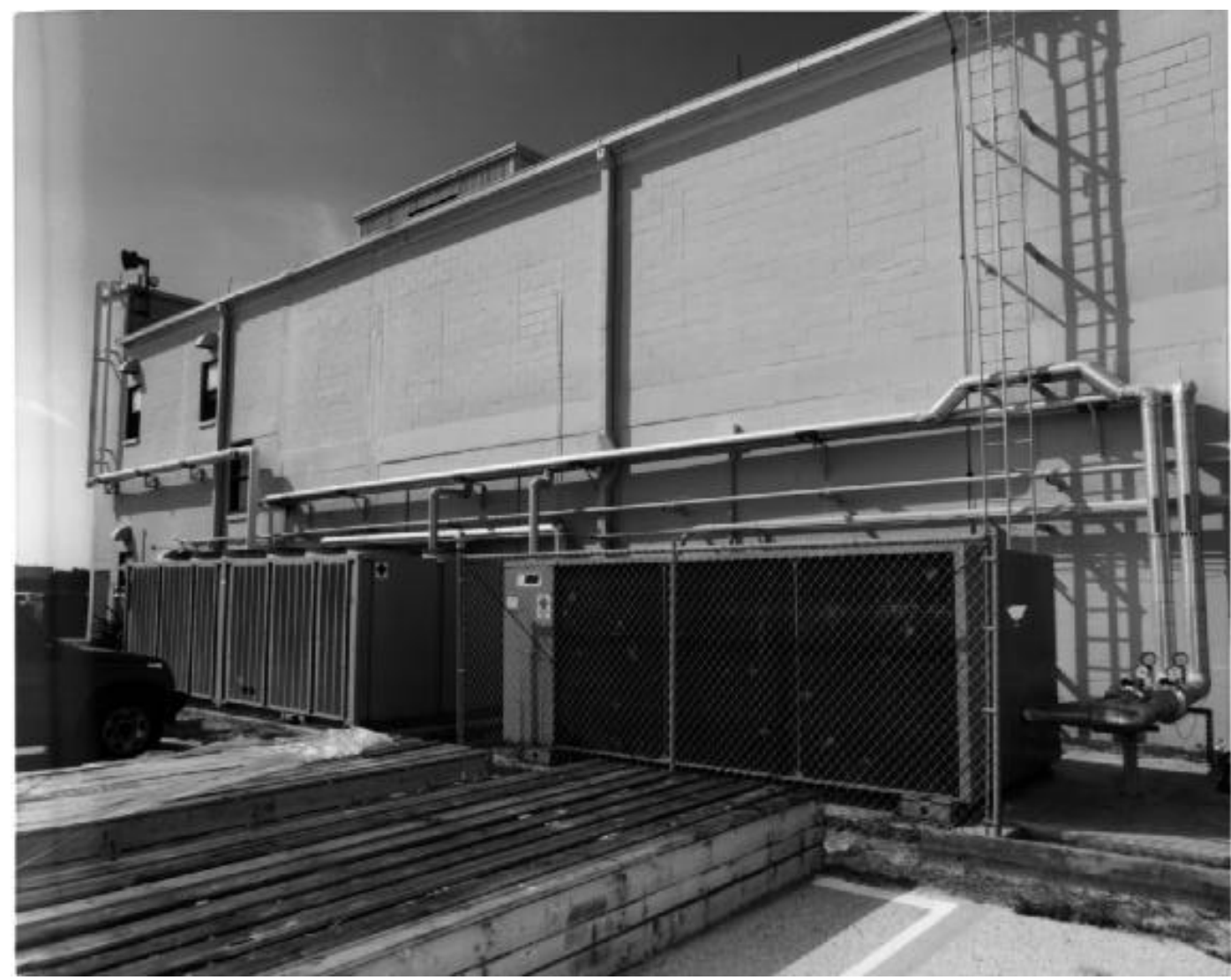

Figure 2 Hangar L Chillers

\section{Heat Pipe Operation}

The heat pipes to be installed during this project are intended to reduce the need for electric and hot water re-heating on the three main air handlers. The heat pipe evaporator will be installed immediately up-stream of the cooling coil at each air handler and the condenser will be installed immediately down-stream of the coil. This arrangement will have the effect of pre-cooling the air stream before it contacts the cooling coil and reheating the air leaving the coil. The heat pipes are used to transfer some of the sensible heat from the air entering the coil to the air leaving the coil thus reducing or eliminating the need for additional auxiliary re-heat (assuming that the supply air was indeed already cooler than was required to meet the sensible space load). The heat pipes essentially have the effect of reducing the sensible heat ratio (SHR) of the coil. The latent load is expected to remain the same before-and-after the retrofit, but less chilled water energy will be required to remove the same amount of moisture since less sub-cooling of the air will be needed. The intended result of the heat pipe retrofit is to use less energy for re-heat and less energy for chilled water. A slight increase in fan power may be expected to result from installation of the heat pipes due to a higher pressure drop. 


\section{Evaluation Approach}

The energy savings from these retrofits will be evaluated by comparing the energy used before the retrofit and after the retrofit. Direct measurements of the primary energy quantities will be made over an extended period of time. Direct comparisons of before-and-after energy use will be shown for periods with comparable cooling loads. Empirical models of the system performance will be derived from the measured data and simulation models will be used to calculate annual energy savings.

The energy savings attributed to the heat pipes are expected to be derived from:

1. reduced reheat power

2. reduced chiller power

The electricity used for re-heat and for the chiller will be measured directly as part of the evaluation. Typical hourly load shapes for mid-summer and cooler season months will be reported. We expect to report annual $\mathrm{kWh}$ and peak kilowatts for the re-heat and chillers, for the system with and without heat pipes. The sensible and latent energy removed from the air flow at each air handler will also be carefully measured. These quantities provide the basis for comparing the system performance in the before and after retrofit periods, and also provide inputs for developing functional models of the reheat and chillers.

In addition to energy savings, interior humidity conditions may be improved after the retrofit. The present system appears to allow the inside RH to float above the set point during the summer. The chillers presently appear to be operating at maximum capacity during the summer months, and still the cooling loads are not met. To the extent that new technology provides improved interior temperature and $\mathrm{RH}$ conditions, we plan to use the functional models to:

1. calculate how much less energy the New system would use to achieve the Old conditions, or:

2. calculate how much more energy the Old system would use to achieve the New conditions

The heat pipe project should be able to take credit for improved conditions that were achieved without buying a new chiller.

We will also observe the data carefully to try to identify possible problems in system operating performance that could develop because of the retrofit. In particular, it is possible that the system with heat pipes may experience an inability to meet sensible loads during peak summer cooling season. This possibility is indicated in the pre-retrofit data as periods during which no reheat is required during the summer and neither the sensible nor latent load is presently met. The heat pipes will provide reheat during these periods. It is also possible that the systems with heat pipes could use more steam for humidification in winter when the heat pipes provide dehumidification when it is not needed. 


\section{Instrumentation Plan}

The evaluation plan requires that the thermal performance of the existing HVAC system be measured over an extended period. Instruments have been installed to measure the heat removed at the cooling coil for each air handler, the re-heat energy for each air handler, and the total electric power for the two chillers.

\section{Data Logger}

A Campbell Scientific CR10X data logger system was installed to record the signals from the sensors measuring thermal performance. The sensors are sampled once every 30 seconds. Data are averaged over a period of one hour and stored in the CR10X memory. Forty two variables are presently stored on an hourly basis. At this rate, the CR10X memory can accommodate approximately three months of stored data. Stored data are transferred via modem approximately once each week to our computers for analysis and archiving. The data logger is located in the mezzanine electrical room, reasonably near all three air handlers.

\section{Energy Flow Measurements at Each Air Handler}

The total heat removed at the cooling coil of each air handler is measured on the air side and on the water side. These two heat flow quantities should be equal and are compared in our analysis to assure good quality in the measured data. The latent and sensible heat removed is measured only on the air side. Measurement of entering and leaving temperature, relative humidity, and mass flow rate are required on the air side. On the water side, entering and leaving chilled water fluid temperature and flow rate are measured.

The temperature and relative humidity $(\mathrm{RH})$ of the air is measured in four locations at each air handler. The supply, return, outside and mixed (outside and return) conditions are measured. The sensor used for these measurements is a CS500 temperature and relative humidity probe supplied by Campbell Scientific. The nominal accuracy for these sensors is $0.4 \mathrm{C}$ for temperature and $3 \%$ or better for RH. Each sensor is located at the center of duct sections at locations where the flow is expected to be well mixed. An array of points was sampled at each sensor location to verify that the flow was well mixed with respect to temperature and RH. The ducts happen to be appropriately configured to facilitate this measurement. The sensor location for the supply air sampling point was limited due to the location of HEPA filters. Sensors could not be located down stream of the filters.

The supply and return air flow rate for each air handler was measured in a short term test using the NREL tracer gas monitoring system. The tracer gas Sulfur hexafluoride $\left(\mathrm{SF}_{6}\right)$ is injected into a duct at a known, constant rate. The concentration of the $\mathrm{SF}_{6}$ is measured at a down stream point where the tracer gas is well mixed with the air stream. The total air flow rate is equal to the dosing rate divided by the concentration. The air flow rates are reasonably assumed to be constant over long periods of time. 
The entering and leaving chilled water temperatures for each cooling coil are measured with Type T multi-junction thermopiles and reference thermocouples. The thermocouple junctions are installed on the exterior surface of the steel chilled water pipes. The accuracy of the temperature difference measurement is typically $0.1 \mathrm{C}$ or better. The standard pipe insulation is replaced after installation of the thermocouples and extra insulation is added to assure reasonably accurate indication of fluid temperature difference.

The chilled water flow rate for each cooling coil was measured in a short term test using a Controlotron model 1010 ultrasonic flow meter. This meter is temporarily mounted on the exterior surface of the steel chilled water pipes. The nominal accuracy of this flow measurement is 2 percent. Measurements were taken over a period of at least 24 hours and were found to be constant during this period of operation. We understand that the fluid is a solution of water with approximately 10 percent propylene glycol.

\section{Electric Power Measurements}

Electric power used by the chillers and re-heat elements is measured directly using Hall Effect watthour transducers, Ohio Semitronics model WL40R. The nominal accuracy of these transducers is 0.5 percent. One transducer is used for each chiller and one for the total re-heat power for each air handler with electric re-heat, AHU-2 and AHU-3. The chiller watt transducers are located in the chiller electrical enclosures and are connected to a separate CR10 data logger outside the building.

The re-heat energy for air handler AHU-1 is supplied via a heat exchanger by steam from a boiler located near the hangar. The re-heat energy for this system is determined by measuring the rise in temperature in the supply air at the air handler and the supply air at diffusers in the zones. The diffuser supply air temperature is measured with single-channel temperature logger made by Onset Computer Corporation. This air handler supplies conditioned air to the clean room areas. We were not allowed to enter this area, but Life Science Support Facility personnel placed these sensors for us. The sensors record data for a period of 75 days. EG\&G maintains records of monthly oil use by the boiler.

\section{Measured Data}

\section{Air Flow Rates and Chilled Water Flow Rates}

The measured flow rates shown in Table 2 can be compared to the nominal values listed in Table 1, above. The measured air flow rate in AHU-1 is about 20 percent lower than nominal, and the chilled water flow rate is somewhat higher than design values. The measured air flow rates in AHU-2 and AHU-3 are 18 percent higher and 14 percent higher, respectively. These measured air flow rates will be compared to the measured flow rates after the retrofit to determine any change in air flow due to the heat pipe installation. 
Table 2. Pre-retrofit measured flow rates.

\begin{tabular}{|c|c|c|c|}
\hline Air Handler & $\begin{array}{c}\text { Chilled water } \\
\text { flow, GPM }\end{array}$ & $\begin{array}{c}\text { Supply air } \\
\text { flow, CFM }\end{array}$ & $\begin{array}{c}\text { Outside air } \\
\text { flow, CFM }\end{array}$ \\
\hline AHU-1 & $79 / 87$ & 12,600 & \\
\hline AHU-2 & 61 & 6,800 & \\
\hline AHU-3 & 58 & 9,900 & \\
\hline
\end{tabular}

\section{Air Handler Thermal Performance}

The measured hourly thermal performance of each cooling coil is shown in Figures 3-6 for the week of September 1-7, 1996. These data are typical of peak summer cooling conditions. Figure 3 shows a time-series graph of the hourly heat removed (or cooling load) at each coil. This graph shows that the heat removed is nearly constant as a function of time, implying that the coils are operating at their maximum capacity. Figure 4 shows a graph of return air drybulb temperature and relative humidity $(\mathrm{RH})$ for the same period of time. The return air conditions are a good indication of the typical zone temperatures and $\mathrm{RH}$. The return temperature shows a daily fluctuation with a high of approximately $25 \mathrm{C}(77 \mathrm{~F})$ in the afternoons, and a low of approximately $22 \mathrm{C}(72 \mathrm{~F})$ in the early morning hours. The relative humidity is approximately 70 percent for AHU-1 and 60 percent for AHU-2 and AHU-3. These return air temperature and RH conditions indicate that the pre-retrofit system may not meet peak the zone sensible and latent loads.

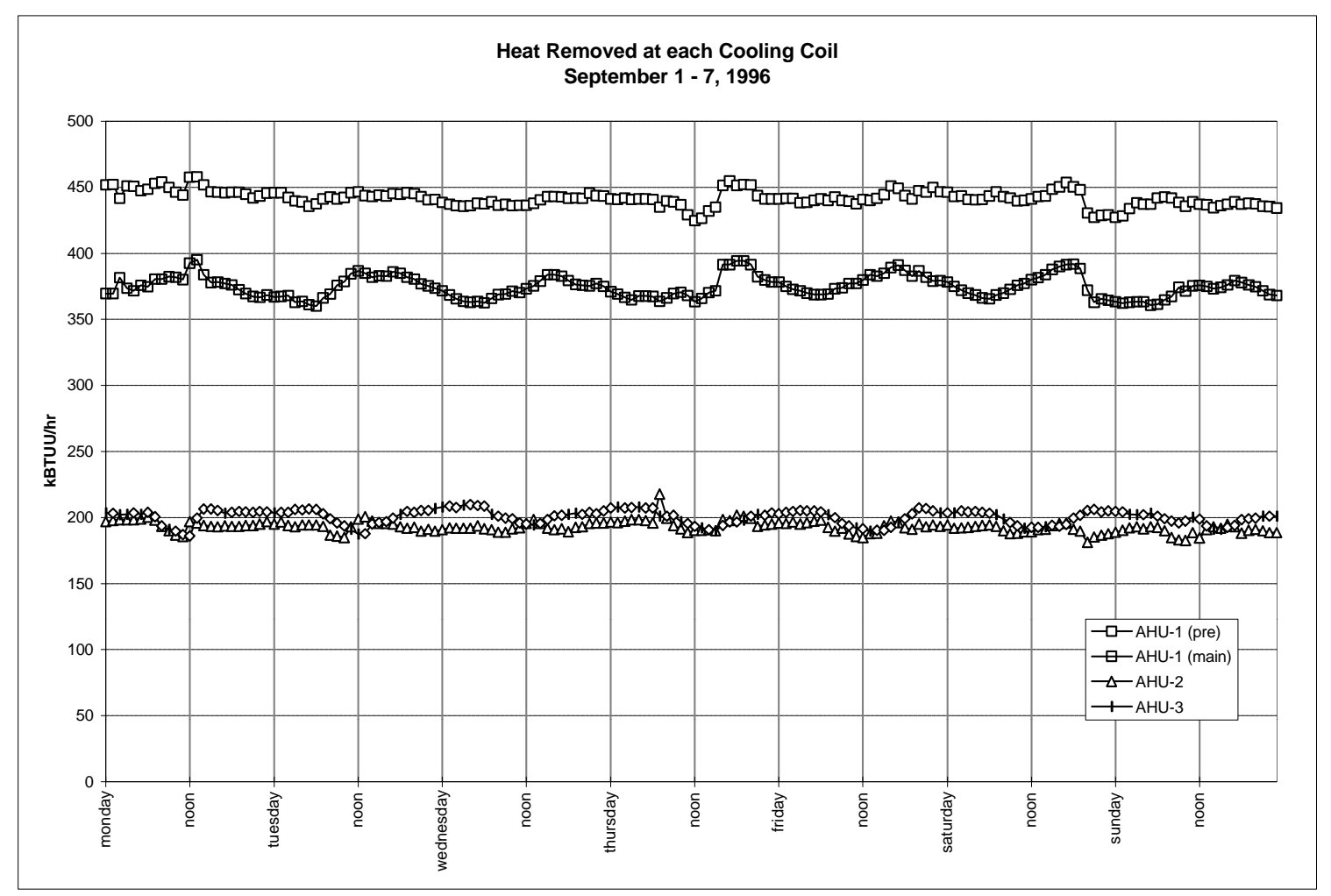

Figure 3 Heat Removed, September 1 - 7, 1996 


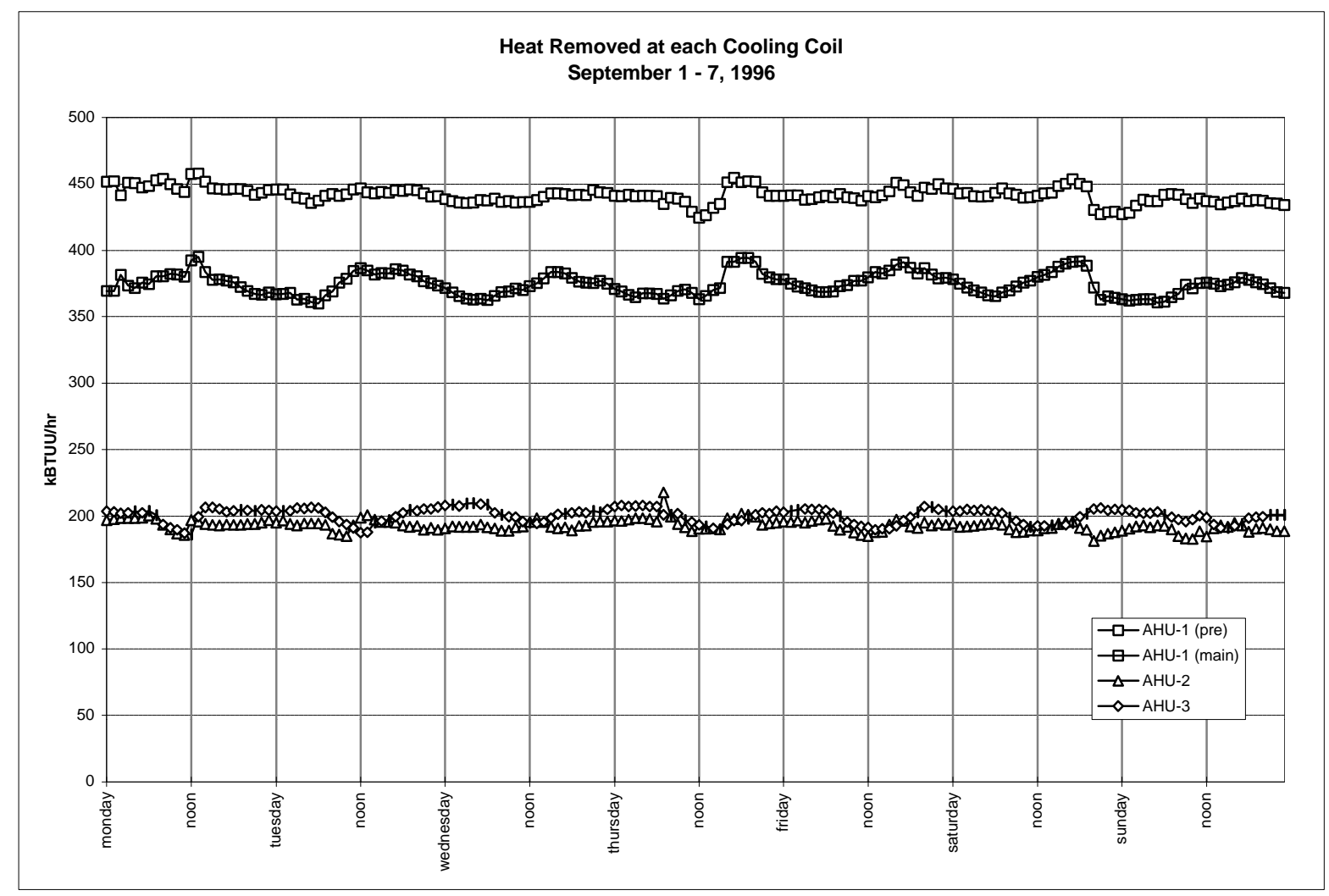

Figure 4 Return Air Temperature and Relative Humidity, September 1 - 7, 1996

Figure 5 shows a time-series graph of the hourly Outside or make-up air for AHU-1 and AHU-2 for the week of September 1-7, 1996. AHU-1 draws its make-up air from inside the hangar while AHU-2 draws its make-up air from outside. Daytime high temperatures are typically above $35 \mathrm{C}(95 \mathrm{~F})$ and nighttime low temperatures are around $27 \mathrm{C}(80 \mathrm{~F})$. The air inside the hangar is almost always warmer than the outside air, especially at night. It appears that cooling loads would be minimized if make-up air were drawn from outside.

Figure 6 shows a time-series graph of the hourly sensible heat ratio (SHR) for each cooling coil for the week of September 1-7, 1996. The SHR for AHU-1 main coil is nearly constant at about 0.3 . The SHR for the AHU-1 pre-coil varies between 0.45 and 0.65 , and appears to be responding to variations in outside temperature. The AHU-2 SHR is nearly constant at about 0.6 and the AHU-3 SHR is nearly constant at about 0.7 . The heat pipe retrofit is expected to change the SHR of each coil. The pre-retrofit values of SHR will be compared to post-retrofit values. 


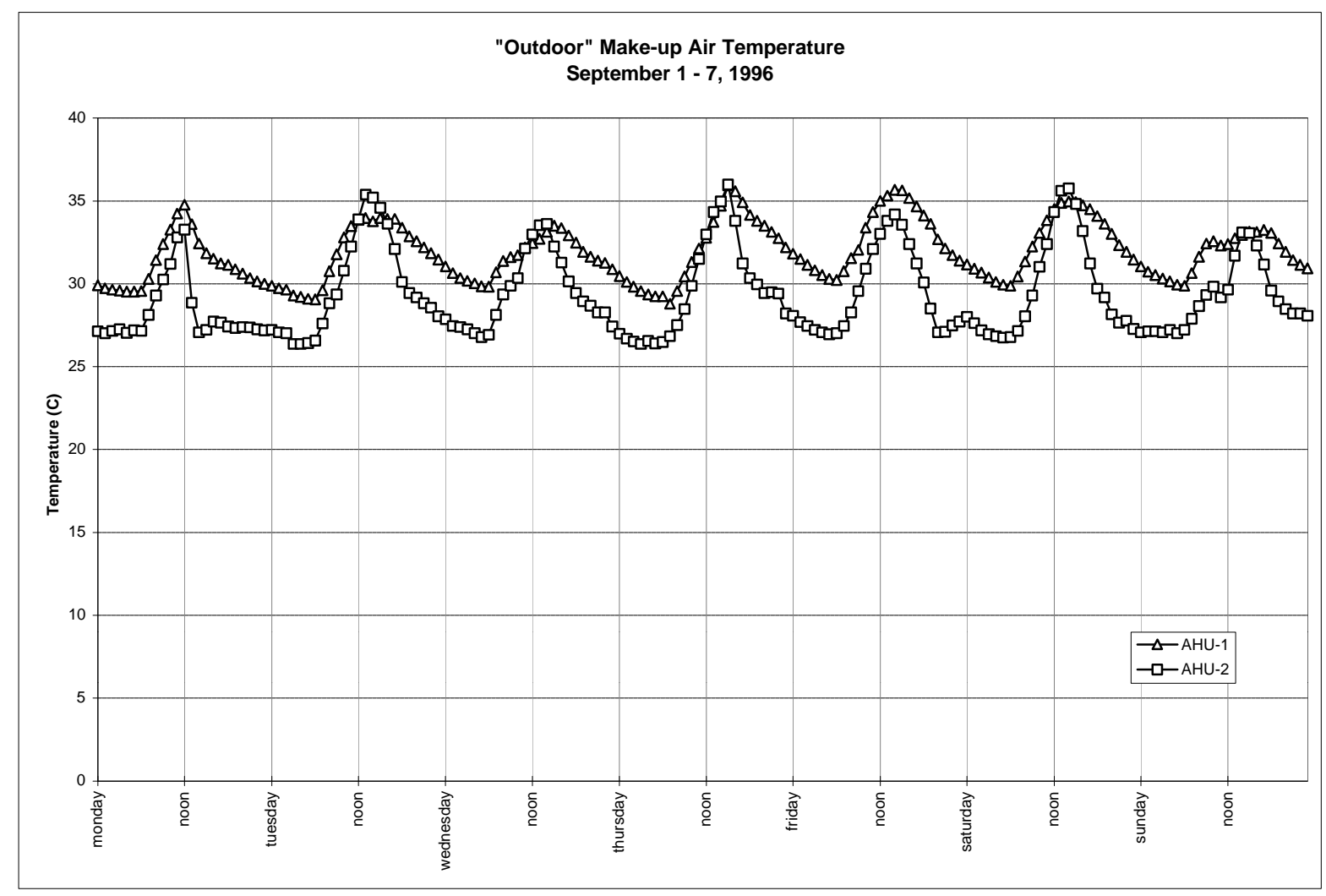

Figure 5 "Outdoor" Make-up Air Temperature, September 1 - 7, 1996

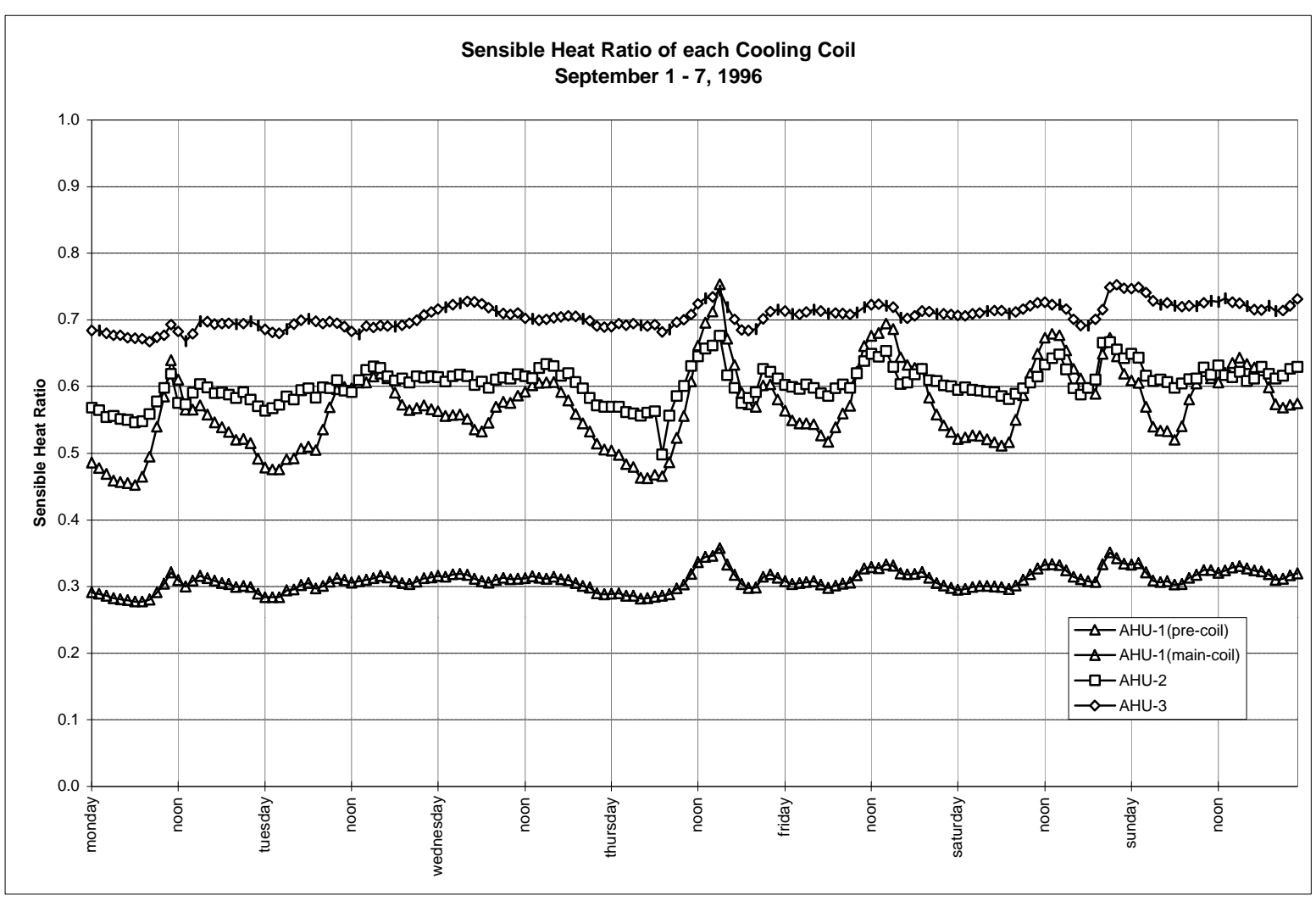

Figure 6 Sensible Heat Ratio, September 1 - 7, 1996

Appendix A-11 
Figures 7-10 show plots of the cooling coil thermal performance data for the week of October 28 - November 3, 1996. These data show performance during the season of moderate and low cooling loads. AHU-2 and AHU-3 are still operating near capacity, but AHU-1 cooling loads are lower than the peak loads shown in August and September. Figure 8 shows that the zone temperature and $\mathrm{RH}$ are closer to their nominal set points than they were during peak cooling conditions. Figures 9 and 10 show that the latent loads approaches zero (SHR approaches 1.0) as the outside air temperature drops to around $15 \mathrm{C}$ ( $59 \mathrm{~F}$ ).

The data presented in the these figures show representative system performance during the pre-retrofit period. We believe that an adequate range of data is available for comparison to post-retrofit performance.

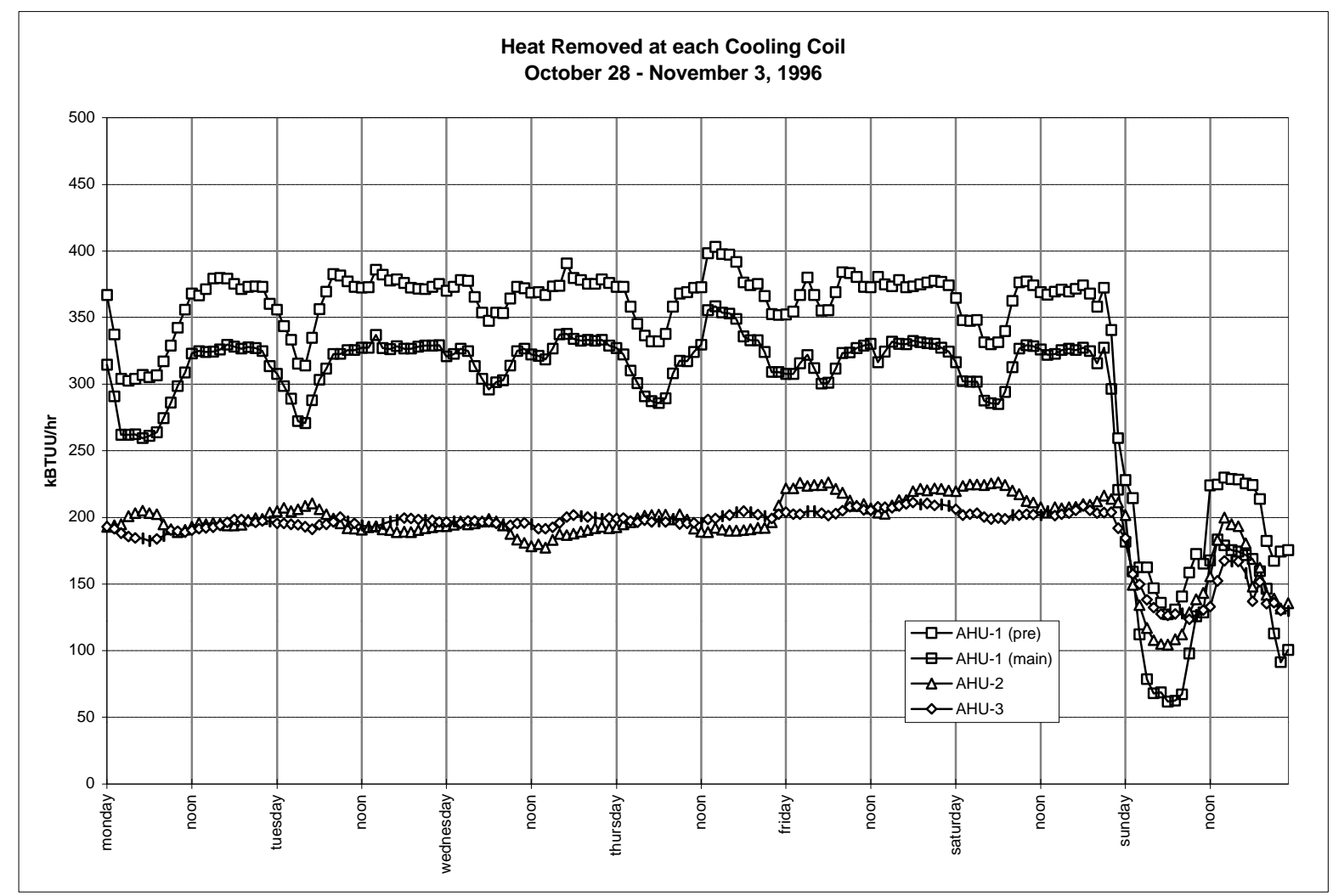

Figure 7 Heat Removed October 28 - November 3, 1996 


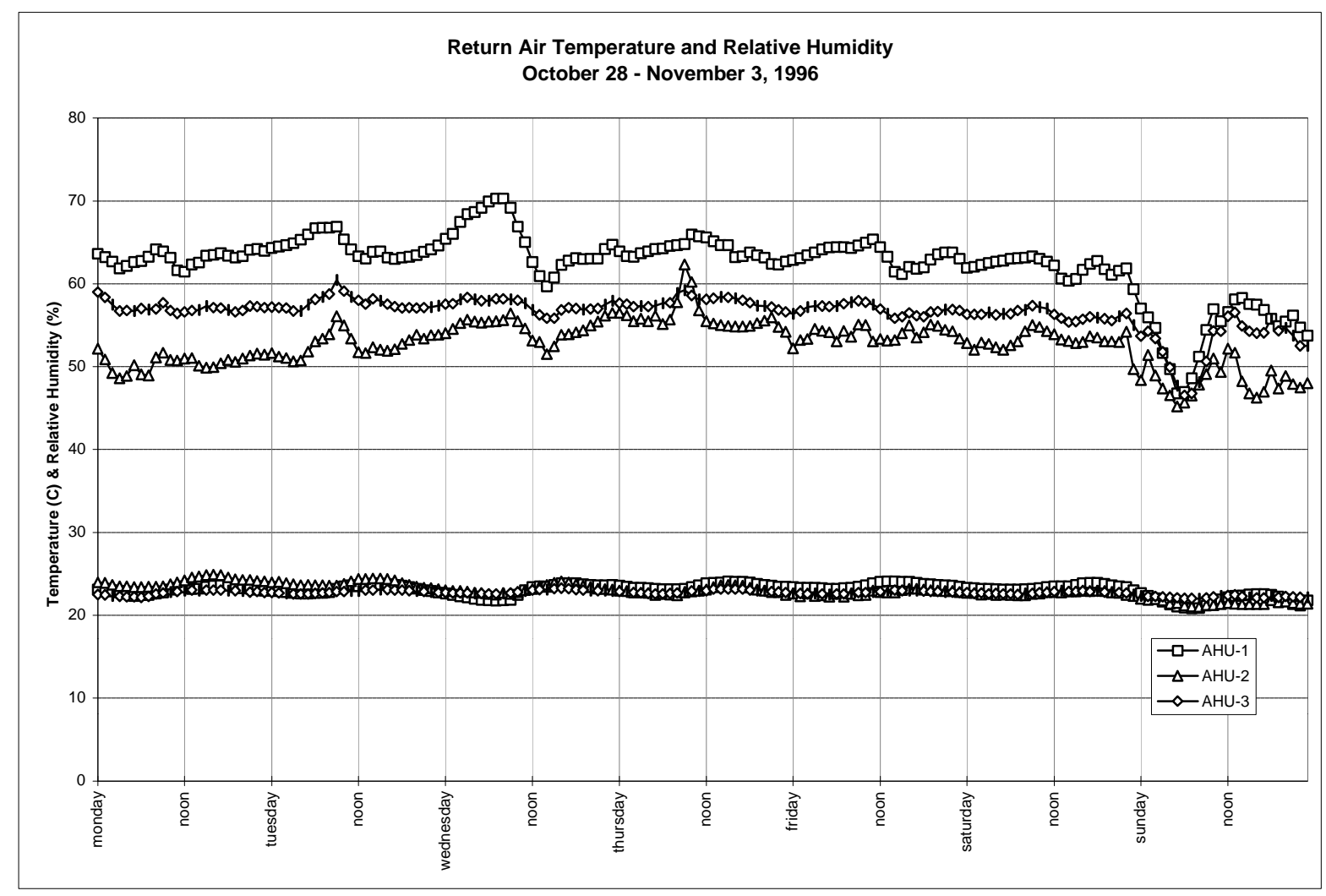

Figure 8 Return Air Temperature and Relative Humidity, October 28 - November 3, 1996

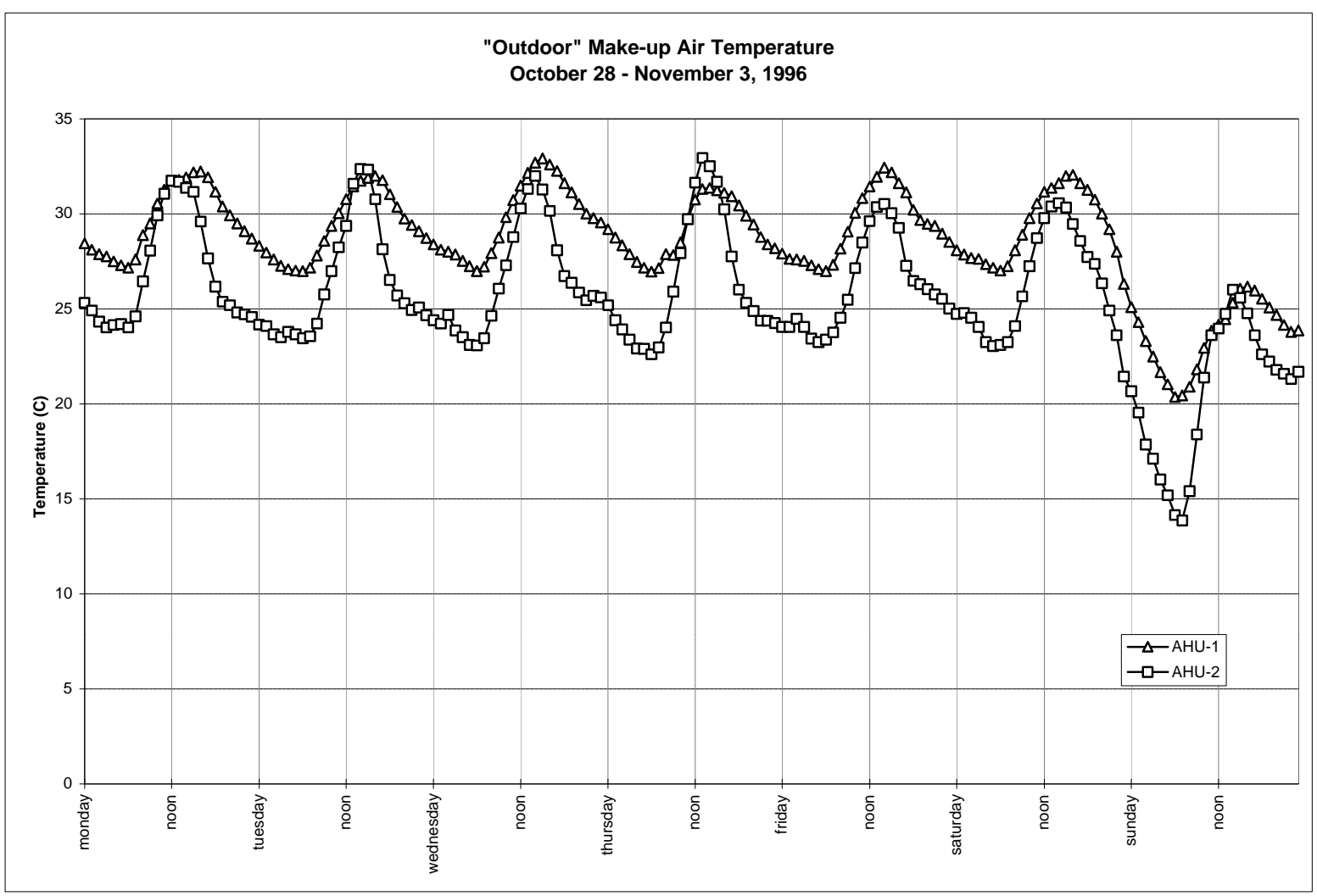

Figure 11 “Outdoor” Make-up Air Temperature, October 28 - November 3, 1996 


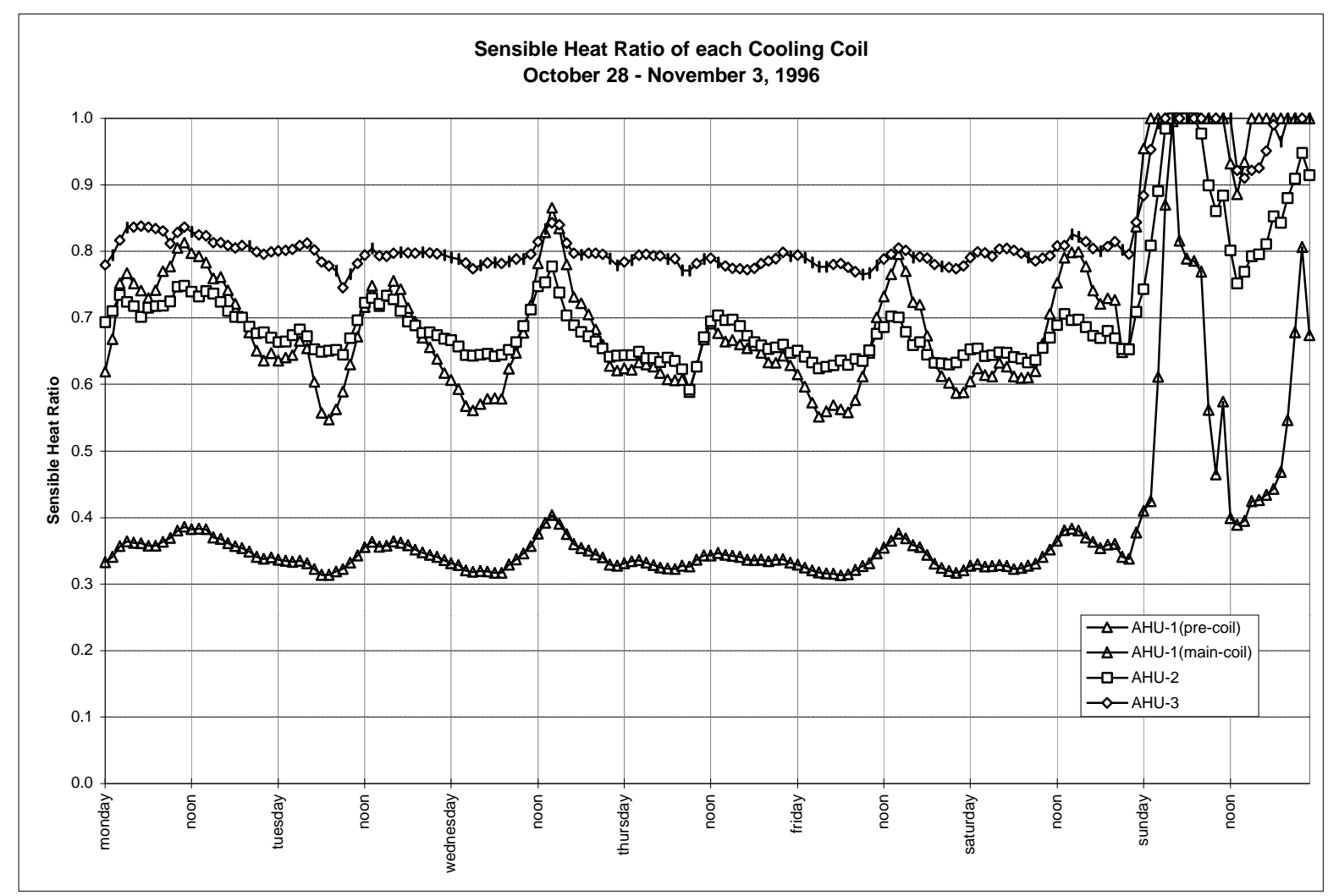

Figure 10 Sensible Heat Ratio, October 28 - November 3, 1996

\section{Re-heat Electric Power for AHU-2 and AHU-3}

In Figure 11, the measured electric reheat power is shown as an hourly time-series graph for the week of September 1-7, 1996. The reheat power for AHU-2 is nearly zero during the entire period. Relating this to the information in Figures 3-6 implies that the latent load is not met, and that the sensible load is only marginally met when the coil is operating under peak cooling conditions. There will not be any electric power savings from the heat pipes in this air handler during peak cooling conditions since no electric power is presently used. Since the sensible load is only marginally met in AHU-2 before the installation of the heat pipes, there is a concern that the sensible load may not be met after the retrofit. Reheat power for AHU-3 during this period typically varies from around $4 \mathrm{~kW}$ in the afternoon to more than $8 \mathrm{~kW}$ at night. 


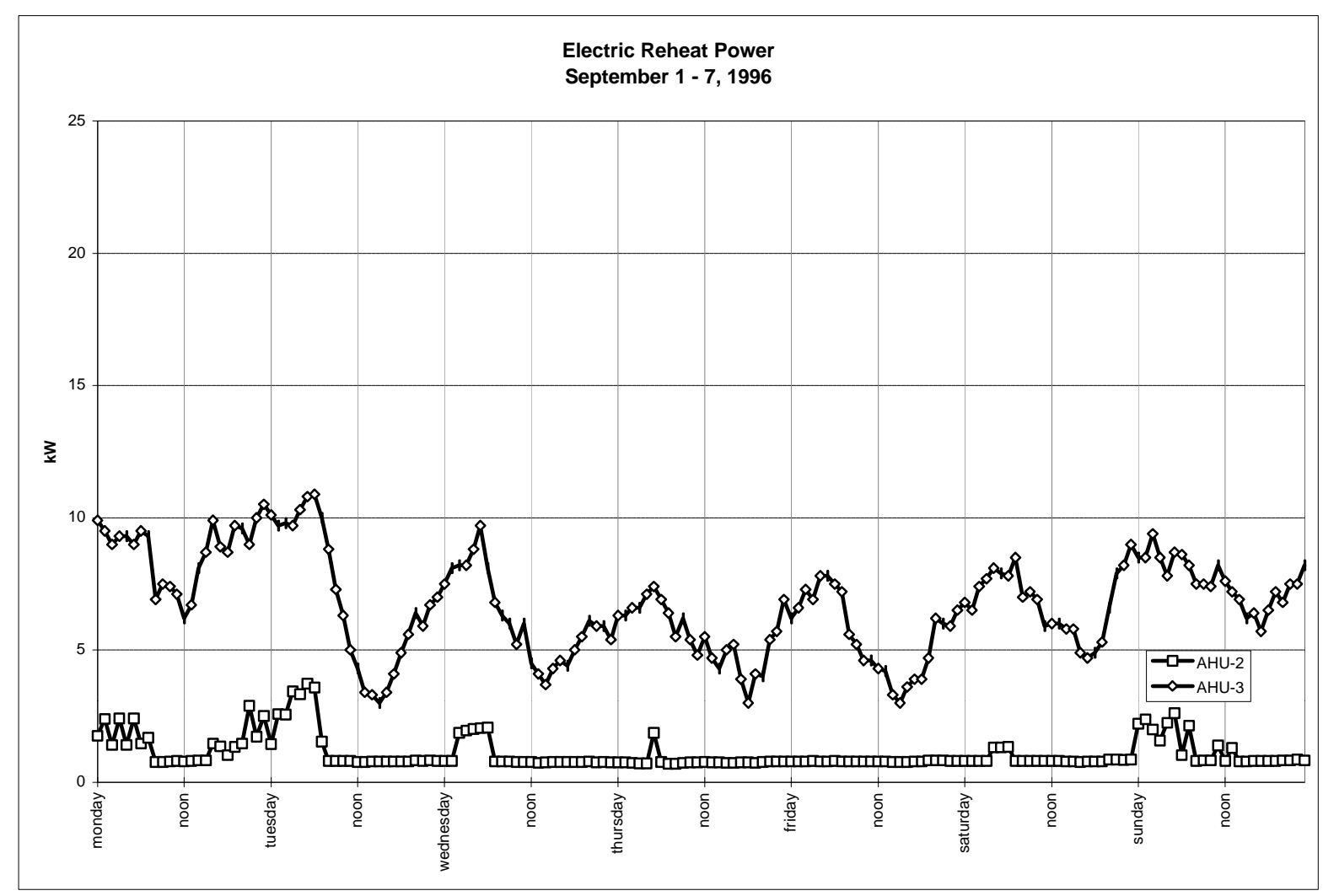

Figure 11 Electric Reheat Power, September 1 - 7, 1996

Similar data for reheat power for the week of October 28 - November 3, 1996 are shown in Figure 12. Both air handlers require substantial reheating, with power increasing as the outside air temperature decreases later in the week. Note that the reheat power is highest when the SHR (from Figure 10) is highest. That is, the reheat power is greatest when the latent load is small. This may indicate incorrect operation of the cooling coil control system rather than an optimum opportunity for heat pipe savings. 


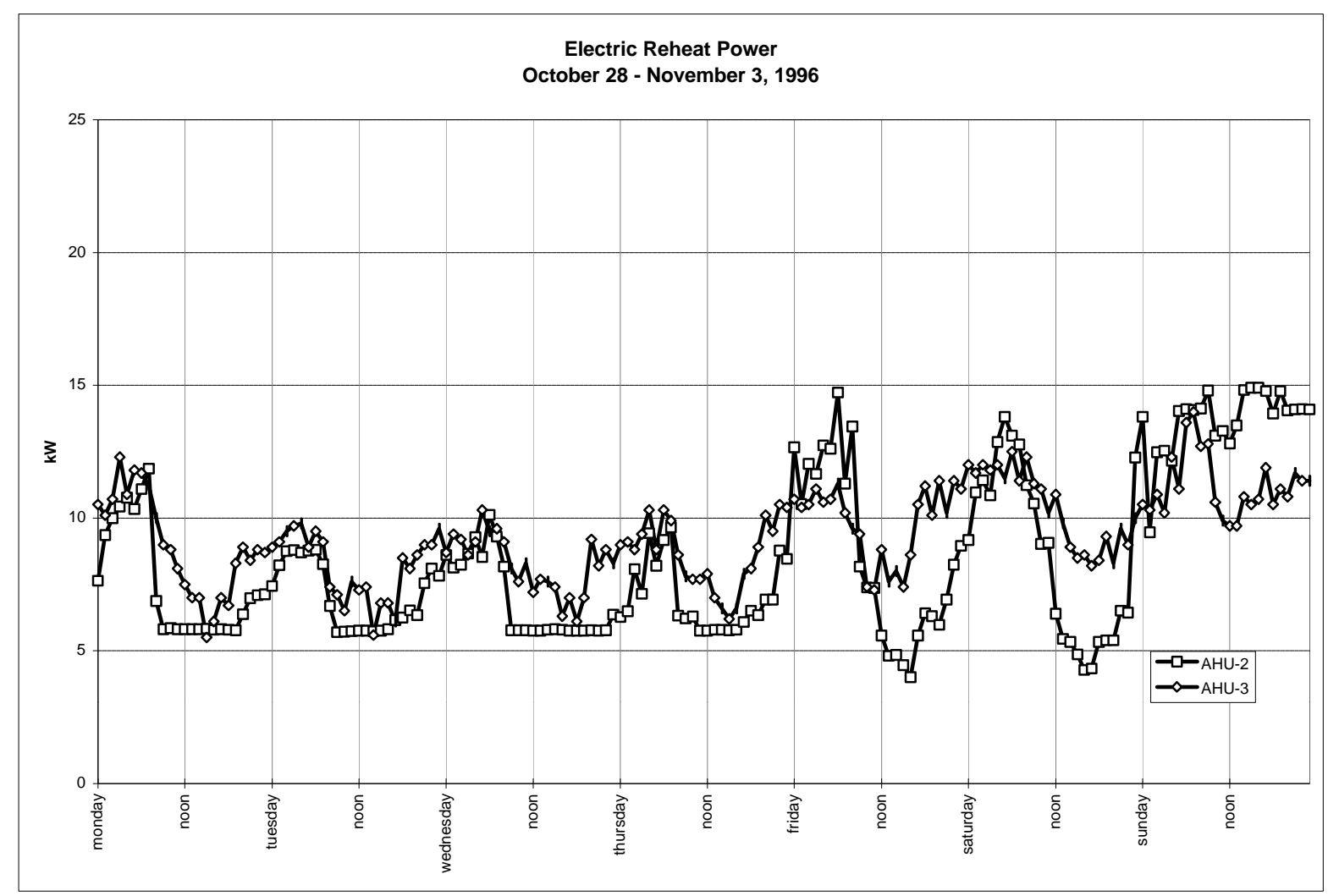

Figure 12 Electric Reheat Power, October 28 - November 3, 1996

Figure 13 shows the AHU-2 average hourly profile for reheat power for typical weeks in August, September, October, and November. Figure 14 shows similar information for AHU3. Reheat power is lowest in August and September, and highest in November. Each curve exhibits a daily variation with minimum reheat required in the afternoon, and maximum reheat required in the early morning hours. This performance is consistent with the observation that the maximum sensible cooling loads are during daytime hours.

Weekly total reheat power for AHU-2 and AHU-3 is shown in the bar chart in Figure 15.

The data presented in the these figures show representative system performance during the pre-retrofit period. We believe that an adequate range of reheat power data is available for comparison to post-retrofit performance. 


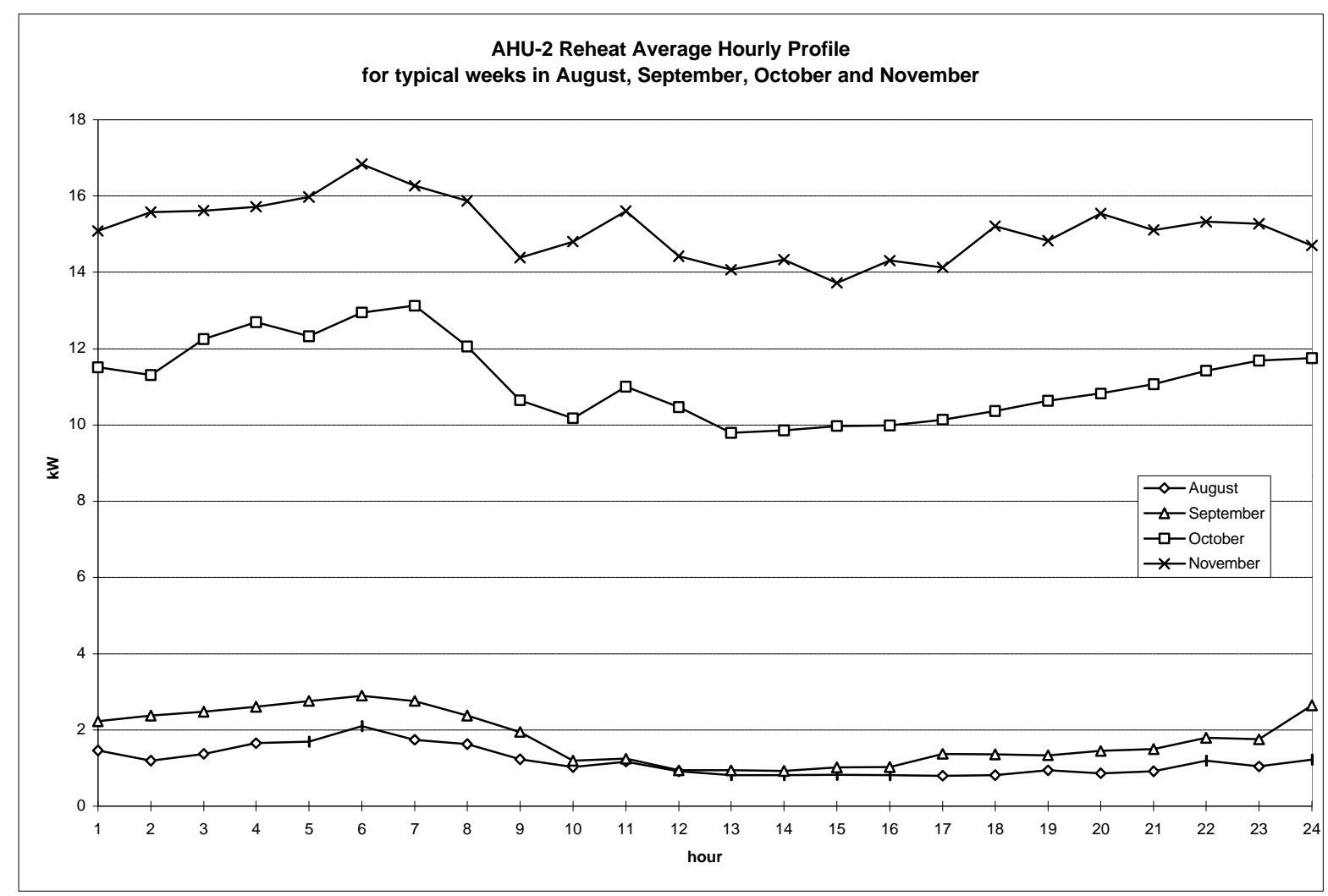

Figure 13 AHU-2 Reheat, Average Hourly Profiles, August - November, 1996

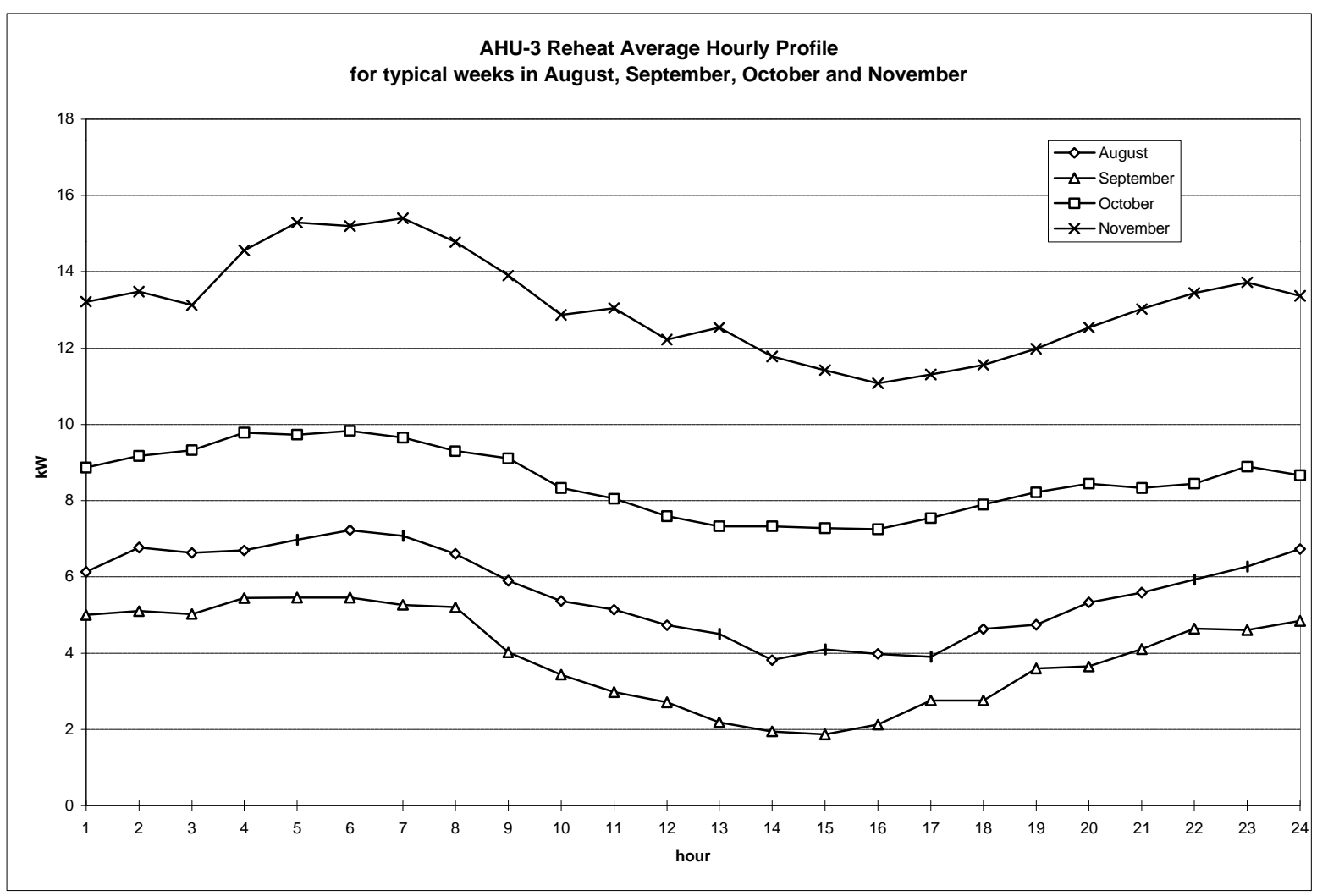

Figure 14 AHU-3 Reheat, Average Hourly Profiles, August - November, 1996 


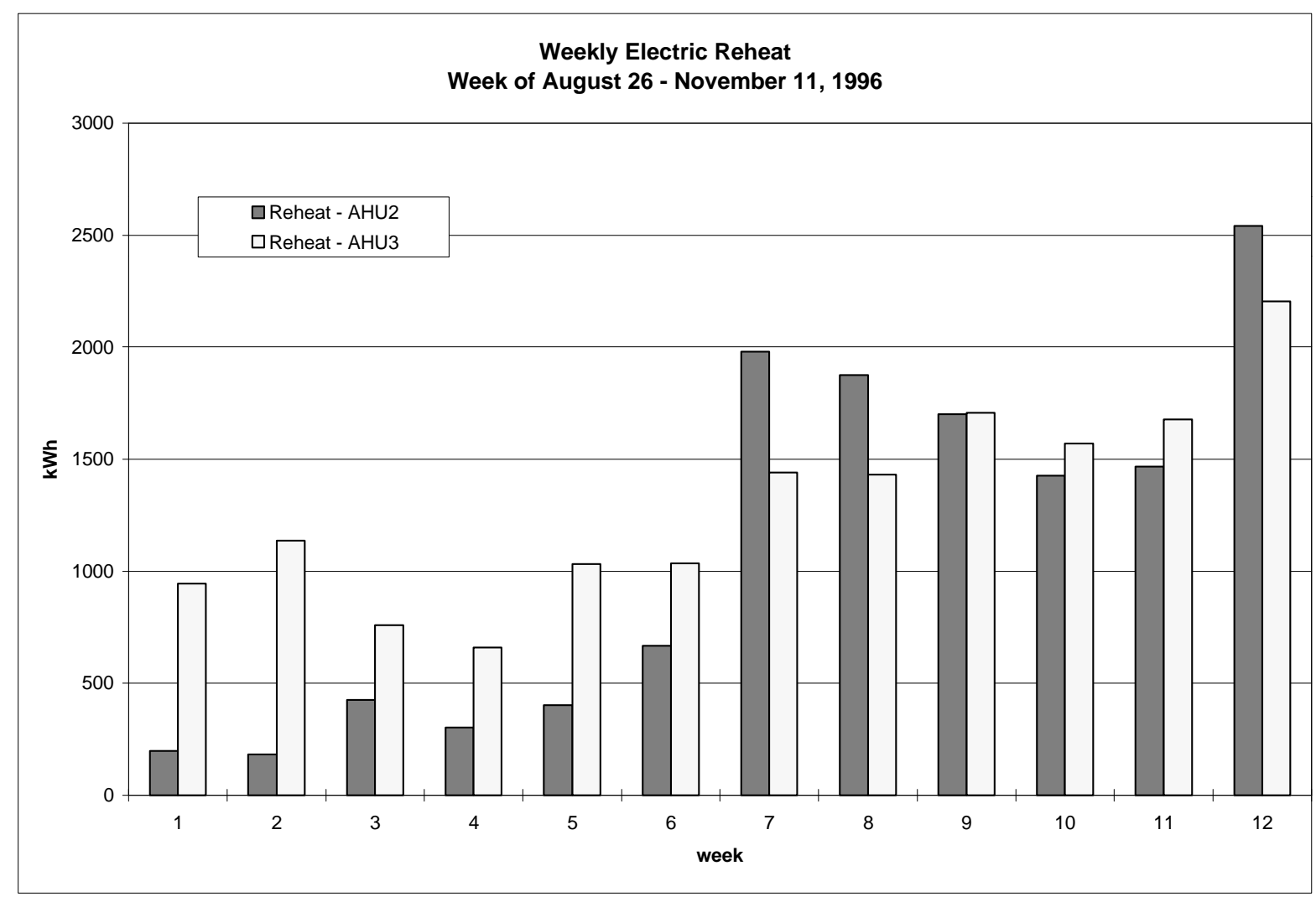

Figure 15 Weekly Electric Reheat, August 26 - November 11, 1996

\section{Chiller Electric Power}

Figure 16 shows hourly electric power data for the 110 ton chiller and the 55 ton chiller during the week of September 1-7, 1996. Both chillers exhibit a small daily variation with minimum power in the early morning and maximum power in the afternoon. The chillers operate continuously at near full power. Figure 17 shows chiller electric power for the week of October 28 - November 3, 1996. The chiller power drops substantially as the outside temperature decreases later in the week. 


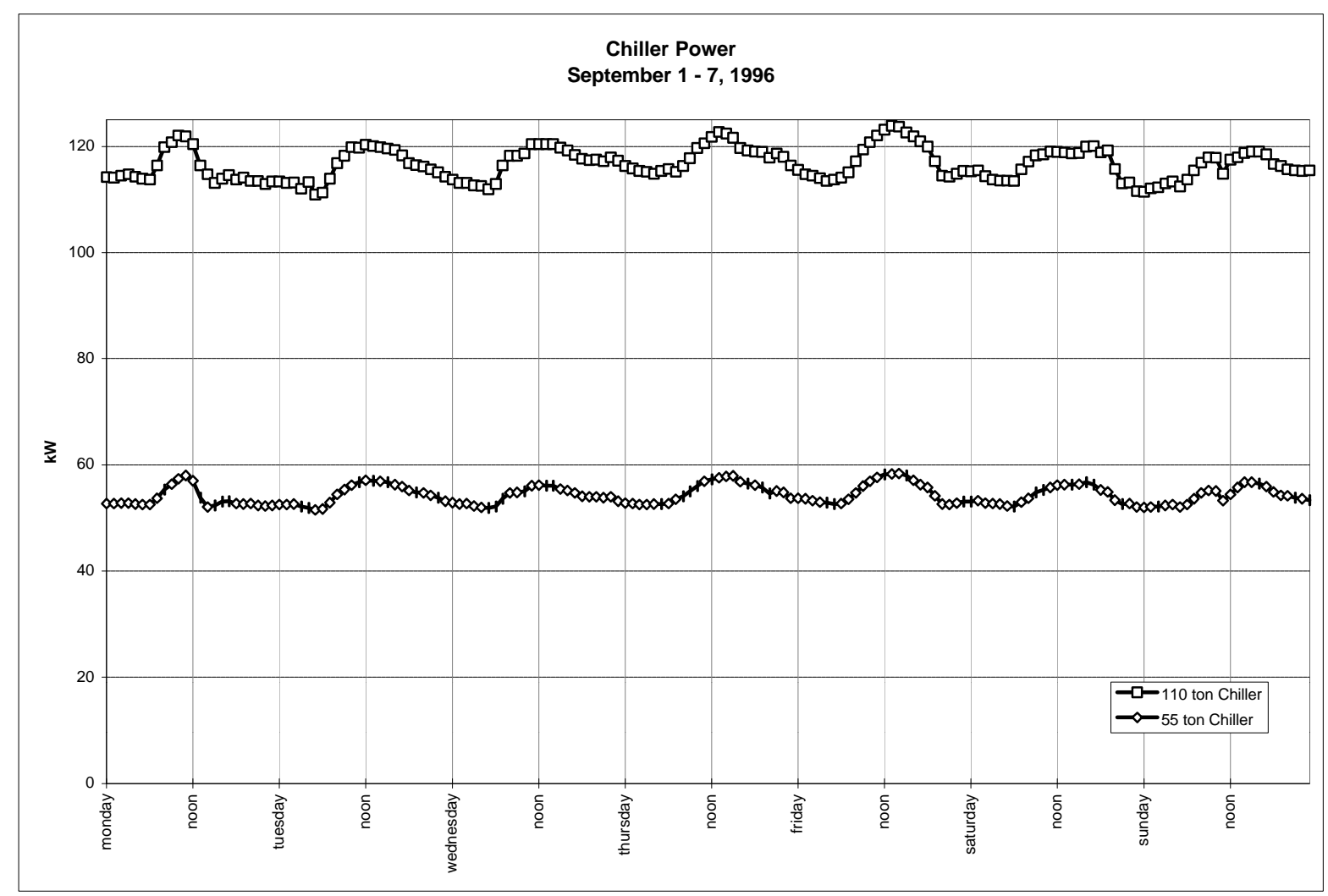

Figure 16 Chiller Power, September 1 - 7, 1996

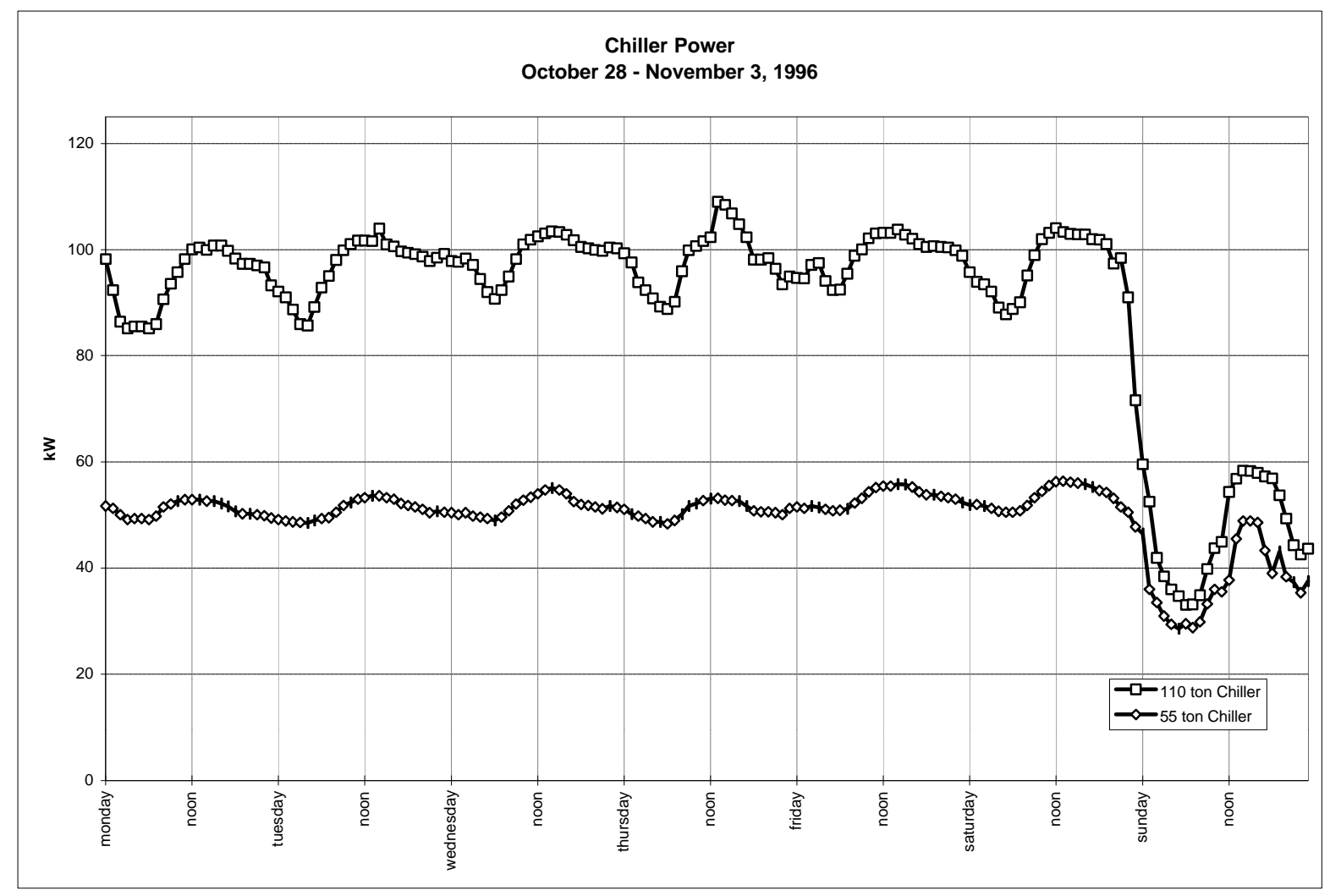

Figure 17 Chiller Power, October 28 - November 3, 1996 
Figure 18 shows the 110 ton chiller average hourly electric power profile for typical weeks in August, September, October, and November. Figure 19 shows similar information for the 55 ton chiller. Chiller power is highest in August and September, and lowest in November. Each curve exhibits a daily variation with maximum chiller power in the afternoon, and minimum power in the early morning hours.

Weekly total chiller power for both chillers is shown in the bar chart in Figure 20.

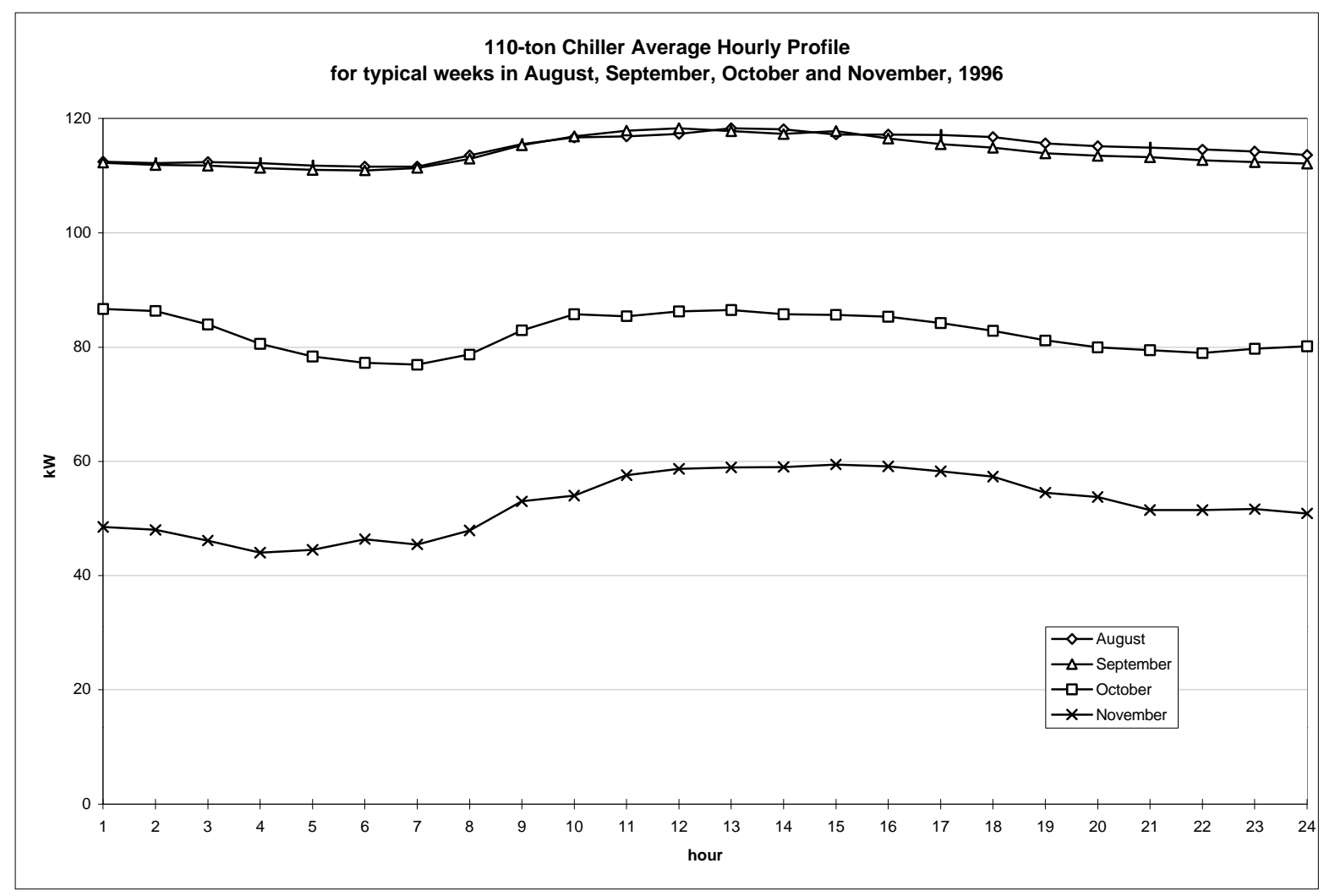

Figure 18 110-ton Chiller Average Hourly Profile 


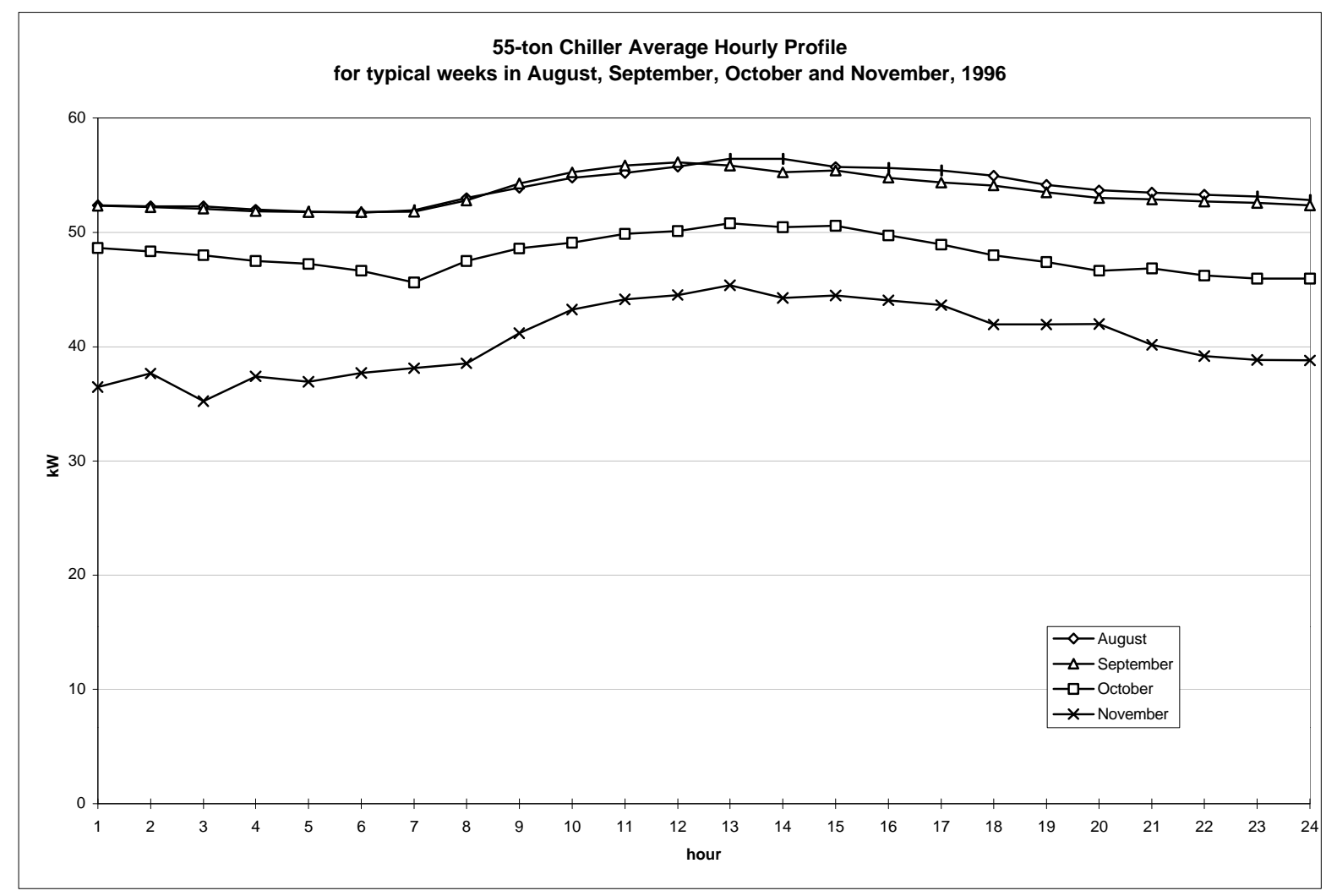

Figure 19 55-ton Chiller Average Hourly Profile

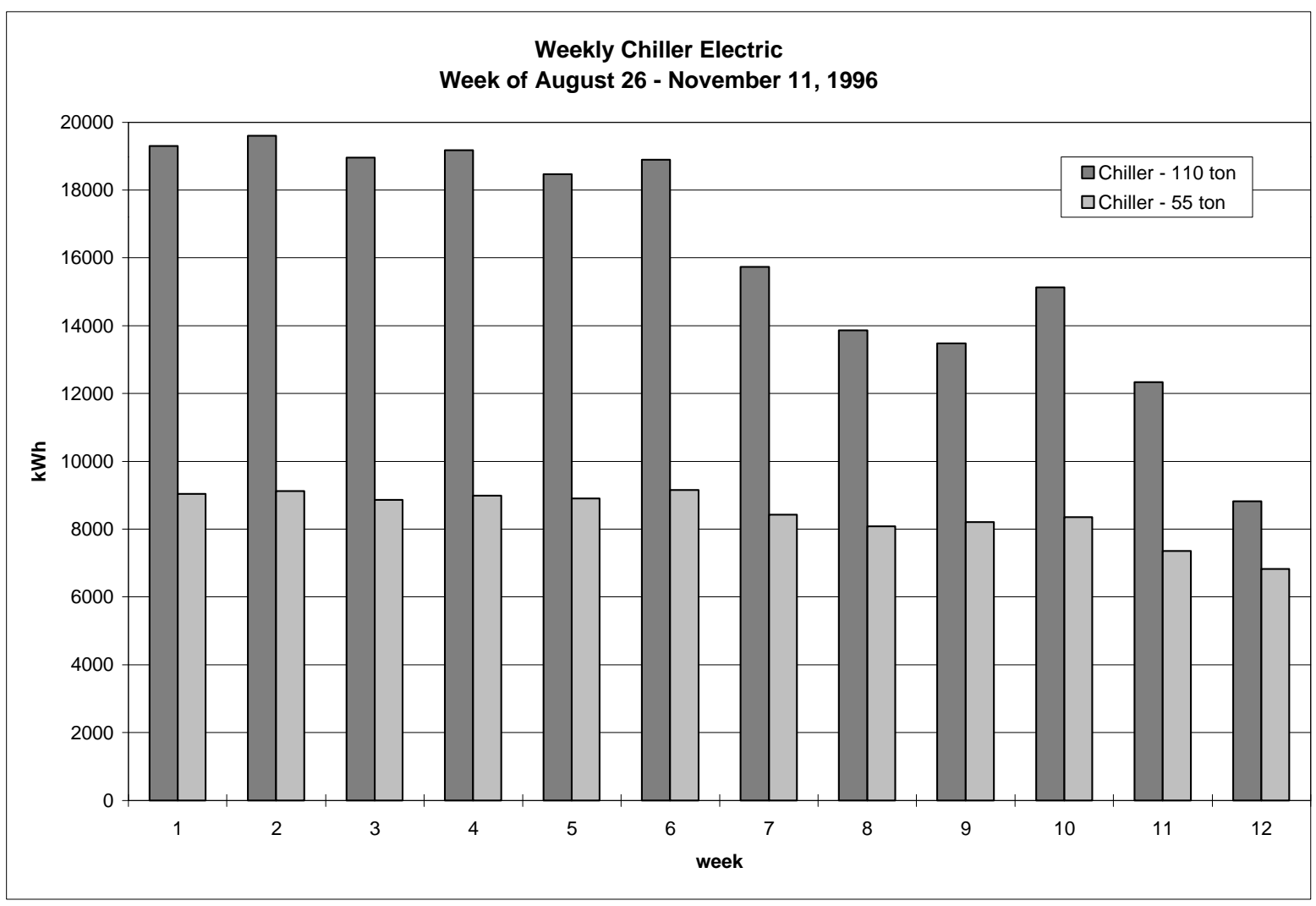

Figure 20 Weekly Chiller Electric Use, August 26 - November 11, 1996 
Energy Consumption and Cost Data, FY 1996

The following table provides monthly total energy use and cost data for Hangar L, including total electric $\mathrm{kWh}$, fuel oil delivered to the boiler storage tank, and total cost. We expect to find a reduction in fuel oil requirements when there is a reduced requirement for hot water reheat for AHU-1 due to heat pipe operation.

Table 3. Energy Consumption and Cost Data from EG\&G Report BOC DRD 1.0.13-2

\begin{tabular}{|c|c|c|c|}
\hline FY 1996 & kWh & $\begin{array}{c}\text { \#2 fuel } \\
\text { gallons }\end{array}$ & $\begin{array}{c}\text { Energy Cost } \\
\$\end{array}$ \\
\hline & & & 24,095 \\
\hline Oct & 454406 & 3124 & 19,690 \\
\hline Nov & 285480 & 5819 & 28,665 \\
\hline Dec & 451984 & 7744 & 10,872 \\
\hline Jan & 141520 & 4116 & 20,939 \\
\hline Feb & 322522 & 4662 & 20,624 \\
\hline Mar & 319588 & 4270 & 21,918 \\
\hline Apr & 366322 & 4186 & 19,980 \\
\hline May & 340172 & 3794 & 22,183 \\
\hline Jun & 385184 & 3752 & 22,282 \\
\hline Jul & 388836 & 2800 & 27,575 \\
\hline Aug & 458986 & 3472 & 22,426 \\
\hline Sep & 396692 & 2240 & \\
\hline Total & 4311692 & 49979 & 261,248 \\
\hline
\end{tabular}

\section{Assessment of Pre-retrofit Performance}

This report has described the measured performance of the Hangar L cooling systems scheduled to receive the heat pipe retrofit. Direct measurements of the chiller power, reheat power, cooling load, and air handler performance have been made. These measurements are expected to provide adequate data for a robust evaluation of the heat pipe performance.

Complete, continuous data have been recorded since August 15, 1996. The heat pipe retrofit was completed in December, 1996. The data acquisition system will remain in place and the post-retrofit monitoring will begin immediately following the retrofit. Post-retrofit data collection is expected to continue through August 1997. With the retrofit occurring in December, system performance over an appropriate range of weather conditions will be measured both before and after the retrofit. 


\section{Acknowledgments:}

This work was funded by the DOE/NREL FEMP program under NREL Subcontract No. AAR-6-16320-01. We appreciate the support and encouragement of Karen Thomas as the NREL project manager. We thank Will Miner and his staff (Dynamac Corp) and Bill Ruppert and Mike Mann (EG\&G) for their substantial assistance in our work on-site at KSC. 


\section{Appendix B Post-Retrofit Evaluation Report}




\section{New Technology Demonstration Program Kennedy Space Center Hangar L Heat Pipe Project: Post-Retrofit Monitoring and Evaluation Report}

November, 1997

National Renewable Energy Laboratory

Subcontract No. AAR-6-16320-01

C. E. Hancock

Paul Reeves

815 Alpine \#6

Boulder, CO 80304

(303) 447-8458 


\section{New Technology Demonstration Program \\ Kennedy Space Center Hangar L Heat Pipe Project: \\ Post-Retrofit Monitoring and Evaluation Report}

November, 1997

\section{Summary}

Heat pipe heat exchangers were installed on three air handlers at Hangar $\mathrm{L}$ at the Cape Canaveral Air Station, Cape Canaveral, Florida in December of 1996. These retrofits are intended to improve the dehumidification performance of the cooling systems, reduce the electric and steam energy required for re-heating air and reduce electric energy used by the chillers.

The energy savings from these retrofits will be evaluated by comparing the energy used before the retrofit and after the retrofit. Complete, continuous system performance data have been recorded since August 15, 1996. This report describes the results of post-retrofit performance monitoring. A previous report (January, 1997) described the system performance for the pre-retrofit period. A subsequent report (December, 1997) will provide a detailed evaluation of the effects of the heat pipe retrofit. In that report, direct comparisons of before-and-after energy use will be made for periods with comparable cooling loads. Empirical models of the system performance will be derived from the measured data and simulation models will be used to calculate annual energy savings. 


\section{System Description}

The NASA Life Sciences Support Facility is located in Hangar L at the Cape Canaveral Air Station, Cape Canaveral, Florida. Laboratory and office areas have been constructed inside the original hangar structure. The hangar is approximately 175 feet wide, 150 feet long, and 30 feet high, yielding a foot print area of about 26,000 square feet. There are approximately 20,000 square feet of conditioned space inside the hangar including offices, labs, and clean rooms. There are very few windows and essentially no direct solar gains on conditioned spaces. Most of the cooling load is due to internal gains from operation of lights and equipment and from conditioning of outside air for ventilation. Normal operating hours for personnel at the building are 0700 through 1700. Much of the equipment and interior lighting remains in operation 24 hours per day.

Three air handlers serve the majority of the conditioned lab and office space. Air handler AHU-1 is located on the main floor of the hangar and supplies conditioned air to the clean room areas of the facility. It operates with 100 percent outside air. The outside air first passes through a pre-cool coil before it enters the main cooling coil. The heat pipe was installed at the pre-cool coil. The two coils are supplied with chilled water (in parallel) from a 110 ton chiller located on the north side of the building. Both temperature and relative humidity in the conditioned space are intended to be controlled by this system. Humidity control is accomplished during periods of high latent loads by cooling the supply air below the point required to meet the sensible load, thus condensing enough moisture from the air to meet the required RH set point. The dry bulb temperature in the space is maintained by reheating the sub-cooled air to meet the temperature set point. Hot water supplied by a local oil-fired steam boiler is used for re-heat on this system. If the RH in the conditioned space drops below the humidistat set point, steam from the boiler is injected in the air flow stream to humidify the air.

Air handlers AHU-2 and AHU-3 are located on the mezzanine level above the office spaces on the south side of the building. (Note that our AHU-3 is designated AHU-1(Mezzanine) in the original mechanical plans) Chilled water is supplied (in parallel) by a 55 ton air-cooled chiller located on the north side of the building. Figure 1. shows a photograph of AHU-3. The chillers located on the north side of the hangar are pictured in Figure 2. Humidity control is accomplished by sub-cooling the air flow to condense sufficient moisture from the air, and then re-heating to maintain the dry bulb temperature set point. Re-heating is accomplished by electric heaters in the supply ducts to each zone. Steam can be injected in the supply ducts to humidify the air during rare periods of low humidity in cool weather.

The heat pipes are intended to transfer some of the sensible heat from the air entering the coil to the air leaving the coil thus reducing or eliminating the need for additional auxiliary reheat for moisture control (assuming that the supply air was indeed already cooler than was required to meet the sensible space load). The heat pipes essentially have the effect of reducing the sensible heat ratio (SHR) of the coil. The intended result of the heat pipe retrofit is to use less energy for re-heat and less energy for chilled water. A slight increase in fan power may be expected to result from installation of the heat pipes due to a higher pressure drop. 


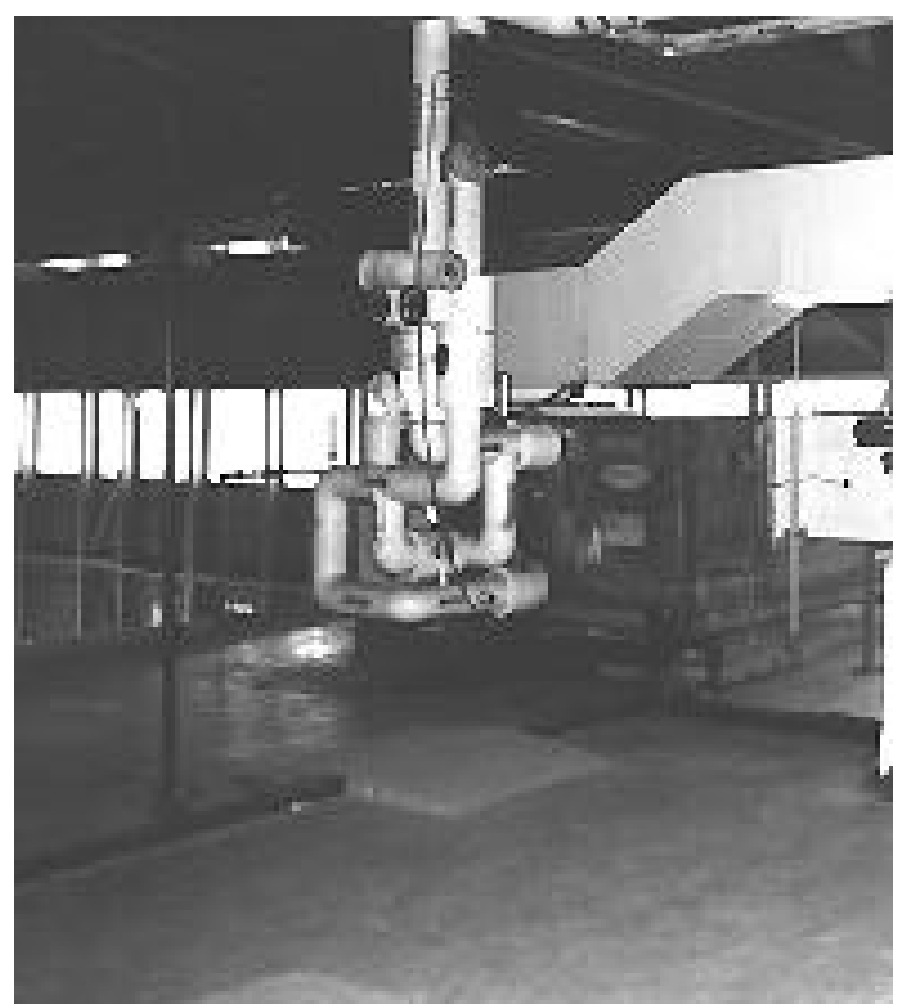

Figure 1 AHU-3

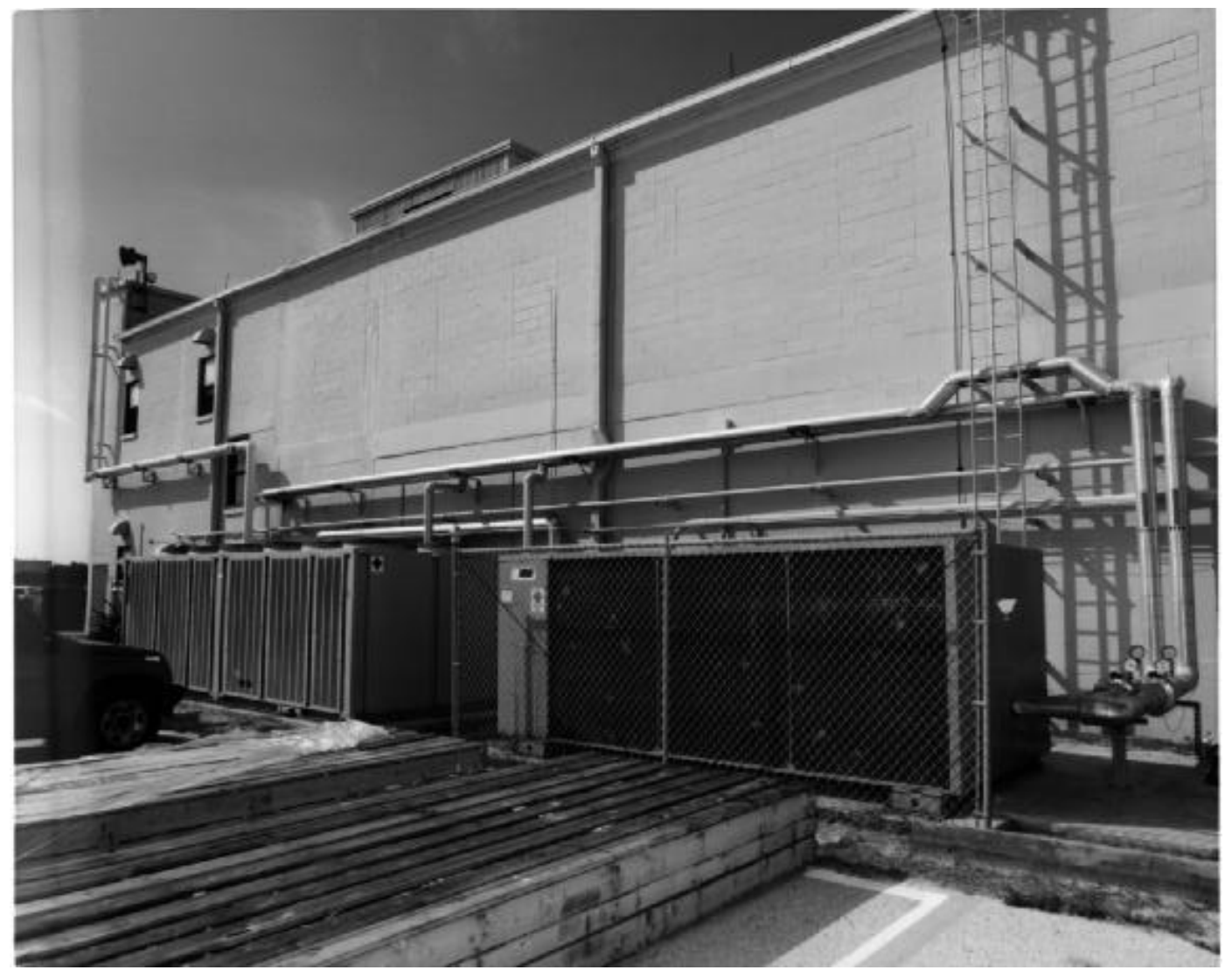

Figure 2 Hangar L Chillers

Appendix B-4 


\section{Evaluation Approach}

The energy savings from the heat pipe retrofits will be evaluated by comparing the energy used before the retrofit and after the retrofit. Direct measurements of the primary energy quantities have been made over an extended period of time. The pre-retrofit performance was described in a previous report (January, 1997). This present report describes the postretrofit system performance. Some preliminary observations of before-and-after energy use are made in this report. A subsequent report will make detailed comparisons of before-andafter energy use, and use empirical models of the system performance and simulation models to calculate annual energy savings.

The energy savings attributed to the heat pipes are expected to be derived from:

1. reduced reheat power during periods when either electric or steam re-heat would be used to raise the main supply air to the minimum temperature required by the space loads

2. reduced chiller power during periods when main supply air reheat is required and the chiller is running at less than full load

The data collected during the post-retrofit period, as well as values calculated from monitored data, are presented in this report in a number of different formats. Typical weeks, average profiles and weekly sums are used to present the data in a meaningful way.

Week long periods during January, March and August were chosen to represent "lowcooling", "moderate cooling", and "high cooling" periods, respectively. These weeks were chosen based on the weather conditions, the amount of continuous data collected and the uninterrupted operation of the cooling equipment. Daily profiles were created by averaging the data for typical weeks in each month of the post retrofit period. Weekly totals were calculated for select data and presented for each week of the post-retrofit period.

Average hourly profiles for reheat and chiller power are created by averaging the daily profiles of a typical week in each month of post-retrofit data. Total weekly reheat and chiller power are shown for the entire post-retrofit period

The sensible and latent energy removed from the air flow at each air handler is reported for the three weekly periods along with the sensible heat ratio (SHR) is reported for each coil. These quantities provide the basis for comparing the system performance in the before and after retrofit periods, and also provide inputs for developing functional models of the reheat and chillers.

In addition to energy savings, interior temperature and humidity conditions may be modified by the heat pipe retrofit. Return air temperature and relative humidity are reported for each of the air handlers during typical period of operation. 


\section{Post Retrofit Measured Performance Data}

\section{Air Flow Rates}

The supply air flow rates were measured for each air handler both before and after the retrofit. Table 1. displays the CFM for each air handler as specified in the design documents, as measured before the retrofit, and as measured after the retrofit. The installation of the heat pipes adds resistance to the air flow, which could result in lower flow rate, higher fan power, or both. The air flow measurements indicate that the flow rate increased by about 10 percent for AHU-1 and decreased by about 5 percent for AHU-3 after the installation of the heat pipes. These changes are not considered significant. The air flow for AHU-2 appeared to drop by about 25 percent after the retrofit, from 6,800 CFM to 5,000 CFM. This may not constitute a serious problem since the design flow rate was originally 5,765 CFM. The resulting measured flow rate after the retrofit is about 13 percent below nominal.

Table 2. Supply air flow rates.

\begin{tabular}{|c|c|c|c|}
\hline Air Handler & $\begin{array}{c}\text { As Designed } \\
\text { CFM }\end{array}$ & $\begin{array}{c}\text { Before Retrofit } \\
\text { CFM }\end{array}$ & $\begin{array}{c}\text { After Retrofit } \\
\text { CFM }\end{array}$ \\
\hline AHU-1 & 15,800 & 12,600 & 13,800 \\
\hline AHU-2 & 5,765 & 6,800 & 5,000 \\
\hline AHU-3 & 8,675 & 9,900 & 9,400 \\
\hline
\end{tabular}

\section{Air Handler Thermal Performance}

The measured hourly thermal performance of each cooling coil is shown in Figures 3-6 for the week of August 11-17, 1997. These data are typical of peak summer cooling conditions. Figure 3 shows a time-series graph of the hourly heat removed (or cooling load) at each coil. This graph shows that the heat removed is nearly constant as a function of time, implying that the coils are operating near their maximum capacity. Compared to a similar period before the retrofit, AHU-2 and AHU-3 show heat removed to be about 10 percent higher in the postretrofit period. For AHU-1, the post retrofit heat removal is lower for the pre-cool coil and higher for the main coil. These observations are consistent with expected operation of the heat pipes.

Figure 4 shows a graph of return air dry-bulb temperature and relative humidity $(\mathrm{RH})$ for the same period of time. The return air conditions are a good indication of the typical zone temperatures and RH. The return dry bulb temperature from each AHU shows a daily fluctuation with a high in the afternoons, and a low in the early morning hours. The average temperature for AHU-1 is approximately $25 \mathrm{C}(77 \mathrm{~F})$ and the relative humidity is approximately 70 percent. These conditions are similar to the pre-retrofit conditions. (Note that for AHU-1 this is the exhaust air condition, not return.) The daily average return temperature for AHU-2 is typically $26 \mathrm{C}(79 \mathrm{~F})$ and the $\mathrm{RH}$ is between 45 percent and 50 percent. AHU-2 may not be adequately meeting the sensible cooling load as evidenced by 
the relatively high return temperature. (Note that air flow measurements indicated a significant reduction in flow rate for AHU-2 after the retrofit.) The average return temperature for $\mathrm{AHU}-3$ is $22.5 \mathrm{C}(72.5 \mathrm{~F})$ and the $\mathrm{RH}$ is 55 percent.

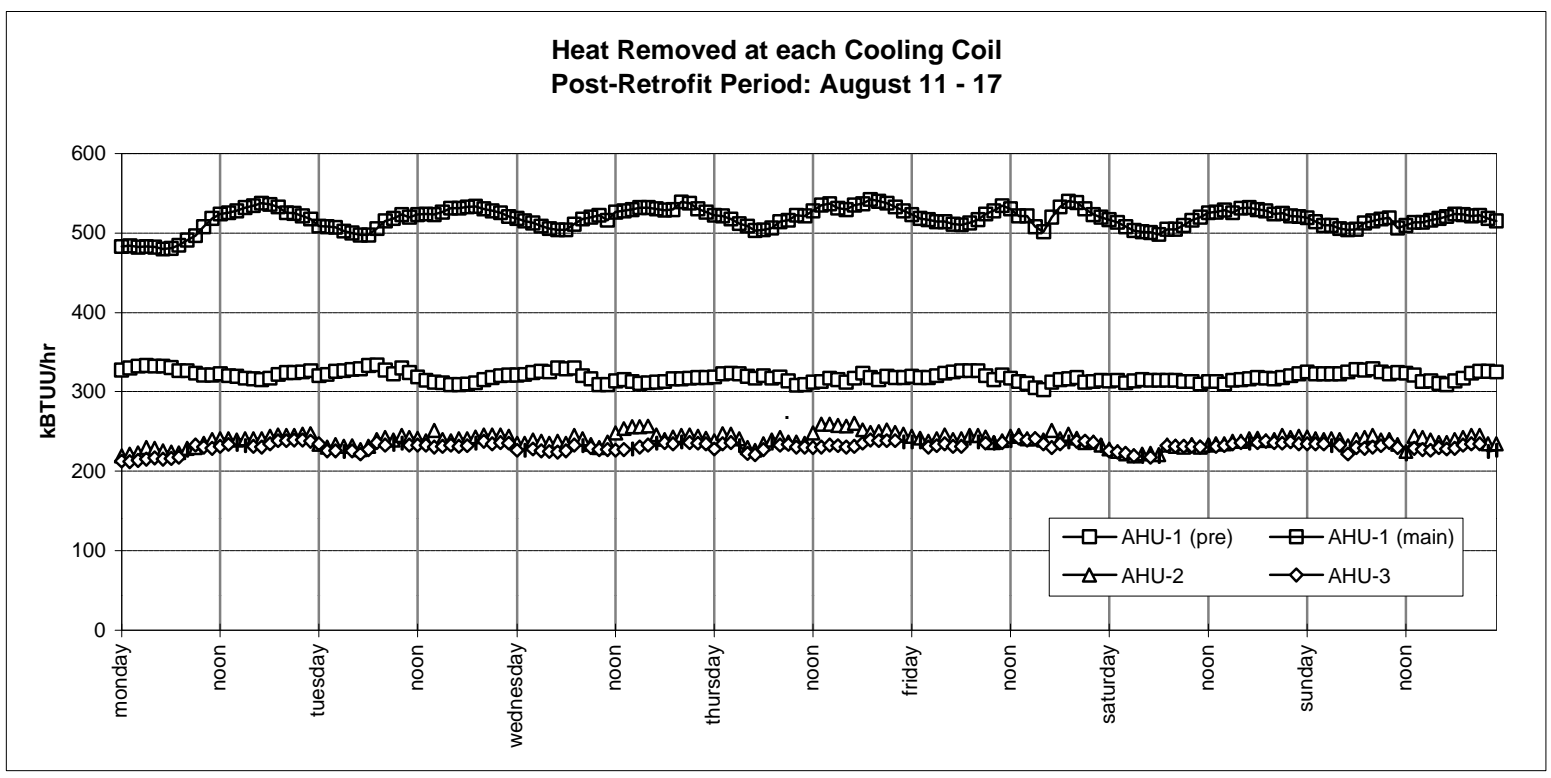

Figure 3 Heat Removed, High Cooling Period: August 11 - 17, 1997

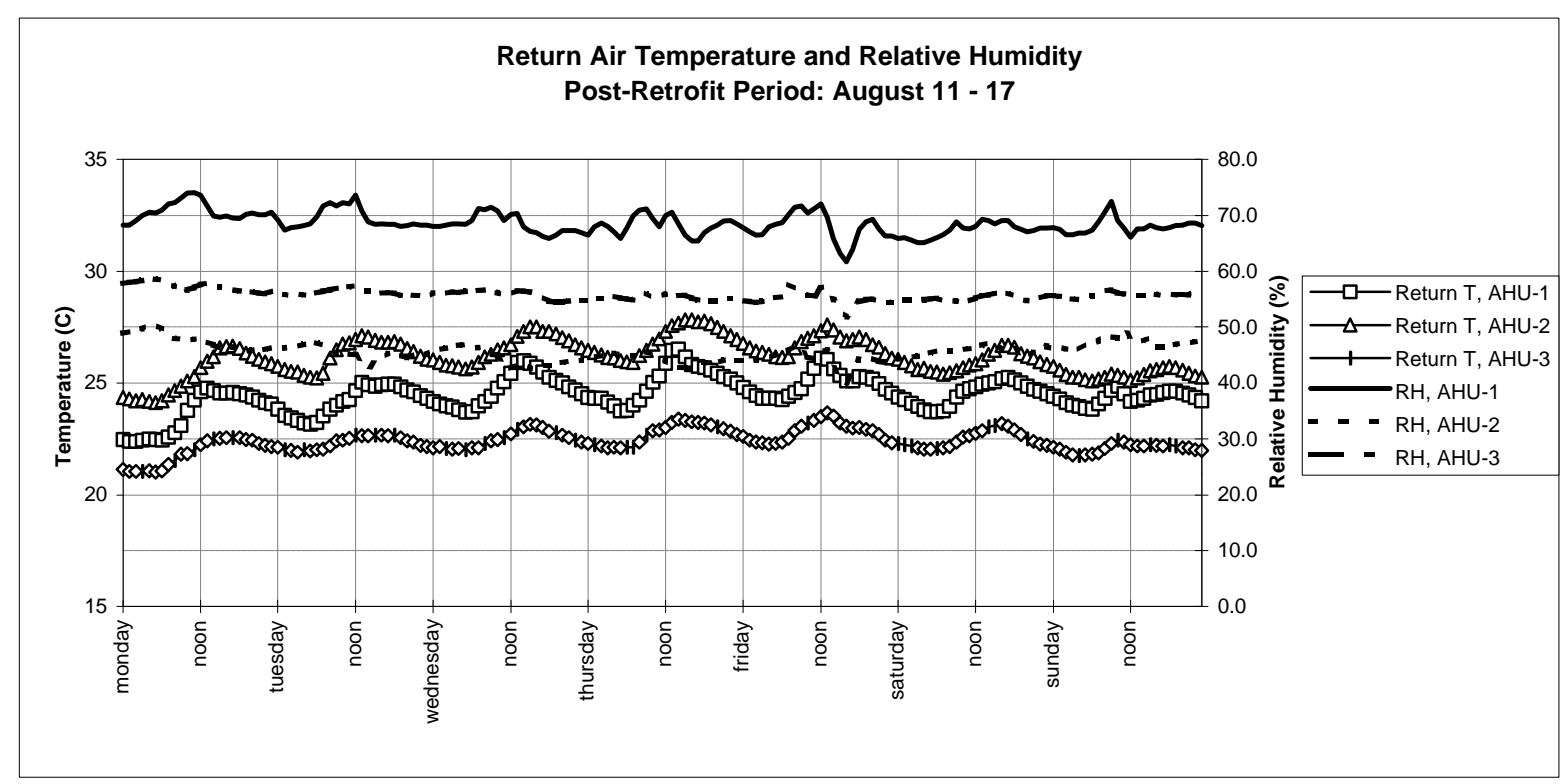

Figure 4 Return Air Temperature and Relative Humidity, High Cooling Period: August 11 - 17, 1997 
Figure 5 shows a time-series graph of the hourly Outside or make-up air for AHU-1 and AHU-2 for the week of August 11-17, 1997. AHU-1 (and AHU-3) draws its make-up air from inside the hangar while AHU-2 draws its make-up air from outside. Daytime high temperatures are typically above $35 \mathrm{C}(95 \mathrm{~F})$ and nighttime low temperatures are around $27 \mathrm{C}$ (80 F). The air inside the hangar is almost always warmer than the outside air, especially at night. It appears that cooling loads would be minimized if make-up air were drawn from outside. This condition has not changed since pre-retrofit monitoring started.

Figure 6 shows a time-series graph of the hourly sensible heat ratio (SHR) for each cooling coil for the week of August 11-17, 1997. The SHR for AHU-1 main coil is nearly constant at about 0.38 . This value is somewhat higher than during the pre-retrofit period and is a result of the heat pipe installed on the pre-cooling coil. The SHR for the AHU-1 pre-coil varies between 0.50 and 0.75 . The AHU-2 SHR varies between 0.55 and 0.60 and the AHU-3 SHR varies between 0.65 and 0.70. It appears that AHU-2 and AHU-3 have slightly lower SHR in the post-retrofit period. This is the expected effect of the heat pipes.

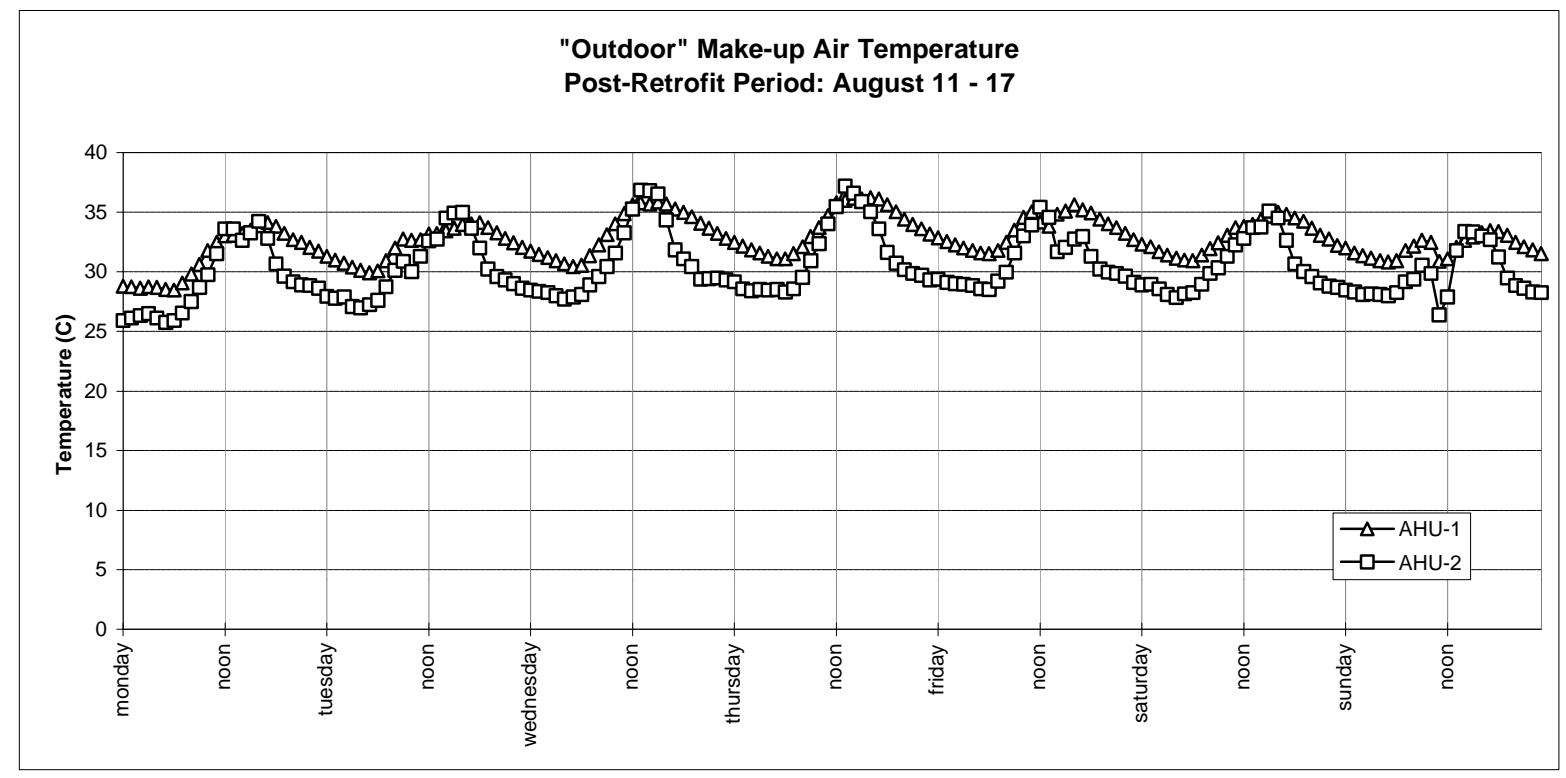

Figure 5 "Outdoor" Make-up Air Temperature, High Cooling Period: August 11 - 17, 1997 


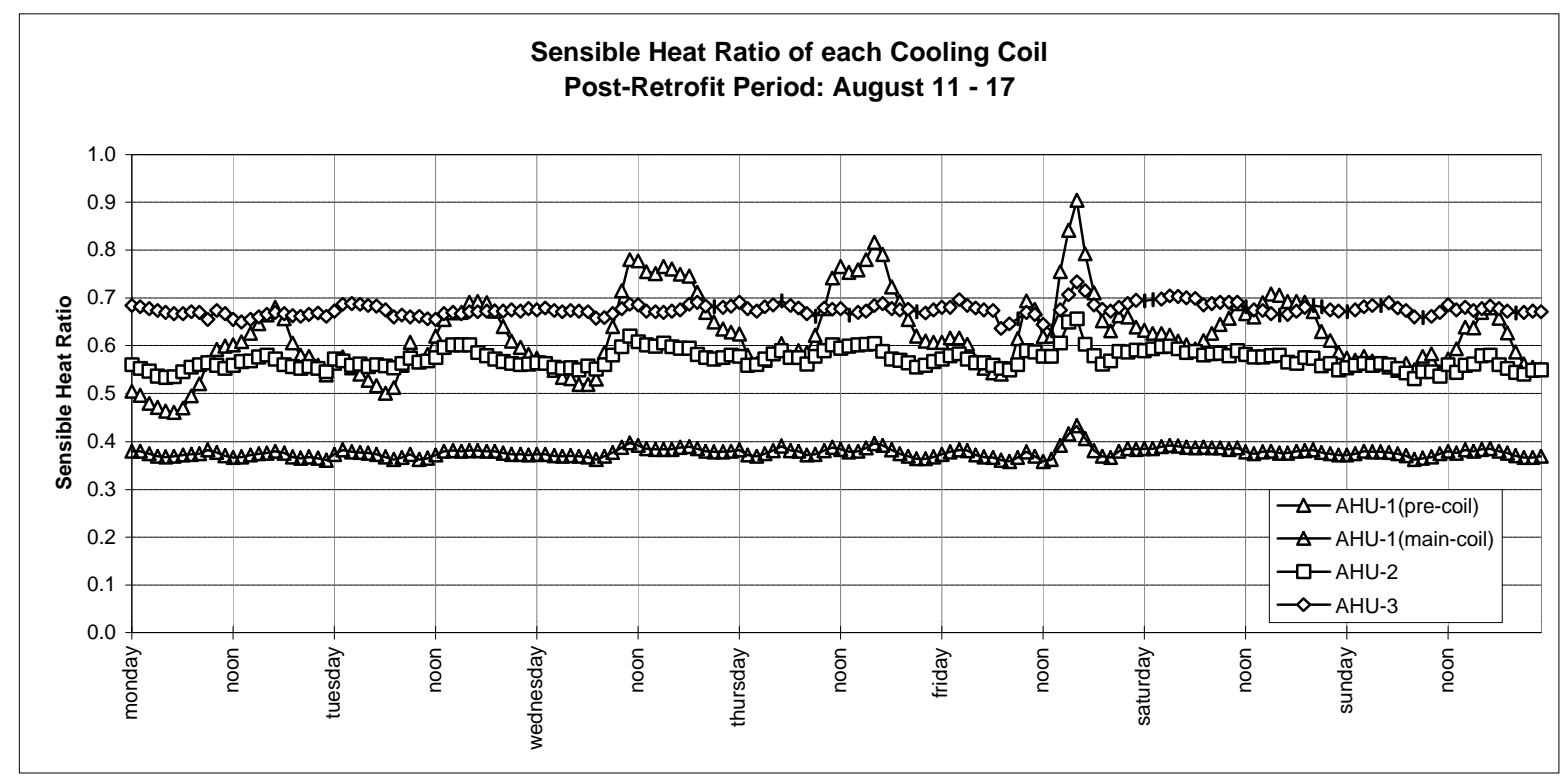

Figure 6 Sensible Heat Ratio, High Cooling Period: August 11 - 17, 1997

Figures 7-10 show plots of the cooling coil thermal performance data for the week of March 24-30, 1997. These data show performance during the season of moderate cooling loads. AHU-2 and AHU-3, which have a relatively small fraction of outside air, are still operating near capacity. AHU-1 cooling loads are lower than the peak loads shown in August. Figure 8 shows that the zone temperature and RH are closer to their nominal set points than they were during peak cooling conditions. Figures 9 shows the outside air temperatures for AHU1 and AHU-2 for the March 24-30 period. Figure 10 shows that the SHR and latent loads for each coil are generally lower than during peak cooling periods.

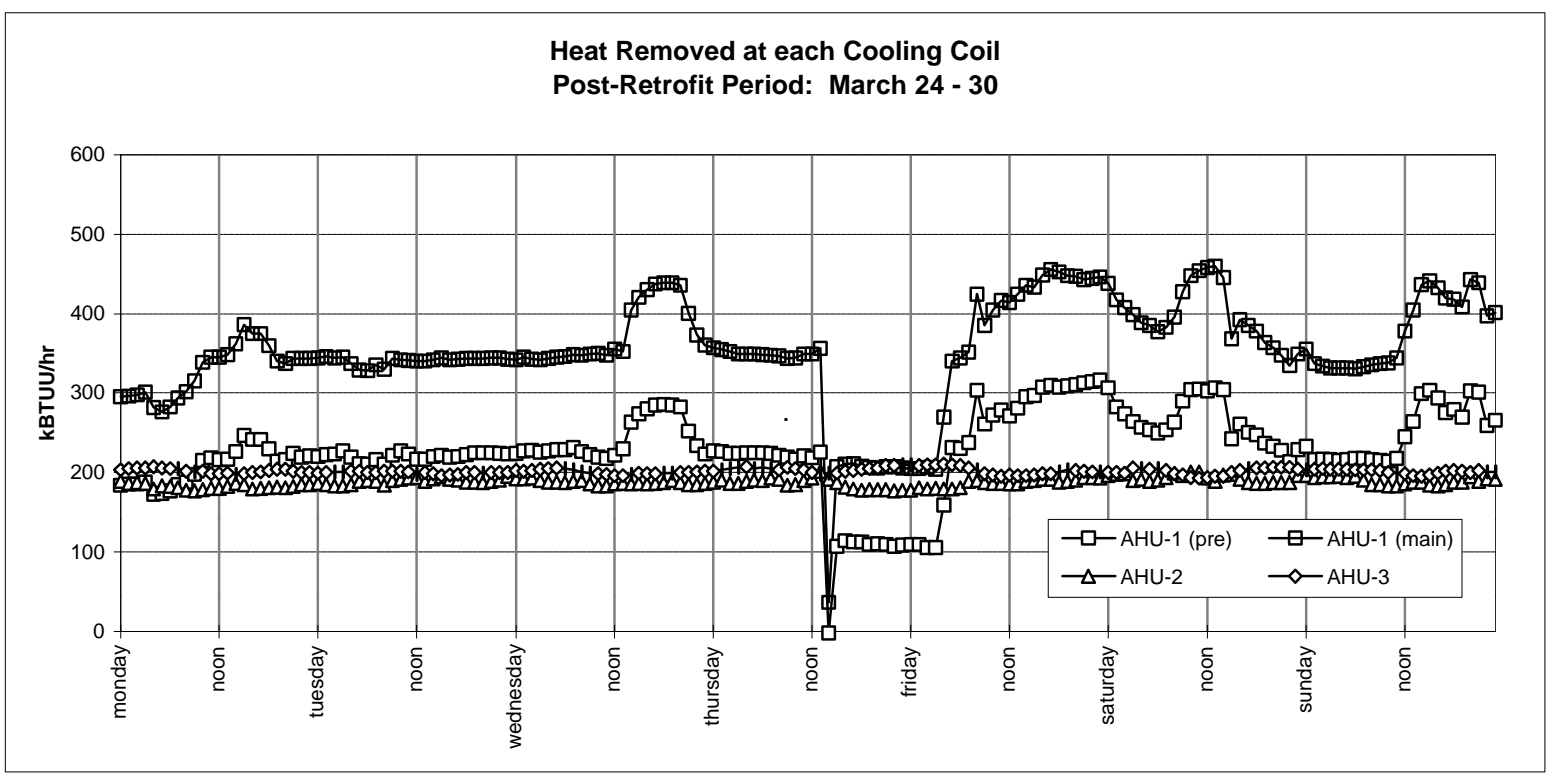

Figure 7 Heat Removed, Moderate Cooling Period: March 24 - 30, 1997 


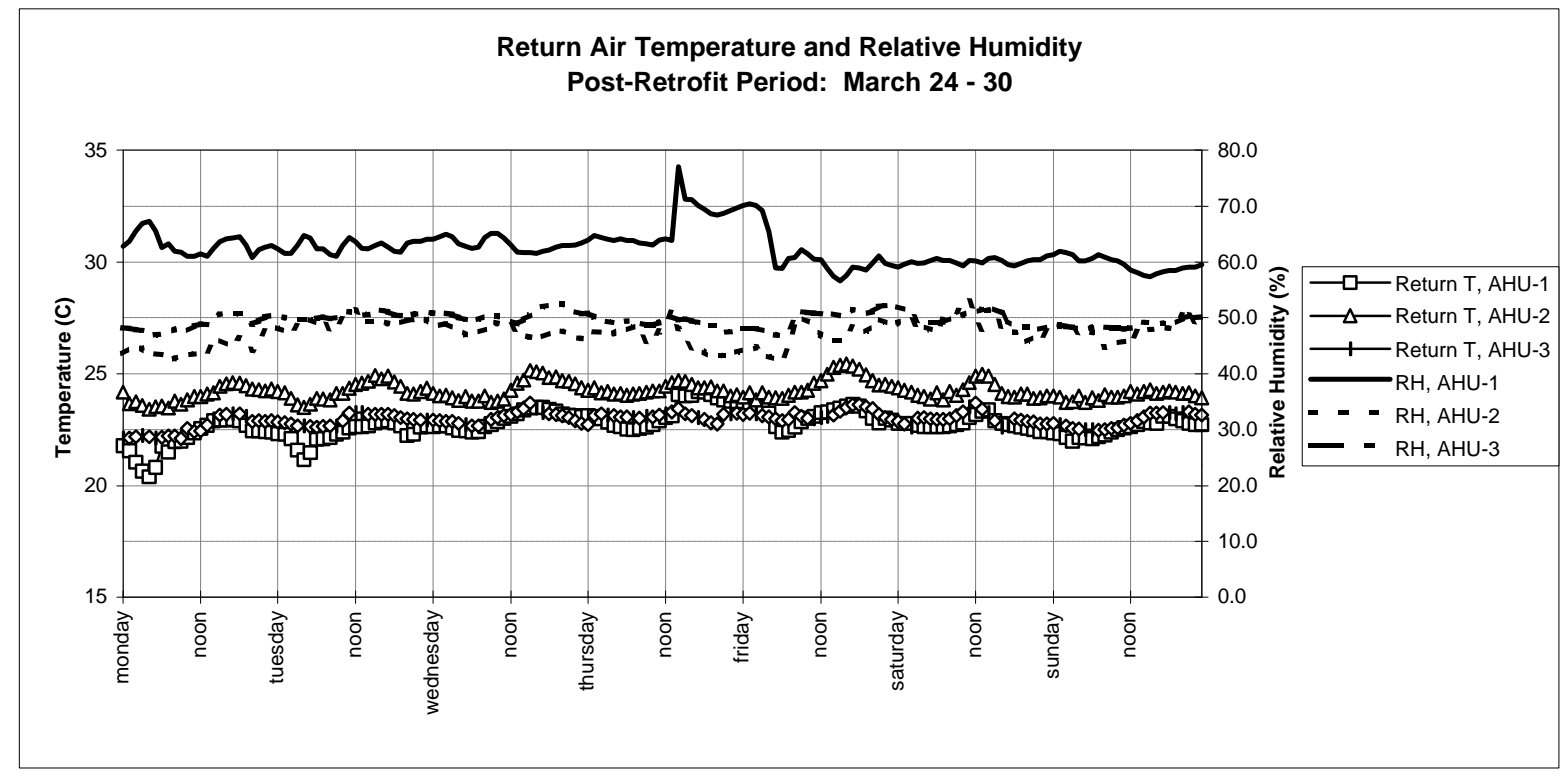

Figure 8 Return Air Temp. and Relative Humidity, Moderate Cooling Period: March 24 - 30, 1997

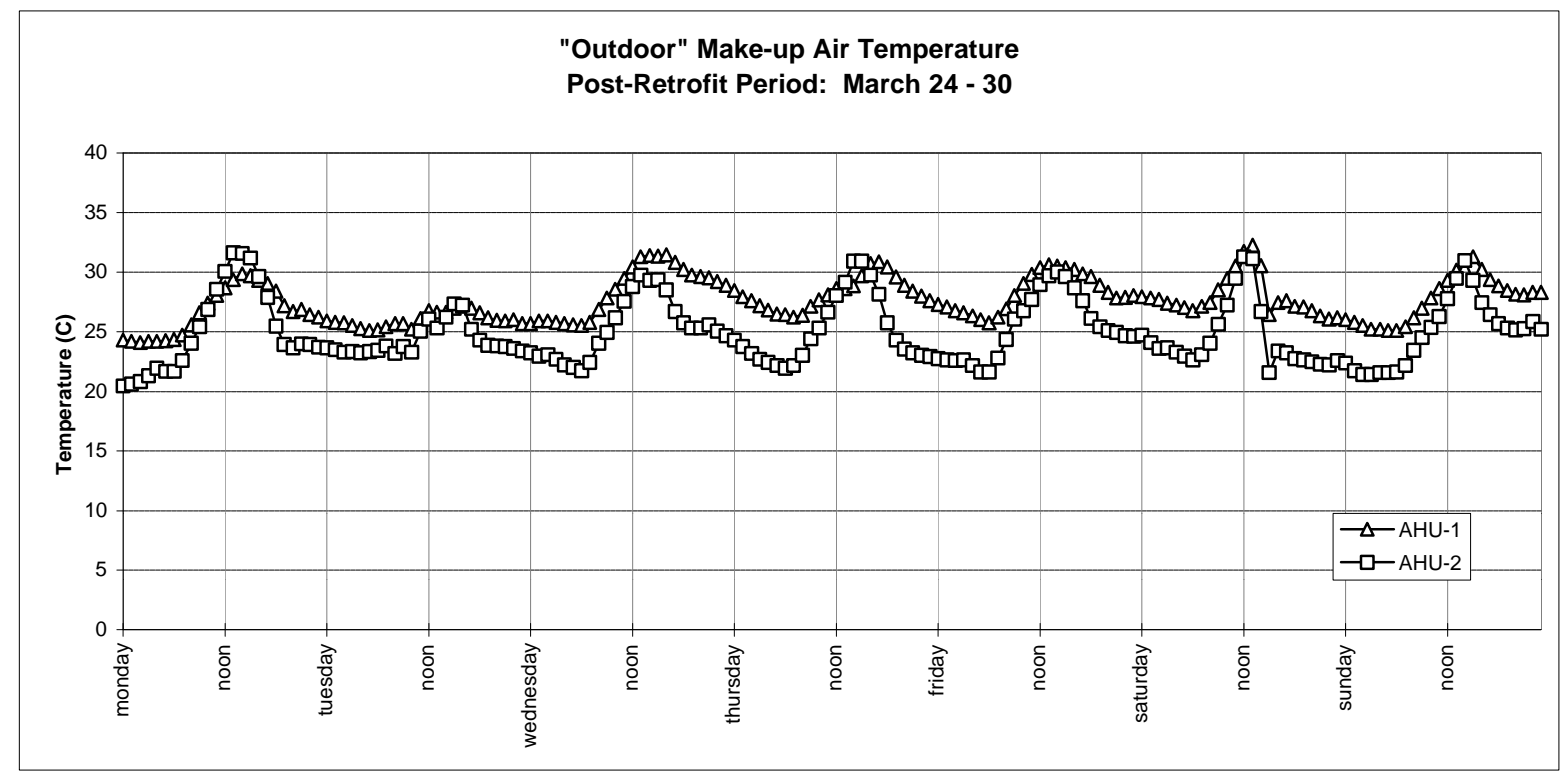

Figure 9 “Outdoor” Make-up Air Temperature, Moderate Cooling Period: March 24 - 30, 1997 


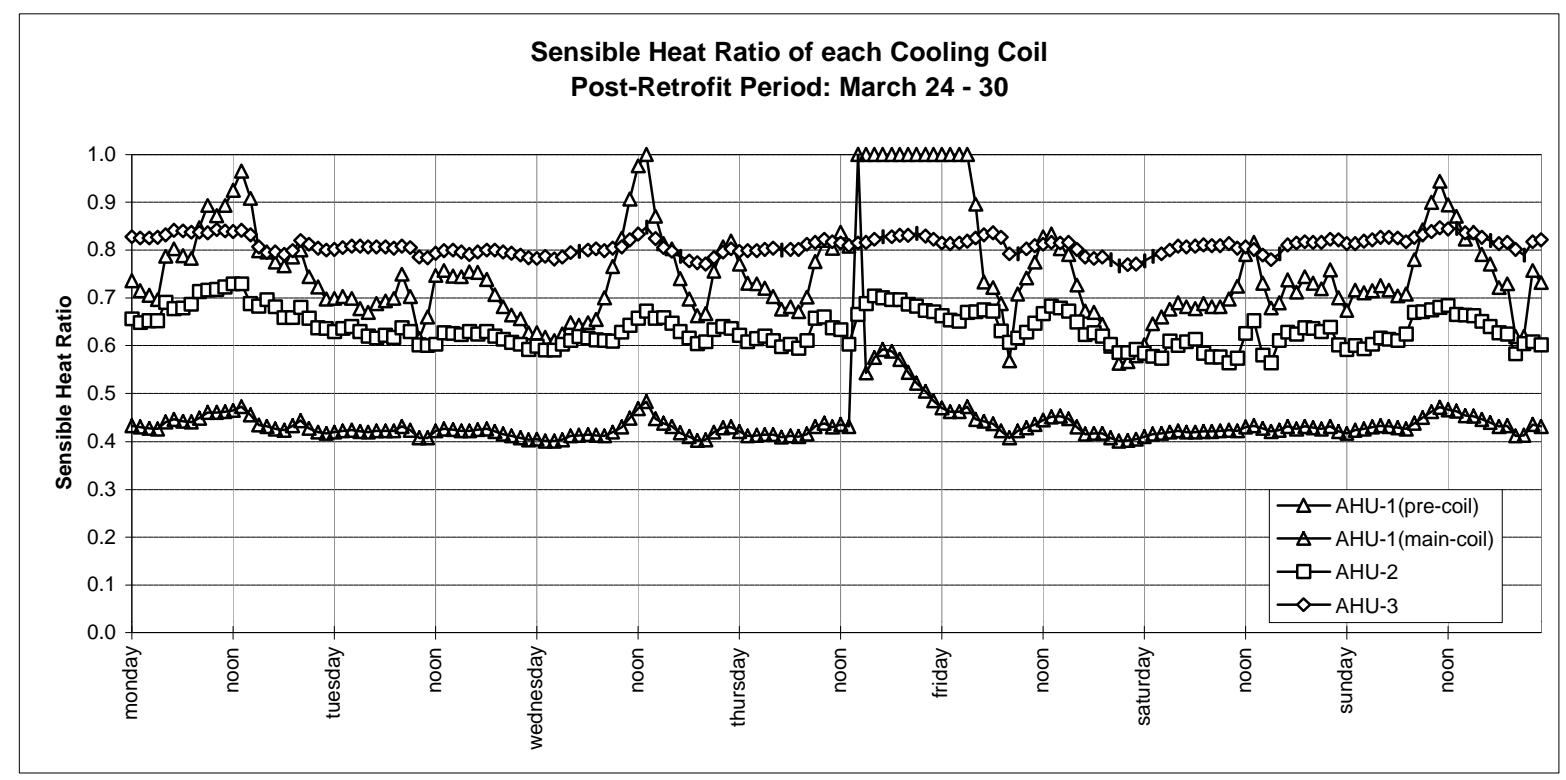

Figure 10 Sensible Heat Ratio, Moderate Cooling Period: March 24 - 30, 1997

Figures 11-14 show system performance data for January 20-26, 1997, the chosen colder, or "low cooling" period. Figure 11 shows that some cooling is required at each coil, although the loads are quite small compared to other seasons. The return air temperature and RH data in Figure 12. indicate that inside conditions are adequately controlled. The outside air dry bulb, Figure 13, temperatures ranged from about 9C (48F) to $28 \mathrm{C}(82 \mathrm{~F})$. It rarely gets cold at Cape Canaveral. Figure 14 shows the SHR, indicating that very little latent heat is removed during this cool weather period, except at the pre-cool coil.

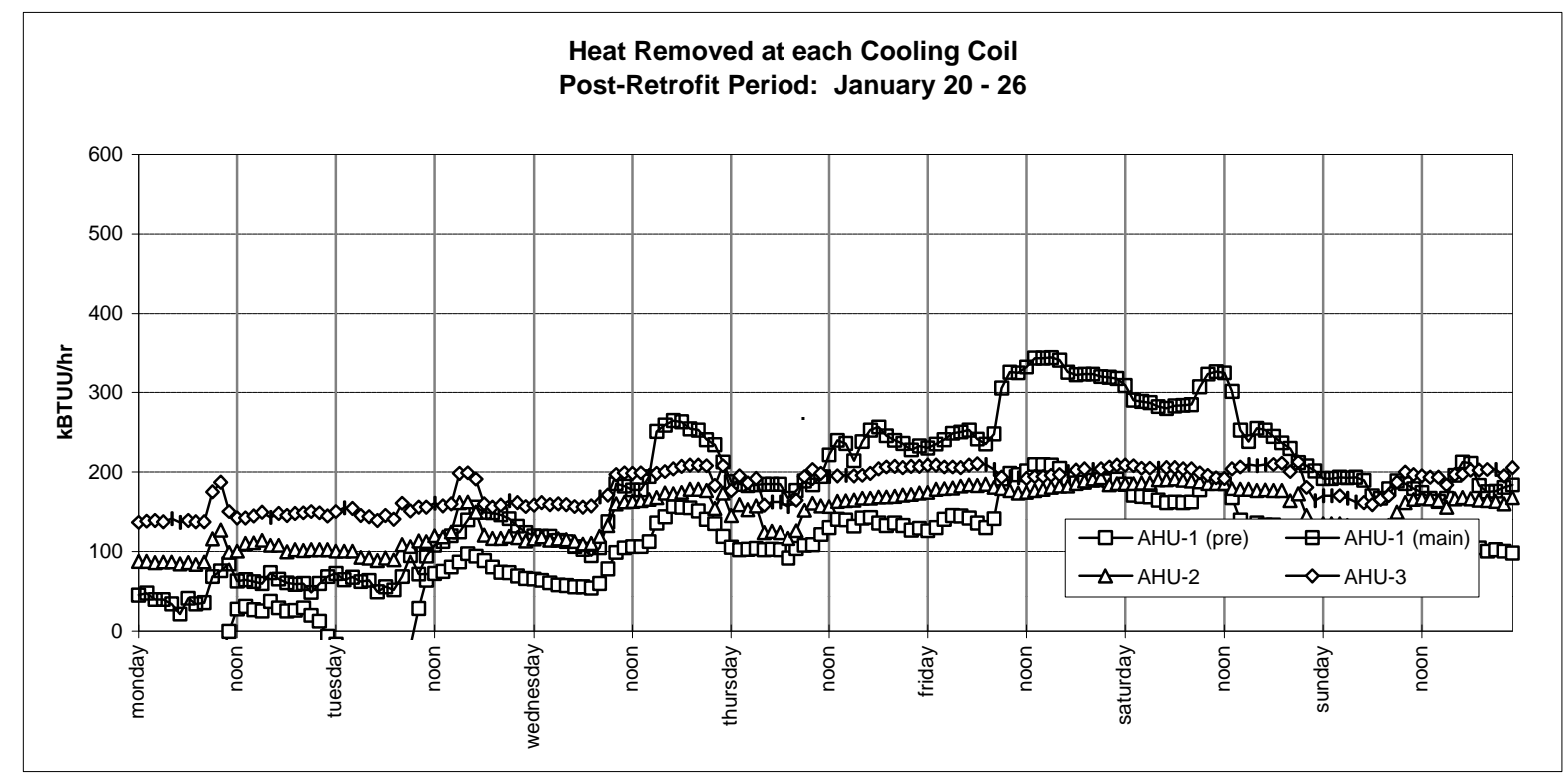

Figure 11 Heat Removed, Low Cooling Period: January 20 - 26, 1997 


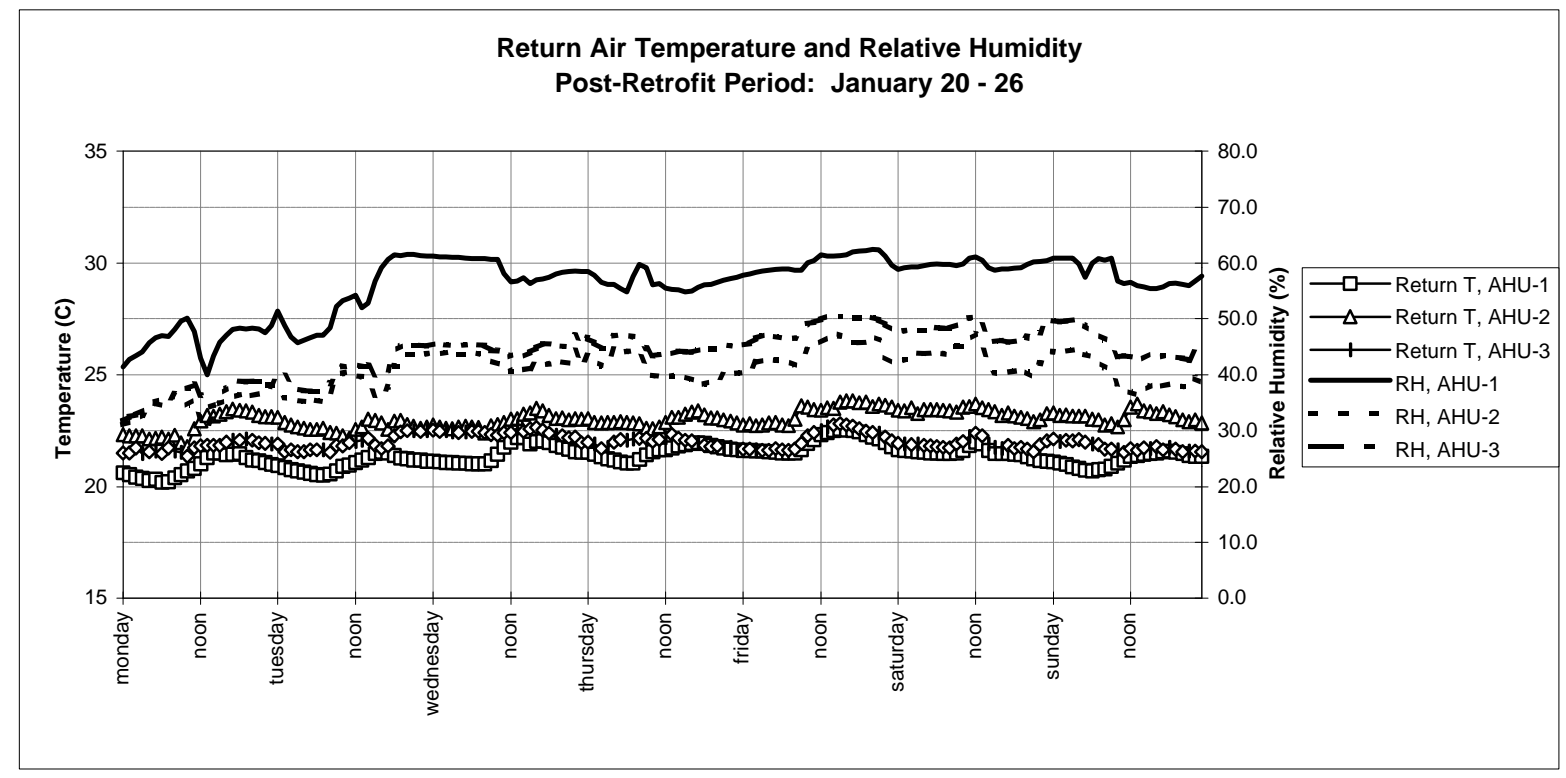

Figure 12 Return Air Temp. and Relative Humidity, Low Cooling Period: January 20 - 26, 1997

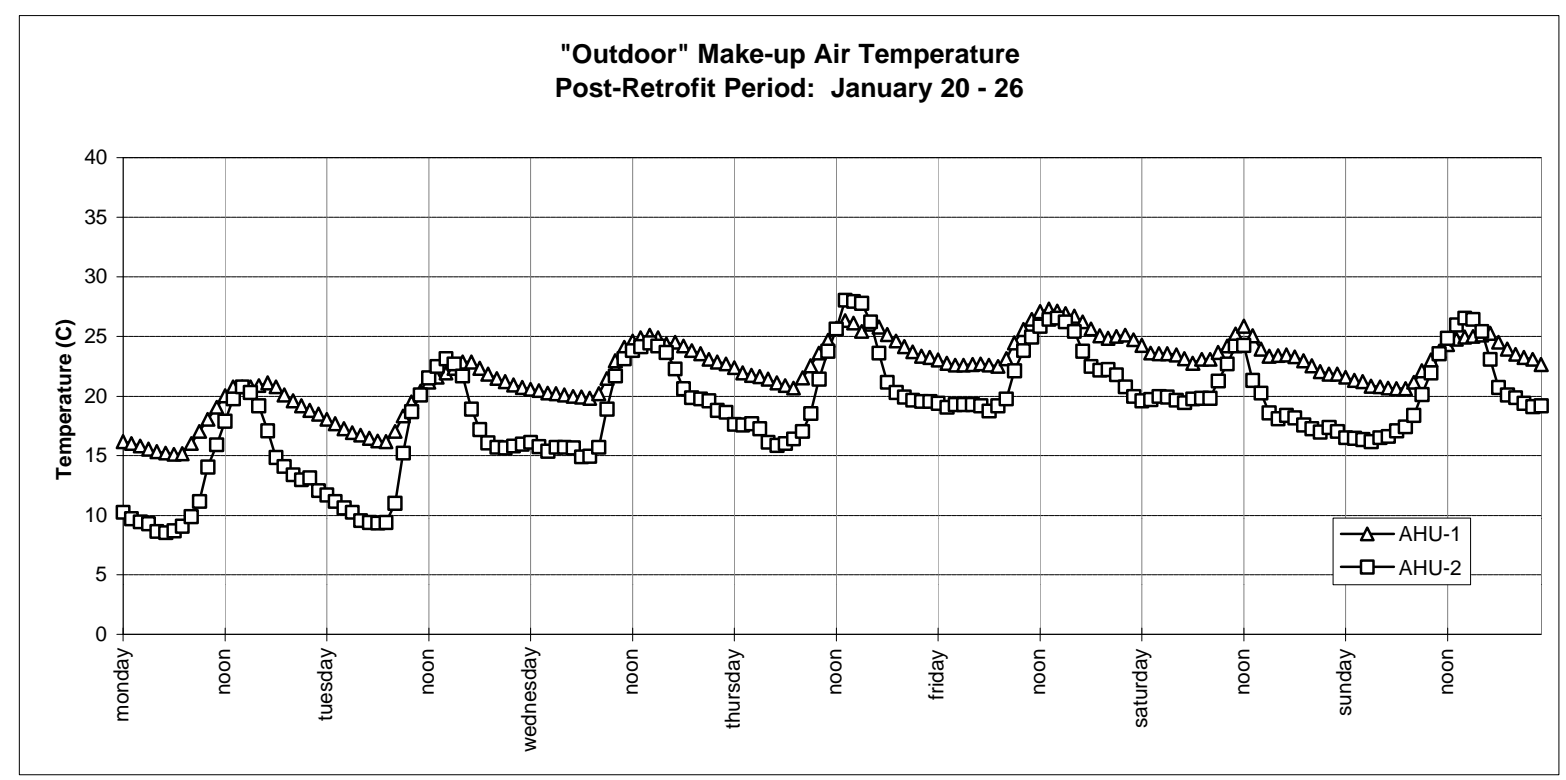

Figure 13 “Outdoor” Make-up Air Temperature, Low Cooling Period: January 20 - 26, 1997 


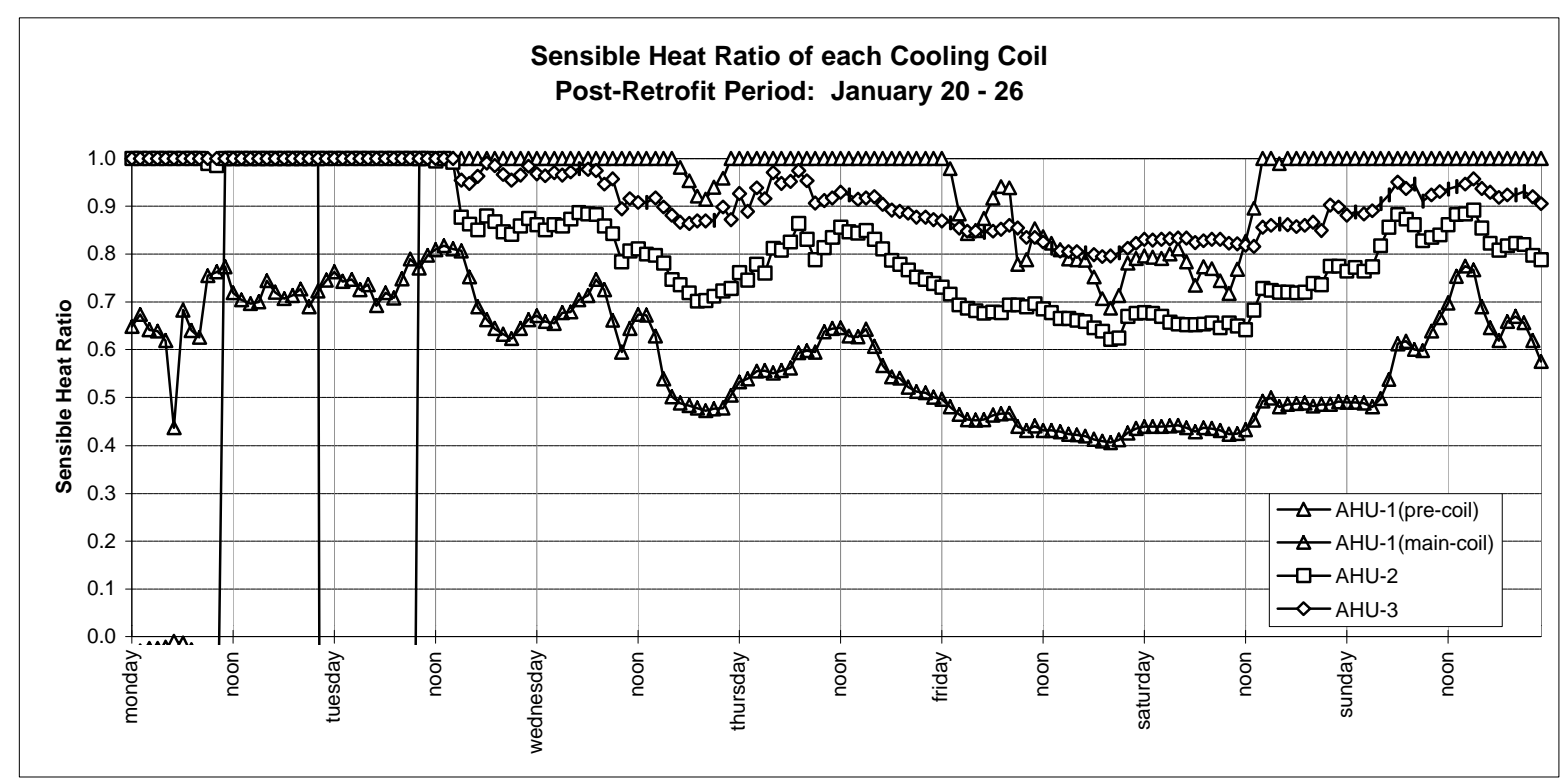

Figure 14 Sensible Heat Ratio, Low Cooling Period: January 20 - 26, 1997

\section{Re-heat Electric Power for AHU-2 and AHU-3}

In Figure 15, the measured electric reheat power for AHU-2 and AHU-3 is shown as an hourly time-series graph for the week of August 11-17, 1997, the "high cooling" period. The reheat power for AHU-2 is zero during the entire period. The reheat power for AHU-2 was near zero during the pre-retrofit period so there is not much opportunity for savings during peak cooling conditions. Figure 8. showed that the return temperature for AHU-2 was sometimes above $27 \mathrm{C}(80 \mathrm{~F})$ indicating that the sensible cooling loads may not be met during this period. Reheat from the heat pipes may cause sensible overheating in this zone which was not meeting the cooling loads before the retrofit.

Reheat power for AHU-3 during this period typically varies from about $3 \mathrm{~kW}$ to nearly $5 \mathrm{~kW}$ with small daily variations. This is 2 to $3 \mathrm{~kW}$ lower than for a comparable period before the retrofit, an expected effect of the retrofit. 


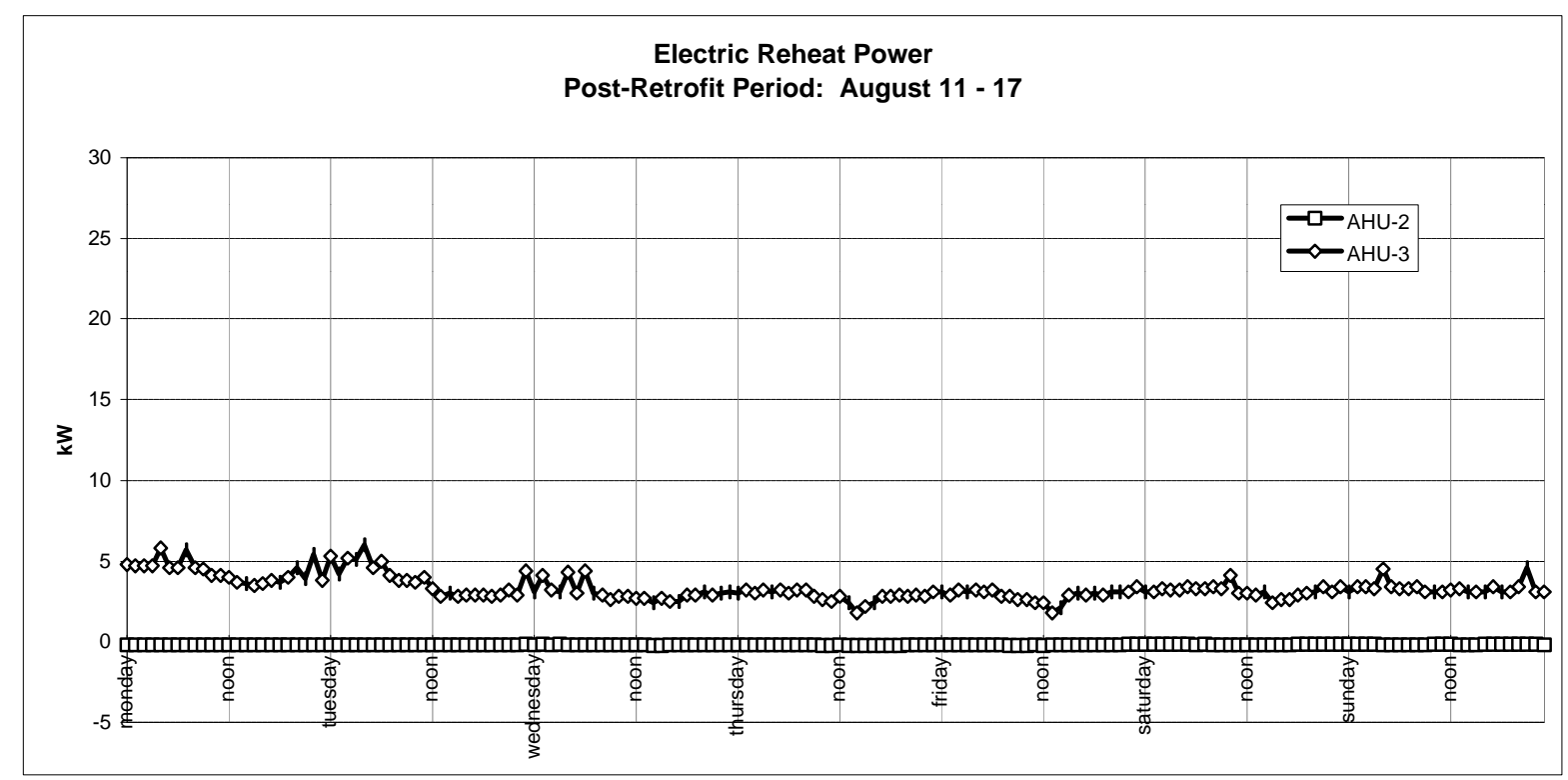

Figure 15 Electric Reheat Power, High Cooling Period: August 11 - 17, 1997

Similar data for reheat power for the week of March 24-30, 1997 are shown in Figure 16. Reheat for AHU-2 typically ranges between zero and $5 \mathrm{~kW}$ with excursions to $10 \mathrm{~kW}$ during cooler periods. Reheat for AHU-3 typically ranges between $6 \mathrm{~kW}$ and $10 \mathrm{~kW}$ with an excursion to $15 \mathrm{~kW}$ during the cooler period. Both systems require the highest amount of reheat during the January cool period shown in Figure 17, up to $25 \mathrm{~kW}$.

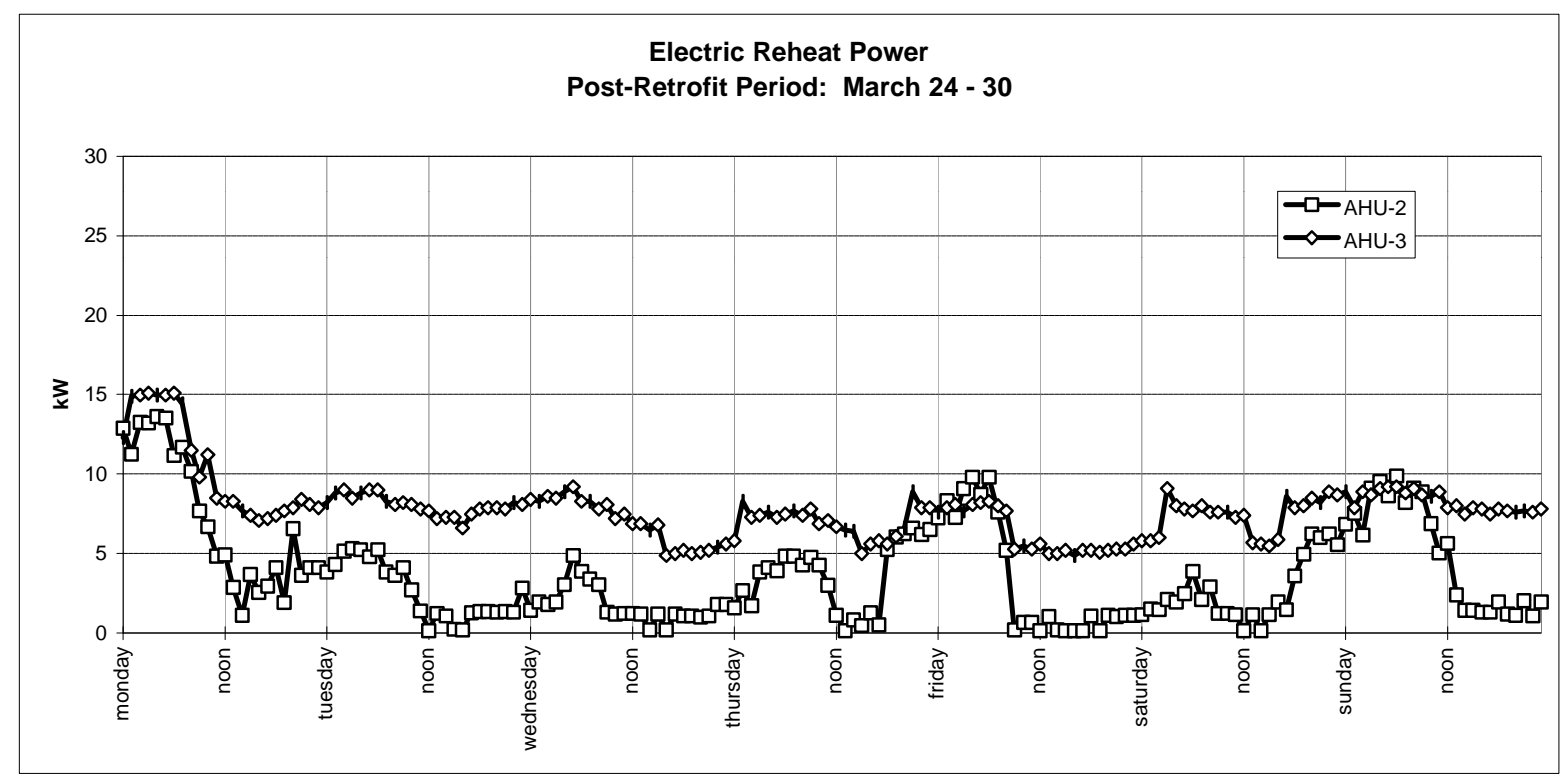

Figure 16 Electric Reheat Power, Moderate Cooling Period: March 24 - 30, 1997 


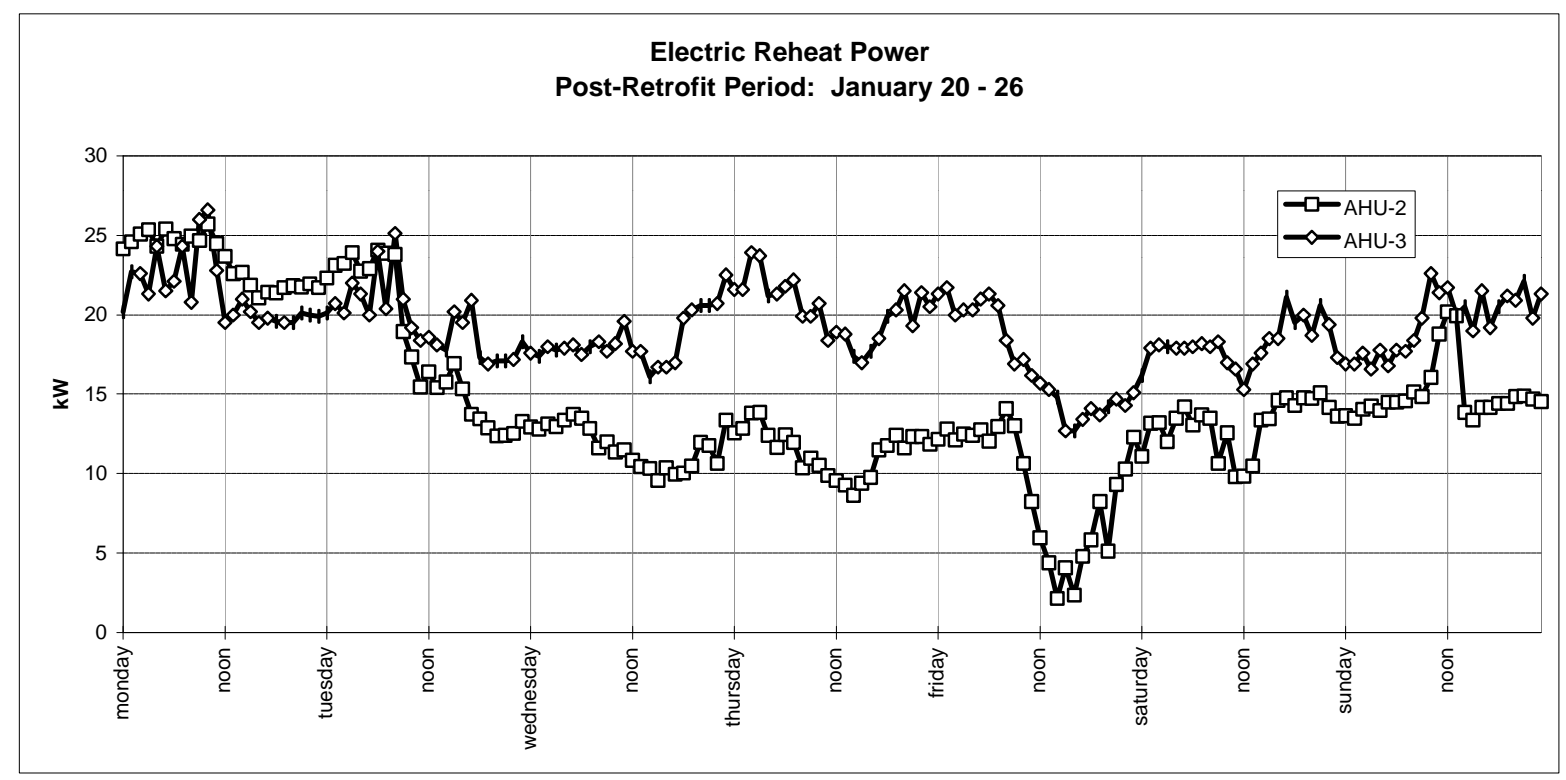

Figure 17 Electric Reheat Power, Low Cooling Period: January 20 - 26, 1997

Figure 18 shows the AHU-2 average hourly profile for reheat power for typical weeks in January through September, 1997. Each curve represents the average of a typical week during the month. Figure 19 shows similar information for AHU-3. Reheat power is lowest in August and September, and highest in January and February. Each curve exhibits a slight daily variation with minimum reheat required in the afternoon, and maximum reheat required in the early morning hours. This performance is consistent with the observation that the maximum sensible cooling loads are during daytime hours. The differences in reheat power for the pre-retrofit and post-retrofit periods for the same months year-to-year are small.

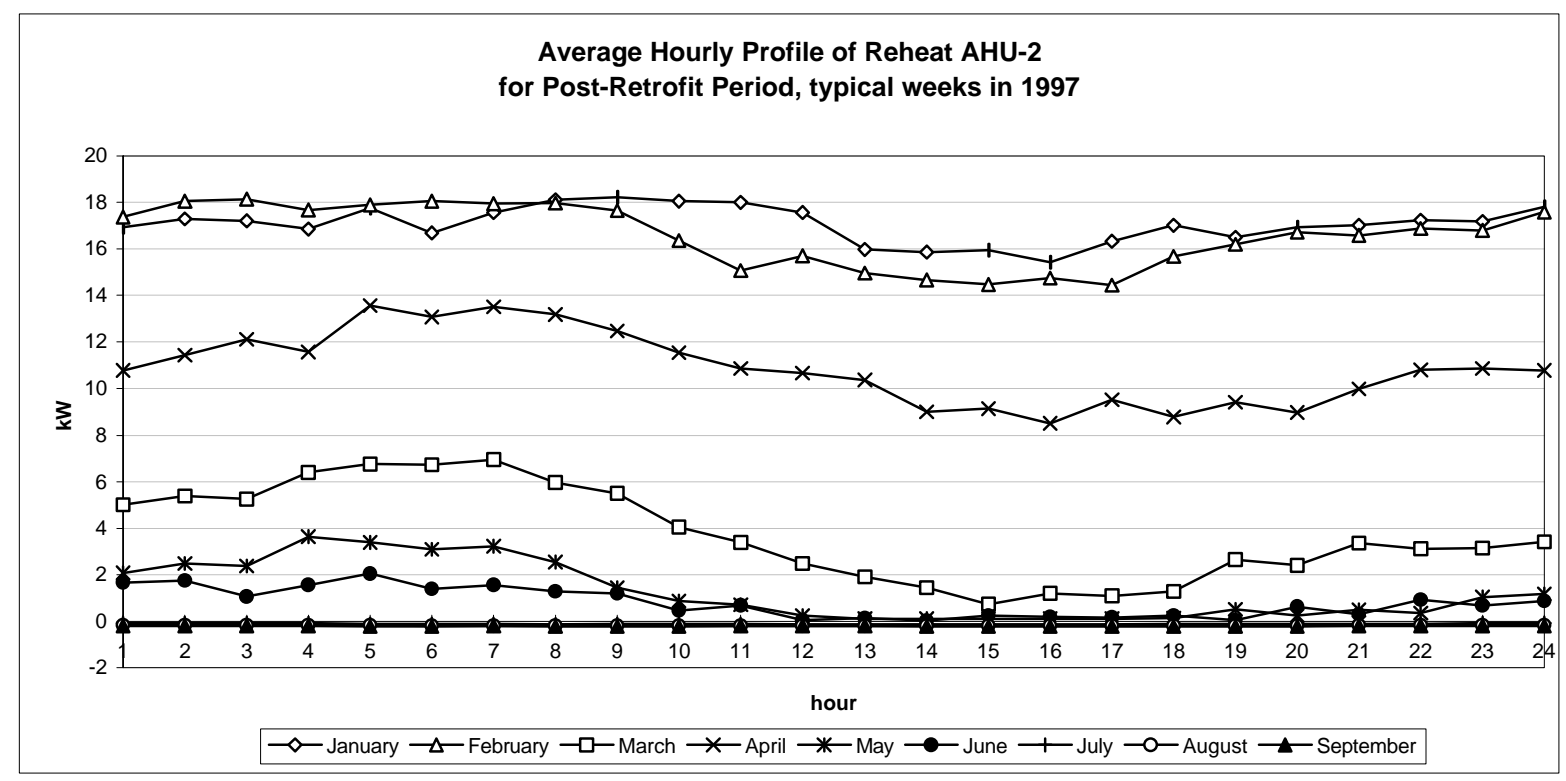

Figure 18 AHU-2 Reheat, Average Hourly Profiles, January - September, 1997 


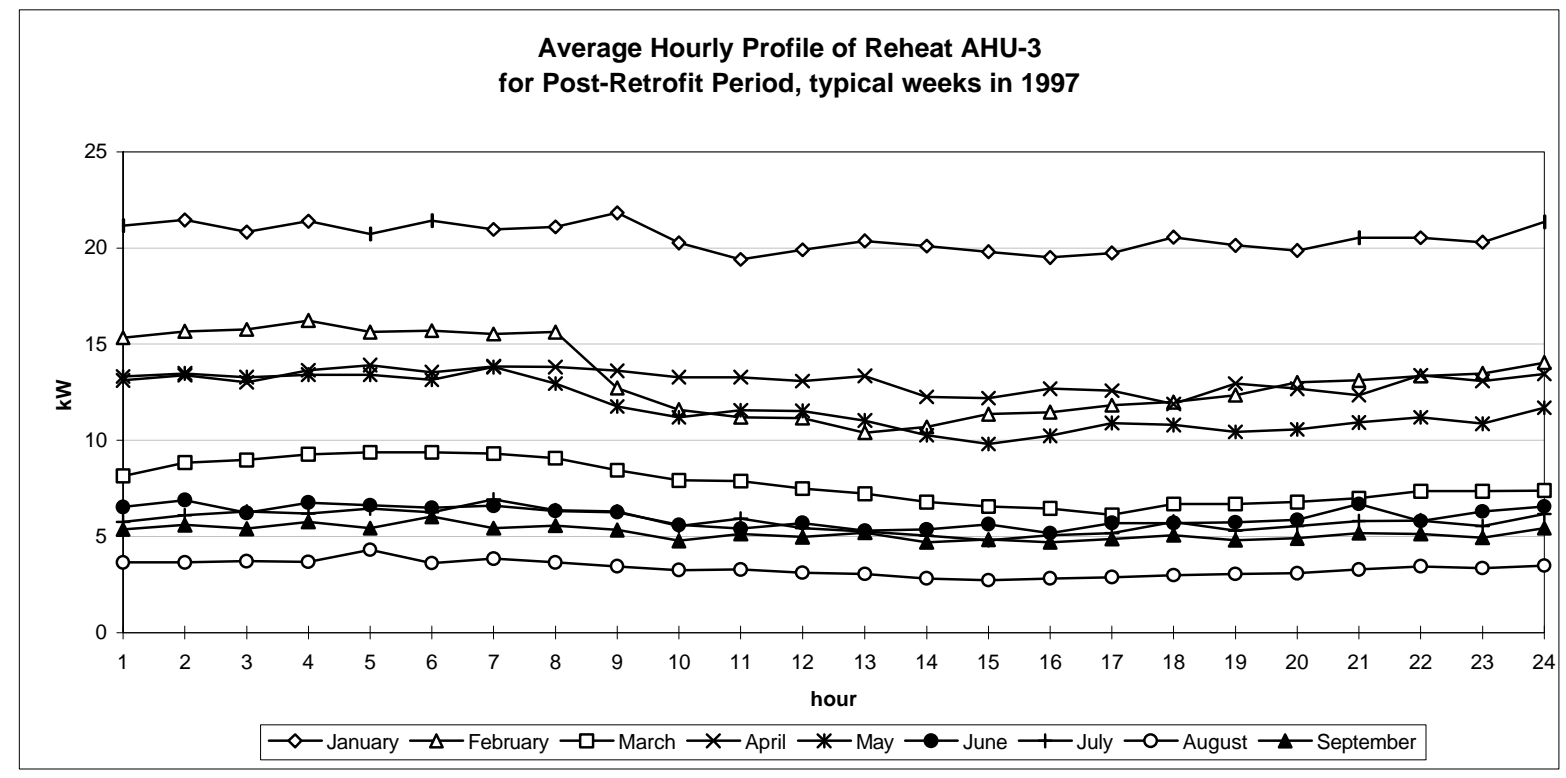

Figure 19 AHU-3 Reheat, Average Hourly Profiles, January - September, 1997 
Weekly total reheat power (kWh) for AHU-2 and AHU-3 is shown in the bar chart in Figure 20. Reheat data for AHU-2 are missing for weeks 6-11. AHU-2 requires no reheat energy during July, August and September. We have noted that the zones served by AHU-2 may experience overheating during this period. Reheat power is highest when outside dry bulb temperatures are lower, and reheat power is lowest during the periods with hottest outside temperatures. The trend was apparent both before and after the heat pipe retrofit. Much of the electric reheat energy for these systems is not associated with reheat during periods of high latent loads, but rather is required to meet sensible heating loads during cool weather.

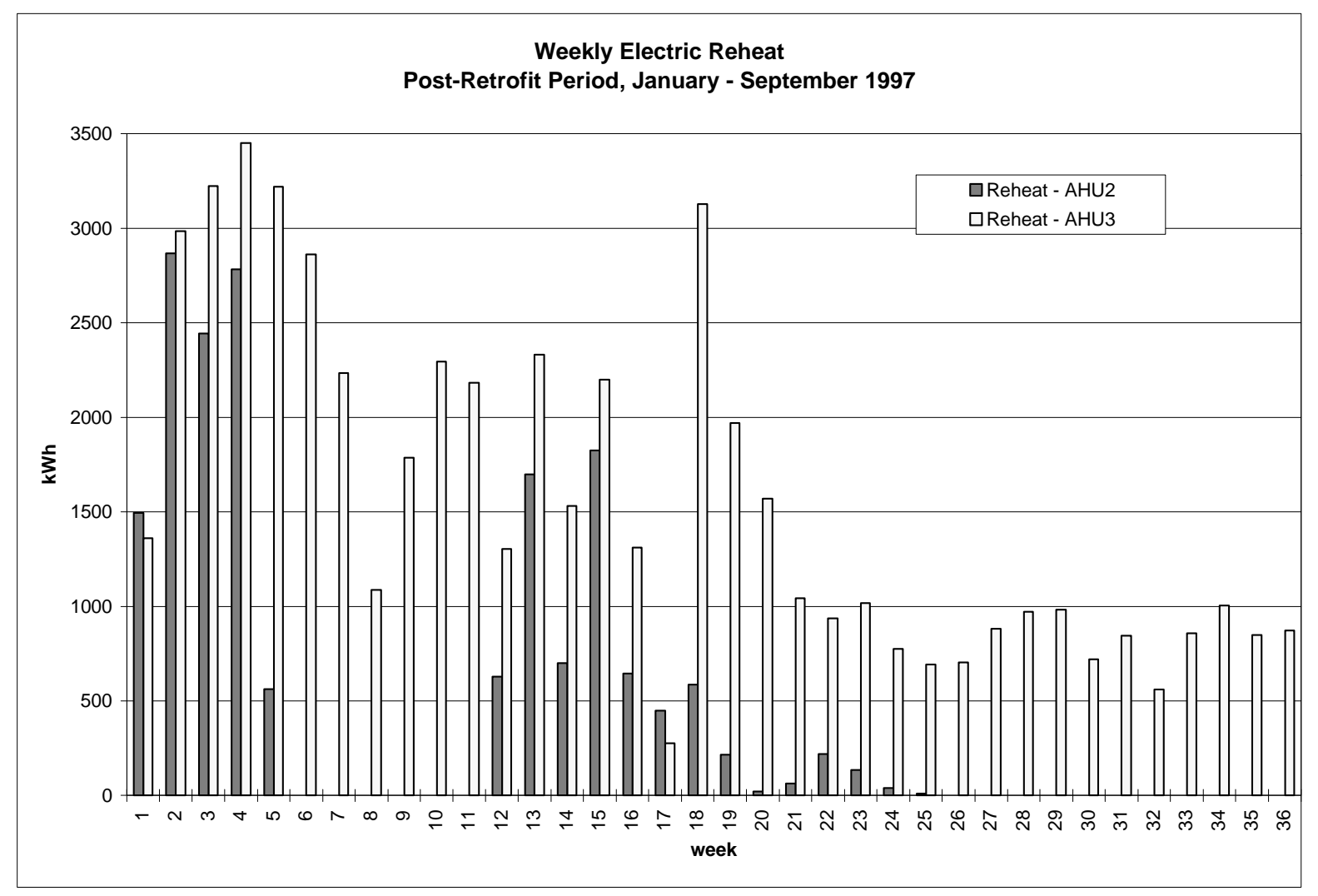

Figure 20 Weekly Electric Reheat, January 6 - September 14, 1997 


\section{Chiller Electric Power}

Figure 21 shows hourly electric power data for the 110 ton chiller and the 55 ton chiller during the week of August 11-17, 1997. The 110 ton chiller has a peak demand of approximately $120 \mathrm{~kW}$, and the 55 ton chiller has a peak of approximately $62 \mathrm{~kW}$. Both chillers exhibit a small daily variation with minimum power in the early morning and maximum power in the afternoon. The chillers operate continuously at near full power. Figures 22 and 23 show chiller electric power for the weeks of March 24-30, and January 2026,1997 , respectively. The larger chiller in particular experiences substantially reduced power during cooler periods.

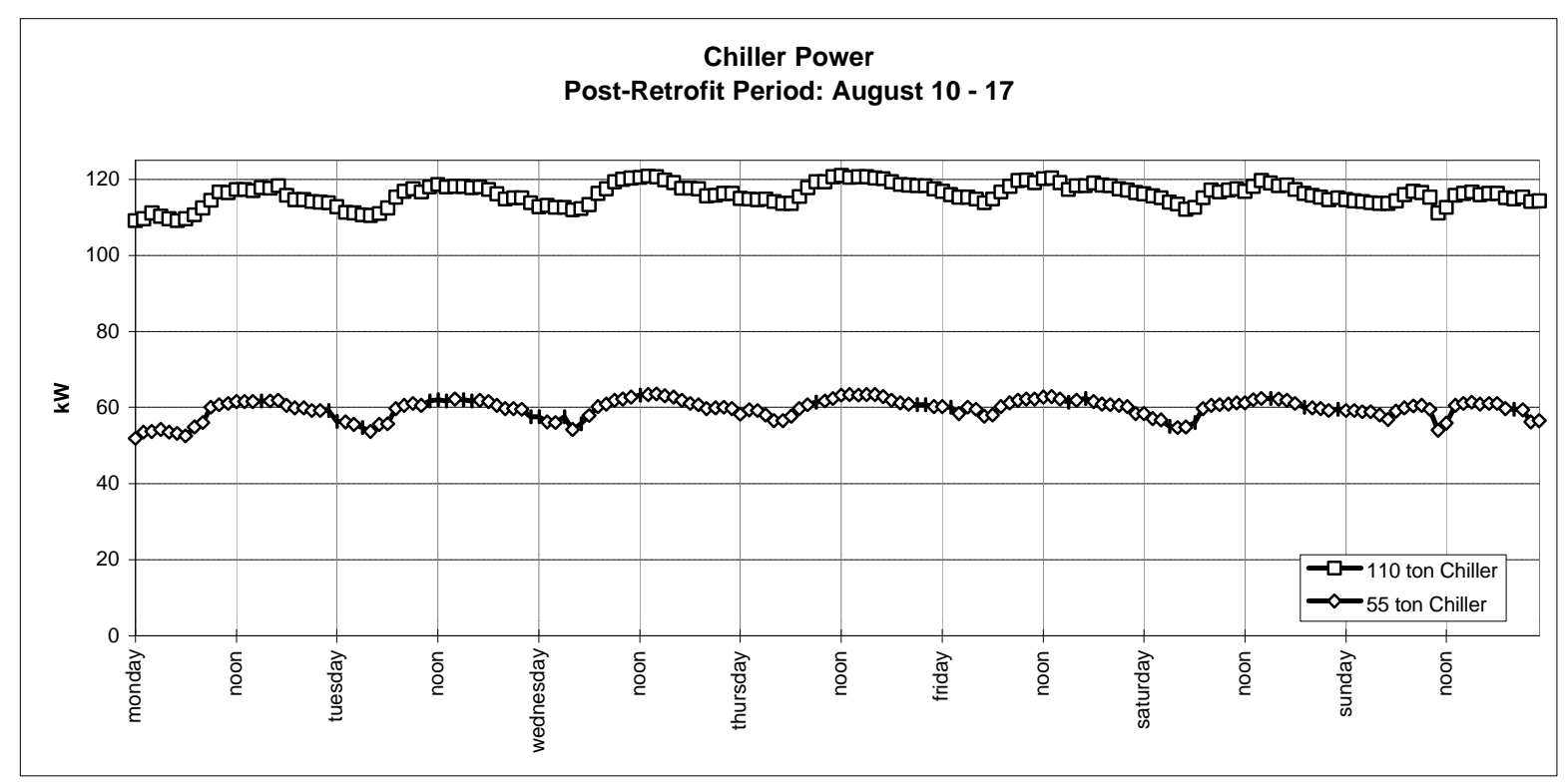

Figure 21 Chiller Power, High Cooling Period: August 11 - 17, 1997

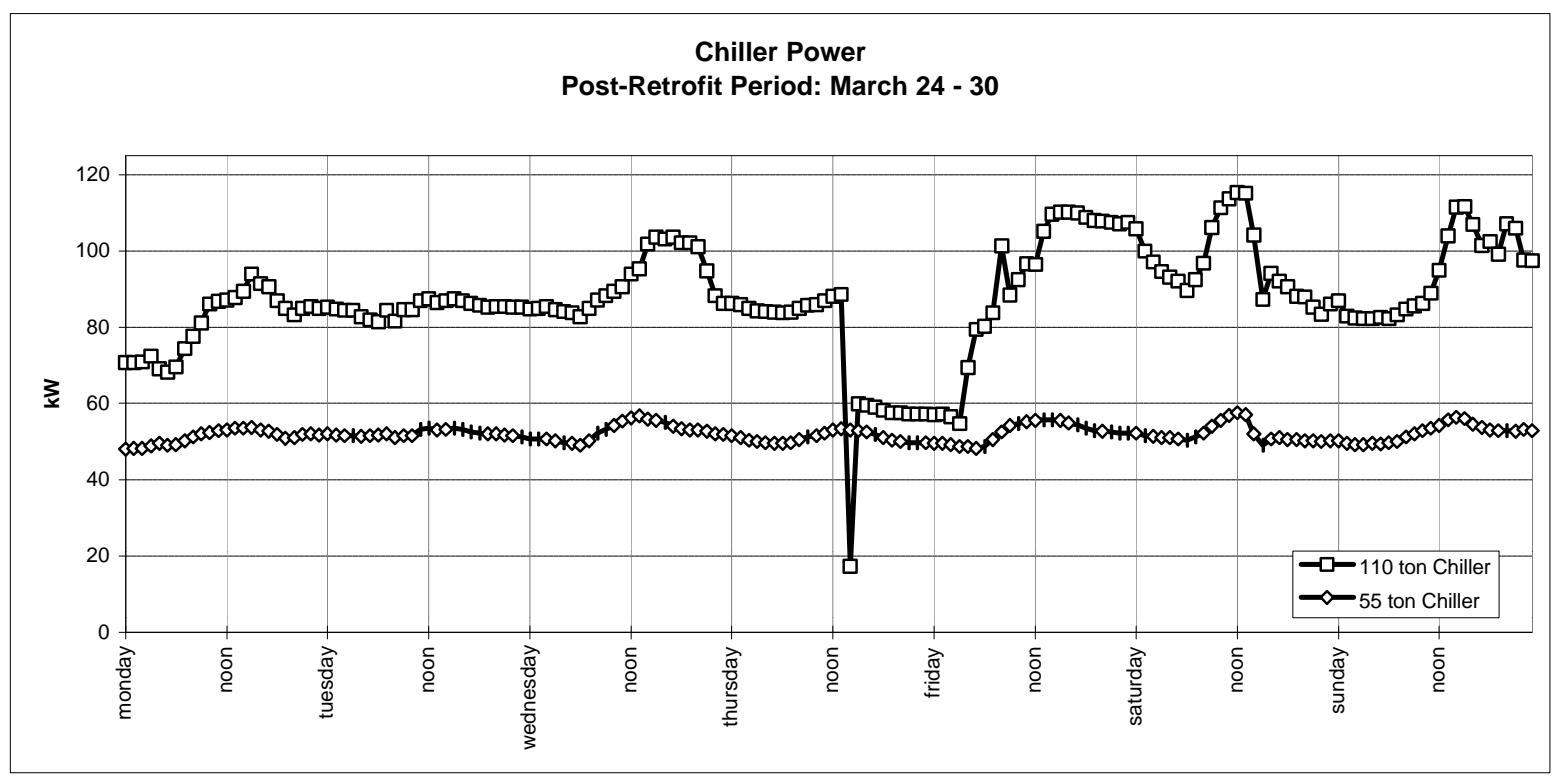

Figure 22 Chiller Power, Moderate Cooling Period: March 24 - 30, 1997 


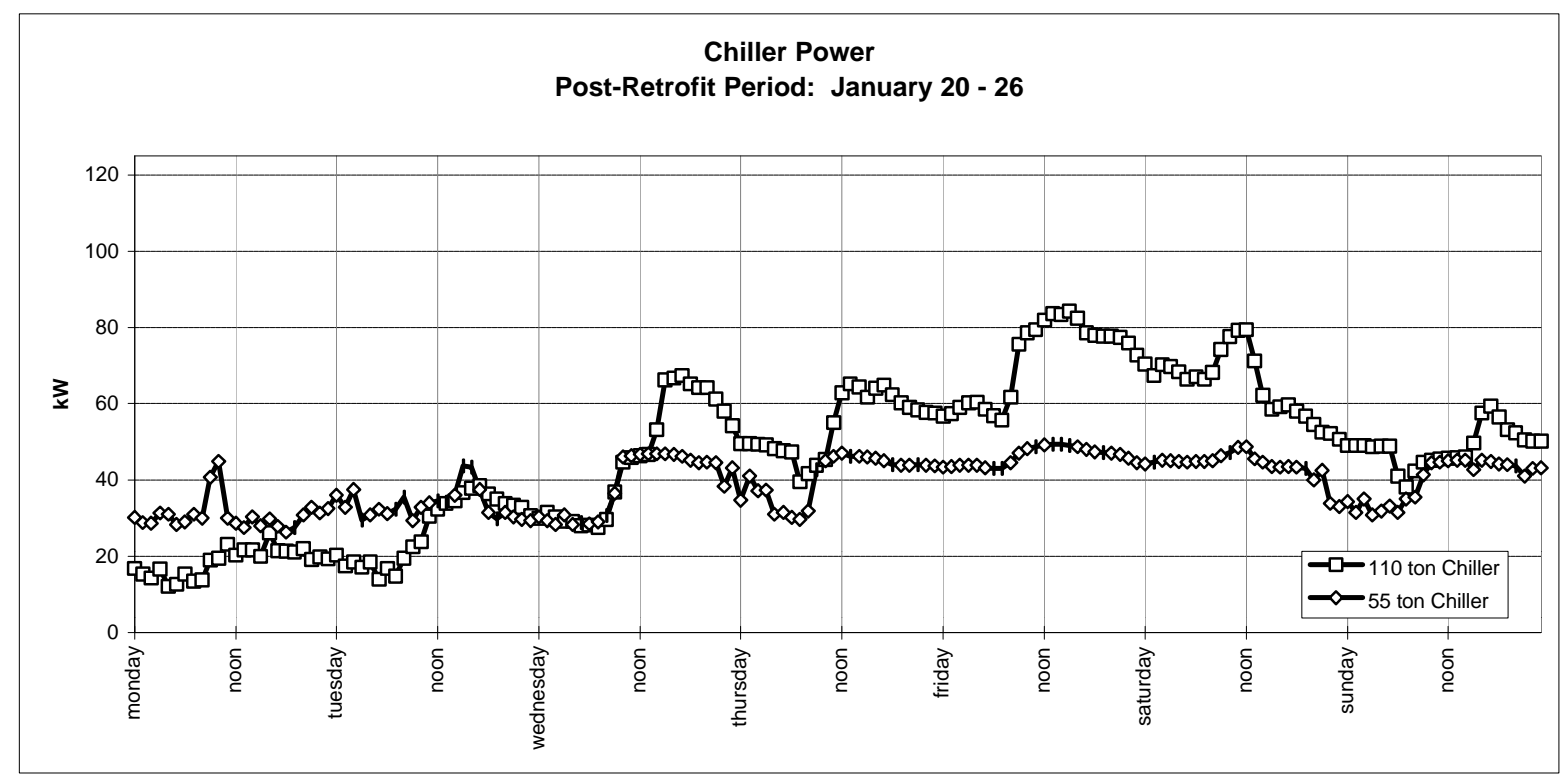

Figure 23 Chiller Power, Low Cooling Period: January 20 - 26, 1997

Figure 24 shows the 110 ton chiller average hourly electric power profile for typical weeks in January through September, 1997. Figure 25 shows similar information for the 55 ton chiller. Chiller power is highest in August and September, and lowest in November. Each curve exhibits a daily variation with maximum chiller power in the afternoon, and minimum power in the early morning hours.

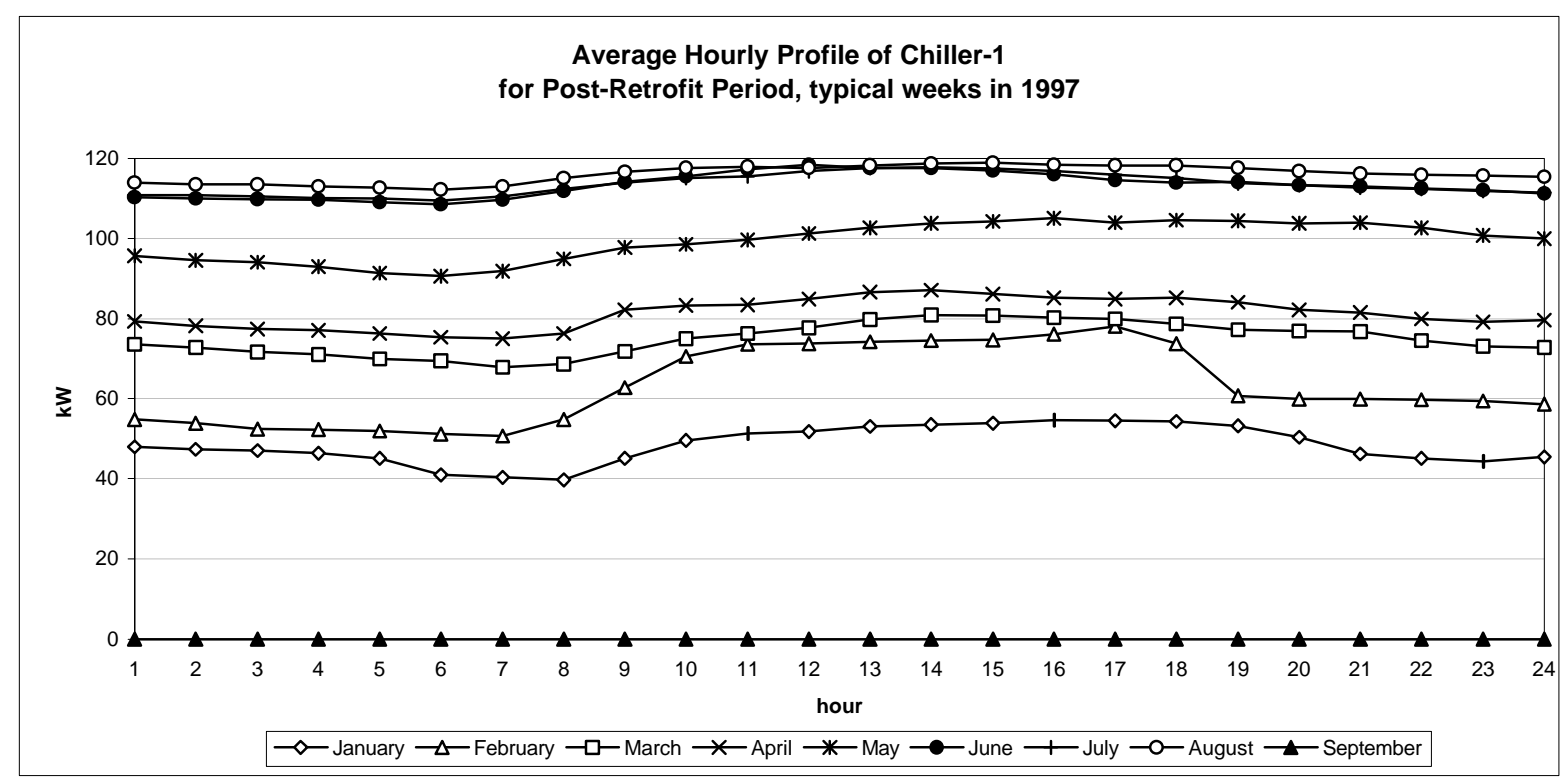

Figure 24 110-ton Chiller Average Hourly Profile, January - September, 1997 


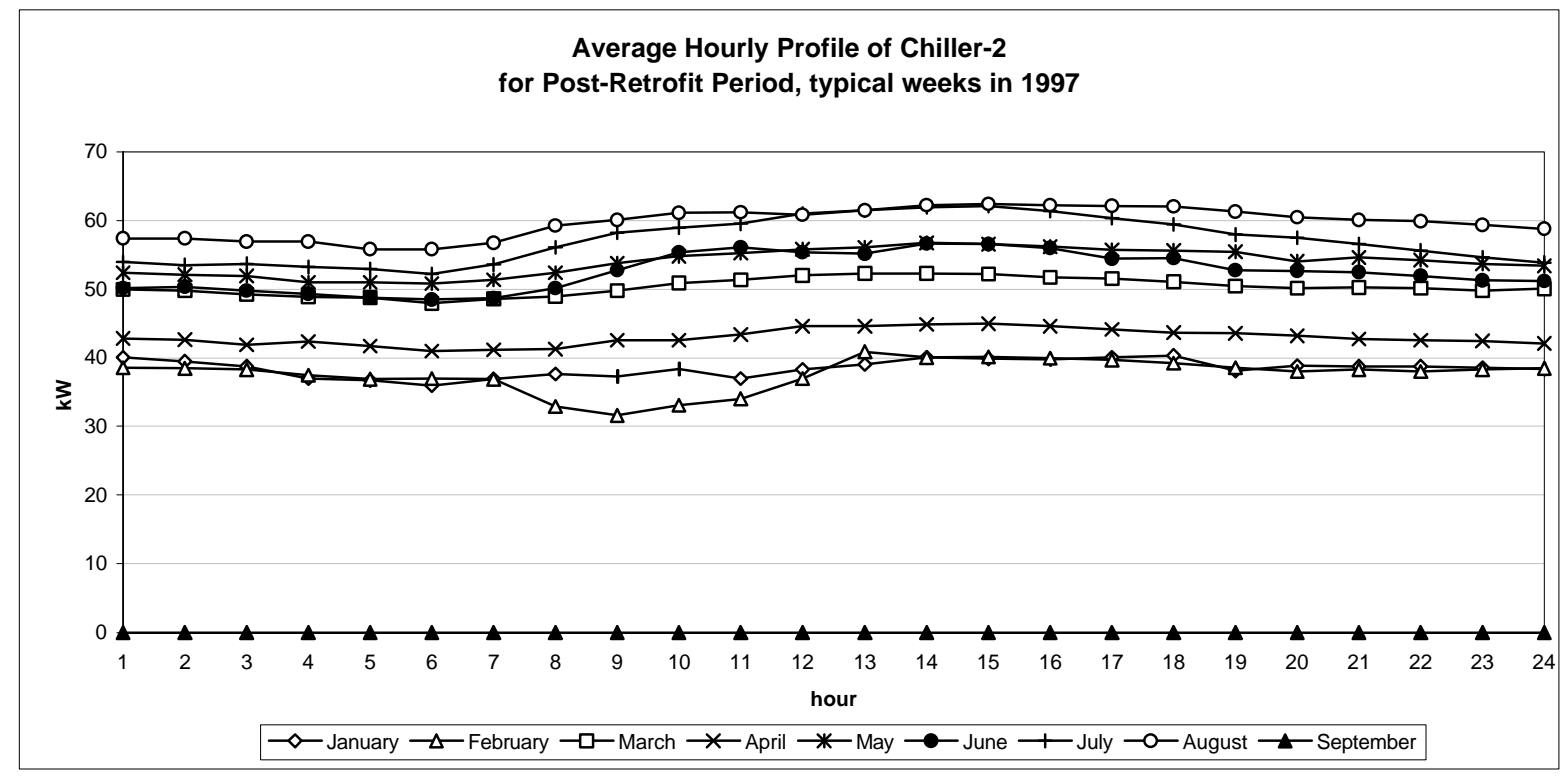

Figure 25 55-ton Chiller Average Hourly Profile, January - September, 1997 
Weekly total chiller power for both chillers is shown in the bar chart in Figure 26 for the January through September 1997 period. The 110 ton chiller uses more than 19,000 kWh per week in the peak cooling season and about $8,000 \mathrm{kWh}$ per week in coolest weather. The 55 ton chiller exhibits somewhat less seasonal variation with summer peaks of nearly 10,000 $\mathrm{kWh}$ per week and winter lows of less than 7,000 kWh. The 110 ton chiller serves AHU-1 which uses 100 percent outside and therefore has a cooling load which is more strongly dependent on outside air temperature. These weekly totals for chiller power in the postretrofit period can be compared to the pre-retrofit period.

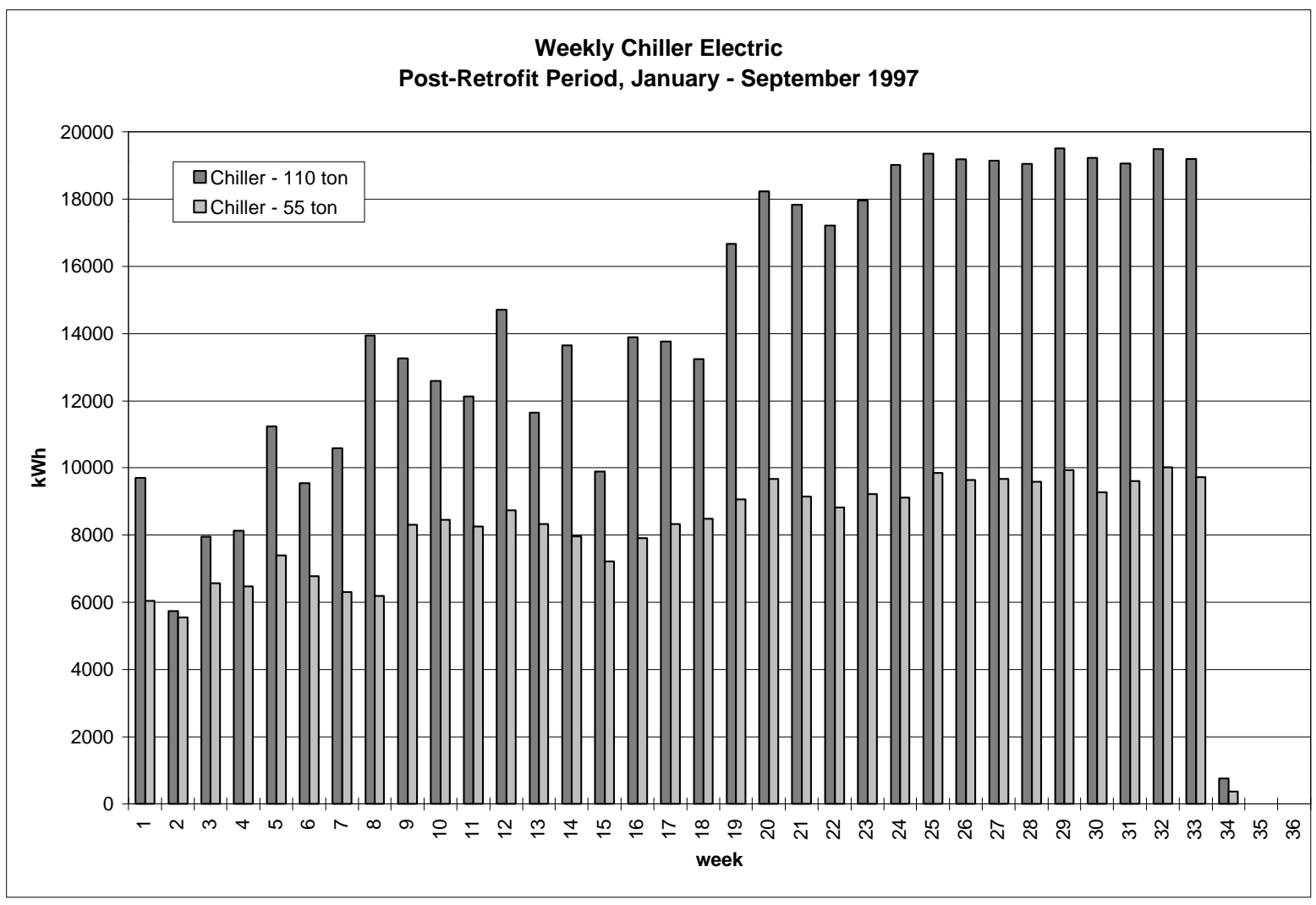

Figure 26 Weekly Chiller Electric Use, January 6 - September 14, 1997 


\section{Assessment of Post-retrofit Monitoring}

Complete, continuous data have been recorded since August 15, 1996. The retrofit was completed in December, 1996. Following the retrofit, data have been recorded from January through September, 1997 to characterize post-retrofit performance. Initial observations have been made to directly compare similar periods before-and-after the retrofit. A subsequent report in December, 1997 is intended to provide a detailed evaluation of the heat pipe performance in these systems.

\section{Acknowledgments}

This work was funded by the DOE/NREL FEMP program under NREL Subcontract No. AAR-6-16320-01. We appreciate the support and encouragement of Karen Thomas as the NREL project manager. We thank Will Miner and his staff (Dynamac Corp.) and Bill Ruppert (EG\&G) for their substantial assistance in our work on-site at KSC. 


\section{Appendix C Detailed Measured Performance Graphs}




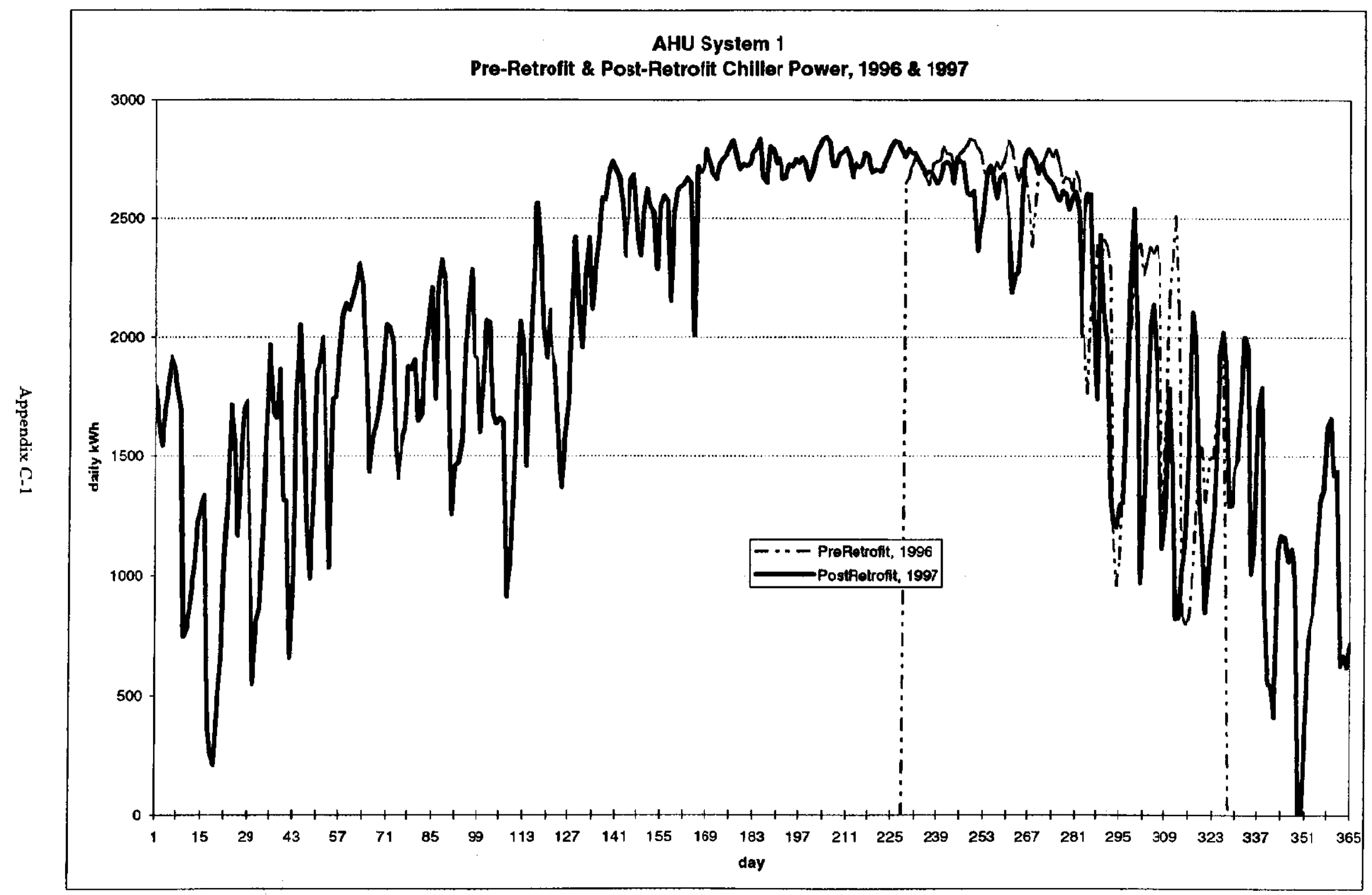




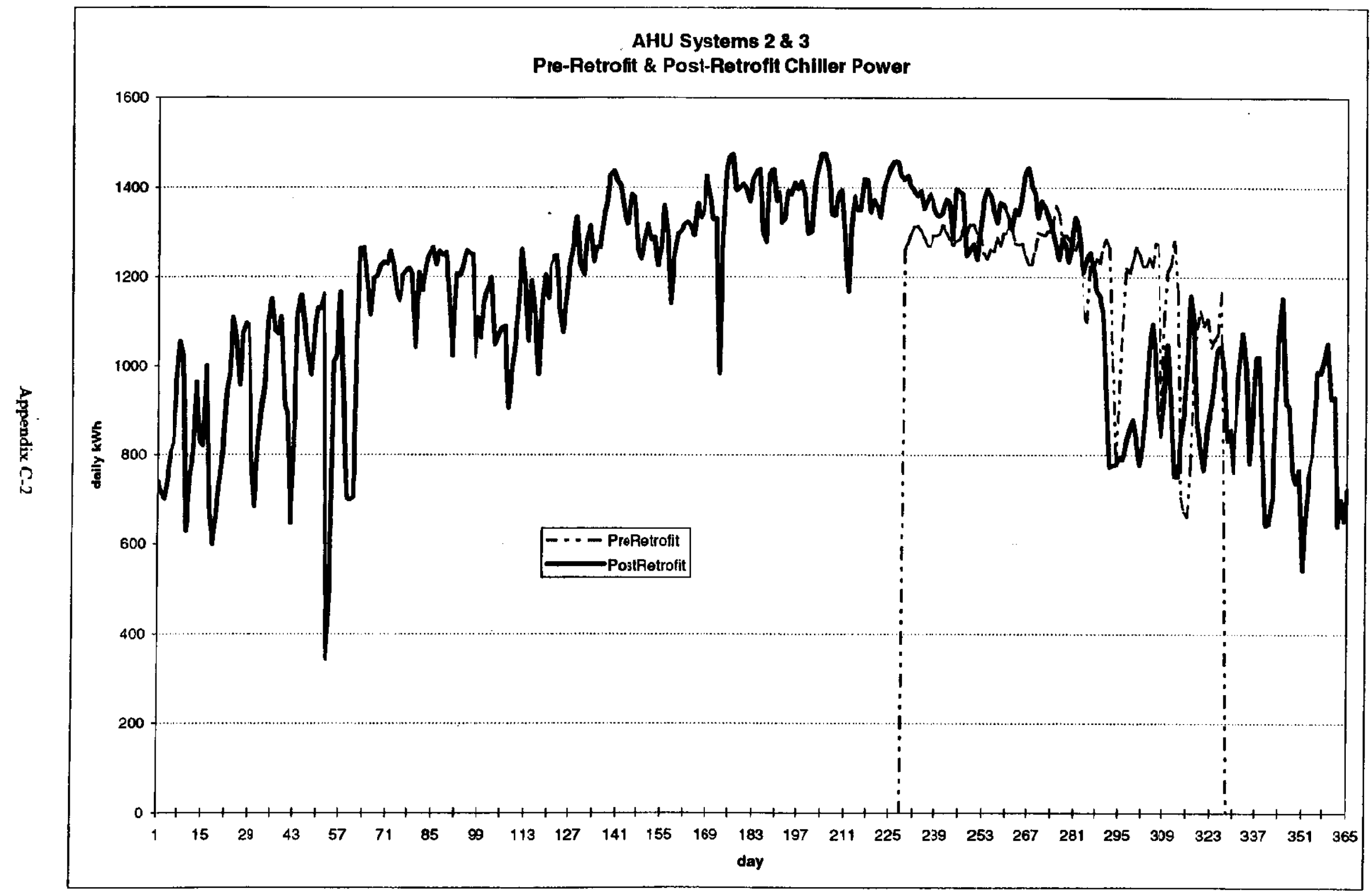




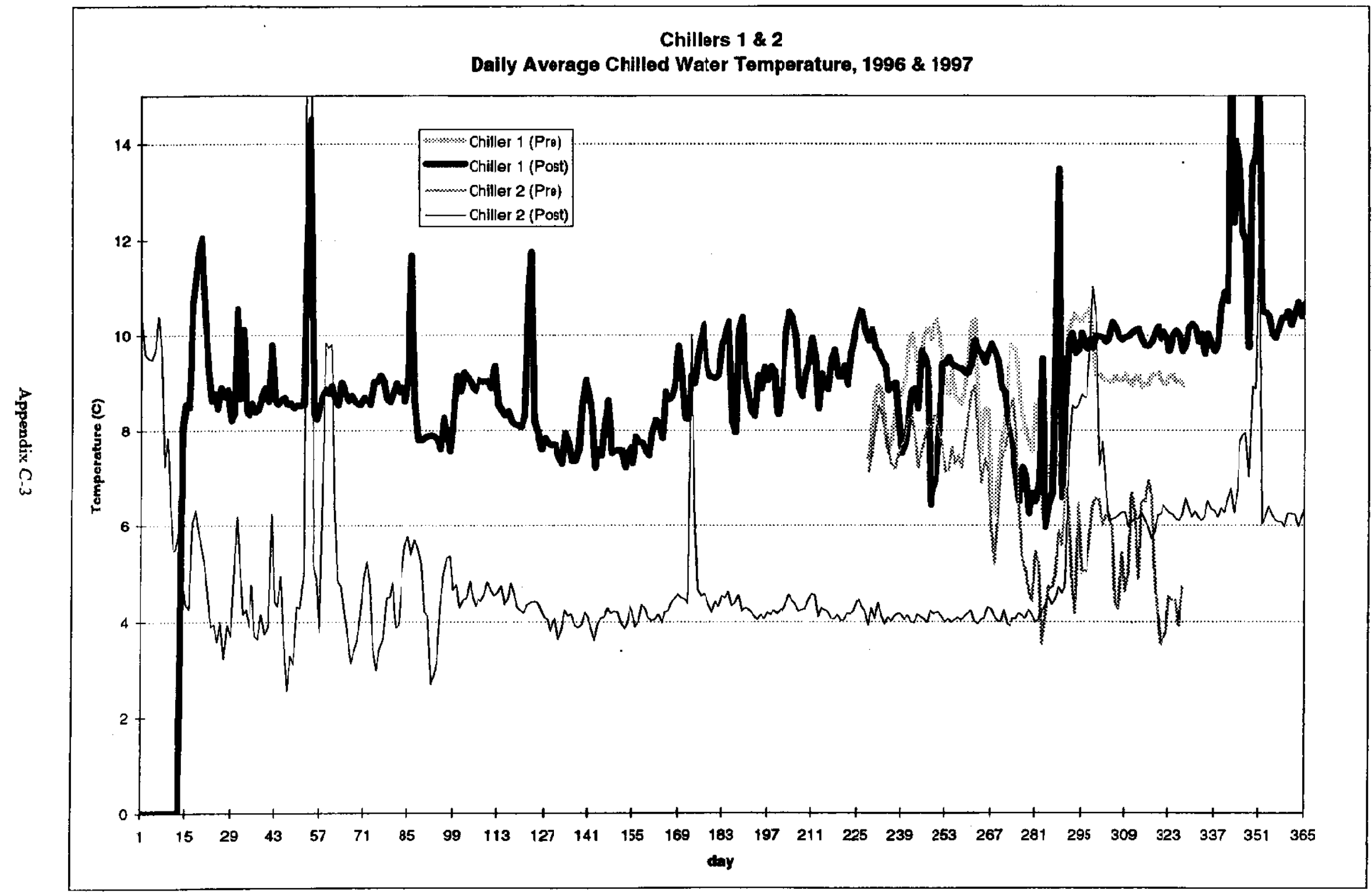




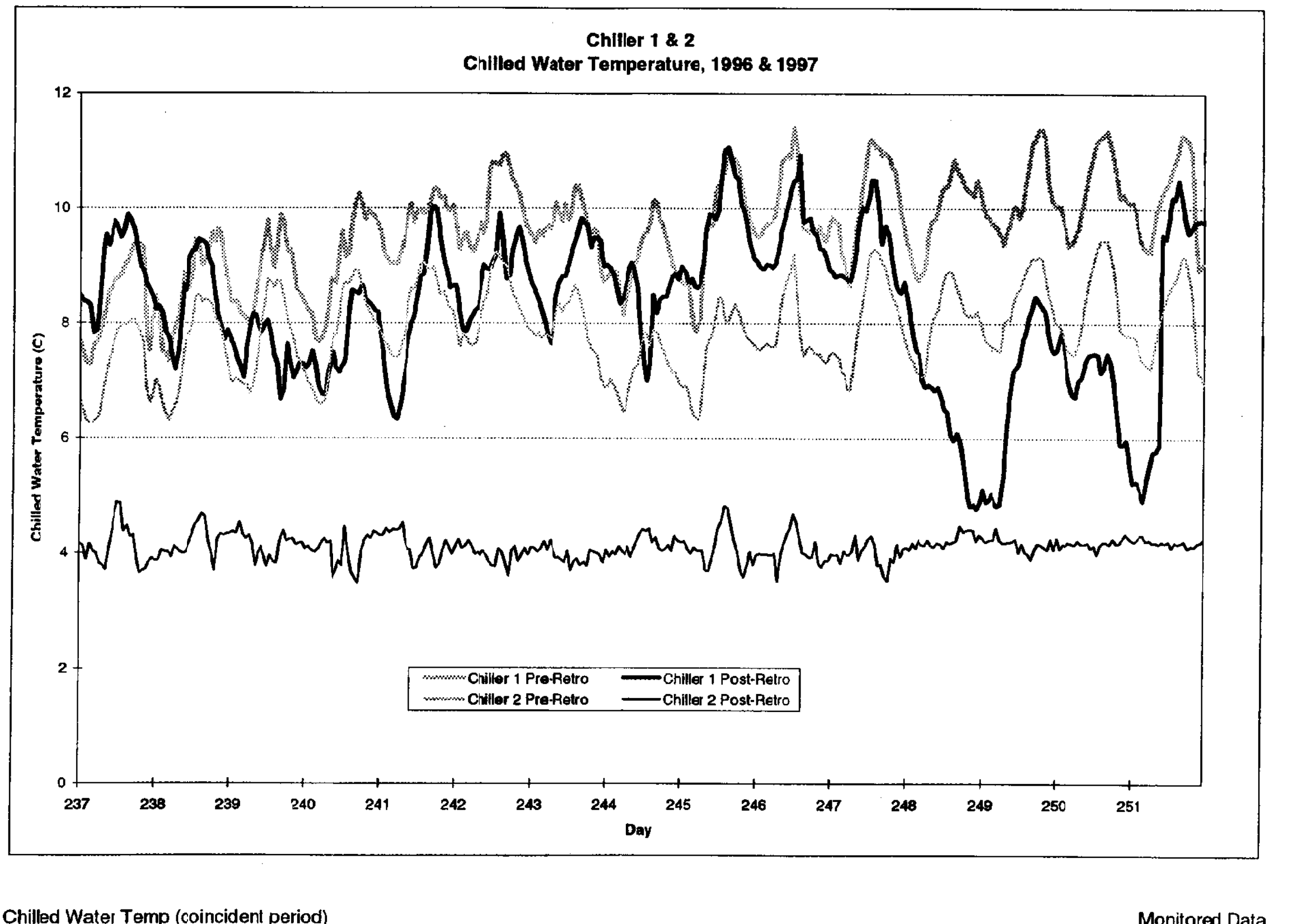




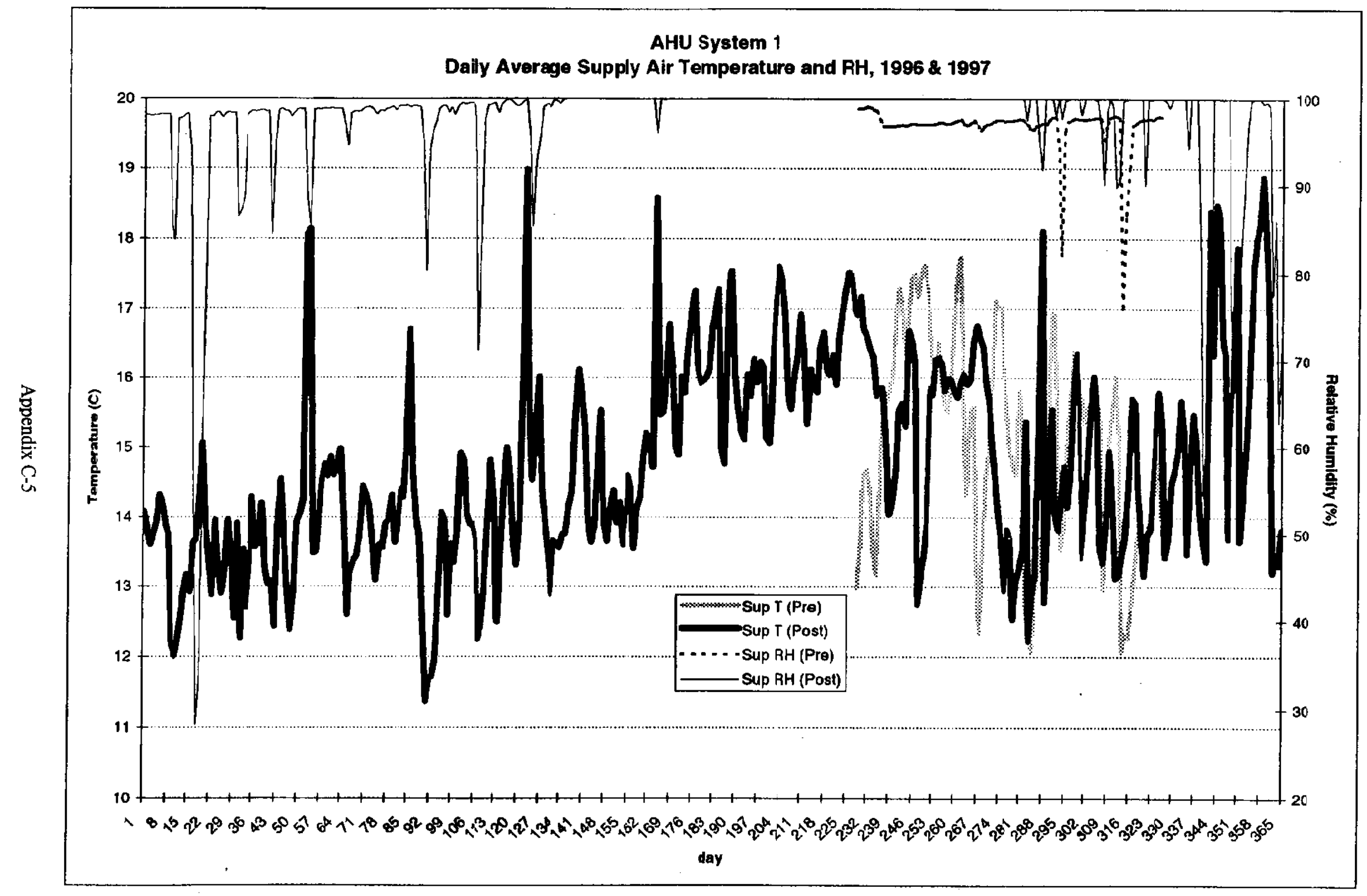




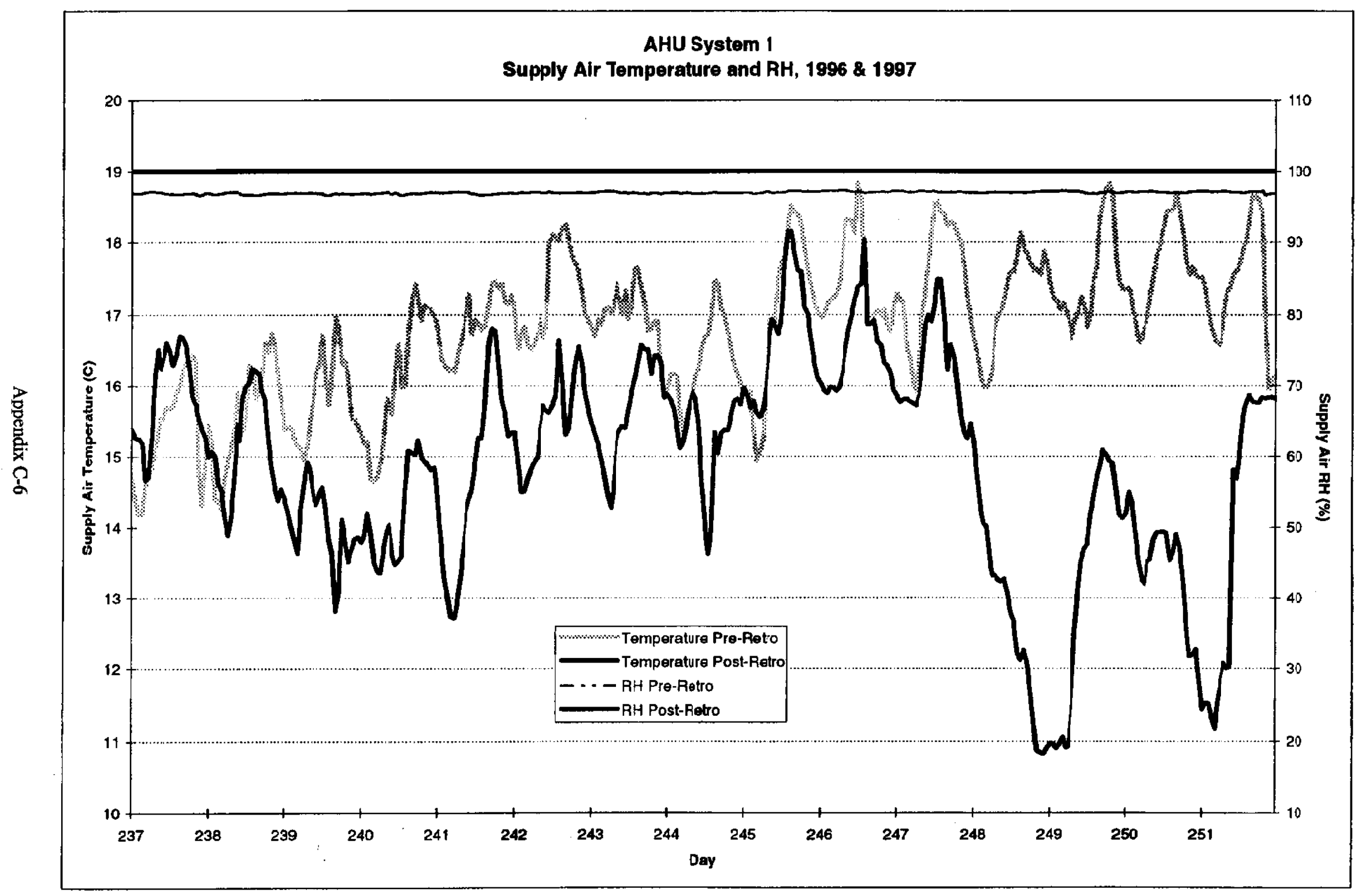

AMU- 1 Supply Air Temp and RH (coincident period)

Monitored Data 


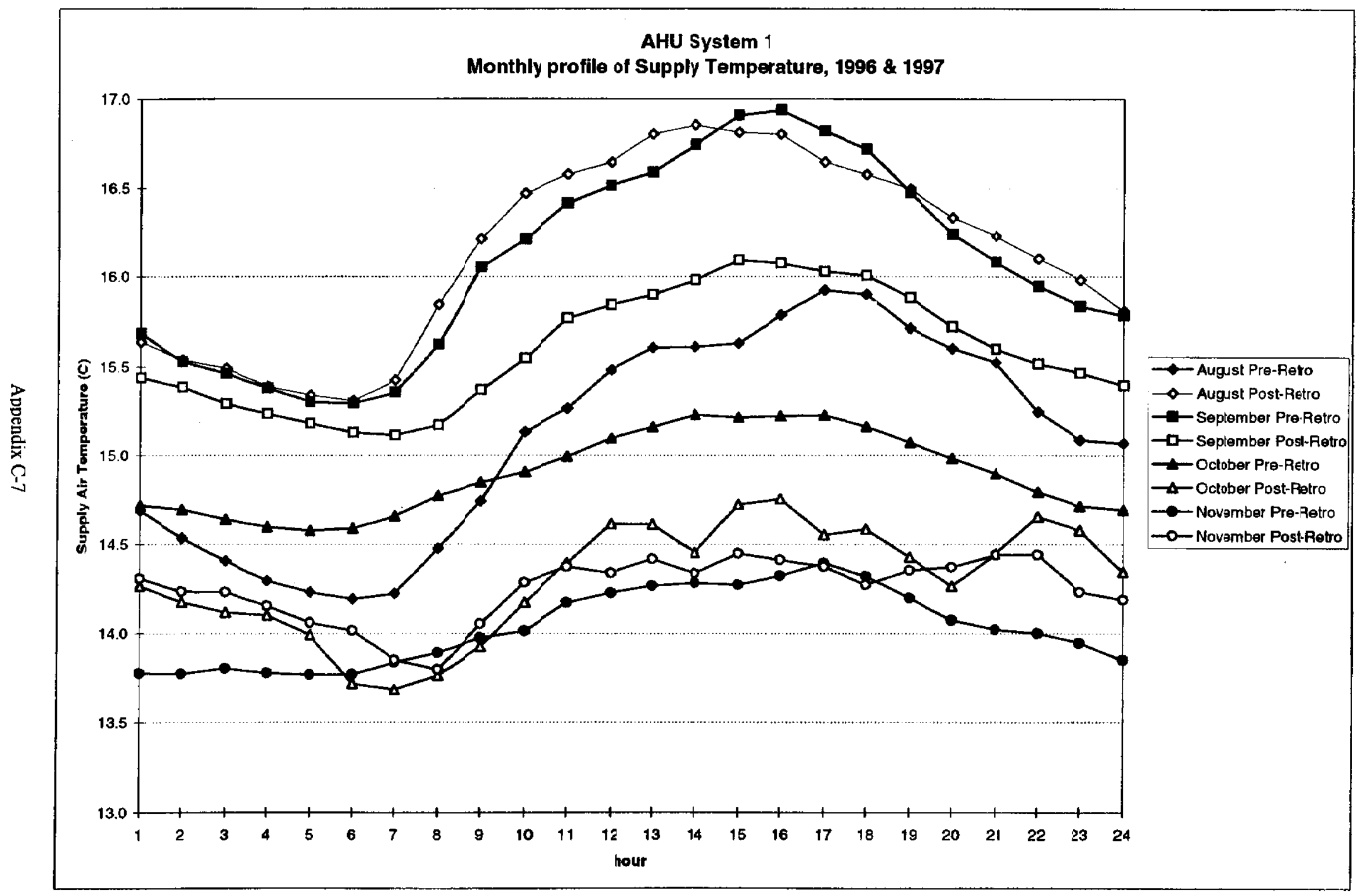




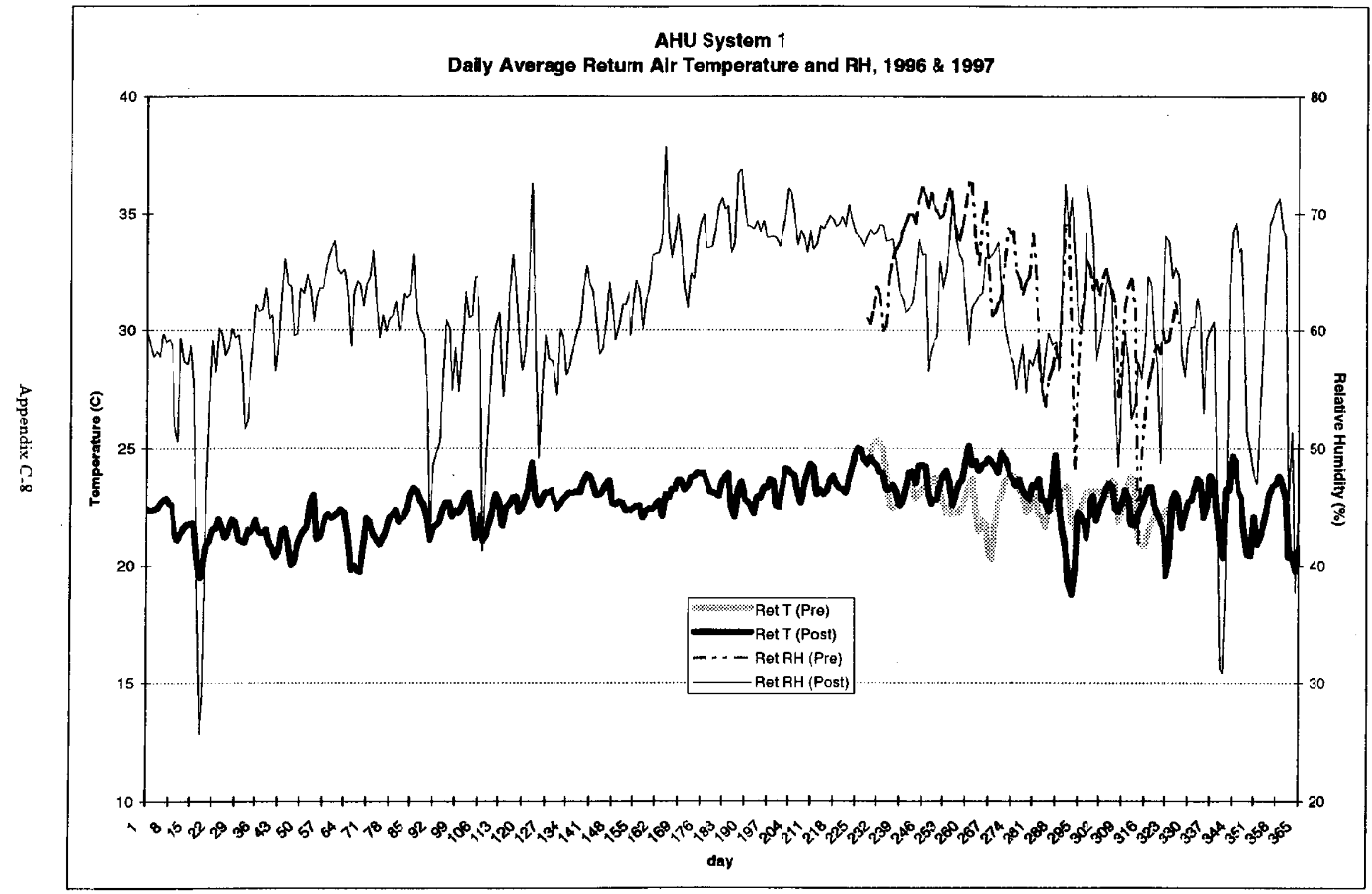




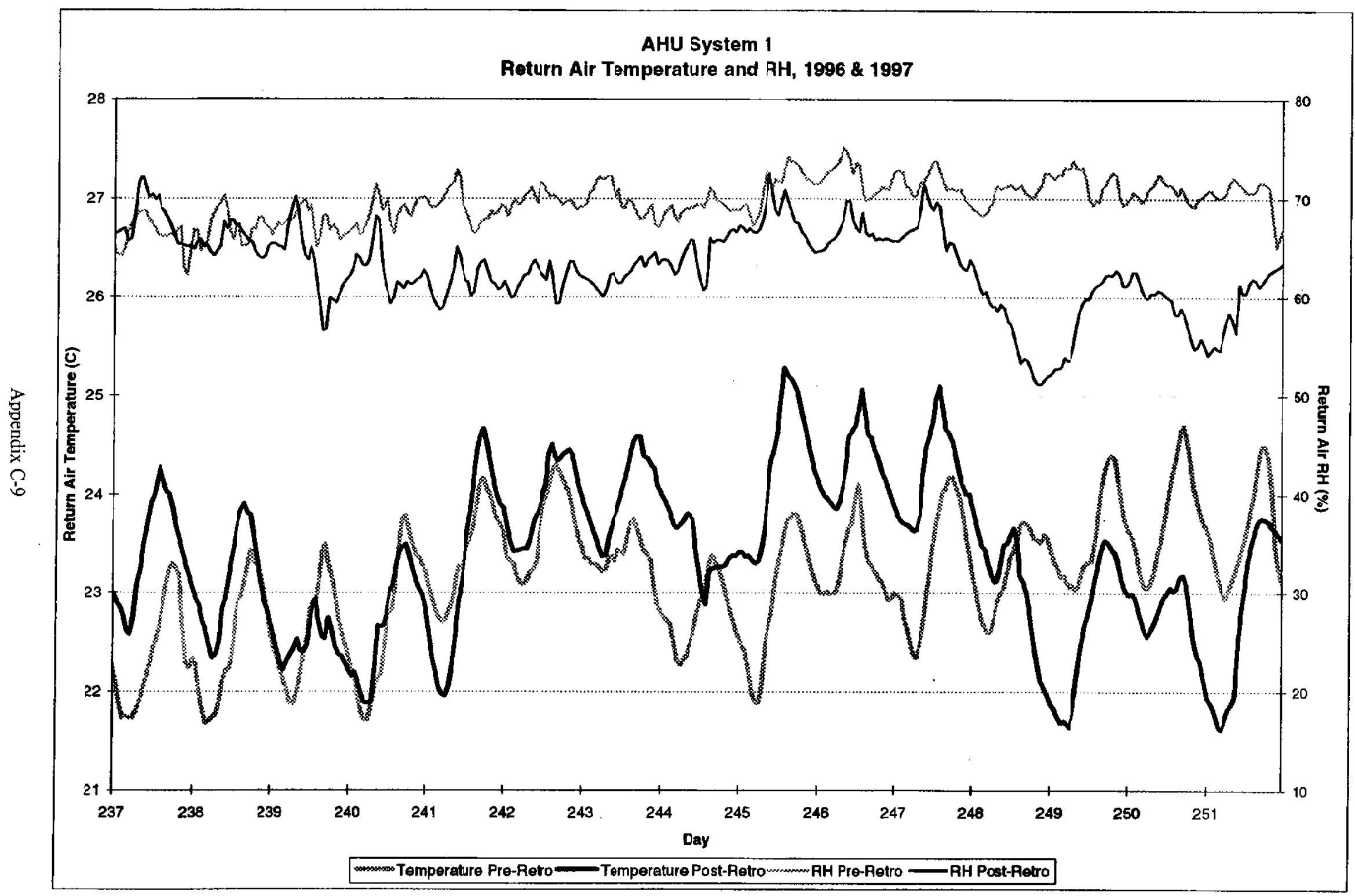




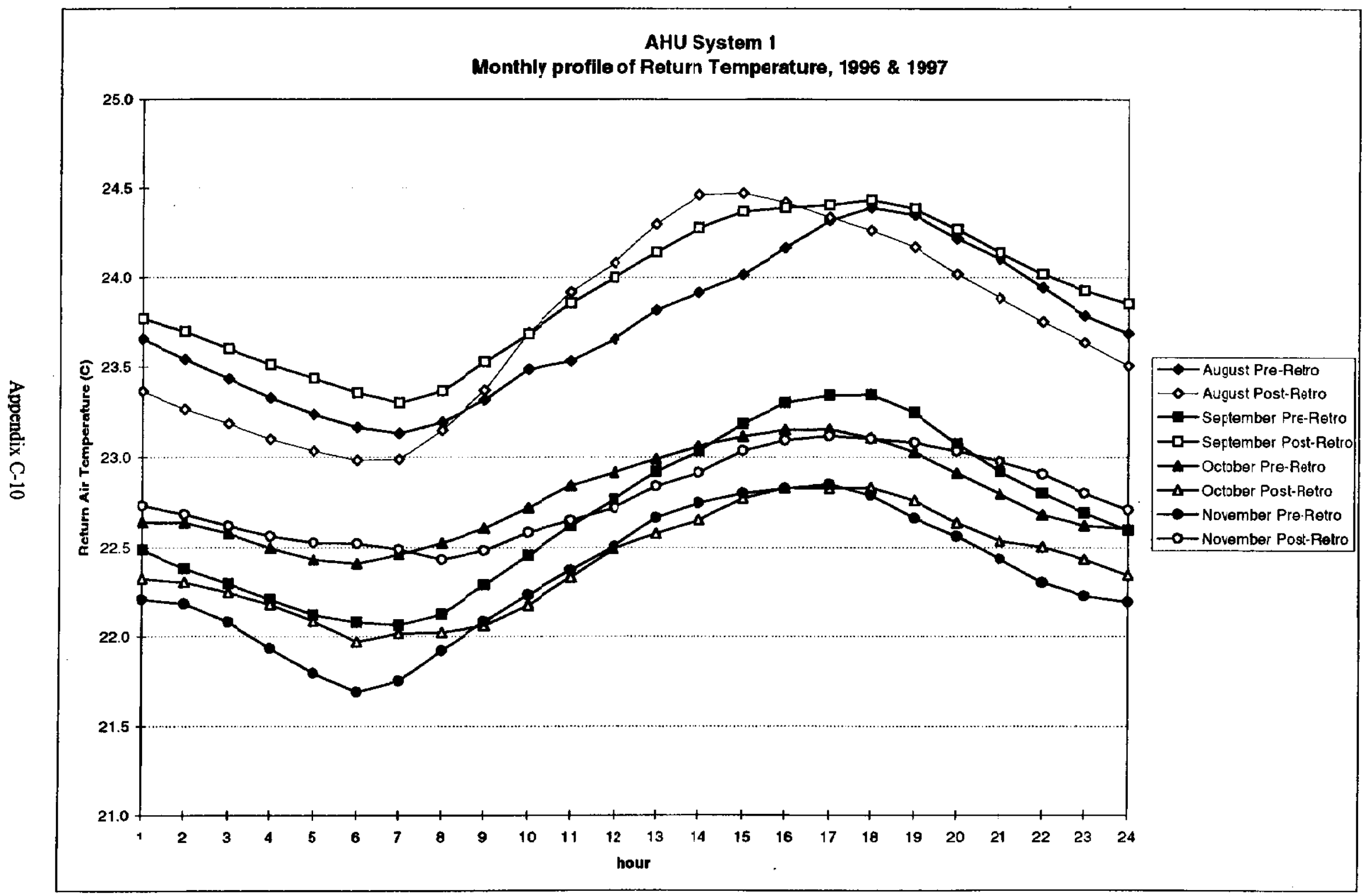




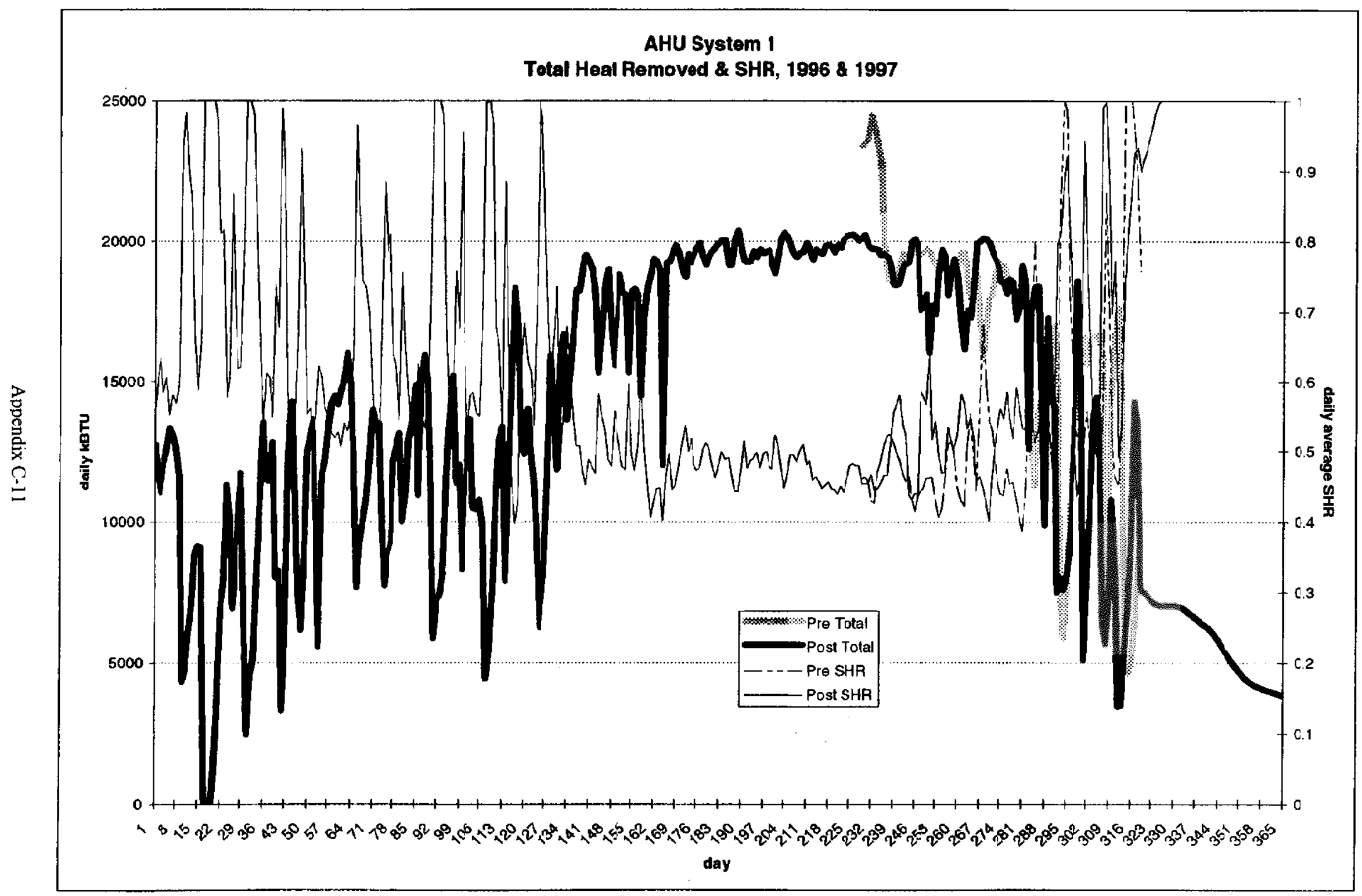




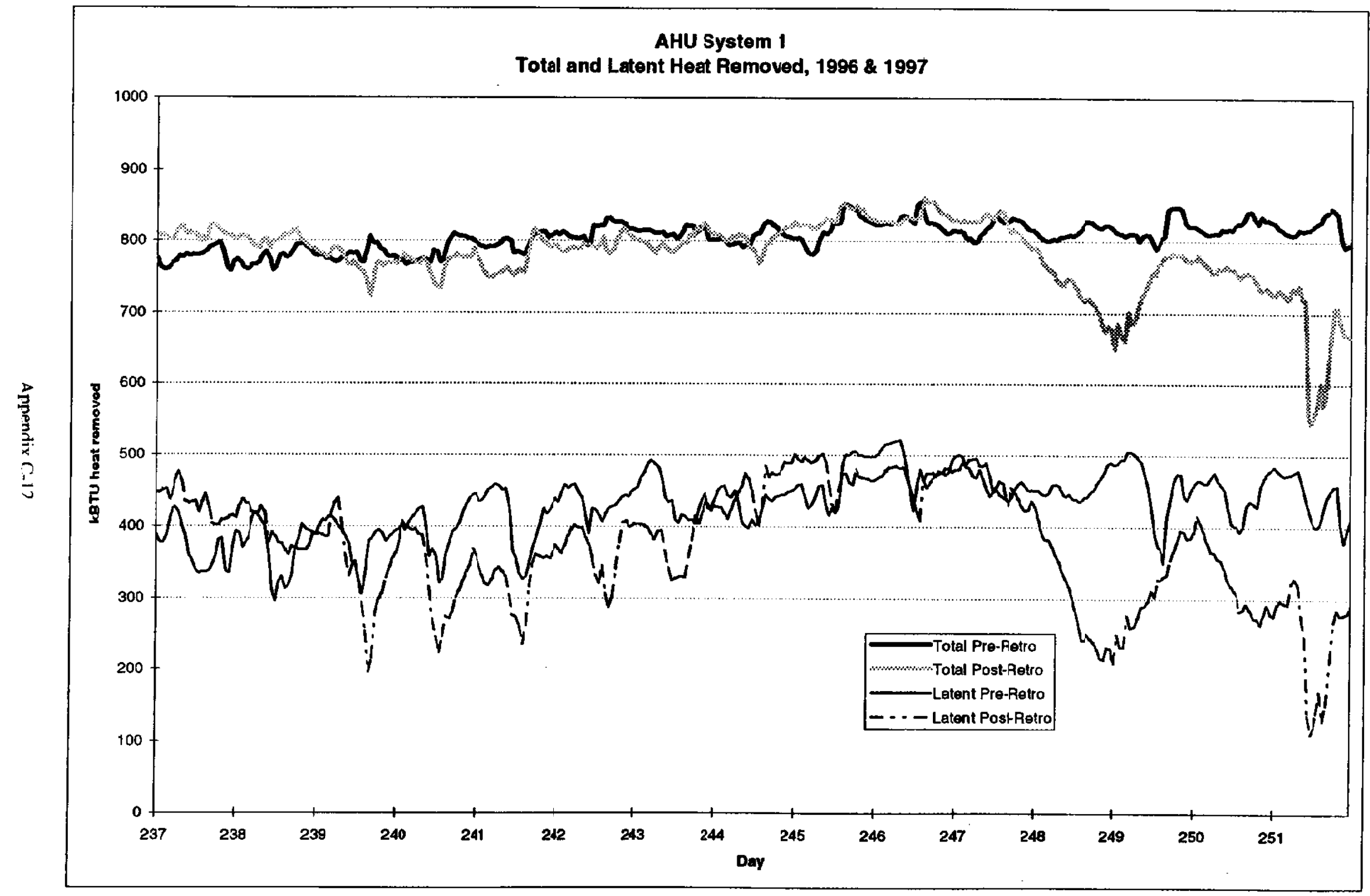




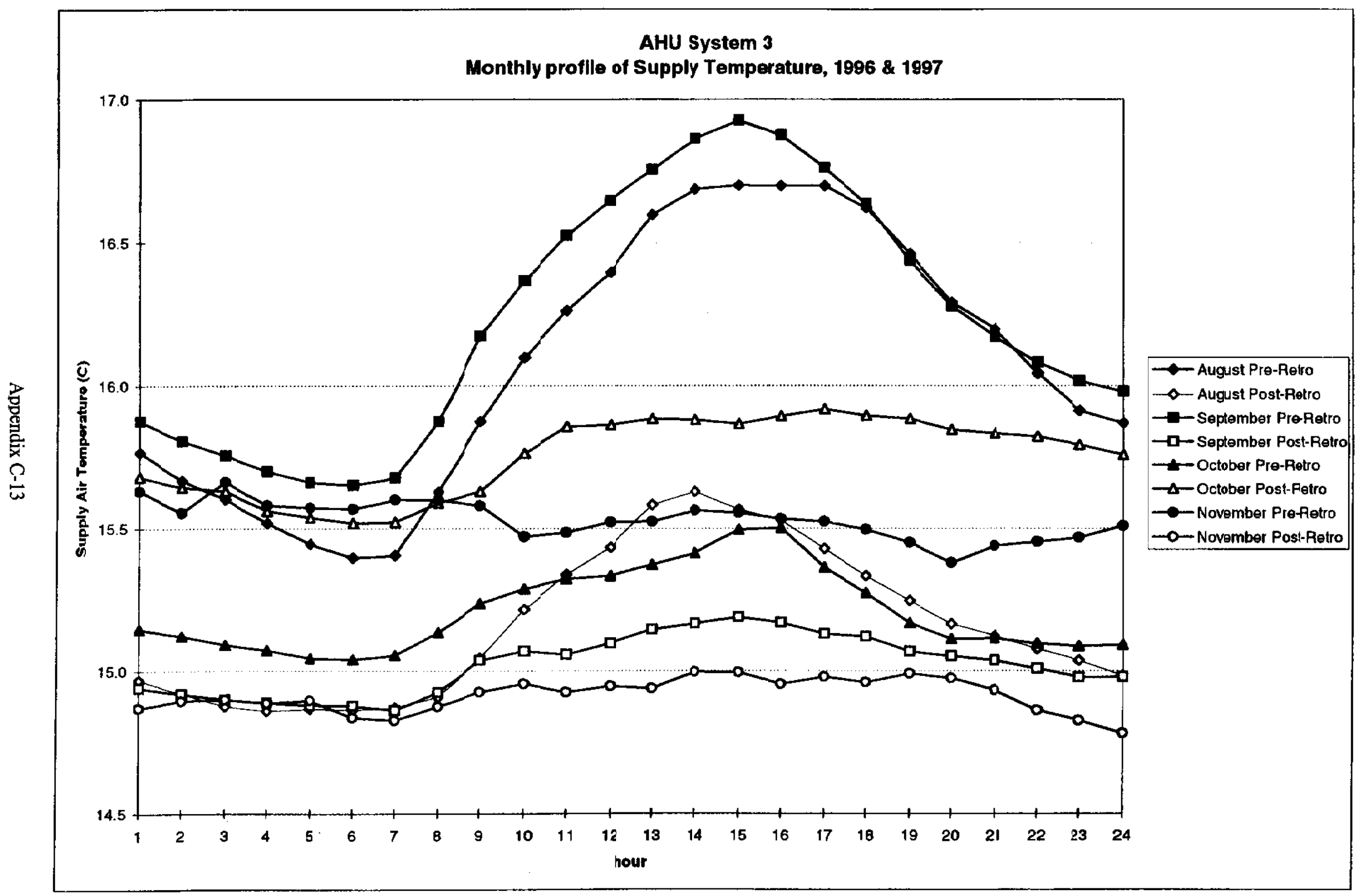




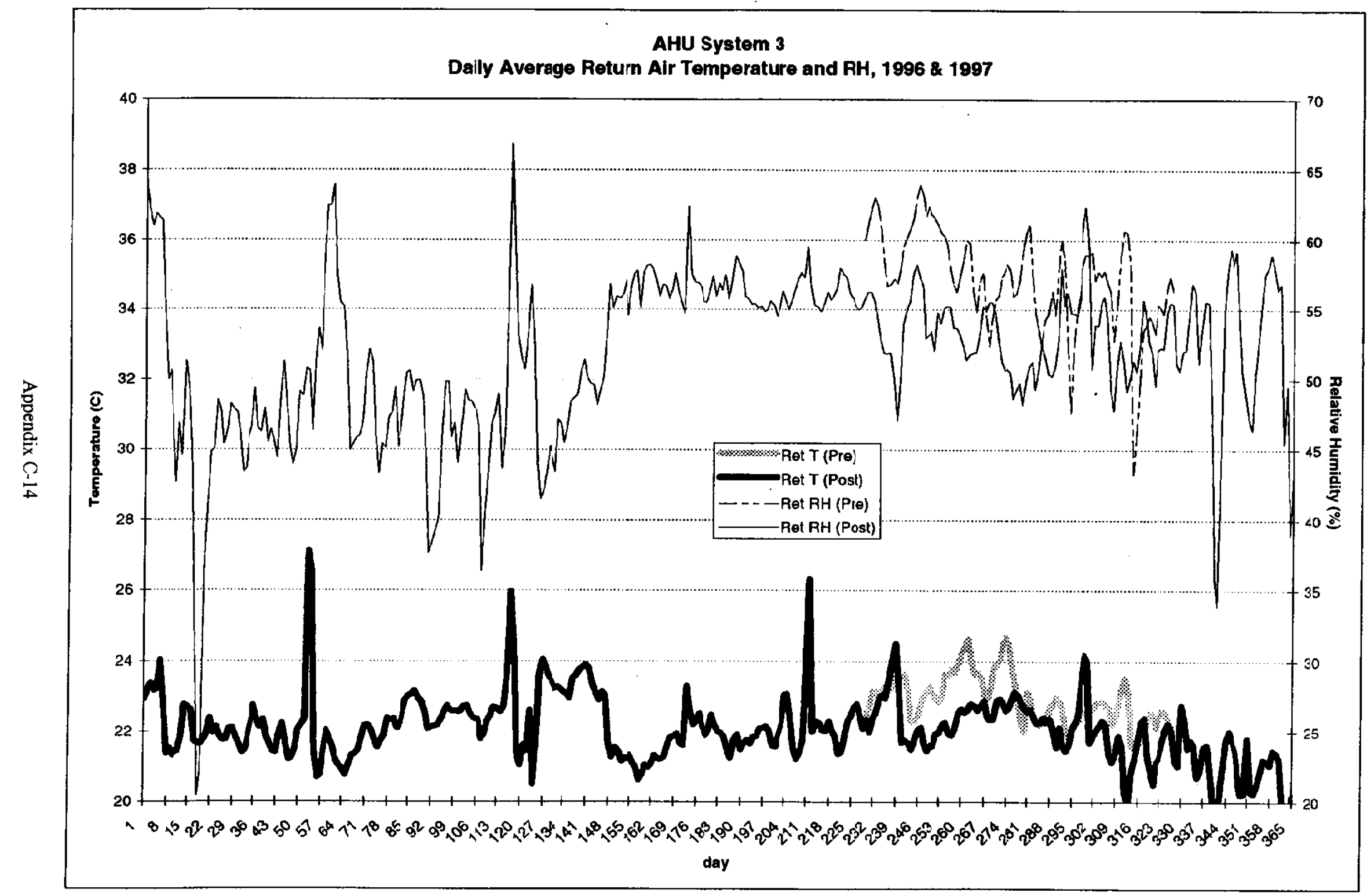




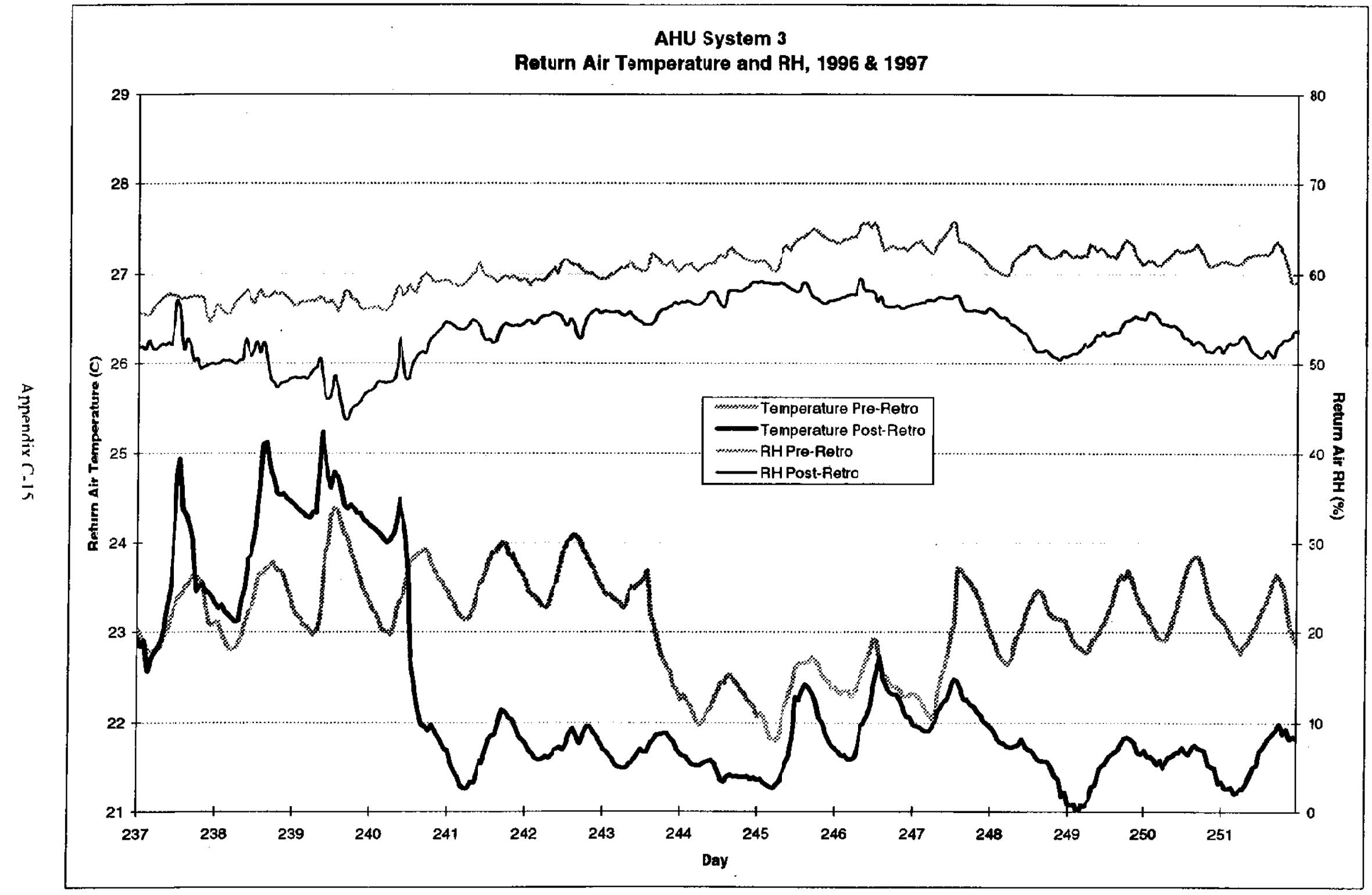




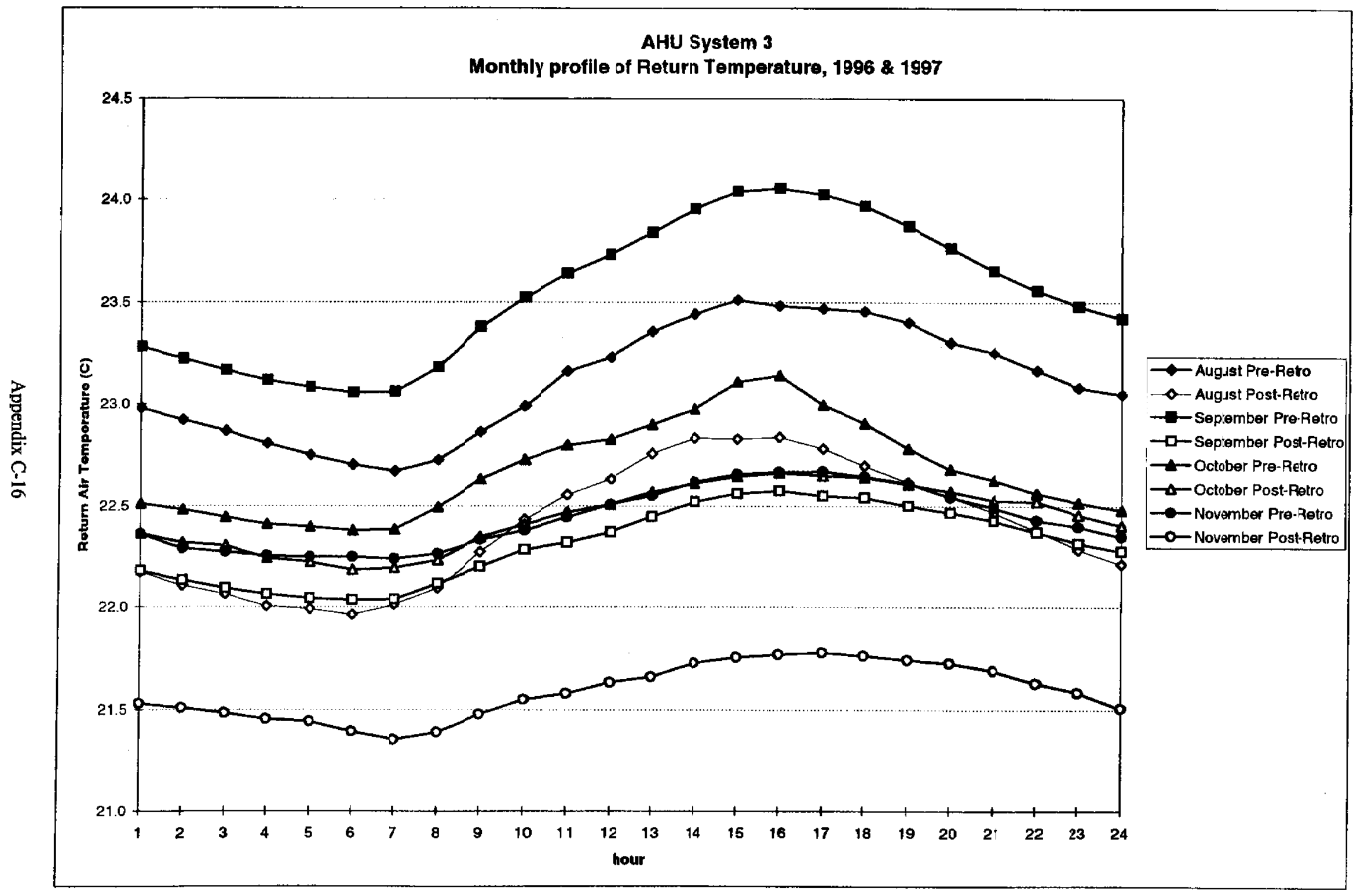




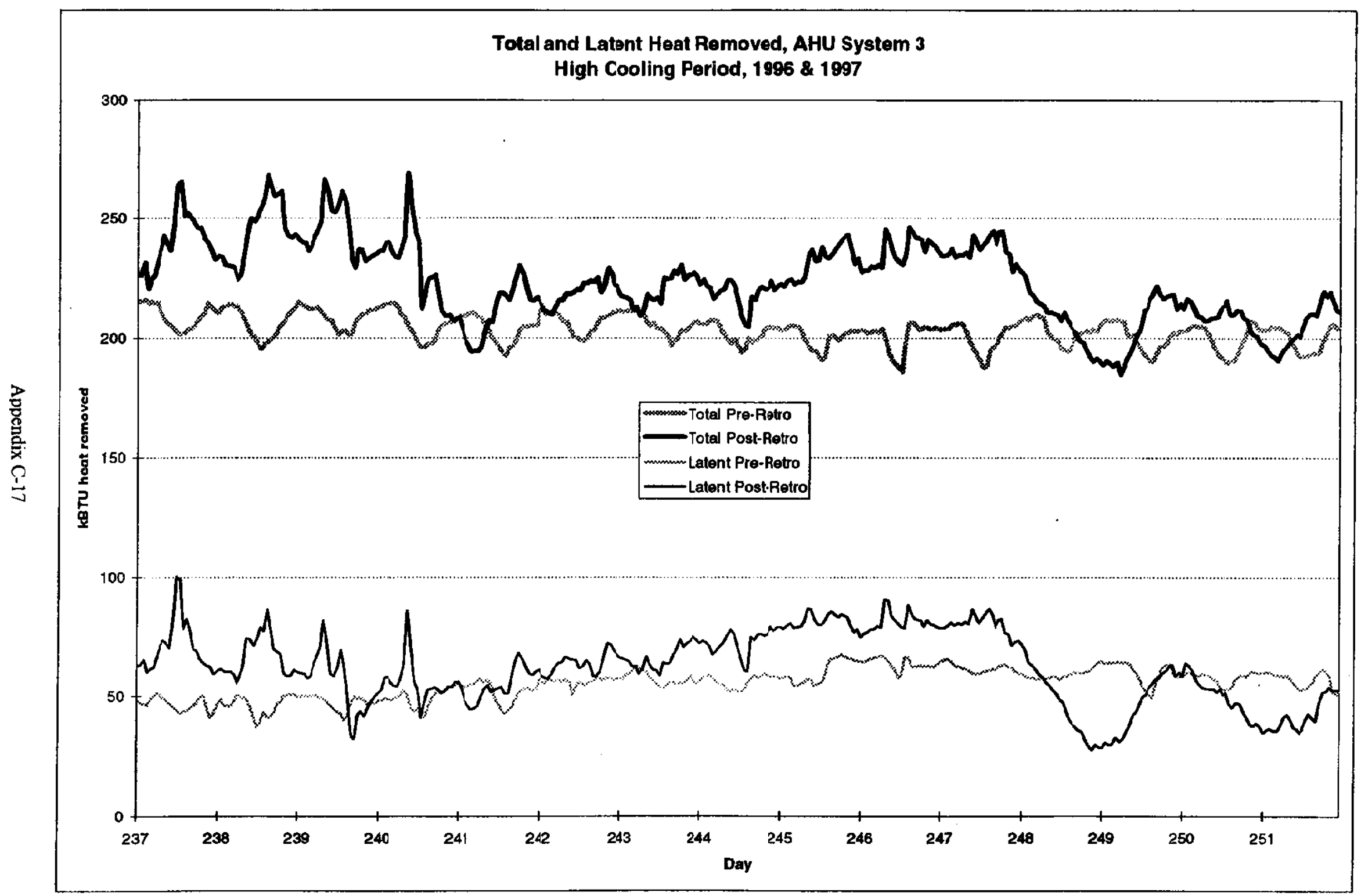




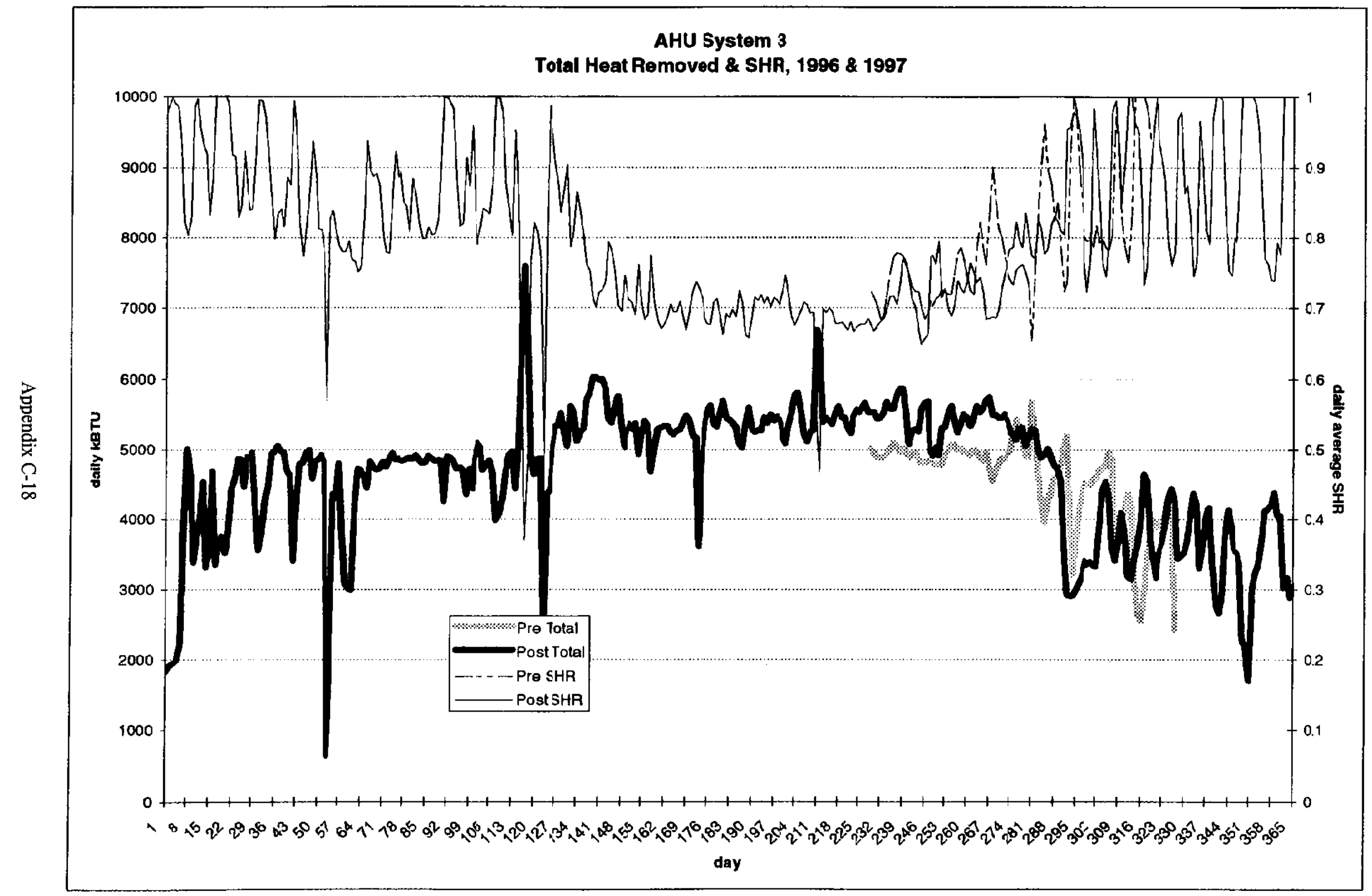




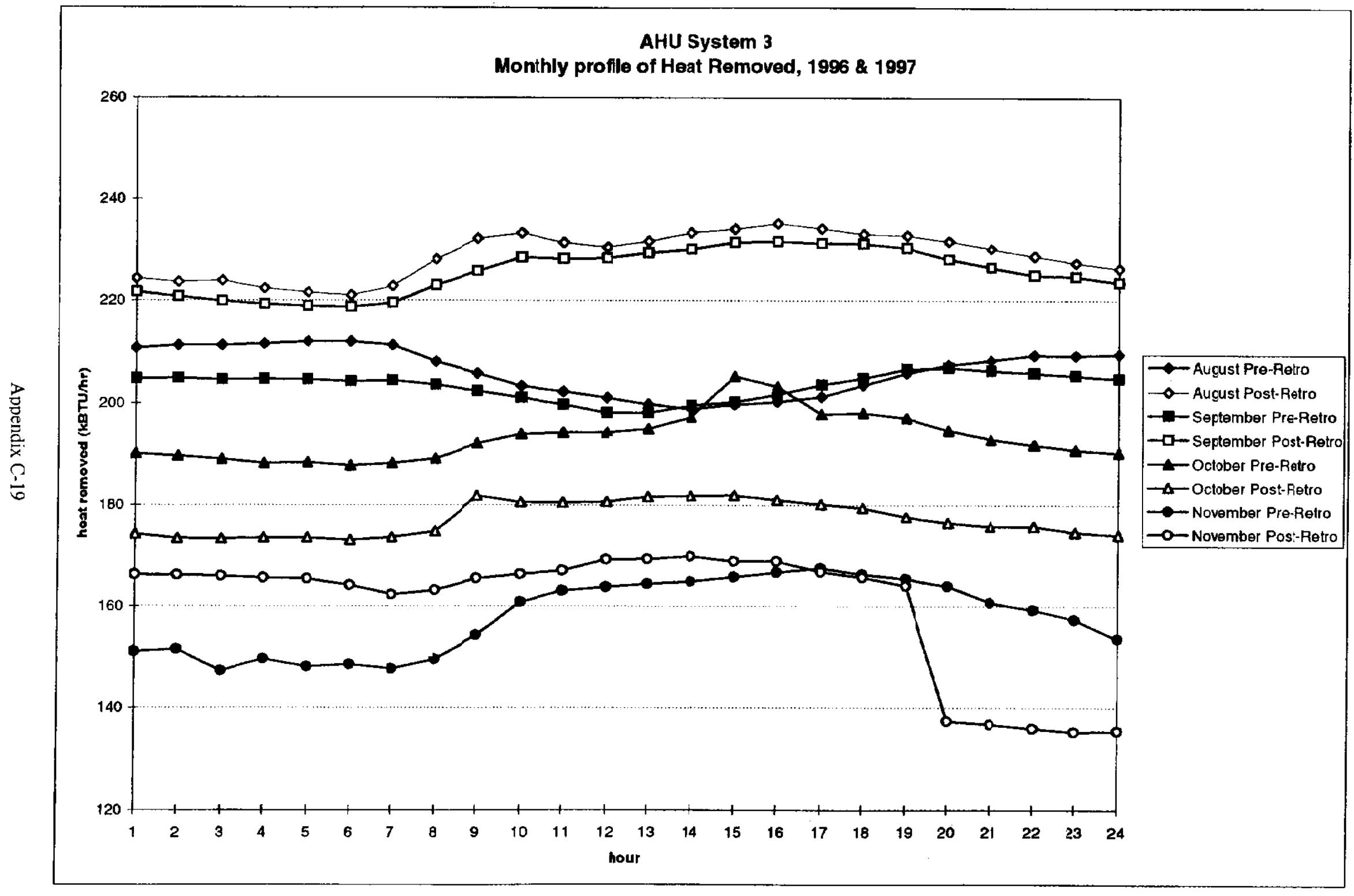




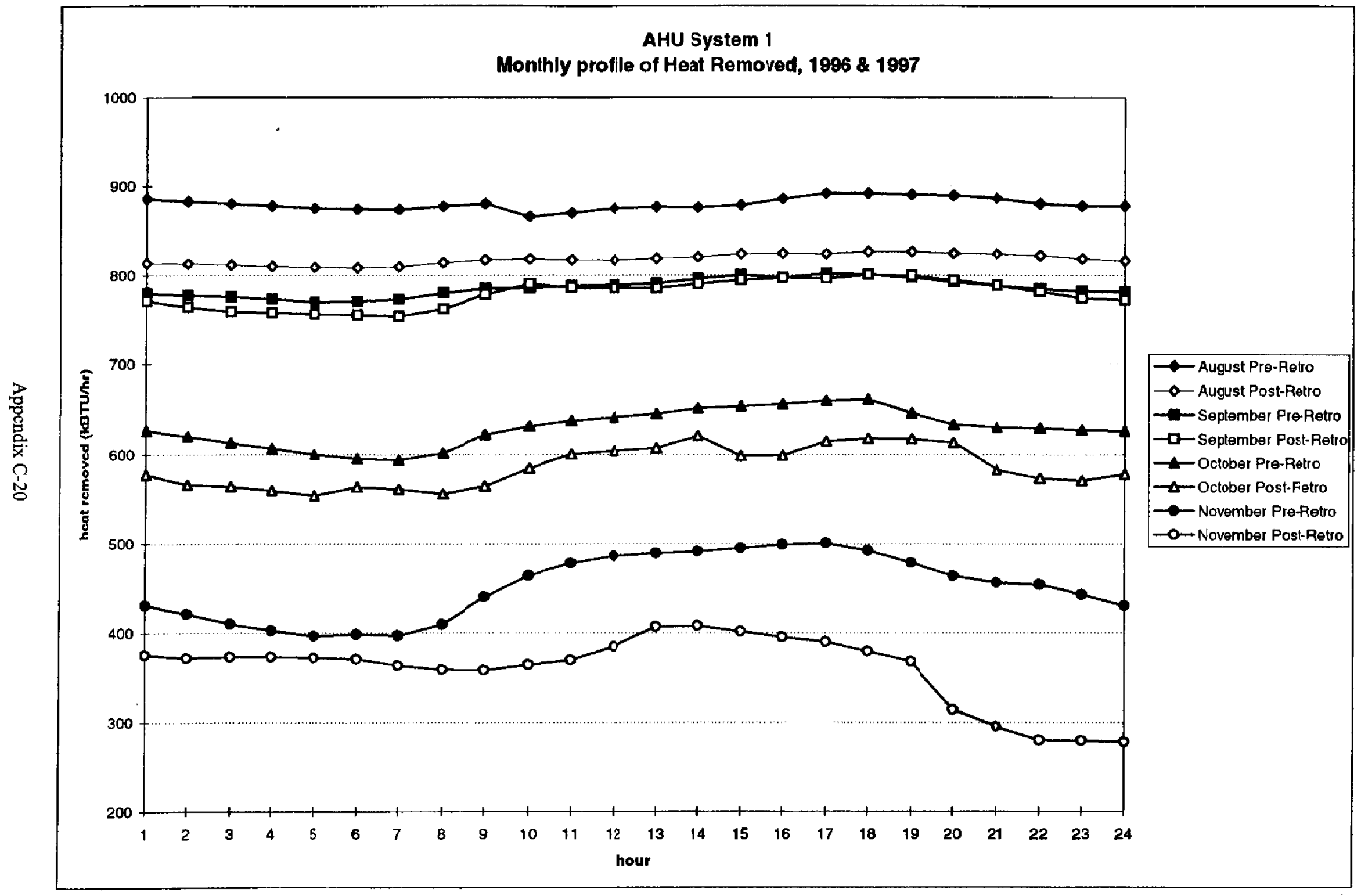




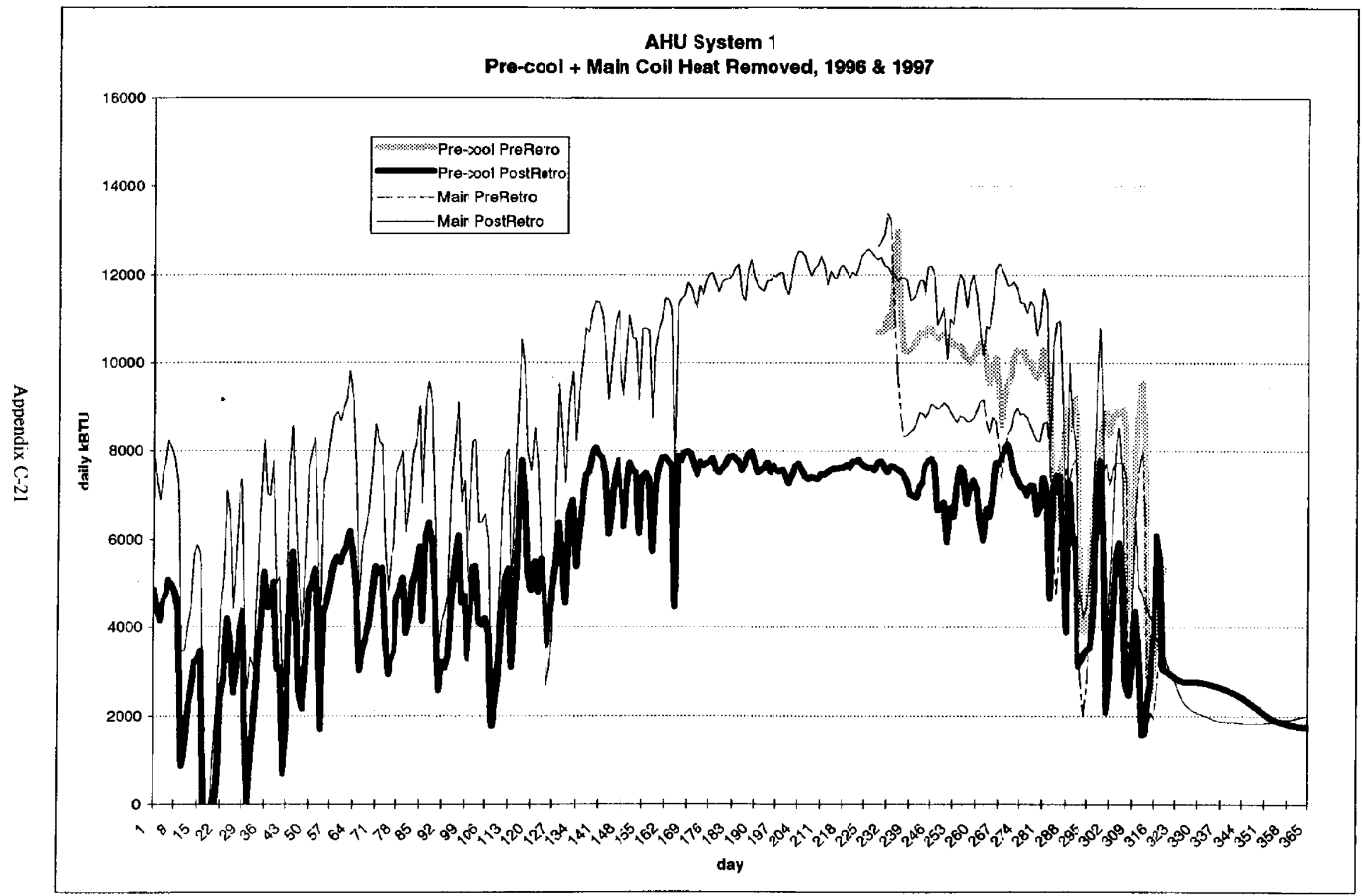




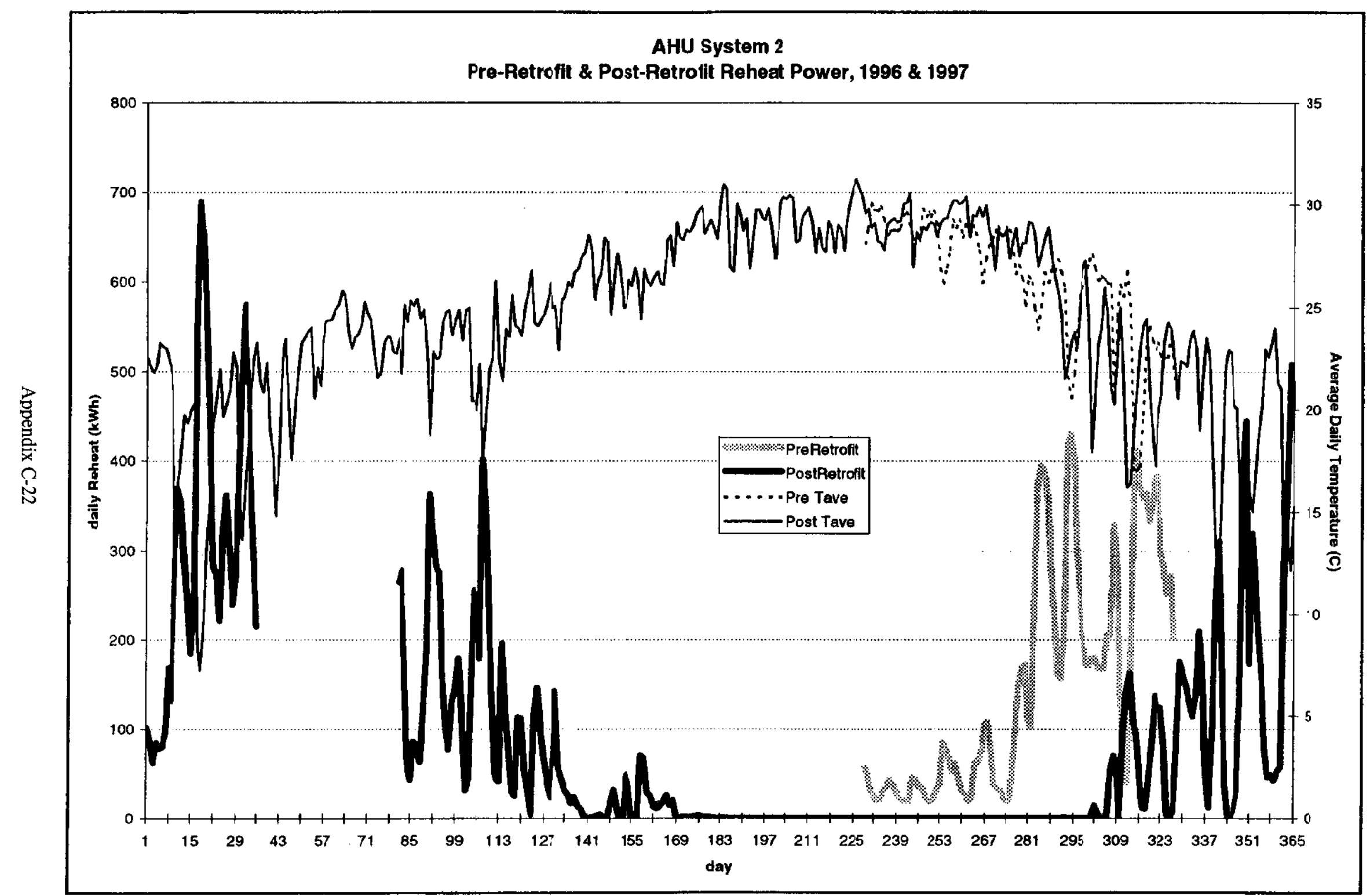




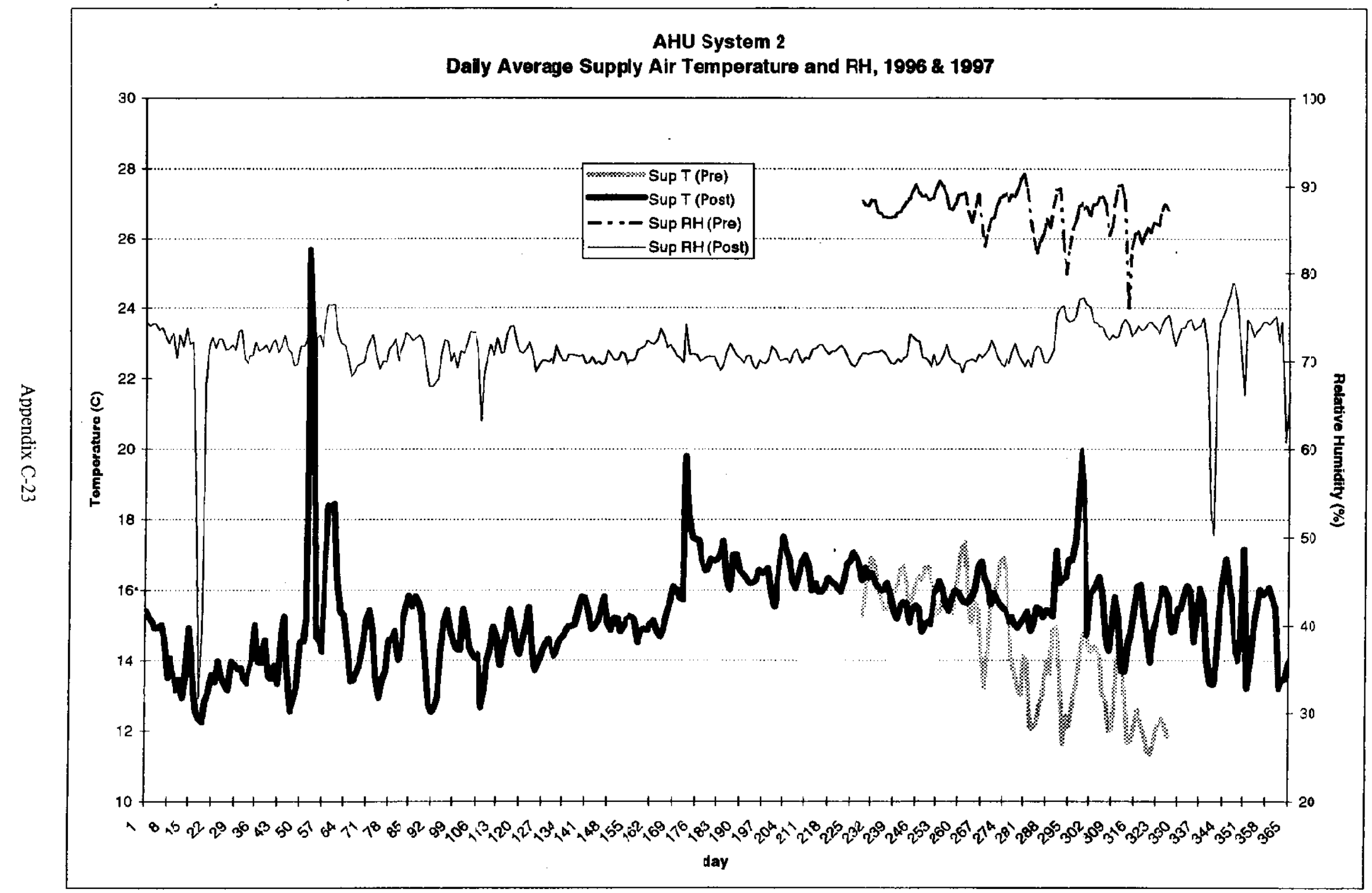




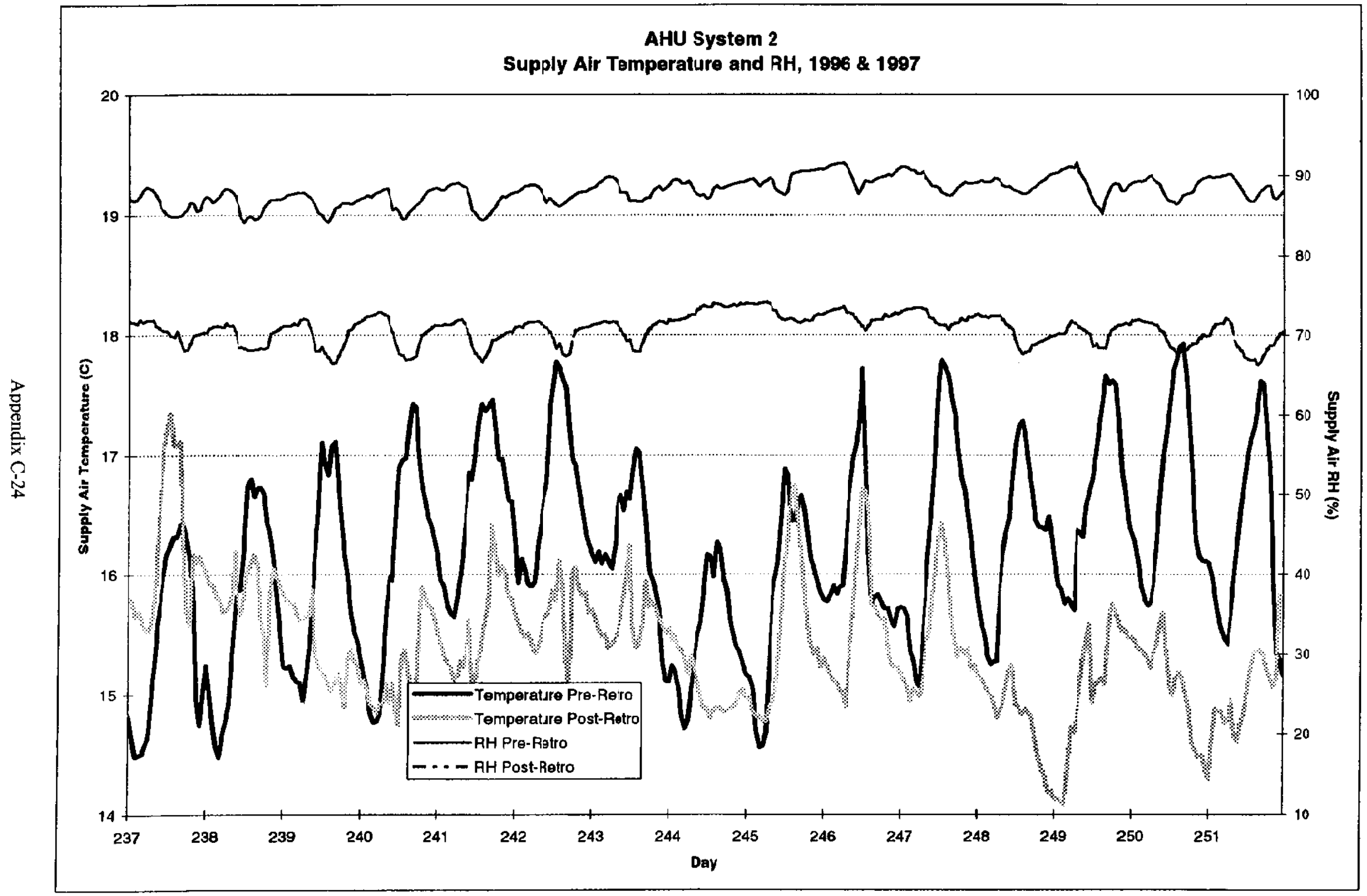




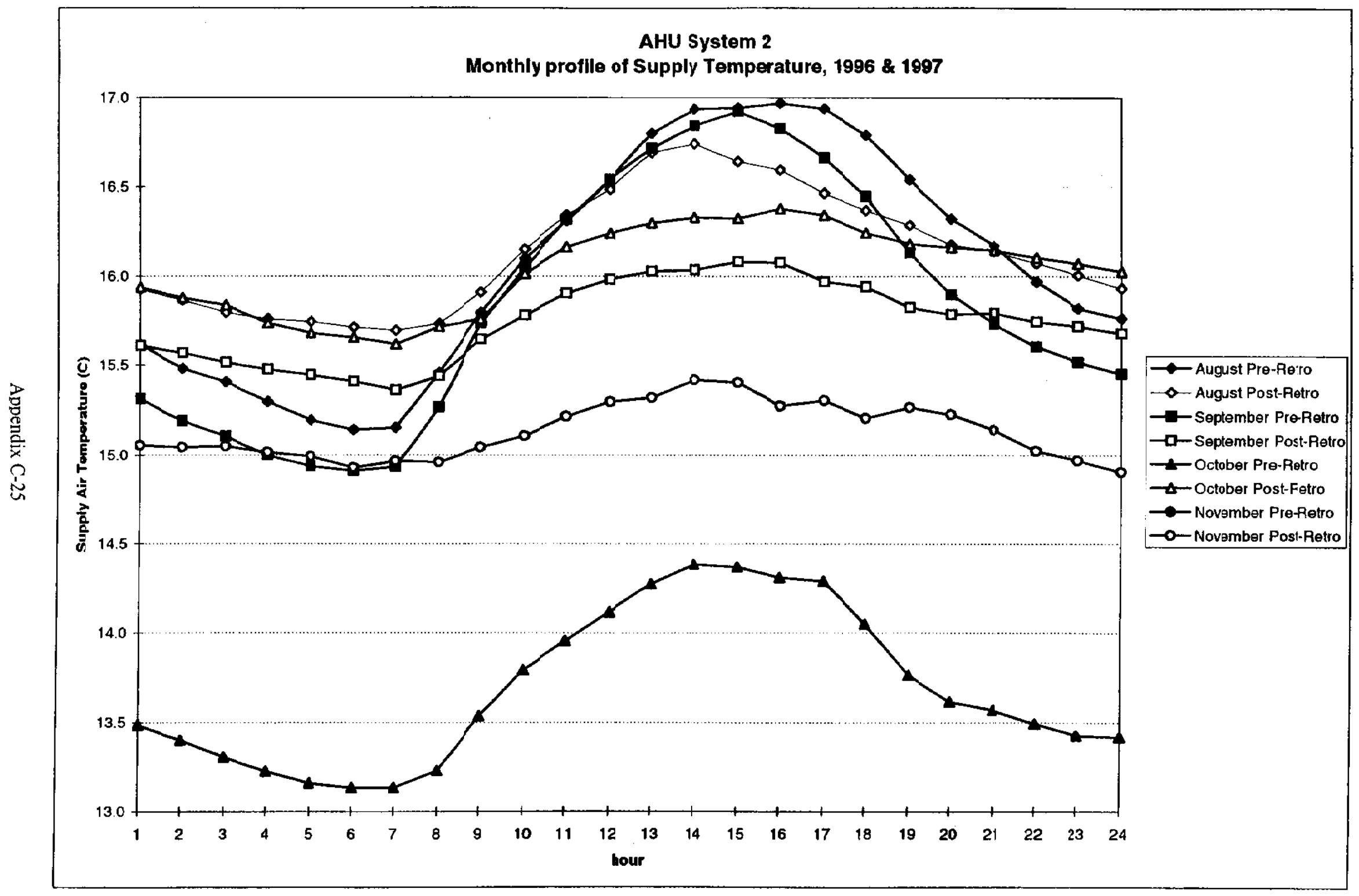




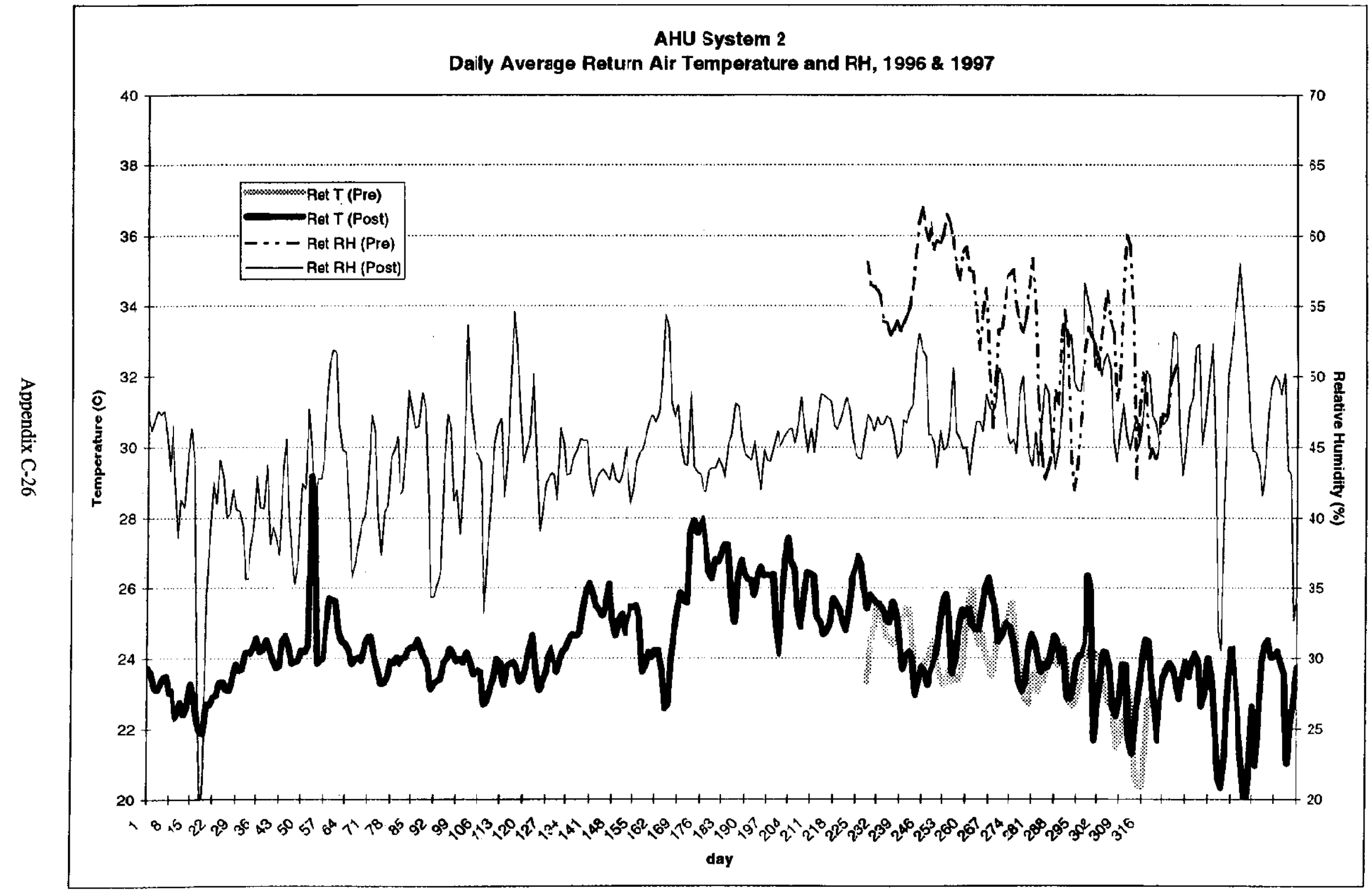




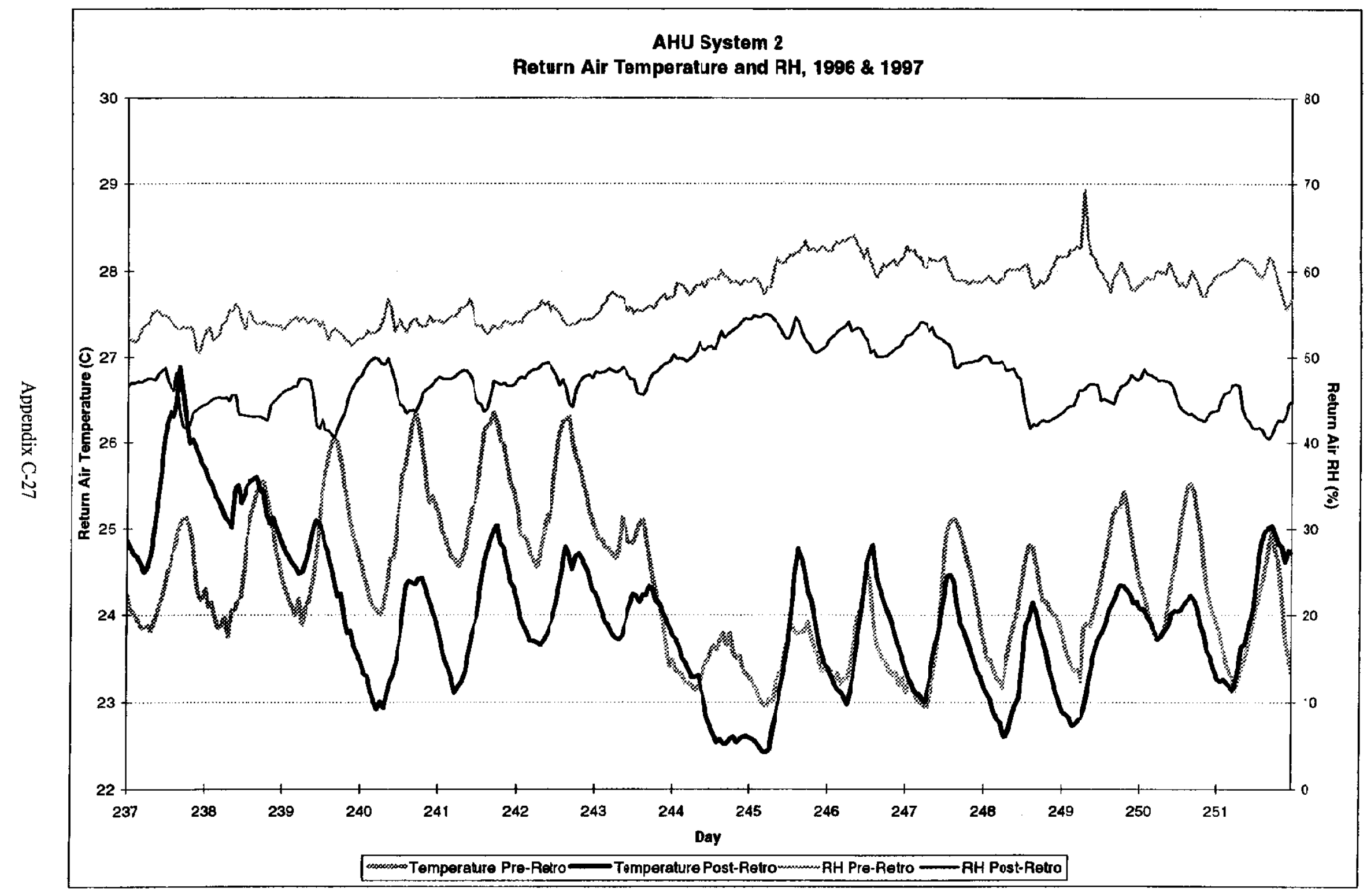




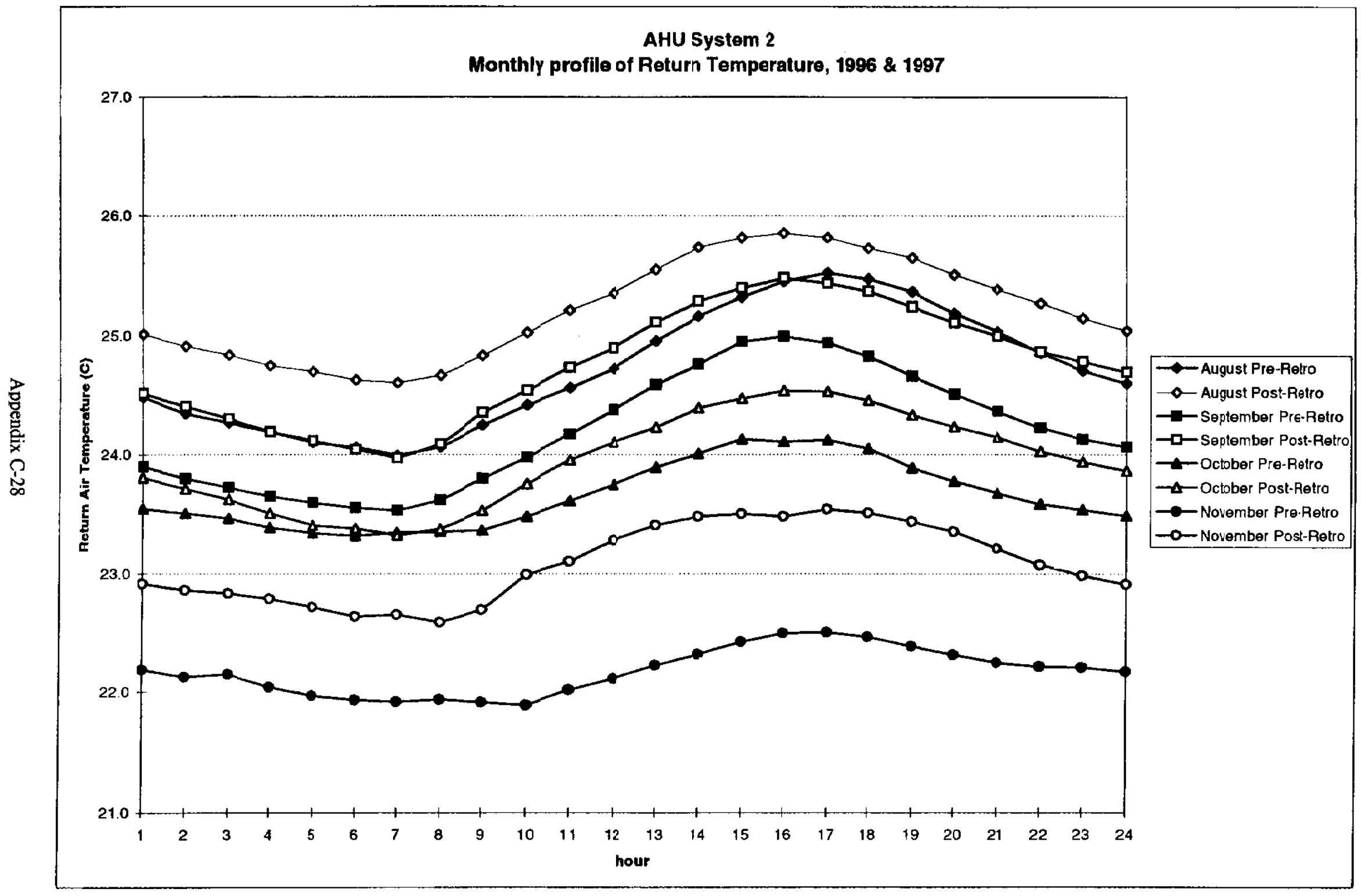




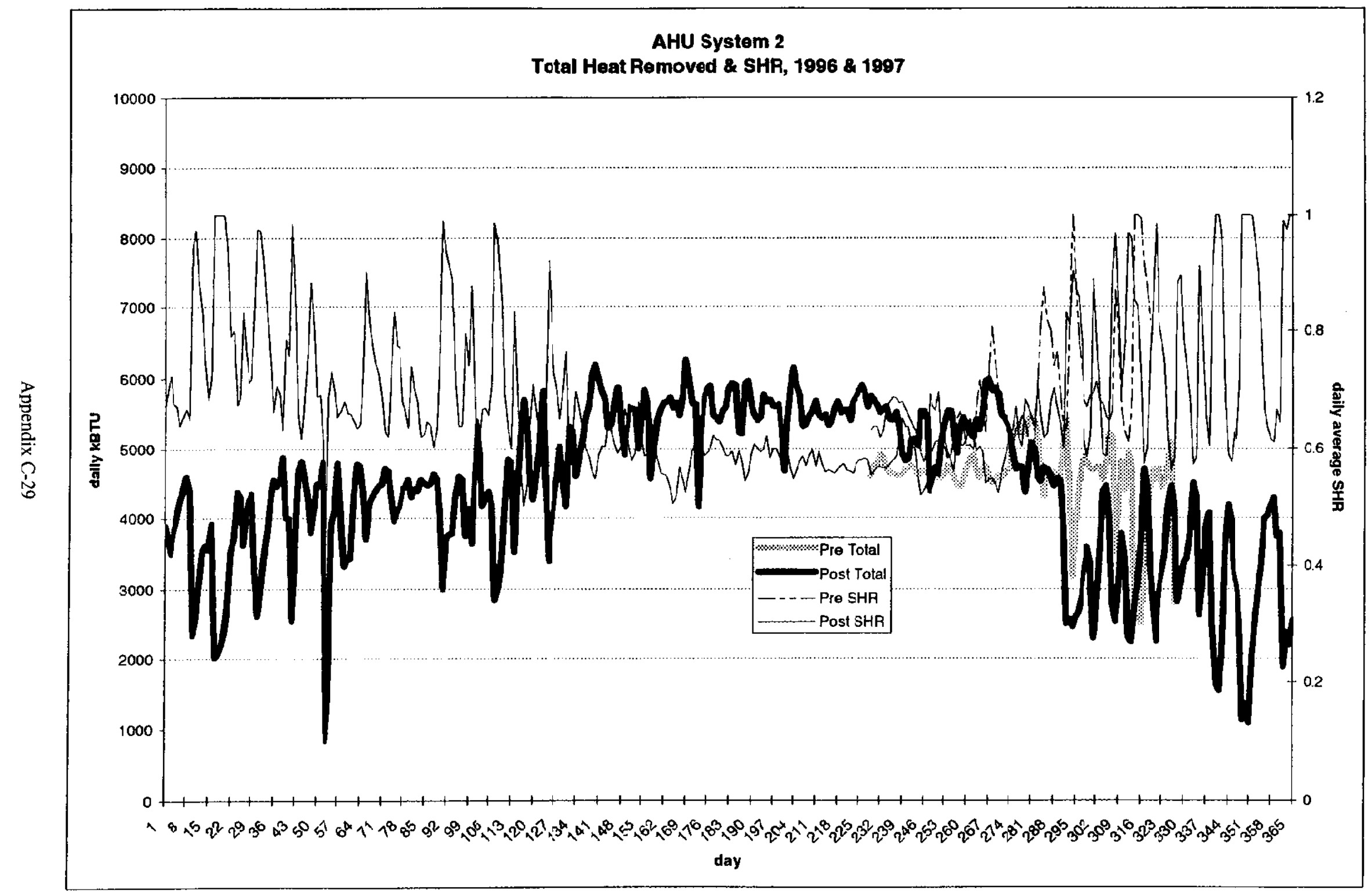




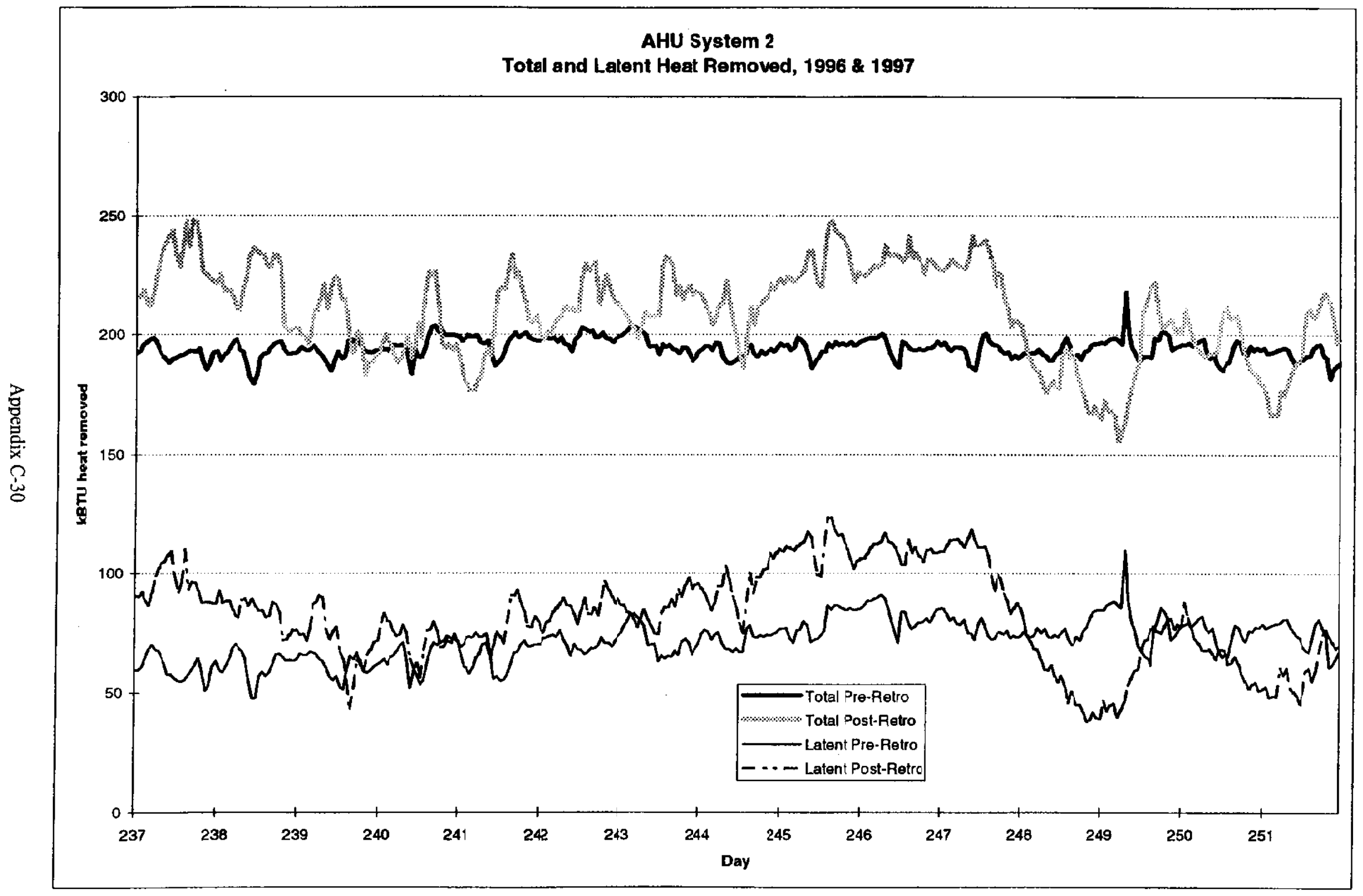




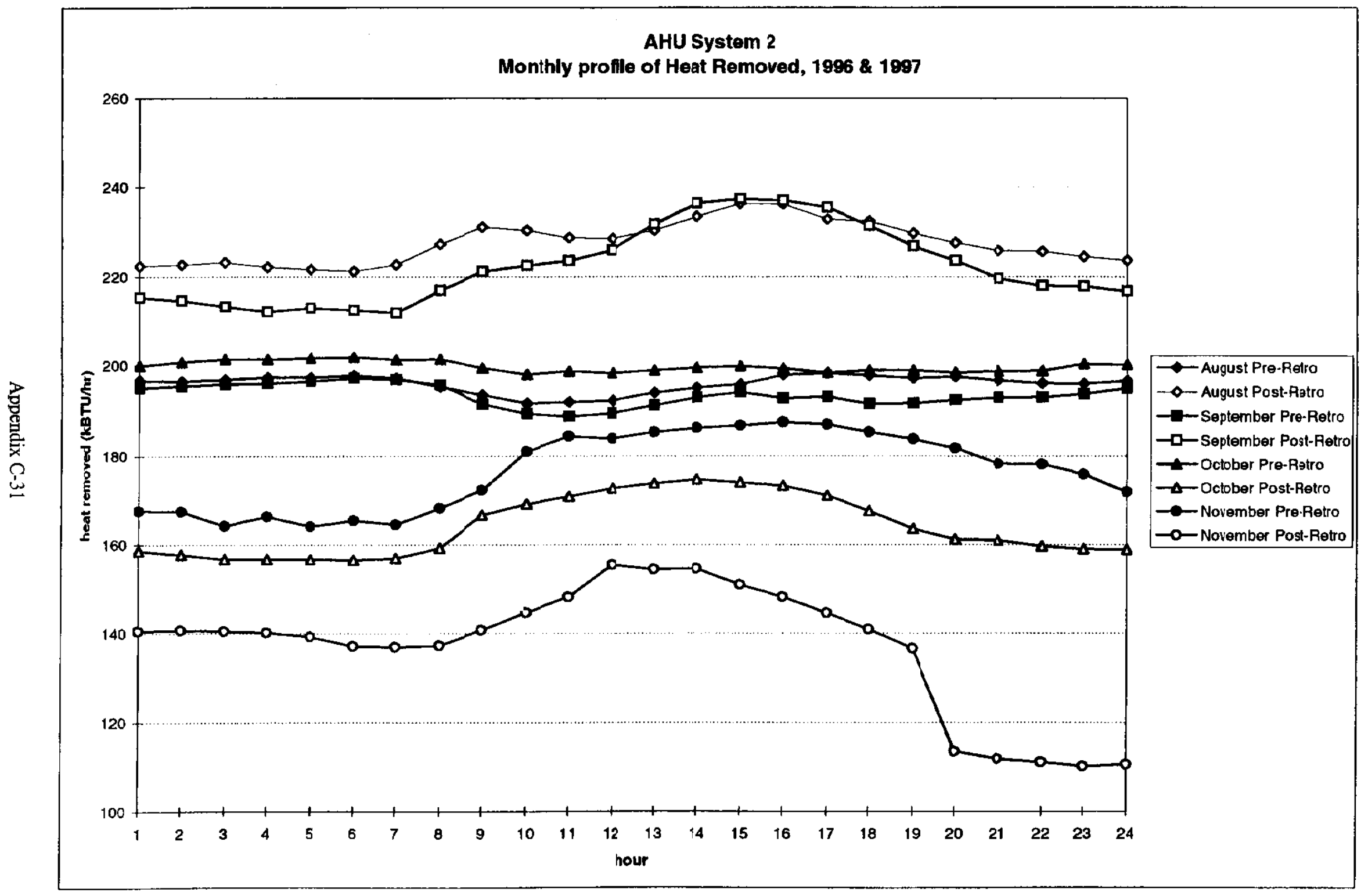




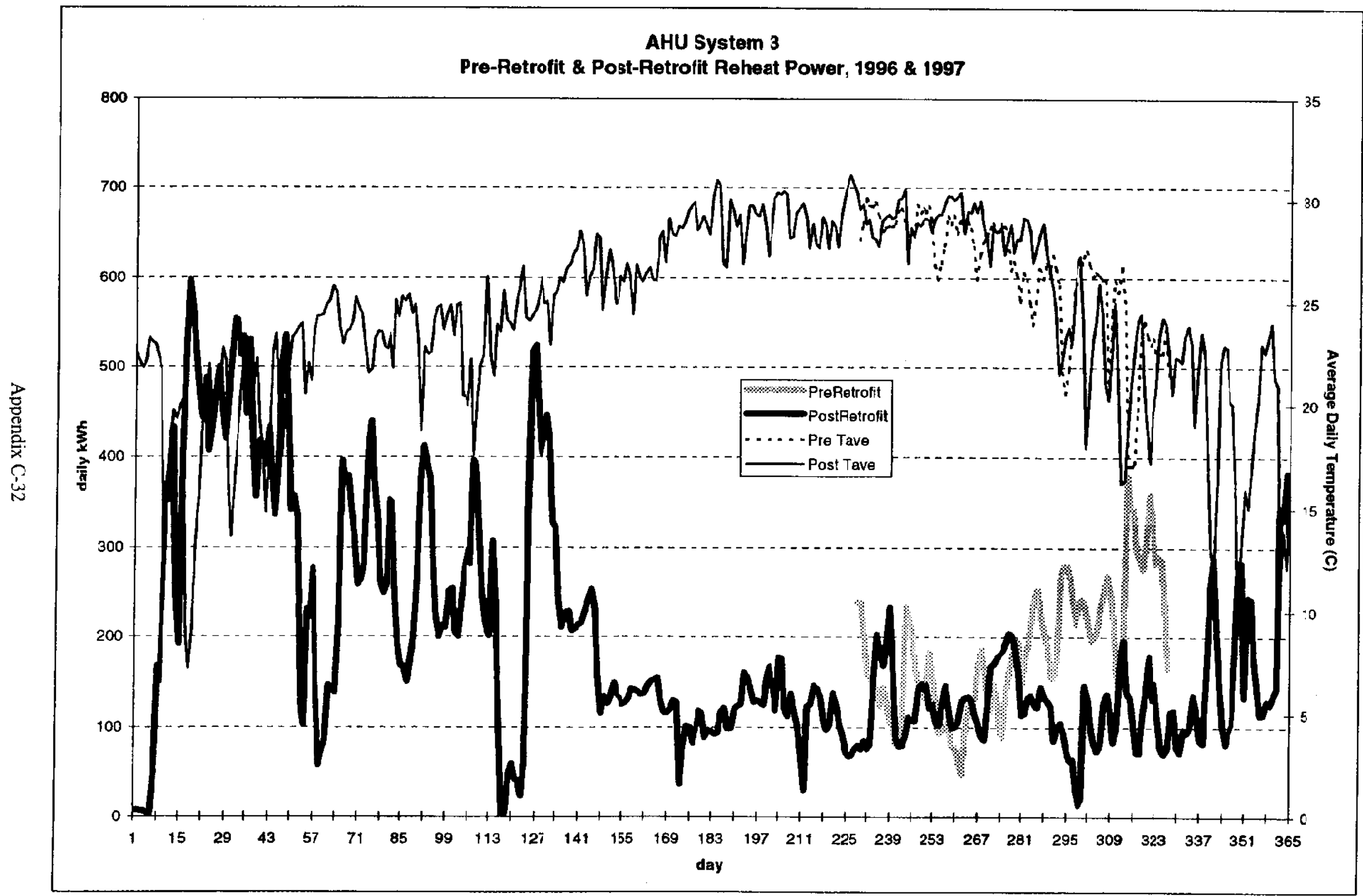




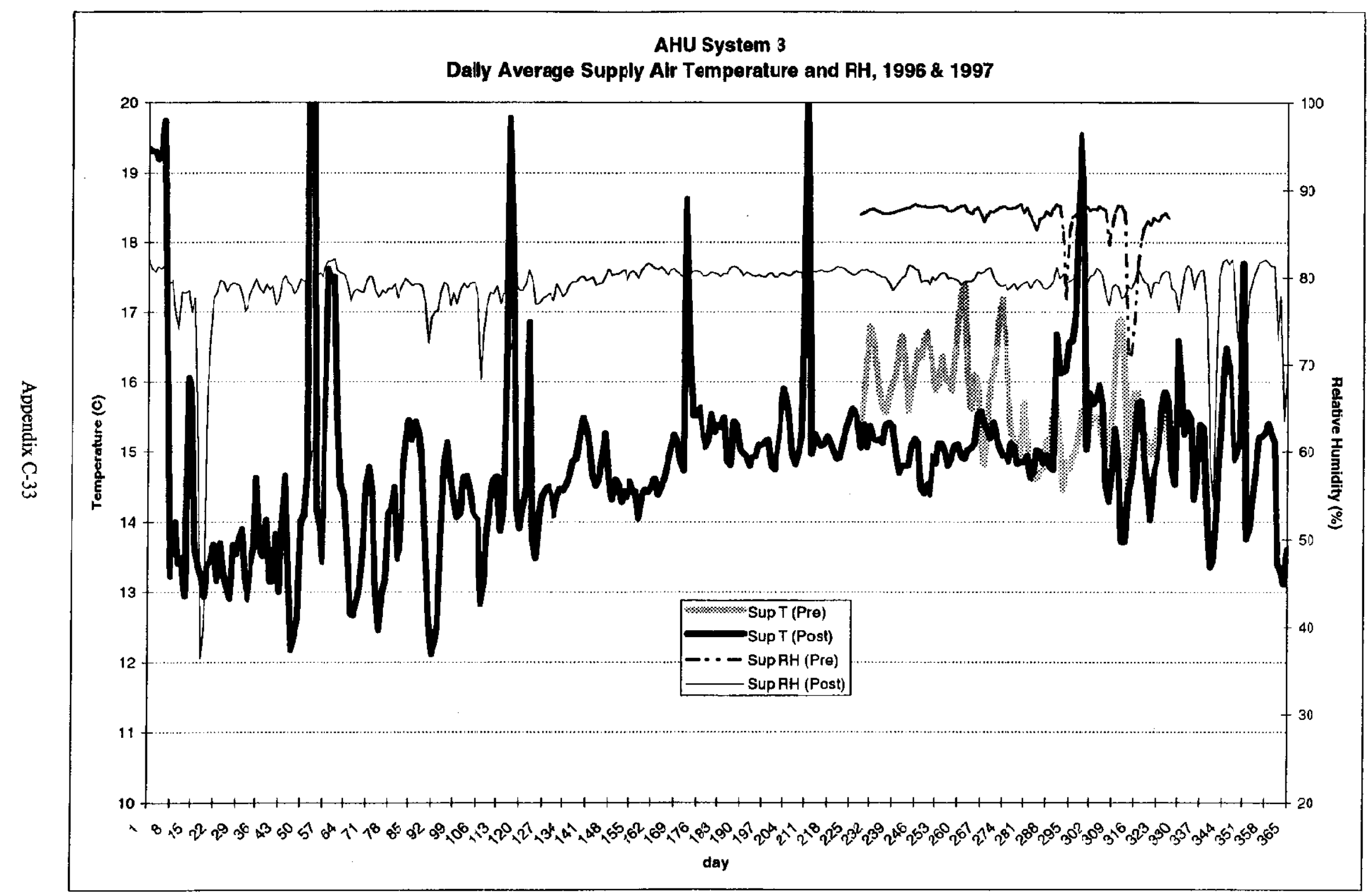




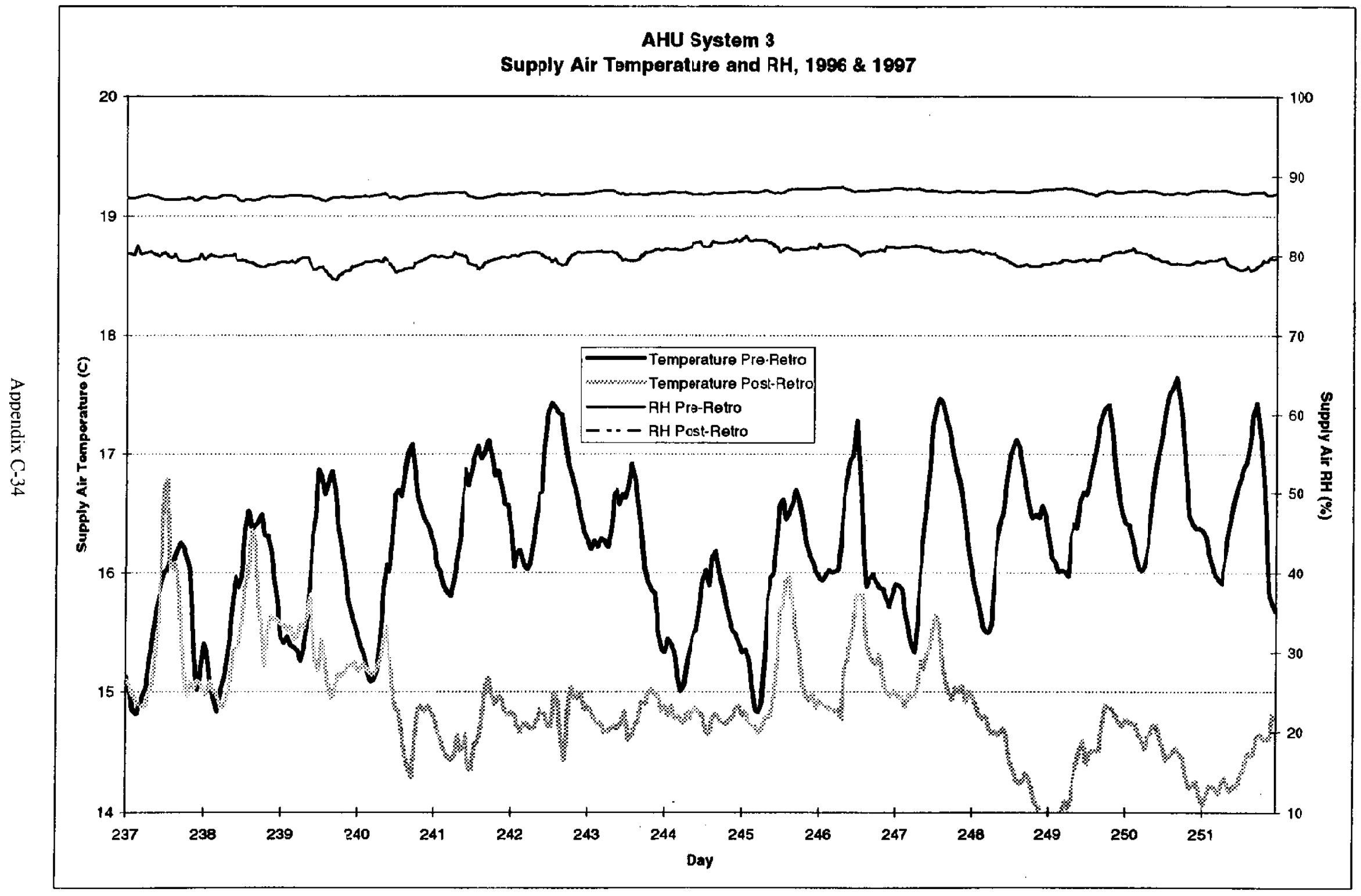




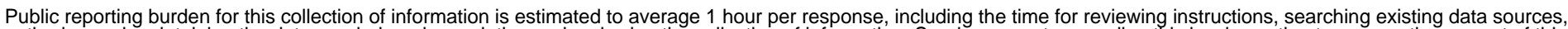

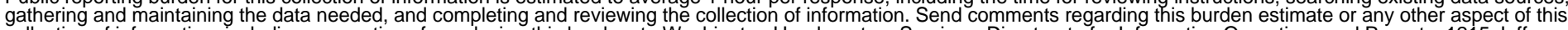

Washington Headquarters Services, Directorate for Information Operations and Reports 1215 Jefferson Davis Highway, Suite 1204, Arlington, VA 22202-4302, and to the Office of Management and Budget, Paperwork Reduction Project (0704-0188), Washington, DC 20503.
1. AGENCY USE ONLY (Leave blank)
2. REPORT DATE
3. REPORT TYPE AND DATES COVERED
March 1999
Technical Report

4. TITLE AND SUBTITLE New Technology Demonstration Program Kennedy Space Center Hangar L Heat Pipe Project:

Performance Evaluation Report

5. FUNDING NUMBERS

AS02.2010.

6. $\operatorname{AUTHOR}(S)$

Ed Hancock, Paul Reeves (Mountain Energy Partnership)

7. PERFORMING ORGANIZATION NAME(S) AND ADDRESS(ES)

8. PERFORMING ORGANIZATION REPORT NUMBER

Mountain Energy Partnership

815 Alpine \#6

Boulder, CO 80304

9. SPONSORING/MONITORING AGENCY NAME(S) AND ADDRESS(ES) AGENCY REPORT NUMBER

National Renewable Energy Laboratory

1617 Cole Boulevard

TP-710-24738

Golden, Colorado 80401-3393

11. SUPPLEMENTARY NOTES

12a. DISTRIBUTION/AVAILABILITY STATEMENT

12b. DISTRIBUTION CODE

National Technical Information Service

U.S. Department of Commerce

5285 Port Royal Road

Springfield, VA 22161

13. ABSTRACT (Maximum 200 words)

In December of 1996, heat pipe heat exchangers were installed on three air handlers at Hangar $L$ at the Cape Canaveral Air Station, Kennedy Space Center, Cape Canaveral, Florida. These retrofits were implemented with the intent to improve the dehumidification performance of the cooling systems, reduce the electric and steam energy required for reheating air, and reduce electric energy used by the chillers.

Audits were conducted before and after the heat pipes were installed and a detailed monitoring system was set up to record hourly operating conditions of each of the three air-handling units. The audit information and monitored data were used to create a simulation model of the three air-handling systems and annual energy savings were predicted.

Energy savings for air handling unit 1 (AHU-1) were found to be negligible. Heat pipe installation in AHU-1 may have been inappropriate because of the design of the original cooling coils. Annual savings for AHU-2 are small, primarily because the required reheat for the system was already small. AHU-3 was the best application for the heat pipes and showed savings of 70,000 kWh per year. Interior humidity conditions improved after installation of the heat pipes for AHU-2 and AHU-3.

\section{SUBJECT TERMS}

heat pipes, heat exchangers, air handlers, humidity, dehumidification, reheating, chillers, energy savings, cooling coils,
15. NUMBER OF PAGES

16. PRICE CODE
17. SECURITY CLASSIFICATION OF REPORT unclassified

\author{
18. SECURITY CLASSIFICATION \\ OF THIS PAGE \\ unclassified
}
19. SECURITY CLASSIFICATION OF ABSTRACT unclassified

20. LIMITATION OF ABSTRACT

UL 